\title{
Patient education in physical therapy
}

Citation for published version (APA):

Sluijs, E. M. (1991). Patient education in physical therapy. [Doctoral Thesis, Maastricht University]. Nederlands Instituut voor Onderzoek van de Eerstelijnsgezondheidszorg.

https://doi.org/10.26481/dis.19911107es

Document status and date:

Published: 01/01/1991

DOI:

10.26481/dis.19911107es

Document Version:

Publisher's PDF, also known as Version of record

\section{Please check the document version of this publication:}

- A submitted manuscript is the version of the article upon submission and before peer-review. There can be important differences between the submitted version and the official published version of record.

People interested in the research are advised to contact the author for the final version of the publication, or visit the DOI to the publisher's website.

- The final author version and the galley proof are versions of the publication after peer review.

- The final published version features the final layout of the paper including the volume, issue and page numbers.

Link to publication

\footnotetext{
General rights rights.

- You may freely distribute the URL identifying the publication in the public portal. please follow below link for the End User Agreement:

www.umlib.nl/taverne-license

Take down policy

If you believe that this document breaches copyright please contact us at:

repository@maastrichtuniversity.nl

providing details and we will investigate your claim.
}

Copyright and moral rights for the publications made accessible in the public portal are retained by the authors and/or other copyright owners and it is a condition of accessing publications that users recognise and abide by the legal requirements associated with these

- Users may download and print one copy of any publication from the public portal for the purpose of private study or research.

- You may not further distribute the material or use it for any profit-making activity or commercial gain

If the publication is distributed under the terms of Article $25 \mathrm{fa}$ of the Dutch Copyright Act, indicated by the "Taverne" license above, 
PATIENT EDUCATION IN PHYSICAL THERAPY 
Voor mijn ouders 


\title{
PATIENT EDUCATION IN
}

\section{PHYSICAL THERAPY}

\author{
PROEFSCHRIFT \\ ter verkrijging van de graad van doctor \\ aan de Rijksuniversiteit Limburg te Maastricht, \\ op gezag van de Rector Magnificus, Prof. Mr. M.J.Cohen, \\ volgens het besluit van het College van Dekanen, \\ in het openbaar te verdedigen \\ op donderdag, 7 november 1991 om 16.00 uur \\ door
}

Emmarentiana Maria Sluijs 


\section{Promotores:}

Prof. Dr. J. van der Zee

Prof. Dr. G.J. Kok

\section{Beoordelingscommissie:}

Prof. Mr. Dr. R.P.T.M. Grol (voorzitter)

Dr. L.M. Bouter

Prof. Dr. F. ten Hoor

Prof. Dr. E.C. Klip, R.U. Groningen

Prof. Dr. R.A.B. Oostendorp, V.U. Brussel

CIP-GEGEVENS KONINKLIJJKE BIBLIOTHEEK DEN HAAG

Sluijs, E.M.

Patient education in physical therapy / E.M. Sluijs, - Utrecht : Nederlands instituut voor onderzoek van de eerstelijnsgezondheidszorg NIVEL

Proefschrift, RU Limburg, Maastricht. - Met lit. opg. - Met samenvatting in het nederlands.

ISBN 90-6905-159-1

Trefw.: fysiotherapie ; patiëntenvoorlichting.

Wordprocessing and lay-out Bernadette Kamphuys

Cover Mieke Cornelius

Correction and translation T.S.Preston, S.Wadsworth,

I.E.C.de Beer, Chr.Kool van Langenberghe

Printing Boekbinderij Post

Het in dit proefschrift beschreven onderzoek werd gefinancierd door het Praeventie Fonds 


\section{Contents}

page

Preface

1 Overview

2 A checklist to assess patient education in physical therapy practice: development and reliability

3 Patient education in physical therapy: towards a planned approach

4 Patient education in physical therapy as related to the patient, the illness and the kind of treatment applied

5 Differences between physical therapists in attention paid to patient education

6 Patients' compliance in physical therapy as related to patients' attitudes and therapists' behavior

7 Patient compliance with exercises: different theoretical approaches to short-term and long-term compliance

Summary

Samenvatting

Literature

Appendices 1-10

Dankwoord

Curriculum vitae 



\section{Preface}

This large scale study on patient education in physical therapy started in 1987 and was funded by the Praeventie Fonds (Prevention Fund). The study describes the way in which physical therapists in non-institutional care in the Netherlands currently inform, instruct and advise their patients. The results are based on audiotaped sessions of physical therapy treatments.

The study was initiated for three reasons: Firstly, patient education is inherently connected with physical therapy and is an essential part of most treatment regimens. Secondly, patient education is an important tool in prevention. Nowadays preventive activities are increasingly practised by physical therapists and that implies at the same time increasing attention to patient education. Thirdly, in physical therapy, just as in medical practice, many patients do not follow prescriptions and advice automatically. Research has shown, however, that compliance can be enhanced by improving the way instructions and advice are given. This makes it important to investigate the way in which physical therapists currently educate their patients and to search for possibilities for improvement of patient education in physical therapy.

The thesis contains the following subjects. Chapter 1 starts with a general overview of the main results of the study. Chapter 2 describes the development and the reliability of a checklist which was used to assess the way in which physical therapists educate their patients. Chapter 3 concerns the programming of patient education. The way in which physical therapists spread their educational activities throughout the entire course of treatment is analysed. The Chapters 2 and 3 are based on a first longitudinal study of 25 patients whose entire course of treatment was audiorecorded.

The next Chapters contain a second study based on 1837 audiorecordings made by 84 physical therapists. Chapter 4 relates the education given by the physical therapists to the illness, the kind of treatment applied and to the characteristics of the patient. In Chapter 5 the differences between physical therapists in their attention paid to patient education are analysed. Chapter 6 describes patient compliance with home exercise programmes as well as the main reasons for patients' non-compliance.

Chapter 7 comprises a theoretical exploration of the difference between short-term and long-term compliance and the implications of this difference for physical therapy practice. The Chapters are written as separate publications; some of them have already been published in Scientific Journals. 
$\therefore$

औ. 


\section{OVERVIEW}

\section{Introduction}

This thesis concerns patient education by physical therapists. We investigated the way in which physical therapists currently inform, instruct, advise and counsel their patients. The results of the study are described in six publications, which are brought together in this book.

In this overview, the outlines and the main results of the study are discussed along with further research questions. We shall particularly focus on the implications for practice and possibilities for improvernent of patient education in physical therapy, because that was the main motive for starting the study.

This overview is not structured along the chronological order of the articles in the book, but along the following subjects:

1 The relevance of patient education in physical therapy. We shall argue that patient education is an essential part of physical therapy treatment and explain why research on this subject is needed.

2 Methodological issues. The study was conducted by means of audiorecorded treatments; the pros and cons of this method are described.

3 Results: educational activities in physical therapy. The way in which physical therapists currently educate their patients is described and analysed, together with patient compliance with exercise regimens. In addition we investigated whether general prerequisites for the quality of patient education are met.

4 Conclusions and recommendations. The main conclusions and recommendations for physical therapy practice are discussed and further research questions are formulated.

\section{The relevance of patient education in physical therapy}

Patient education is "a plannedl learning experience using a combination of methods such as teaching, counseling and behavior modification techniques which influence patients' knowledge and health behavior" ". The latter part of the definition conveys, that the aim of patient education is to influence patients' knowledge and health behavior. Influencing patients" health behavior is the aim in the majority of physical therapy treatments and an essential part of them. In fact, physical therapists are 
Two studies were conducted: a preliminary study and a large scale study. Both concern physical therapy in non-institutional care.

Material of the preliminary study (Chapters 2 and 3).

227 audio recordings of physical therapy treatment sessions.

227 registration forms completed by the physical therapists.

The recordings - made by six physical therapists - cover the entire course of treatment of 25 patlents.

This material was used to develop a checklist with educational activities (appendix 1, page 189) and to test the reliability of the checklist (Chapter 2). In addition, the way in which the educational acthities were spread out throughout the entire course of treatment was analysed (Chapter 3 ).

Material of the large scale study (Chapters 4,5 and 6 ).

1931 registration forms completed by the physical therapists (appendix 2, page 192)

1837 audile recordings of physical therapy treatment sessions

1681 questionnaires completed by patients (appendix 3, page 193)

222 questionnaires completed by physical therapists (appendix 4, page 199)

Sample of physical therapists. From the Nivel Register of Physical Therapists a representative sample was taken of 300 physical therapists with as criterlon working at least 3 days a week. They were asked to make audio recordingsi of treatment sessions and to complete a registration form for each session. In addition, they were asked to complete a once-only questionnaire on their vlews with regard to patient information. The therapists thus knew that the study concerned patient education.

Physical therapist respondents. The questionnaire was returned by 222 physical therapists (response $74 \%$ ). The audiorecordings were made by 84 physical therapists (response $28 \%$ ). A nonresponse analysis (appendix 5, page 210) showed two significant differences between respondents and non-respondents.

1. More men than women participated: $37 \%$ of the male physical therapists participaled (63 out of 170 ) as against $16 \%$ of the female therapists ( 21 out of 130 ).

2. The participating physical therapists encountered more problems in educating patients: $68 \%$ of the participating physical therapists reported one or more problems in educating patients as against $42 \%$ of the non-participating therapists.

Patient respondents. The patients who participated were unselected. The physical therapist was requested to involve in the investigation the first 25 patients whom he or she saw in a certain week. The physical therapists completed a registration form on 1931 patients and asked permission to make an audio recording; 1837 patlents gave permission for the recording and 94 patients refused (response $95 \%$ ). When patients refused, no recording was made.

The average number of recordings per physical therapist is 22 . The physical therapist operated the recorder personally; there was no researcher present.

Patient questionnaire. The 1837 patients who participated were given a questionnaire by the physical therapist upon completion of the session. The therapist requested the patients to complete the questionnaire immediately upon returning home. Of the patients, 1681 returned the questionnaire (response 92\%). The patients returned the questionnaire direct to Nivel and knew that the physical therapist would not see the information. The patients were informed that the study concerned the communication between therapist and patient.

Procedure. The audiotapes were assessed by three trained observers: a physical therapist, a hyglenist and a psychologist. The tapes were divided among them at random. The assessment was performed by means of a checklist with a reliability expressed in Cramer's $V$ from .71 to .90 (Chapter 2). The tapes were scored by listening (and relistening) directly to the audiotapes; no transcriptions were made.

A code number was assigned to the tape, the registration form and the questionnaire of each patient. This made it possible to compare the data of these three sources. 
not the physical therapists paid extra attention to patient education during the recorded sessions could not be checked. One patient remarked (in the questionnaire) that she got more time and attention than usual and one physical therapist told us that a patient delayed discussing an alcohol problem until the recorder was stopped. On the whole however, the physical therapists said that making audiorecordings did not interfere with treatment and that therapist and patient often forget the recorder after the first few minutes. This was proven by the fact that the therapists often forgot to stop the recorder after the patient had left, as the observers noticed. In addition it should be noted that it would have been very difficult for physicial therapists to maintain a shift in behavior during all the - on average 22 - treatments they recorded.

The study purposed to give a representative picture of individual patient education by physical therapists in non-institutional care in the Netherlands. On the whole this aim was achieved, but some remarks should be made. The response of the physical therapists was rather low: out of a random sample of 300 therapists, $79 \%$ completed the questionnaire but only $84(28 \%)$ made audiorecordings. Making audiorecordings for research purposes, quality assessment or peer review - is as yet very uncommon in physical therapy in comparison with for example General Practice. This may have caused the low response.

A non-response analysis (see appendix 5, page 210) showed two significant differences between respondents and non-respondents.

First, more men than women participated: $37 \%$ of the male physical therapists participated ( 63 out of 170 ) as against $16 \%$ of the female therapists ( 21 out of 130 ).

Second, the participating physical therapists encountered more problems in educating patients: $68 \%$ of the participating physical therapists reported one or more problems in education patients as against $42 \%$ of the non-participating therapists.

In these two respects the respondents do not represent the physical therapist population in the Netherlands. This finding has the following implications for interpreting the results. First, it appeared that female therapists counsel their patients more frequently than male therapists, but this difference is small and they do not differ in their opinions about counseling tasks (Chapter 5 , page 90 ). Second, there is a relation between the problems that therapists encounter in educating patients and two educational activities: therapists who encounter problems pay more attention to informing the patient about illness and about advice. This relationship is weak but significant at the bivariate level but is not significant at the multivariate level (Chapter 5, page 88 and 89 ). Thus, although physical therapists who are aware of the difficulties in educating patients are over-represented in the study (perhaps that was a reason to participate), there are no reasons to assume that this has drastically influenced the results.

The education given by the therapists in each session was assessed by means of a checklist with educational items (Chapter 2). The number of informative 'statements" or 'remarks' that the therapist gave on each item was counted. This resulted in the amount of information given. Assessing the amount of information, however, does not automatically imply that each type of information is equally important or that "more 
information is always better'. Although more information provides for greater understanding, when too much information is given patients appear to forget parts of it ${ }^{10}$. Because until now nothing is known about what patients remember or forget of the physical therapists' instructions we started by picturing the current situation. Future research should consider the adequate amount of information that patients should receive per session.

The interrater and intrarater reliability of the checklist themes was tested in the preliminary study and showed average scores of .76 and .81 respectively, expressed in a Cramer's $V$ coefficient of association. The interrater reliability was tested by a physical therapist and a psychologist, who rated a random sample of 33 audiotapes independently. They had three weeks of training in using the system. In general it appeared that the factual information was more reliably scored than the subjective judgements about the therapist-patient relationship. The assessors particularly disagreed about 'the degree of interest shown by the physical therapist' and about 'the extent to which the therapist used the patient's knowledge and ideas'. These results may partly be due to the differences in professional background among the two observers. It might be interesting for future research to investigate if physical therapists and psychologists have different views on a 'good relationship'.

For reason of time saving the intrarater reliability was tested by one of the two observers. A second random sample of 36 audiotapes rated by the psychologist were again rated by the same assessor after a six week period. The reliability coefficients ranged from .71 to .85 . The intrarater reliability of the relationship score was .85 which can considered to be satisfactory.

\section{Results: educational activities in physical therapy}

The main results of the study will be discussed in terms of the five educational activities that are common in physical therapy (Chapter 2): 1 . instructions for home exercises, 2. advice about illness behavior 3 . general health education 4 . teaching about illness and, 5. counseling. Next the quality aspects are discussed and the chapter will end with the differences between physical therapists.

\subsection{Instructions for home exercises}

A very important element in physical therapy treatment is the exercises that patients should regularly perform at home. For example exercises aimed at strengthening muscles, mobilisation or extending range of motion.

In $1178(64 \%)$ of the 1837 recorded sessions the physical therapists instructed the patients to exercise at home (Chapter 4). Patients with back pain, traumata and postoperation conditions received the most exercise instructions. On the whole, however, the differences in the number of exercise instructions between complaints were small (explained variance 1,6\%).

The number of exercise instructions that patients received showed a striking decline 
in the course of treatment (Chapter 3). The therapists gave many instructions in the first and (particularly) in the second session with the patient but in the follow-up sessions this number gradually declined: after the eighth session only few exercise instructions were given. Perhaps the patients then knew what to do, at least the therapists seem to assume this. Knowing what to do, however, although a necessary condition for compliance, is not a sufficient condition. It is important to make a distinction between teaching patients to manage the exercises on the one hand, and motivating patients to comply with exercises on the other hand. Particularly in the second phase of treatment physical therapists have the opportunity to shift their attention to patients' compliance, which, as will be seen, is considered open to improvement.

Only about one third of the patients (35\%) wrote in the questionnaire that they fully complied with the prescribed exercises; $41 \%$ said they exercised 'rather regularly' and $22 \%$ stated that they exercised a little or not at all (Chapter 6). There were no differences between men and women but compliance was related to patient's age and education. Older patients reported more compliance than younger patients and low-educated patients complied significantly better than high-educated patients. In particular, high-educated younger women reported less compliance.

The kind of illiness was not related to compliance: patients with back pain for example did not differ from patients with neck/shoulder pain. The characteristics of the illness, however, were related to compliance: less compliance was seen when patients perceived the complaints as chronic and, conversely, more compliance was reported when the patients had considerable hindrance from the complaints. These findings are in line with the general literature on patients' compliance. The possibility of overcoming hindrance or disability is a motivating factor for compliance. When recovery is impossible and patients suffer from chronic complaints, compliance appears to compete with many other priorities in life ${ }^{11}$.

These figures aboutnon-compliance make it obvious that non-compliance is a problem in physical therapy just as it is in medical practice. ${ }^{4}$. The findings imply that physical therapists are confronted with two problems. Firstly, they have to discover who complies and who does not. This is necessary because otherwise the reason for a falling treatment remains unclear. Discovering non-compliance requires that careful non-threatening questions are asked because patients hardly dare to admit noncompliance $^{12}$. Secondly, physical therapists are faced with the most difficult task of motivating non-compliant patients to comply. This requires insight into the causes of non-compliance, which we shall describe next.

The results of our study revealed that patients' non-compliance was for the greater part explained by two major factors. The first and most important one is 'the barriers that patients perceive to compliance'. This finding is in line with research on the Health Belief Model and Decision Theories ${ }^{13}$. A second factor, significantly but less strongly related to non-compliance, is the 'lack of positive feedback'.

Let us first describe the kind of barriers perceived. The patients who stated that they 
did not exercise at home mentioned the following problems in the questionnaire. As major problem patients mentioned 'lack of time': exercises did not fit into their daily routines or were not adjusted to their situation' ( $35 \%$ of the problems mentioned). In addition, they reported that they forgot to exercise $(22 \%)$, lack of motivation (17\%), and that exercising caused pain or discomfort ( $14 \%$ ). Two problems were significantly more often reported by higher educated patients: 'lack of time" and 'forgetting to exercise". Patients with radiating back pain mentioned more 'other problems' but on the whole the problems are unrelated to the kind of illness.

The problems mentioned by the patients could be interpreted as poor excuses for not exercising, but then the real difficulties that people encounter in changing behavior or habits are wrongly overlooked. When one examines these problems seriously from a patient's point of view and when one looks at the way in which the physical therapists currently prescribed exercise programs, some directions for improvement become obvious.

According to general research findings on patients' compliance it appears to be important that regimens are tailored to patients' particular situation and daily routines. In addition, the barriers that patients encounter must be explored and efforts should be made to resolve them in mutual cooperation with the patient ${ }^{14}$. It appears that the physical therapists used these - compliance enhancing - strategies only incidentally, that is to say in fewer than $10 \%$ of the sessions (appendix 6, page 212). Examples of these strategies were: put a sticker on the telephone that reminds you to exercise when the telephone rings; perform the neck/shoulder exercises every time you visit the bathroom; do pelvic floor exercises in the bus to work; exercise while listening to Michael Jackson. Perhaps even more effective were the solutions in which the exercises were replaced by integrating the necessary motions or movements into sports or hobbies or into dally routines like walking or cycling. The idea behind integrating exercises into patients' daily routines is that patients are reminded to exercise each time the daily routines are performed. In this way exercising is connected to daily routines and as such can become a habit just like patients' usual activities. This mechanism is one of the main principles of Learning Theories and the way in which physical therapists can utilize it is described extensively in Chapter 7 . Because currently the physical therapists seldom use these strategies, we were unable to investigate their effect on patients' compliance. We consider this subject a high priority for future experiments and research.

A second factor in non-compliance was the lack of positive feedback that patients perceived. It appeared that patients who did not know 'whether or not the physical therapist appreciated their efforts' and patients who said 'the therapist was unsatisfied with their exercising" were less compliant than the patients who received positive feedback.

This finding is in line with many results in patients' compliance research. It is also in line with the basic principle of 'positive reinforcement' in Learning Theories: these theories state that human behavior is largely influenced by its positive consequences. 
The way in which physical therapists can utilize this theory (and strategies derived from it) to enhance patients' compliance is described in Chapter 7. We consider it important that these strategies are taught in vocational training.

\subsection{Advice and information}

Giving advice and information is just a practice in physical therapy, as is prescribing exercises (Chapters 2 and 4): in $1268(69 \%)$ of the 1837 sessions, patients received one or more pieces of advice. For example: to correct posture or locomotion $(33 \%)$, to make adjustments in work, sports or hobbies (19\%), to take rest $(15 \%)$ or to apply self-care (13\%) (appendix 6, page 212). The most pieces of advice were given to patients with radiating back pain and the fewest to patients with neck/shoulder pain. Patients received curative advice - for example 'applying ice" - as well as preventive advice, for example 'wearing better shoes'. Many types of advice were both curative and preventive in nature and a clear distinction is difficult to make. For example: 'sitting with a straight back facing a monitor at the right height', 'the right way of lifting', 'raise the slab' etc. Such measures can be curative but may also have a long-term preventive effect.

In physical therapy these preventive aspects of treatment are considered to be of increasing importance and many authors have argued that these tasks should be extended ${ }^{15}$. When we look at the course of physical therapy treatment, an opportunity for it shows up. It was found that the physical therapists gave relatively less advice in the second phase of treatment than in the first phase (Chapter 3). Hence this second phase offers an opportunity to focus on measures to prevent recurrence of symptoms in the future. This requires that physical therapists make an 'educational' plan, integrated into and parallel to the treatment plan. Such a plan enables the distribution of advice systematically along the course of treatment (Chapter 3). A logical sequence for devising such a plan is: pain-relieving measures in the first sessions, curative measures in the follow-up sessions and preventive measures in the latter stage of treatment. More research is needed to investigate whether such a planned approach can provide for a systematic extension of preventive tasks in physical therapy.

Measuring patients' compliance with advice fell outside the scope of this study. Thus we do not yet know whether or not patients comply (in the long term) with the many pieces of curative and preventive advice that they received. What we do know are the problems that patients said they encountered in following advice ${ }^{16}$. Of the patients, $38 \%$ mentioned one or more problems in following advice. Surprisingly, these problems differed from the exercise problems. Whereas 'time' was the greatest problem with exercises, following advice gave problems with 'the feasibility and fittingin of advice' (25\% of the problems) and with 'difficulty in changing lifestylle' (16\%)'. Examples are: "my work requires a stooped posture", "teaching requires all my attention so I forget to correct my posture", "I have two small children so I cannot avoid lifting", "I cannot easily change a fifty-year-old habit".

It can be concluded that exercise problems apparently differ from 'advice problems'. This can be understood because exercising implies 'adding something to one's 
activities' and advice usually implies 'changing one's behavior". More important for daily practice is the finding that problems are not identical among patients but that considerable differences between patients exist. The implications for physical therapy are the same as Bartlett formulated for medical practice: "clinicians should explicitly address the causes of patient non-adherence; they should not assume they know the reasons for patient non-adherence; careful questioning is essential" ${ }^{12}$.

\subsection{General health education}

General health education is defined as promoting a healthy lifestyle and is as such directed at primary prevention (Chapters 2 and 4). In $23 \%$ of the 1837 sessions the physical therapists paid attention to general health education: this concerned fitness and sports $(8 \%)$, health and illness $(6 \%)$, painkillers or medicine (5\%), weight control or nutrition (3\%). Smoking, alcohol and drugs were discussed in only 12 sessions (0.7\%) (appendix 6, page 212). Our analysis indicated that general health education was unrelated to particular diseases, treatment elements or other variables that we measured. It was however most strongly related (explained variance $46 \%$ ) to the questions patients asked and their 'probings' (initiating a new subject). Patients asked for example whether 'painkillers were addictive' or 'if the complaints were caused by smoking'. Or patients remarked that they 'ought to do more sports' (during laborious exercising); or, that they 'ought to lose weight' (during massage). The latter sometimes inspired physical therapist and patient to exchange delicious recipes but usually the physical therapist pointed to the importance of losing weight.

These results indicate that discussing general health topics depends heavily on the initiatives of the particular patient and is not a systematic activity in physical therapy treatments. In fact this finding provides an opportunity for physical therapists to extend their preventive role to the subject of general health education: patients seem to desire it because they ask for it. This finding is in line with Lyne's observations ${ }^{17}$. She also noticed that patients sometimes ask questions lying outside the competence of physical therapists. It seems that the responsibilities and boundaries of general health education in physical therapy are not yet clear. From this it can be derived that the profession should try to reach a consensus about their particular tasks on the subject of general health education.

\subsection{Teaching and providing information about the illness}

The three preceding activities - exercise instructions, advice and health education are aimed at changing patients' behavior. The purpose of 'teaching and providing information about the illness' is to increase patients' knowledge and insight (Chapters 2 and 4). In $80 \%$ of the sessions patients received information about the complaints, the (possible) causes or the prognosis. It was most frequently given in the first session with the patient (Chapter 3 ). The analyses revealed that the physical therapists gave more information to high-educated patients and less to older patients (Chapter 4). The amount of information that patients received was rather strongly related to the number of questions that patients asked (corr .53).

It may be concluded that teaching and informing patients about illness is a regular 
activity in the majority of the physical therapy treatments. It is interesting to mention that the questions that patients asked often were ellicited by the information that the therapist gave. For example the physical therapists' explanation about wear of joints elicited questions such as: 'is it caused by my heavy job; is it grave or serious; how long will it last; can it be cured or will it remain or get worse?' and so on. In general, a reciprocal relation was seen: 'questions elicited information' and 'information elicited questions'. It may therefore be concluded that "giving information" is not unidirectional. It is a characteristic of the interaction between therapist and patient.

\subsection{Counseling about stress related problems}

Counseling within a physical therapy setting does not mean psychiatric care or psychotherapy: it means providing insight into the mind-body togetherness and giving care and support when patients are suffering (Chapter 2 and 4 ). In 421 sessions (23\%) the therapists counseled their patients: they gave for example supportive care when patients suffered from handicaps or pain $(11 \%)$ or discussed the relation between physical symptoms and stress-related problems ( $8 \%$ ) (appendix 6, page 213). The analyses showed some interesting results. Firstly it proved that counseling occurred significantly more during massage as compared with exercise therapy or applying modalities. The conversation was often initiated by the patients' 'probings' (corr .57). Surprisingly, counseling was unrelated to the length of the session, which is in contrast with counseling in general practice ${ }^{18}$. Secondly, not the complaints as such but the perceived psychosocial nature of the complaints explained part of the counseling activities (corr .34). However, half of the patients with psychosocial complaints were not counseled. Women's complaints were more often perceived as psychosocial in nature than men's and they were also more frequently counseled. What do these results imply for physical therapists?

Firstly, it seems that applying massage serves more than one purpose: physical therapists utilized the massage time to counsel the patient on psychosocial problems or distress. The quiet atmosphere and the close contact with the patient facilitated such conversations: patients often began to talk about their problems.

Secondly, perceiving women's complaints as more psychosocial in nature than men's is also found in medical practice ${ }^{19}$. The cause of this is still unknown and research on this subject is continuing. The finding that counseling is related to the (perceived) psychosocial nature of the complaints is not surprising. What is puzzling is the fact that half of the patients with psychosocial complaints were not counseled. Perhaps the physical therapists took the somatic complaints as the 'primary point of application' according to the directives in their job requirements. But this leaves unexplained the great differences between physical therapists that we found (Chapter 5). Further research is needed, particularly because many complaints are considered to be caused or influenced by psychosocial problems or stress ${ }^{20}$.

\subsection{Quality aspects of education}

Patient education in physical therapy does not occur in a vacuum but is part of and integrated into the entire treatment (Chapter 2). It implies that patient education 
appears to full advantage only when general standards for the quality of care are met. These quality aspects at the same time contribute to the effects of patient education in terms of patients' recall and compliance ${ }^{21}$.

At least three prerequisites are considered to contribute to the quality of (educational) care: 1. education should be adjusted to patient's demands and perceptions, 2 . the care-giver should establish a trustful relationship with the patient, 3. a planned and systematic treatment approach should be followed:

A rule of thumb in patient education literature is that education should be attuned to patients' perceptions, expectations and demands ${ }^{22}$. Research has proven that patients are more inclined to accept, to remember and to follow instructions and advice when their expectations are met ${ }^{23}$. Our results indicate that this prerequisite is not yet met in physical therapy (Chapter 4). Only in $12 \%$ of the sessions patients were asked to state their expectations or demands, and only in $4 \%$ of the sessions the therapists asked which self-care activities the patient had applied or was applying currently (appendix 6, page 213). As a consequence it happened that physical therapists prescribed measures that the patient already had tried but that had not helped (we heard it on the audiotapes) or prescribed regimens that were unfeasible because they did not fit into patients' routines or daily life (as was proven by the problems and barriers that patients encounter). From this, it can be assumed with a fair degree of certainty that patients' compliance with the regimens will be enhanced when regimens are better fitted to patients' wishes and circumstances. This is particularly relevant for long-term compliance as can be understood from a theoretical point of view, which we worked out in Chapter 7 . It is obvious that physical therapists have a good opportunity to enhance the quality of patient education by adjusting their education to patients' demands. Research should assess whether such an approach does in fact result in better patient compliance.

The relationship between physical therapist and patient was judged by means of a five-item scale comprising the following aspects of the physical therapist's behavior: reinforcing performance, showing concern for pain, showing interest in the patient, being involved in treatment, facilitating patient's participation (Chapter 2). The observers rated these items on the basis of the physical therapist's verbal behavior; the non-verbal behavior could not be assessed, as was noted. In general the relationship was judged to be rather good (Chapter 4). Surprisingly, the relationship appeared to be significantly 'better' when exercise therapy was applied than when other treatment elements were applied. The cause of this is as yet unknown. It may be that exercise therapy - compared with massage and applying physical agents - requires active participation by the patient, resulting in mutual cooperation and therefore in a better relationship. This finding deserves further research as well as the non-verbal aspects of the communication. In doctor-patient communication non-verbal affective behavior displays a stronger correlation with the quality of care than the verbal affective behavior of the doctor ${ }^{9}$. 
A planned and systematic approach to treatment was more frequently followed by the physical therapists who worked in health centers (Chapter 5). It means working according to a general four-step 'problem-solving' approach, namely 1) identifying the problem 2) setting a treatment goal 3) making a rational treatment plan and, 4) assessing goal achievement. Such an approach is taught in vocational training and can be recognized in practice. Particularly in the first session the therapists informed the patients about their treatment plan and treatment approach. This treatment plan, however, does not cover all the educational aspects, as we have argued before (Chapter 3). It is recommended to complete the treatment plan with an 'educational" plan, parallel to and integrated into the treatment plan. It means 'setting educational goals', 'planning which educational activities in which sequence are required to reach these goals' and 'evaluating whether the goals are achieved". Such a planned approach facilitates a systematic distribution of educational activities among all the sessions with the patients and has proven to contribute to the effects of education ${ }^{6}$.

\subsection{Differences between physical therapists}

There are great differences between physical therapists in their opinions about patient education as well as among their actual educational activities (Chapter 5).

In respect with the opinions, the greatest differences concern the physical therapists' expectations about their patients" compliance and their opinions about counseling tasks. For example, some therapists expect $50 \%$ of their patients to maintain longterm exercising after treatment has stopped, whereas other therapists expect none of their patients being able to maintain exercising. There is also little consensus about counseling tasks: $46 \%$ of the physical therapists consider counseling subsidiary to physical therapy, whereas $51 \%$ consider counseling an essential part of physical therapy treatment.

The extent in which physical therapists actually counseled their patients also showed great differences among physical therapists. In addition, the therapists differed significantly in health educational activities and in the number of exercise instructions they gave their patients.

The relation between the physical therapists' opinions and their actual behavior was rather weak. Although this is not inconsistent with much attitude research, it remains a disappointing result. Nevertheless, the differences in behavior could partly be explained by three factors:

Firstly, education was significantly related to the length of the treatment session: therapists who spent more time with their patients gave more education. Secondly, therapists who perceived many positive effects of their education, also educated their patients more frequently. The latter means that therapists who thought that their education contributed to patients' knowledge, their well being, a sooner recovery, and so on, invested more in education than therapists who did not think so. Perhaps the latter considered it wasted effort and time. Thirdly, therapists who were optimistic about their patients" compliance gave more exercise instructions than therapists who were pessimistic about their patients' compliance. Surprisingly, however, patients' self 
reported compliance with home exercises showed no significant relationship with the optimistic or pessimistic views of their physical therapist.

It is obvious that this finding, as well as the great differences between physical therapists, deserve further research. For physical therapy practice, however, it seems equally important to invest in the development of directions or standards for patient education in physical therapy. Such standards may reduce the current differences between physical therapists.

\section{Conclusions and recommendations}

We shall summarize the main conclusions and the recommendations for practice and next some questions for further research are mentioned.

\subsection{Conclusions and recommendations for practice}

Our results clearly point out that patient education is a normal part of physical therapy treatment in the Netherlands: in $97 \%$ of the sessions some educational activity take place. Most frequently the physical therapists give information about the illness, exercise instructions and curative or preventive advice. These educational activities are inherently connected with physical therapy treatment. This accentuates the importance af the communicative aspects of treatment.

Two educational activities occur less frequently: general health education and counseling the patient on stress-related problems. Both occur in fewer than a quarter of the sessions, indicating that health education and counseling are not (yet) a regular part of physical therapy treatment. However, discussing general health matters seems to be desired by the patients, because they often initiate the conversation about general health matters and psychosocial problems. This finding made us conclude that physical therapists have the opportunity to extend their educational tasks to the subjects of health education and counseling. The development of standards for health education and counseling seems useful because these tasks are as yet unclear: our results show that half of the patients with psychosocial complaints are counseled whereas the other half are not. In sum, the professional tasks on general health education and on counseling can be extended and redefined.

Our results show that compliance enhancing strategies are as yet not incorporated in physical therapy treatment. Whether physical therapists consider it their task to stimulate the patients ${ }^{x}$ compliance or whether they consider it the patient's own choice and responsibility was not asked. The great differences in the therapists' opinions about patients' compliance, however, suggest that they may also differ about their own role in compliance. We hold the view that, ultimately patients make their own choices but that the physical therapists share responsibility in the patient's compliance by prescribing feasible regimens and making it easy for patients to comply. From such a point of view, the way in which physical therapists currently educate their patients can 
be improved by using the main principles of patient education and compliance research. Three opportunities for improvement show up: the planning of education, resolving barriers and using compliance-enhancing strategies: We discuss them successively.

Firstly, it seems important that physical therapists make an educational plan running parallel to and integrated into the treatment plan. According to our findings the amount of information declines in the second phase of treatment, in particular information about home exercises. This provides an opportunity for physical therapists to shift attention in this second phase from exercise-managing to exercise compliance. Both aspects should be incorporated in the educational plan. In addition the educational plan should be built up in a systematic way in accordance with the logical order in giving instructions and advice: pain-relieving measures, curative measures, preventive measures. Such a systematic planning and rational phasing makes it easier to attend to all the educational aspects and facilitates an optimal use of the entire period of treatment.

Secondly, it is important that physical therapists prevent or resolve compliance problems. Our results showed that the main reason for non-compliance is the barriers that patients perceive and encounter in their attempts to comply. Currently, however, physical therapists seldom try to prevent or resolve these problems. This provides an opportunity for improvement. The principle of 'tailoring' can be used to prevent problems: instructions and advice are tailored to the patient's particular situation and circumstances. This prevents prescription of unfeasible regimens. Next, systematic attempts to resolve remaining problems can be undertaken in co-operation with the patient. This requires that the therapist carefully explores the kind of problems that each patient encounters because these differ considerably per patient. Preventing and resolving compliance problems requires concern for the difficulties that patients encounter in their attempts to comply and looking at the regimen from the patient's point of view.

Thirdly, in addition to a systematic planning of the education and resolving compliance problems, one can utilize the basic principles of learning theory - reminders and positive feedback - to stimulate compliance. The physical therapist can - together with the patient - search for cues in patient's daily activities that remind the patient of the behavior and give positive feedback about patient's efforts or performance to reinforce compliance. Such a behavioral approach generally contributes to patients' compliance, at least on the short-term during the treatment period.

Long-term compliance, after treatment has stopped, is far more difficult to obtain, because the stimulating and supervising role of the health care provider is absent. Long-term compliance can be understood from Leventhal's Selfregulation theory. Briefly, this theory states that coping with illness depends on the individual's perceptions of health and illness and on the way, in which outcomes of coping are appraised. Although the applicability of this theory in physical therapy remains to be tested, at 
least two principles seem useful for long term compliance in physical therapy (Chapter 7). Firstly "physical therapists can try to adjust their advice as close as possible to patient's perceptions and their usual coping-patterns because the latter are independent of the health care provider. For this purpose one should ask the patients which self-care activities they already have tried or what kind of measures they are used to take. Secondly, it is important that patients can cope with changing circumstances in the future. For this purpose the physical therapist should explain the mechanism underlying their advice and teach the patient how to translate or generalize advice to new situations. In fact, physical therapist should enable patients to choose their own appropriate solutions. This requires a considerable change in the physical therapists' attitudes and behavior.

Applying compliance-enhancing strategies has consequences for the traditional twicea-week sessions in physical therapy practice. It may be necessary to spread out the sessions over a longer period of time, particularly in the second phase of treatment. In addition, it may be useful to add follow-up sessions or to extend the treatment with extra sessions in the case of long-term compliance. In short, physical therapists should discover an adequate spread of treatment to make optimal use of complianceenhancing strategies.

Finally, it seems highly relevant that compliance enhancing strategies are taught in vocational training. The skills should be explicitly taught in integration with the treatment to provide that they become a habit in practice. For that reason it may be important that the clinical instructors (in school and during apprenticeship) acquire these skills, because they function as models for the new physical therapists. For the practising therapists is seems important that compliance-enhancing strategies are incorporated in the supplementary courses and that they become the subject of peer review meetings. Together these measures will improve the quality of patient education in physical therapy.

\subsection{Further research questions}

On theoretical grounds it is useful in future research, to make a distinction between short-term supervised compliance and long-term unsupervised compliance in physical therapy (Chapter 7). The usual distinction in patient compliance research - short-term and long-term compliance - is only based on an explicit period of time; supervision is not incorporated. This may have contributed to the contradictory results in research findings, because supervision is an essential element in compliance: long-term compliance (say six months) has a quite different meaning when the intervention is still continuing from when the intervention stopped three months previously. As long as the intervention lasts, the health care provider can influence and control the patient's behavior, and this element is lacking when treatment stops. Therefore incorporating the presence or absence of supervision in the definition of short-term and long-term compliance can contribute to a better understanding of patient compliance and to the
comparability of research findings. 
The practical implications of this distinction in short-term supervised and long-term unsupervised compliance should be analysed further. On theoretical grounds supervised compliance requires a different approach from unsupervised compliance. We have argued (Chapter 7) that a behavioral approach seems adequate when shortterm supervised compliance is the goal (as is proven by many research findings) and that the self-regulation theory can be adequate when long-term unsupervised compliance is required. As long as the intervention lasts, the health care provider can utilize the basic principles of the behavioral approach (cues and positive feedback) to stimulate the patient's compliance.

When treatment has stopped this influence of the health care provider is absent and the patient has to regulate his behavior by himself. This implies that long-term compliance requires an other approach than short-term compliance. Leventhal's Selfregulation approach can be helpful, because this approach explicitly aims to enhance patients' self-control and patients' feelings of self efficacy. The way in which this approach could be used by physical therapists is described in Chapter 7 . It seems worthwhile to investigate if this approach can contribute to long term compliance in physical therapy.

In the same line of thought, research is needed on the difference between compliance with curative measures and compliance with preventive measures. In physical therapy, curative measures are usually connected with supervision but in addition they are characterized by at least four elements that are absent in the case of preventive measures:

- curative measures aim at success in the shortest time possible;

- both the physical therapist and the patient can evaluate whether the goal is reached (disappearance of symptoms);

- expected recovery can be a strong motivation to comply;

- and the symptoms often function as cues for compliance.

In contrast, compliance with preventive measures is usually aimed at the long term; evaluation of goal attainment is impossible (symptoms may return despite preventive measures); the motivating factor of expected recovery is lacking and the absence of symptoms implies the absence of reminding cues. This difference between curative and preventive measures implies that different approaches are indicated. The consequences for physical therapy should be investigated.

From our research we conclude that it can be fruitful to analyse the differences in compliance behavior and the theoretical and practical implications connected with it. We followed a three-step approach that can be useful for other researchers in other health care settings. The three steps are: firstly, making a detailed analysis of the compliance behavior at hand; secondly, on the basis of this analysis the best-fitting theory or model can be chosen; thirdly, from this theory or model the recommendations for practice can be derived and understood. In short, such a systematic approach reveals the theoretical and practical consequences of the differences in 
compliance behavior. We recommend that other researchers in other settings will continue along this line of thought.

Research on the effects of compliance-enhancing strategies in physical therapy is highly relevant. It is important to discover which strategies are effective and to investigate whether different strategies are needed for the different forms of compliance behavior: short-term supervised versus long-term unsupervised compliance and compliance with curative versus preventive measures. In addition it can be assumed that compliance with home exercises differs from compliance with advice. Discovering the most adequate strategy in all these situations has scientific relevance but is above all important for physical therapy practice.

An other priority for research is the development of a valid and reliable measurement tool to assess compliance. In our study we used a rather broad indication of patient's compliance with exercises. When - in future research - the effects of different compliance-enhancing strategies are analysed, a more detailed assessment of patient's compliance is needed. The tool to be developed must adequately deal with the different gradations of compliance concerning both exercises and advice. The latter is rather complicated because patients receive different kinds of advice (palliative, curative and preventive) and the pieces of advice are spread out over the entire period of treatment. Nevertheless, attempts to define and assess patient compliance uniformly are highly relevant, because it can also enhance the knowledge about exercise therapy as such. Research on the effects of exercise therapy has found contradictory results: some studies show positive effects, whereas other studies show no effect ${ }^{24}$. It is as yet unclear if this lack of effect is caused by patient's non-compliance with the exercises or that some forms of exercise therapy are more effective than other ones. Therefore, it is important to assess patient compliance uniformly in future research to make research findings comparable and to enhance the knowledge about exercise therapy.

Finally, the barriers that patients perceive should be further investigated. They are the main reason for non-compliance in physical therapy practice and therefore we need to know more about how these barriers hinder compliance. This knowledge is also relevant from a theoretical point of view because the concept of barriers plays a role in many theories. Although most barriers can easily be understood without any theoretical framework, the exact meaning of barriers is not yet clear. This rather broad concept can have different meanings, as our results showed. Firstly, it proved that the barriers differed considerably in nature: besides the difficulties connected with unlearning (bad) habits there were for example situational and motivational barriers. Secondly, the difference between 'perceived' barriers and 'real encountered' barriers should be analysed. This difference may imply that different methods are indicated for removing or resolving barriers. Therefore, we conclude that it has both practical and theoretical relevance to gain more insight into the problems that patients encounter in their attempts to comply. 


\section{Literature}

1 Bartlett EE.

At last, a definition (editorial).

Patient Education and Counseling 7; 1985, 4: 323-324.

2 Dishman RK.

Exercise adherence: its impact on public health.

Champaign: Human Kinetics Books, 1988.

3 Campen $C$ van, Sluijs EM.

Patient compliance: a survey of reviews (1979-1989).

Utrecht: Nivel, 1989. NIVEL-Bibliographies, 38.

4 Haynes RB, Taylor DW, Sackett DL (eds.).

Compliance in health care.

Baltimore, etc.: The Johns Hopkins University Press, 1979.

5 Mullen PD, Green LW, Persinger GS.

Clinical trials of patient education for chronic conditions: comparative meta-analysis of intervention types.

Preventive Medicine 14; 1985: 753-781.

6 Liedekerken $P C_{1}$ Jonkers $R_{s}$ De Haes WFM, Kok GJ, Saan JAM.

Effectiveness of health education.

Assen: Van Gorcum, 1990.

7 Sluijs EM, Kuijper EB.

Problemen die fysiotherapeuten ervaren bij het geven van voorlichting aan patienten: een inventarlsatie. (Problems physical therapists encounter in educating patlents.)

Nederlands Tijdschrift voor Fysiotherapie 100; 1990, 5: $128-132$.

8 Siluijs EM.

Patièntenvoorlichting door fysiotherapeuten (1): antwikkeling van het observatieprotocol. (Patient education in physical therapy: development of the observation form)

Utrecht: Nivel, 1988.

9 Bensing JM.

Doctor-Patient communication and the quality of care: an observational study of instrumental and affective behavior into general practice.

Utrecht: Nivell, 1991. Dissertation.

10 Ley $\mathrm{Ph}$.

Giving information to patients. In: Eiser JR (ed.). Social psychology and behavioral sclence.

New York: John Wiley \& Sons, 1982: 339-373.

11 Gerber KE.

Compliance in the chronically ill: an introduction to the problem. $\| n$ : Gerber KE, Nehemkis AM (eds.). Compliance: the dilemma of the chronically ill.

New York: Springer Publishing Company, 1986: 12-23. 
12 Bartlett $\mathrm{EE}_{\mathrm{u}}$ Higginbotham $\mathrm{JC}$, Cohen-Colle S, Bird J.

How do primary care residents manage patient non-adherence?

Patient Education and Counseling 16;1990, 1:53-60.

13 Sonstroem RJ.

Psychological models. lin: Dishman RK (ed.). Exercise adherence: its impact on public health. Champaign: Human Kinetics Books, 1988: 125-153.

14 Bartlett EE.

Behavioral diagnosis: a practical approach to patient education.

Patient Counselling and Health Education 4; 1982, 1: 29-35.

15 Spenkelink $G_{\text {, Stelt }} L$ vd; Oostendorp $R$.

TAB 2 duizend: Twentse aanpak bedriffsfysiotherapie 2000. (Physical therapy in industry in 2000) Fysiovisie 1991, febr.: 4-8.

16 Sluijs EM, Hermans IMJ.

Problemen die patiënten ervaren bij het doen van huliswerkoefeningen en bij het opvolgen van adviezen: een inventarisatie. (Problems that patients encounter in exercising and following advice) Nederlands Tijdschrift woor Fysiotherapie 100; 1990, 6: 175-179.

17 Lyrie PA.

The professions allied to medicine: their potential contribution to health education.

Physlotherapy $72 ; 1986,1: 8-10$.

18 Verhaak PFM.

Detection of psychologic complaints by general practitioners.

Medical Care 26;" 1988, 10: 1009-1020.

19 Verbrugge LM.

Gender and health: an updlate on hypotheses and evidence.

Journal of Health and Social Behavior 26; 1985, 3: 156-182.

20 White KL.

The task of medicine: dialogue at Wickenburg.

Menlo Park, California: The Henry ل J. Kaiser Family Foundation, 1988.

21 DiMatteo MR, DiNicola DD.

Achieving patient compliance: the psychology of the medical practitioner's role.

New York: Pergamon Press, 1982.

22 Leventhal $H_{0}$ Zimmerman $R$, Gutmann $M$.

Compllance: a self regulation perspective. In: Gentry WD (ed.). Handbook of behavioral medicine.

New York, etc.: The Gullford Press, 1984: 369-436.

23 Leventhal $H_{*}$ Cameron $L$.

Behavioral theorles and the problem of compliance.

Patient Education and Counseling 10; 1987, 2: 117-138.

24 Koes BW, Bouter LM. Beckerman H, Heijden GJMG van der, Knipschild PG.

Physiotherapy exercises and back pain: a blinded review.

British Medical Journal, 302; 1991, 6792: 1572-1576. 


\section{A CHECKLIST TO ASSESS PATIENT EDUCATION IN PHYSICAL THERAPY PRACTICE: DEVELOPMENT AND RELIABILITY}

E.M. Sluijs

Published in Physical Therapy; 71, 1991, 8: 561-569.

\section{Abstract}

Patient education in physical therapy is gaining attention because it can contribute to patient compliance and prevention. Therefore it deserves research and development.

This article describes the development of an assessment tool for investigating patient education in physical therapy. A checklist of 65 educational activity items was constructed. We tested the applicability of the checklist using 227 audio-taped treatment sessions involving patients from private practices in the Netherlands. The 227 audiotaped sessions covered the entire period of treatment for 25 patients, who received an average number of 9 treatment sessions.

The results showed that all except 1 of the 65 educational activities occurred in the 227 treatment sessions and that no educational activities occurred that could not be rated in the checklist. These findings may indicate that the checklist covers the entire range of educational activities currently applied by physical therapists.

The reliability of the checklist was tested using a subsample of the treatments. The average scores for interrater and intrarater reliability as determined by the use of Cramer's $V$ coefficient of association for ordinal data, were .76 and .81 respectively. The checklist can be used to investigate the current educational activities in physical therapy practice. In addition, the checklist can be used in peer review and it can contribute to the development of standards for the quality of care. 
Physical therapists, by the nature of their profession, are primarily concerned with both the treatment and the prevention of physical disabilities ${ }^{1}$. Since the foundation of the profession around 1900, the preventive role has been exercised in part by educating and advising patients during their course of treatment ${ }^{2}$. When asked directly about health education, physical therapists often state that the treatment is incomplete without an element of advice or education ${ }^{3}$. The profession is trying to extend the physical therapist's educational role and to improve the quality of physical therapy education ${ }^{4,5}$. Some plausible reasons for the increased attention paid to patient education are given. We mention the most important ones.

The disorders and diseases treated by physical therapists often show a high rate of recurrence. Such recurrence is often unavoidable because many of the people treated are chronically ill. Recurrence, however, may be delayed or avoided by educating patients in preventive measures and by enhancing patients' compliance with treatment. Patients often seek advice regarding general health related matters ${ }^{1,3}$. Physical therapists can make a unique contribution to general health education and frequent contact with patients allows an optimal opportunity for achieving this goal ${ }^{4,6,7}$.

In order to extend and improve patient education in physical therapy, one first must know what actually happens in practice: 'how do physical therapists currently educate their patients during regular treatments and how do they stimulate patient compliance and health behavior?' Knowledge of what goes right and what goes wrong in itself gives directions for change. Until the present time, however, little has been known about the current practice of patient education in physical therapy, and high quality standards for (educational) care do not exist. Research on this topic is hampered by the lack of an instrument for the assessment of the educational role of physical therapists. The purpose of this study was to provide such an instrument. We have developed a checklist of educational activities that can be used to assess the extent of patient education provided by physical therapists. This article describes the development of the checklist and the determination of its feasibility and reliability for research purposes.

The study involved physical therapists in non-institutional, ambulatory care or private practice settings in the Netherlands. The practice of physical therapists in the Netherlands is discussed briefly in the following section.

\section{Physical therapy in the Netherlands}

The number of physical therapists is relatively high in the Netherlands (nearly one physical therapist per 1000 people) and the profession is growing rapidly $8,9,10$. About one third work in institutional care and about two thirds in private practice. In ambulatory care, patients are referred to physical therapists either by family physicians 
(approximately $80 \%$ ) or by medical specialists (approximately $20 \%$ ). On average, a course of treatment consists of 12-18 sessions with two or three sessions a week. The range of complaints treated by physical therapists in ambulatory care is extensive. The most frequent complaints are back pain (approximately $33 \%$ ) and neck and shoulder pain (approximately 23\%). Most treatments consist of exercise therapy and/or massage, usually combined with the use of modalities.

\section{Methods}

\section{Development of the educational activity checklist}

Patient education is defined as "a planned learning experience using a combination of methods such as teaching, counseling and behavior modification techniques which influence patients' knowledge and health behavior ${ }^{\text {t1t }}$. This definition was interpreted in its broadest sense in the development of the checklist. We made an inventory of all types of teaching, informative activity or counseling a physical therapist can use to influence patients' knowledge and health related behavior on the basis of a review of the literature. We concentrated on the treatment of individual patients; group treatments were excluded. The literature revealed five educational elements commonly present in physical therapy sessions ${ }^{4,12-19}$.

1 teaching and informing the patient about the illness.

2 instructing the patient to perform home exercises.

3 giving advice and information about illness behavior.

4 giving general health education.

5 counseling the patient about stress-related problems.

At least three precursory conditions also appear to be related to the effects of education in terms of patient satisfaction and compliance $e^{2,14-25}$.
A an open, communicative atmosphere during the treatment.
B a planned and systematic approach to the care given.
C concern for the patient's demands and perceptions.

These 5 elements and 3 conditions were further subdivided in 65 checklist items (see table 2.1). 
1 TEACHING AND PROVIDING INFORMATION ABOUT ILLNESS

- about diagnosis and complaints

- about the cause of the illness

- about the prognosis

- illustrative material to clarify information

- mlscellaneouis or remaining topics

\section{INSTRUCTIONS FOA HOME EXERCISES}

- explaining home exercises

- frequency of each exercise

- number of sessions per day

- exerclse instructions

- the bulld-up of the exercise program

- the bulld-up of each exercise

- exercise lleaflet

- Instructions written by the therapist

- integrating exercises to daily activities

- motivating the patient to comply

- monitoring the patient's compllance

- resolving compliance problems

- miscellaneous or remaining topics

\section{ADVICE AND INFORMATION}

- on taking rest

- on correct posture and movement

- on work, sports or hobbies

- on dally activities

- on self care and domestic medicines

- on adaptations

- on aids and appliances

- on health services

- on family physicians or specialists

- motivating the patient to comply

- monitoring the patient's compllance

- resolving compllance problems

- miscellaneous or remaining topics

\section{GENERAL HEALTH EDUCATION}

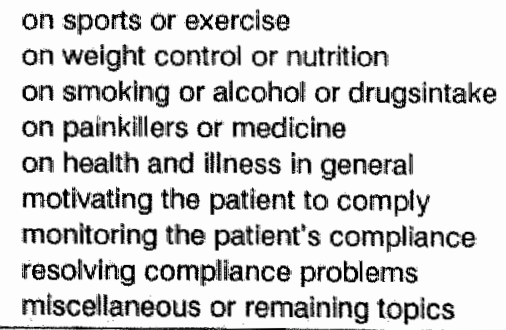

5 COUNSELING ON STRESS-RELATED PROBLEMS

- explaining mind-body relations

- exploring stress-related problems

- supportive care with handlcaps

- supportive care with personal distress

\section{A THERAPIST-PATIENT RELATIONISHIP}

- reinforcing the patient's performance

- showing concern for pain

- showing interest in the patient

- showing involvement in treatment.

- facilitating patient participation

\section{B PLANNED AND SYSTEMATIC APPROACH}

- explaining treatment session

- explaining follow-up treatment(s)

- explaining duration of treatment

- communicating findings from history taking

- communicating findings of the physical examination(s)

- communicating findings of therapy

- explaining aim of physical examination

- explalining alm of exercise therapy

- explaining aim of massage

- explaining aim of a physicall agent

- explaining possible side-effects of treatment

- evaluating the course of treatment

\section{PATIENT'S DEMANDS AND PERCEPTIONS}

- exploring dlemands and expectations

- exploring ideas and perceptions

- exploring self-care activities

- checking the patient's understanding 
The meaning and relevance of the checklist items are discussed in the following paragraphs.

\section{Teaching and providing information about illness}

Teaching and providing information to patients about their illness is defined as making patients understand their illness and its origin. Health care professionals tend to underestimate their patients' need for information ${ }^{23}$; whereas research reveals that this information is highly valued by patients ${ }^{22,26}$. Patients can neither effectively participate in their treatment nor accept responsibility for their own care if they are not informed about what is wrong with them ${ }^{22,27,28}$.

This section of the checklist contains items for the assessment of the physical therapist's teaching about diagnosis, the origin or cause of the illness and the prognosis. This part of the checklist also includes an item for physical therapist's use of illustrative materials to facilitate the patient's understanding of the explanation given.

\section{Instructions for home exercises}

Patient's compliance with a home exercise regime partly depends on the way in which instructions are given. Patient's non-compliance stems partly from misunderstanding or forgetting the instructions $s^{6,21,23}$, or from the inconvenience of the regimen when the exercises are not adapted to patient's activities and daily routines ${ }^{6,21,29-31}$. Encouraging and motivating, the patient to exercise is a contributory factor in patient compliance, as is providing positive feedback ${ }^{2,21,22,32}$. In addition, if the physical therapist monitors the patient's compliance on subsequent visits, and if the therapist resolves the problems the patient encounters in his or her efforts to comply, compliance is more likely 21,24,29,33,34.

These factors noted are included among the thirteen checklist items.

\section{Giving advice and information}

To enable patients to recover from their illness, or to prevent recurrence of the illness, specific advice on the performance of a wide range of activities is indicated. This part of the checklist contains the most important elements, for example, advice about rest, correct posture and locomotion, about work, sports and daily activities, about selfcare and about technical aids and health services. Because the patient's compliance with this advice is as important as his or her compliance with exercises, factors intended to enhance the patient's compliance with advice are included: motivating patients to comply, monitoring compliance and resolving compliance problems.

\section{General health education}

General health education concerns information about a healthy lifestyle. Some authors $^{4-4}$ point out the unique contribution physical therapists can make to this sort of health education. Hayne ${ }^{2}$ suggests that "the physical therapist of the future will surely be an enabler, an educator and above all a preventer". Consequently, this part of the checklist contains items concerning physical activities and sports, obesity and smoking or alcohol or drug intake. Again, motivating the patient to comply, monitoring the 
patient's compliance and resolving compliance problems, are included because this factor may enhance the patient's compliance with general health advice.

\section{Counseling about stress-related problems}

Counseling the patient on stress-related problems is defined as helping the patient explore these problems and discuss ways in which the iliness or complaints are related to them ${ }^{1,7}$. Counseling within a physical therapy setting does not imply psychiatric care or psychotherapy; it means providing insight into the mind-body relation.

A second aspect of counseling is the caring dimension of treatment: the physical therapist can help the patient cope with feelings of distress, fear, and anxiety by listening, understanding, supporting and caring.

\section{Therapist-patient relationship}

A good interpersonal relationship with the patient can result in increased patient satisfaction, better retention of information and better compliance with the pro$\operatorname{gram}^{21,23,35}$. There is no doubt about the relevance of these findings for physical therapists ${ }^{1,15,20}$. The literature reveals several verbal and non-verbal behaviors that contribute to a good therapist-patient relationship. The checklist contains five of the verbal behaviors that could be ascertained from the audio-recordings.

\section{Planned and systematic approach}

A planned and systematic treatment approach is considered to be one of the indicators of the quality of care ${ }^{13,14,25,36,37}$. This approach involves working according to a general four-stage procedure: 1) identifying the problem, 2) setting a treatment goal, 3) making a rational treatment plan, and 4) goal achievement assessment. This information should be shared with the patient. This type of approach can contribute to the efficacy of care and may encourage active patient participation in treatment. This part of the checklist contains 12 items to enable identification of the therapist's approach to caregiving.

\section{Patients' demands and perceptions}

A rule of thumb in patient education is that information must correspond with the demands and perceptions of the patient ${ }^{21,29}$. Patients have their own ideas about health and illness and about ways of coping with illness ${ }^{38,39}$. Compliance is less likely when information and advice are not linked up with these ideas ${ }^{40,41,42}$. So this part of the checklist contains four items to check whether the physical therapist inquires about patients' ideas and requirements.

We should point out that these four items were added at the end of our study. Originally, we focused solely on the provision of information by therapists and not on the routine questions the therapists asked. Thus, we missed the questions that the therapist asked concerning patients' requirements and perceptions: questions that are essential for patient education. Accordingly we completed the checklist afterwards by adding these items, which we will use in future research. 


\section{Subjects and data collection}

The checklist was tested by means of audiotaped treatments of real patients. Out of consideration for patient feelings, we decided to use audiotapes rather than videotapes. The recordings were made by six physical therapists in private practice, four men and two women. They had an average of nine years of experience in physical therapy ( $\mathrm{sd}=4,2$; range $4-17$ years). None of the therapists had specific experience in patient education neither were they specially trained in it. The therapists started the recorders, no observer was present.

The therapists recorded 227 sessions, covering the entire program of treatment for 25 patients. Sixteen of the patients were women; nine were men, with ages ranging from 23 to 68 (mean age $=41.6$ years; $s d=12,5$ ). The patients' complaints involved the back $(n=11)$, neck and shoulder $(n=9)$, and other areas $(n=5)$. The patients were treated twice a week and received an average number of 9 treatment sessions ( $s d=6,3 ;$ range $2-20$ ). The average duration of the treatment sessions was 28 minutes for the first sessions, 22 minutes for the follow-up sessions, and 17 minutes for the last sessions (total mean 22.5 minutes, sd.7.5). This time is the actual face to face contact with the patients; administrative and ather activities were excluded. The patients gave informed consent for the treatments to be audiorecorded. They were told that the study concerned therapist-patient communication.

\section{Testing applicability and reliability}

To test the applicability of the checklist, the 227 audiotaped treatments were rated by means of the checklist. The 227 audiotapes were randomly distributed among two assessors: a psychologist (the author) and a physical therapist (the research assistant). They had three weeks of training in using the system to define the meaning

of each item precisely. These definitions have been described previously in a report ${ }^{43}$. The actual rating occurred without transcription by careful listening and relistening to the tapes.

To investigate the interrater reliability, a random sample of 33 audiotapes rated by the physical therapist, were again independently rated by the psychologist. To assess the intrarater reliability, a random sample of 36 audiotapes rated by the psychologist were again rated by the same assessor after a six week period.

\section{Procedures}

The checklist was used as follows. Each item was initially noted as being present or not present. If it was present, we counted the number of 'informative statements' the therapist made about that particular item. For example, the statement: "Your complaints are not caused by the surgery, overstrained muscles are causing the pain". This example is counted as two informative statements: the first part of the statement informs the patient that the surgical treatment is not the cause of the complaints, the second part of the statement informs the patient that overstrained muscles are the cause. Clearly, making further statements about an item means giving more information or explanation. That is the reason why we assessed the 'number of statements' and not only the presence or absence of an item. We then summed the number of 
statements the therapists gave per theme, for example, about 'home exercises', about "general health education" and so on.

The items on the therapist-patient relationship were rated on a four-point scale. The scale points range from 1 ('bad"relationship) to 4 ("very good" relationship).

\section{Data analyses}

The interrater and intrarater reliability was tested at two levels: the detailed level (the number of statements per item) and the global level (the number of statements per theme). These 'number of statements' are data at the "ordinal" level. The Cramer's $\mathrm{V}$ coefficient of association for ordinal data was used to calculate the reliability coefficients. This statistic is indicated for tables larger than two by two ${ }^{44}$ : frequently more than two statements per item were made. Note, that we did not simply rate the presence or absence of an item, in which case Cohen's Kappa would have been more appropriate.

\section{Results}

\section{The number of informative statements per theme}

We ascertained how many of the 227 sessions dealt with information about each theme to determine whether the educational activities mentioned in the checklist actually occur in daily practice. In addition, we calculated the average number of statements about each theme per session (see table 2.2).

Table 2.2 Number of sessions with and without information per theme and mean numbers of informative statements per theme per session $(n=227)$

\begin{tabular}{|c|c|c|c|c|c|c|c|}
\hline & & infor & lion given & & & mean & \\
\hline & & yes & $\%$ & no & $\%$ & number & sd \\
\hline 1 & teaching about illness & 192 & $85 \%$ & 35 & $15 \%$ & 3.8 & 3.8 \\
\hline 2 & exercise instiructions & 133 & $59 \%$ & 94 & $41 \%$ & $7.7^{*}$ & 7.3 \\
\hline 3 & advice and information & 177 & $78 \%$ & 50 & $22 \%$ & 4.2 & 4.8 \\
\hline 4 & general health education & 82 & $36 \%$ & 1.45 & $64 \%$ & 1.1 & 2.5 \\
\hline 5 & $\begin{array}{l}\text { counselling about stress- } \\
\text { related problems }\end{array}$ & 61 & $27 \%$ & 166 & $73 \%$ & 1.9 & 4.9 \\
\hline A & relationship score & 227 & $100 \%$ & 0 & $0 \%$ & 2.8 & 0.8 \\
\hline B & planned approach & 219 & $96 \%$ & 8 & $4 \%$ & 8.2 & 6.2 \\
\hline
\end{tabular}

*) mean number of exercise instructions when home exercises were given.

w) score on relationship scale ranging from 1 to 4 . 
In the majority of the sessions (85\%), the physical therapists gave the patients information about the illness or the complaints. General health education was provided less frequently (36\%), as was counseling the patient on stress-related problems (27\%). The mean number of statements per theme shows that the therapists in our sample gave the most information on home exercises ( 7.7 informative statements per session) and on advice about illness behavior ( 4.2 informative statements per session). General health education was the topic least discussed.

The therapists gave, on average, 8.2 informative statements per session about their treatment-approach, their treatment plan or their findings. The relationship was, on average, rated as 'rather good', as is indicated by the mean score of 2.8 .

The relatively large standard deviations indicate that great differences existed in the number of statements per session. For example, sometimes the therapist counseled the patient extensively about the way stress could influence the complaints, and thus many statements were scored, whereas an other therapist only made one remark for that theme, for example: "complaints often worsen when stressful events occur".

Part of the difference in the number of statements per session was attributed to the fact that the total amount of education generally declined over the course of treatment, especially concerning home exercises: for example, in the second session a mean of 15 exercise instructions was given, whereas after the seventh session the patients received a mean of 4 exercise instructions per session (see Chapter 3, page 44). In addition to this decline in the amount of education, the therapists gave different types of information over the course of treatment. For example, in the first session, the therapists gave the most information about the illness, and, in the second session they gave the most information about home exercises. Counseling about stress-related problems seemed not to decline but to incline over the course of treatment. The theme general health education did not show many fluctuations over the course of the entire period of treatment.

At the item level, it appeared that all items except one were represented in the 227 sessions, although with different frequencies. The item never rated was 'resolving problems patients encounter in complying with general health advice'."

It also appeared that 'resolving compliance problems' concerning 'home exercises" and concerning "advice and information" seldom occurred in our sample (in less than $2 \%$ of the sessions).

\section{Reliability of the checklist}

The interrater reliability and the intrarater reliability were calculated at the item level (table 2.3) and at the theme level (table 2.4). Because some items occurred infrequently in our sample, we computed the reliability coefficients only for those items that occurred in at least $25 \%$ of the sample: 22 items met this criterion. The reliability coefficients of these items are expressed in a Cramer's $V$ coefficient of association. 


information about diagnosis and complaints
2 information about the cause of the illness
3 information about the prognosis
5 remaining topics conceming the illness
6 explaining home exercises
9 excercise instructions
15 motlvating the patient to comply
16 monitoring the pattent compliance
20 advice on correct posture and movement
30 advice about remaining topics
45 reintorcing the patlent's performance
46 showing concern for pain
47 showing interest in the patlent
48 showing involvement in treatment
49 facilitaling patient participation
50 explaining treatment session
52 explaining duration of treatment
54 communicating findings of examination(s)
55 communicating findings of therapy
57 explaining aim of exercise therapy
60 explaining possible side-effects
61 evaluating the course of treatment

\begin{tabular}{|c|c|}
\hline interrater & intrarater \\
\hline .66 & .65 \\
\hline .70 & .63 \\
\hline .72 & .83 \\
\hline .91 & 89 \\
\hline .90 & .87 \\
\hline .92 & .76 \\
\hline 67 & .81 \\
\hline .69 & .81 \\
\hline .82 & 81 \\
\hline .67 & .55 \\
\hline .76 & .75 \\
\hline .76 & .84 \\
\hline $.13^{*}$ & .64 \\
\hline .65 & .76 \\
\hline $.20^{\star}$ & 64 \\
\hline .60 & .85 \\
\hline .97 & .68 \\
\hline .93 & .74 \\
\hline .83 & .71 \\
\hline .84 & .68 \\
\hline .79 & .83 \\
\hline .59 & .73 \\
\hline
\end{tabular}

*) all coefficients significant $p<.01$ with exception of the two starred coefficients which are not significant, $p>.05$

The majority of the reliability coefficients per item ranged from .70 to .97 , but the reliability was found to be less then .70 for some items (table 2.3). These fluctuations in the reliability per item may be due to the fact that items concerning factual information like 'exercise instructions' or 'duration of treatment' are more reliably scored than items concerning the rather subjective judgements about the relationship: the average interrater reliability of the seventeen 'factual' items was .78 , whereas the average coefficient of the five 'subjective' items was .50 . This difference was not found for the intrarater reliability. It appears that the assessors particularly disagreed about 'the degree of interest shown by the physical therapists' and 'the extent to which the therapist used the patients' knowledge and ideas'. These results may partly be due to the differences in professional background among the two observers, a psychologist and a physical therapist. They seem to have a different view of these two aspects. 
1 teaching and providing information about lliness

2 instructions for home exercises

3 advice and information

4 general health education

5 counseling an stress related problems

A therapist-patient relationstip

B planned and systematic approach

\begin{tabular}{ccc}
\hline interrater & & intrarater \\
\cline { 1 - 1 } .79 & & .71 \\
.90 & & .85 \\
.85 & & .81 \\
.74 & & .82 \\
.84 & & .80 \\
& & .85 \\
.50 & & .85 \\
\hline
\end{tabular}

Table 2.4 presents the reliability coefficients computed per theme. It means that all the statements concerning one theme are summed up, indicating the amount of information the therapists gave about each theme. As could be expected - it was easier to distinguish between themes than between items within a theme - these coefficients were higher than per item and showed fewer fluctuations. The average interrater reliability was .76 and the average intrarater reliability .81. The highest level of reliability was found in 'instructions for home exercises'. The interrater reliability of the relationship scores remains unsatisfactory but not the intrarater reliability.

\section{Discussion}

The purpose of this study was to develop a measurement instrument that can be used to investigate physical therapist's involvement in patient education. The resulting checklist was tested on 227 audiotaped treatments to determine its applicability and reliability.

Applicability of the checklist. This study revealed that the checklist can be used to assess the physical therapists' educational activities in daily practice. In our sample, the checklist items covered the whole range of education in daily practice, because all of the information the therapists gave their patients could be rated on the checklist. The finding that some of the items seldom occurred has important implications regarding the applicability of the checklist: for example, the therapists tried to resolve compliance problems in fewer than two percent of the sessions. In our view, this finding does not mean that these items are thus irrelevant in physical therapy: in the general literature on patient compliance, resolving compliance problems is one of the strategies used to enhance compliance. The checklist can therefore be used to identify which compliance enhancing strategies are currently used infrequently by physical therapists and therefore which aspects should be considered for improvement.

Assigning priorities to particular checklist items depends on the purpose of the education. When the aim is to enhance patients' compliance with exercises and advice, 
some items are highly relevant. For example, adapting exercises to patients" particular situation generally facilitates compliance with the exercise regimens. The same holds true for monitoring patients' compliance and especially for resolving the problems or barriers patients encounter in their efforts to comply. In addition, concern for patients' ideas and perceptions and giving patients positive feedback contribute to their compliance. The relative importance of these items, however, does not imply that other items are irrelevant. Some of the 'important' items, that is activities that are supposed to enhance compliance, are effective only when they are preceded by other items. For example, when patients do not know or remember exactly what to do, they are unable to comply. When the therapists do not explain the reasons for exercising, patients will be less inclined to comply. This information, therefore generally precedes the process of adapting the exercises to patients' particular situation. An other example: physical therapists also can give positive feedback only when they have knowledge about their patients' compliance. Giving positive feedback therefore, should be contingent on carefully investigating whether patients exercise at home. Most important, perhaps, is the fact that the problems and barriers patients encounter can only be resolved when the patients tell their therapist about them. This communication requires an adequate relationship with the patient and an open atmosphere. In short, although some educational activities seem to be very important for facilitating patient compliance, they often must be preceded by other activities presented in the checklist.

Reliability of the checklist. The reliability of the checklist was tested at the item level and at the more global level of the themes. These levels were chosen because they are present in our sequel study on this topic. We intend first to describe the current educational activities in physical therapy (at the level of the themes) and next, to make a detailed study of some relevant topics, for example, compliance enhancing strategies (at the item level). The results indicate that the checklist can be used for research purposes at the level of the themes: the inter and intrarater reliability is on average .76 and .81 respectively. At the level of the items, further work is indicated because the reliability of some items was unsatisfactory. Sound conclusions about the reliability of all of the items can not yet be drawn because our subsample was too small to test all the items. It would be interesting to replicate the reliability study on a much larger sample, but such procedures are extremely time-consuming. A more pragmatic solution would be to select those items of particular relevance, for example, those concerning patient compliance, and retest the reliability of those particular items. It should be noted that our results are based on direct listening to the audiotaped treatments. It may be assumed that transcribing the treatments will yield higher reliability coefficients per item although this hypothesis remains to be tested.

Regarding the therapist-patient relationship, the psychologist and the physical therapist who rated the audiotaped treatments appeared to have different views of a 'good' relationship. The reasons of this phenomenon are as yet unknown and it may be an interesting topic for future research.

Future research. As our study was restricted to testing the checklist only, conclusions 
about the occurrence of patient education activities in physical therapy cannot yet be drawn. The study, however, did reveal several trends that seem worthy of further investigation.

First, it would be interesting to know whether the kind and amount of education required depend on the particular patient and illness. We found large differences between the type and amount of education the patients received, and further research should reveal whether such differences are attributable to the patient and the particular illness or to the attitude of the physical therapist. In addition, it seems relevant to investigate the differences between experienced and unexperienced therapists in educating patients ${ }^{45}$.

Secondly, it appeared that the provision of information declined during the course of treatment. Clearly assessing this pattern of information provision would seem worthwhile. In addition, there could be an investigation of whether it is more effective to spread the information over the entire course of the treatment period to facilitate patient recall. Such an approach requires that the therapists systematically follow an educational plan made beforehand.

Thirdly, it is not yet known whether the checklist can be used in clinical settings. It seems important to investigate whether particular items should be added for particular settings.

Fourth, some authors hold the view that physical therapists have a good opportunity for providing general health education. Investigating the actual involvement of physical therapists in giving general health education in different countries and settings would seem relevant for the developments concerning health education in physical therapy. Finally, we consider it valuable to investigate whether physical therapists currently utilize compliance enhancing strategies and especially, to investigate how patient compliance with exercise regimens and advice depends on the way the physical therapists educate their patients. Such studies can reveal the relevance and priorities of the different checklist items.

Implications for practice. In addition to research, we recommend using the checklist in physical therapy training and practice. Although the checklist cannot be considered as the 'golden standard', it may form a starting point for teaching the skills it entails. The checklist could be used to determine whether the various topics in the checklist are included in the current curriculum. For example whether the students are taught to ascertain patients' demands and perceptions, are they taught to adapt exercises to the patients' situation and so on. If such skills are lacking in the course, they could be added. Most of the activities comprising in the checklist are not time-consuming or are not difficult to apply. It seems necessary that such skills are trained in the vocational training to ensure that physical therapists utilize the skills in their daily practice.

The checklist, or parts of it, may also be of use in peer review or quality assessment. For example, when physical therapists want to discuss the way they give instructions for home exercises in peer-review groups, they can use the checklist items concerning home exercises to check if their instructions cover all of the relevant aspects. Using these checklist items can make it easier to give concrete and directional feedback. 
Finally, we suggest the checklist be used by the physical therapy profession to determine which educational activities are required in the regular tasks of physical therapists, which activities need further development, and which activities are considered to be optional. These priorities might be different in different countries and settings, and the checklist accordingly could be extended with situation-specific items. Reaching consensus about the importance of the different educational activities and compliance enhancing strategies may be an important step in setting standards for the quality of care. 


\section{Literature}

1 Saunders $\mathrm{C}$, Maxwell M.

The case for counselling in physiotherapy.

Physiotherapy $74 ; 1988,11: 592-596$.

2 Hayne CR.

The preventive role of physiotherapy in the National Health Service and industry.

Physiotherapy $74 ; 1988,1: 2-3$.

3 Leathley M.

Physiatherapists and health education: report of a survey.

Physiatherapy $74 ; 1988,5 ; 218-220$.

4 Lyne PA.

The professions allied to medicine: their potential contribution to health education.

Physiotherapy $72 ; 1986,1: 8-10$.

5 Norton S.

Support for physiotherapists in health education.

Physiotherapy 72; 1986, 1:5-7.

6 Mayo NE.

Patient compliance: practical implications for physical therapists: a review of the literature.

Physical Therapy 58; 1978, 9: 1083-1090.

7 Hough A.

Communication in health care.

Physiotherapy $73 ; 1987,2 ; 56-59$.

8. Curfs EC, Groenewegen PP.

Physiotherapy in the Netherlands: an overview.

Physiotherapy Practice 2; 1986: 132-137.

9 Simonds SK, Kanters HW.

Comparative analysis of patient education by four professions in the Netherlands and the United

States.

Patient Education and Counseling 15; 1990, 2: 151-167.

10 Kerssens JJ, Groenewegen PP.

Referrals to physiotherapy: the relation between the number of referrals, the Indication for referral and the inclination to refer.

Social Science and Medicine 30; 1990, 7: 797-804.

11 Bartlett EE.

At last, a definition (editorial).

Patient Education and Counseling 7; 1985, 4: 323-324.

12 May BJ.

Teaching: a skill in clinical practice.

Physical Therapy 63; 1983, 10: 1627-1633. 
13 Beroepsomischrijving fysiotherapeut; (Vocational requirements in physical therapy)

Fyslovisie 2; 1986, 2: 2-6.

14 Bertels $M_{n}$ Brummelen L ten, Dijkum $C J$ van, et al.

Tijd voor kwallitelt: evaluatie-onderzoek fysiotherapie in gezondheidscentra in Amsterdam. (Time for quality: evaluative research physical therapy in health centres.)

Amsterdam: Stichting Universitair Instituut voor Sociaal Wetenschappelijk Onderzoek/Onder-

zoeksplatform in de Eerstelijns Dienstverlening in Amsterdam, 1985.

15 Dickson DA, Maxwell, M.

The interpersenal dimension of physiotherapy: implications for training.

Physiotherapy 71; 1985, 7: 306-310.

16 Glynn Owen OG, Goodge P.

Physiotherapisits talking to patients.

Patient Counselling and Health Education $3 ; 1981,3: 100-102$.

17 Hamillton-Duckett $P$, Kiddd $L$.

Counselling skills and the physiotherapist.

Physlotherapy $71 ; 1985,4: 179-180$.

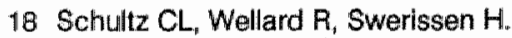

Communication and interpersonal helping skills: an essential component in physilotherapy education?

The Australian Journal of Physlotherapy $34 ; 1988,2: 75-80$.

19 Wagstaff GF.

A small dose of commonsense - communication, persuasion and physiotherapy.

Physiotherapy 68; 1982, 10: 327-329.

20 Croft JJ.

Interviewing in physical therapy.

Physical Therapy 60; 1980, 8: 1033-1036.

21 DiMatteo MR, DiNicola DD.

Achleving patient compllance: the psychology of the medical practitioner's role.

New York: Pergamon Press, 1982.

22 Ice R.

Long-term compliance.

Physical Therapy 65; 1985, 12: 1832-1839.

23 Ley Ph.

Glving information to patients. In: Eiser JR (ed.). Social psychology and behavioral science.

New York: John Wiley \& Sons, 1982: 339-373.

24 Simonds SK.

Indlividual health counselling and education: emerging directions from current theory, research, and practice.

Patient Counselling and Health Education 4; 1983, 4: 175-181.

25 Taylor SH, Gill S.J.

Professional disclosure in the counseling profession: a review of the literature.

Patient Educration and Counseling $5 ; 1983,1: 35-40$.

26 Kindelan $\mathrm{K}$, Kent $\mathrm{G}$.

Patlents' preferences for information.

Journal of the Royal College of General Practitioners $36 ; 1986,291: 461-463$.

27 Steele DJ, Blackwell $B_{,}$Gutmann MC, Jackson TC.

The activated patient: dogma, dream, or desideratum? Beyond advocacy: a review of the active patient concept.

Patient Education and Counselling 10; 1987, 1: 3-23. 
Hyperventilatieklachten. (Hyperventilation) In: Breteler M, Beunderman $R$, Garssen B, Kaptein AA. Behaviorall medicine.

Leiden: Rijks Universiteit Leiden, 1989: 75-85.

29 Bartlett EE.

Behavioral diagnosis: a practical approach to patient education.

Patient Counselling and Health Education 4; 1982, 1: 29-35.

30 Bartlett EE.

Eight principles from patient education research.

Preventive Medicine 14; 1985: 667-669.

31 Dishman RK.

Compliance/Adherence in health-related exercise.

Health Psychology 1; 1982, 3: 237-267.

32 Kok GJ.

Gedragsmodellen in patiëntenvoorlichting. (Behavioral models in patient education) In: Damoiseaux $V$ en Visser APh (eds.). Patiënten- voorlichting: een interdisciplinaire benadering.

Assen, etc.: Van Gorcum, 1988: 61-71.

33 Strecher VJ.

Improving physician-patient interactions: a review.

Patient Counselling and Health Education 4; 1983, 3: 129-136.

34 Stone GC.

Patient compliance and the role of the expert.

Journal of Social Issues $35 ; 1979,1: 35-59$.

35. Feinberg $\mathrm{J}$.

The effect of patient-practitioner interaction on compliance: a revlew of the literature and application in rheumatoid arthritis.

Patient Education and Counseling 11; 1988, 3: 171-187.

36: Sluijs EM, Leden J van der.

Methodisch werken: de ontwikkelingen sinds 1976. (Working methodically: developments since 1976)

Huisarts en Praktijk 31; 1988, 12: 3-7. De kleren van de keizer: supplement bij Huisarts en Wetenschap $31 ; 1988,11$.

37 Weiss SJ.

Consensual norms regarding patient inwolvement.

Social Science and Medicine 22; 1986, 4: 489-496.

38 Pendletón D.

Doctor-patient communication: a review. In: Pendleton D and Hasler $\mathrm{J}$ (eds.). Doctor-patient communication.

London, etc.: Academic Press, 1983: 5-53.

39 Gerber KE

Compliance in the chronically ill: an introduction to the problem. In: Gerber KE, Nehernkis AM

(eds.). Compliance: the dilemma of the chronically ill.

New York: Springer Publishingl Company "1986: 12-23.

40 Leventhal H, Nerenz DR, Steele DJ.

Illness representations and coping with health threats. In: Baum A, Taylor SE, Singer JE (eds.).

Handbook of psychology and health. Vol IV: Social psychological aspects of thealth.

Hillsdalle "New Yersey: Lawrence Erlbaum, 1984: 219-252

41 Southam MA, Dunbar J.

Facilitating patient compliance with medical interventions. In: Holroyd KA, Creer ThL (eds.). Sellmanagement of chronic disease: handbook of elinical interventions and research.

Orlando, etc.: Academic Press, 1986: 163-187. 
42 Leventhal $\mathrm{H}$, Cameron L.

Behavioral theories and the problem of compliance.

Patient Education and Counseling 10;1987, 2:117-138.

43 Slulis EM.

Patientenvoorlichting door fysiotherapeuten (1): ontwikkeling wan het observatieprotocol. (Patient education in physical therapy: development of the observation form)

Utrecht: Nivel, 1988.

44 Agresti A.

Analysis of ordinal categorical data.

New York, etc: John Wiley \& Sons, 1984.

45 Jensen GM, Shepard KF, Hack LM.

The novice versus the experienced cliniclan: insights into the work of the physical therapist.

Physical Therapy $70 ; 1990,5: 314-323$. 


\title{
3 PATIENT EDUCATION IN PHYSICAL THERAPY: TOWARDS A PLANNED APPROACH
}

\author{
E.M. Sluijs
}

Published in Physiotherapy; 77, 1991, 7: 503-508.

\section{Abstract}

Patient education appears to be more effective when it is delivered in a systematic way according to an edlucational programme. We investigated physical therapists' method of educating patients by analyzing the way they program patient education over the entire period of treatment.

We analyzed 227 audiotaped recordings of actual physical therapy treatments. The recordings covered the entire course of treatment for 25 patients. The amount of patient education the therapists provided in each treatment session was assessed by means of a checklist, containing five subjects: 1) teaching and informing the patients about their illness 2) instructions for home exercises 3) advice and information 4) general health education 5) counseling on stress-related problems.

The results show that most information involved the exercises and the least information involved general health education. The therapists gave significantly more information in the first two sessions with the patient, compared with the follow-up sessions. The number of exercise instructions declined over the course of treatment. Giving general health education and counseling did not decline over the course of treatment. The results suggest that physical therapists program some, but not all educational activities throughout the entire course of treatment. It is suggested that physical therapists should draw up an 'educational programme" making it easier for them to program patient education in all the sessions with the patient. 
A planned and systematic approach to patient education contributes to its effectiveness. This view, considered to be a golden rule in the general literature on patient education, is supported by various research findings ${ }^{1}$.

In physical therapy, patient education is receiving increasing attention ${ }^{2-4}$. The topic is, however, not new. Patient education is and has always been a regular part of most treatment regimens.

It is increasingly being recognized that the application of methods deriving from the literature on patient education can contribute to patient compliance and recall and this may, in turn, enhance the effects of treatment ${ }^{5-8}$. One approach is to draw up an educational plan and program the information evenly in stages, throughout the course of treatment. This may facilitate patient compliance with the regimens prescribed.

We do not yet know how physical therapists educate their patients. Neither do we know whether they actually plan their educational activities, or, indeed, whether they program the information they disseminate systematically over the entire period of treatment. Some authors have argued that the treatment setting in physical therapy is optimal for systematically programmed. patient education, as the patient is seen regularly over a longer period of time $e^{9-11}$. Physical therapists can, consequently, utilize the setting to build up their exercise programme step by step thus facilitating the patient's management of the exercises. This graded instructional approach can also be applied to other educational activities in physical therapy. Programming information and advice may also facilitate patient recall ${ }^{12}$ and compliance ${ }^{13}$. Mayo (1978) cautions physical therapists against overloading the patient: "Often, because of a therapist's enthusiasm, a patient is given more instructions than he can cope with, and more changes in life style are demanded than the patient is willing to make" ${ }^{9}$.

As empirical data on this subject is lacking, a pilot study was undertaken to investigate the way in which physical therapists actually do program patient education.

\section{Research question}

The central question is: How do physical therapists spread their educational activities throughout the entire course of treatment? Some knowledge of the way physical therapists currently program patient education may form a starting point for the development of a planned and systematic approach to patient education in physical therapy.

In our study, patient education is defined as "a planned learning experience using a combination of methods such as teaching, counseling and behavior modification techniques which influence patients' knowledge and health behavior" ${ }^{14}$. In physical therapy five educational activities can be distinguished which may be planned and carried out systematically ${ }^{15}$. 
1 teaching and informing the patient about the illness;

2 giving instructions on home exercises;

3 giving advice and information (e.g. on posture or movement);

4 general health education (e.g. On a healthy life style);

5 counseling on stress-related problems and giving care and support.

We have investigated the way physical therapists actually carry out these activities for this study. We focus on the way in which the information given on each topic is distributed throughout the entire programme of treatment.

\section{Methods}

\section{Procedure}

We used audiotaped recordings of physical therapy treatments with actual patients. The recordings were made by six physical therapists working in ambulatory care, 4 men and 2 women. The therapists themselves started the recorder; no observer was present. The therapists had on average nine years experience (range $4-17$ years). None of them had specific experience in patient education, neither were they specially trained in it. It is not possible to determine whether the therapists altered their educational input in response to the trial situation. They stated that recordings did not interfere with the treatment and that both the therapist and the patient often forgot the recorder after the first few minutes. This was supported by the fact that the therapists frequently forgot to stop the recorder when the patient had left - we noticed this ourselves.

The therapists recorded 227 sessions, covering the entire period of treatment for 25 patients. Sixteen patients were women; nine were men. Their ages ranged from 23 to 68 (mean age $=41.6$ years). Their complaints involved the back $(n=11)$, neck $/$ shoulder $(n=9)$ and other areas $(n=5)$. The patients gave informed consent for the treatment to be audio-recorded.

\section{Instrumentation}

A checklist with concrete educational items was used, representing the five educational themes mentioned above. We described the development of the checklist in an earlier publication ${ }^{15}$. The recordings were assessed using this checklist.

To measure the quantity of information in each session, all meaningful informative 'statements' or 'remarks' were counted. For example: "Your complaints are not caused by surgical treatment, overstrained muscles are causing the pain". This example counts as two informative statements: the first - informing the patient that the surgical treatment is not the cause of the complaints and the second that overstrained muscles are the cause.

Counseling was quantified by counting four relevant behaviors: exploring, listening, supporting and explaining.

The total number of informative or counseling statements was recorded for each theme and represents the quantity of information or counseling per theme. 
The reliability of the checklist had been tested beforehand ${ }^{15}$, when the audiotaped treatments were used to assess the inter- and intra-rater reliability. The inter-rater reliability of the five themes ranged from .74 to .90 and the intra-rater reliability ranged from .71 to .85 (expressed in a Cramer's $V$ coefficient of association).

\section{Analysis}

The treatment sessions were labelled first sessions, second sessions, third sessions etc. Sessions eight to twenty were allocated to three classes ( 8 and $9 ; 10$ to $12 ; 13$ to 20). There is also a group of 'final' treatment sessions.

We calculated the number of statements to each theme in each session. Next we compared the average number of statements given in all first sessions, all second sessions, and so on up to and including the final sessions. The differences between groups of sessions were analyzed by means of t-tests.

\section{Results}

The number of treatment sessions with each patient ranged from 2 to 20 , with a mean number of 9 sessions per patient. The therapists spent a mean time of 22.5 minutes at each session, with a range of from 3 to 49 minutes (s.d. 7.5). The time refers to actual contact time with the patient - administrative and other activities performed by the physical therapist were excluded.

Table 3.1 shows how many of the 227 sessions provided information about each theme and the number in which there was no such information. In addition, the table gives the average number of statements on each theme per session. The latter is the sum of all the statements, divided by the 227 sessions.

Table 3.1 Number of sessions with and without information per theme and mean number of informative statements per theme per session $(n=227)$

\begin{tabular}{|c|c|c|c|c|c|c|}
\hline & \multicolumn{2}{|c|}{ information given } & \multirow[b]{2}{*}{ no } & & \multirow{2}{*}{$\begin{array}{l}\text { mean } \\
\text { number }\end{array}$} & \\
\hline & yes & $\%$ & & $\%$ & & $\mathrm{sd}$ \\
\hline teaching about illness & 192 & $85 \%$ & 35 & $15 \%$ & 3.8 & 3.8 \\
\hline exerclse instruction & 133 & $59 \%$ & 94 & $41 \%$ & $7.7^{*}$ & 7.3 \\
\hline advilce and information & 177 & $78 \%$ & 50 & $22 \%$ & 4.2 & 4.8 \\
\hline general health education & 82 & $36 \%$ & 145 & $64 \%$ & 1.1 & 2.5 \\
\hline $\begin{array}{l}\text { counseling on stress- } \\
\text { related problems }\end{array}$ & 61 & $27 \%$ & 166 & $73 \%$ & 1.9 & 4.9 \\
\hline
\end{tabular}

*) mean number of exercise instructions when home exercises were given 
In the majority of the sessions $(85 \%)$, the physical therapists gave the patients information about their illnesses or complaints, for example about the origin of the symptoms or about the cause of the pain. General health education (advice about a healthy life style) was provided less frequently (in $36 \%$ of the sessions) as was counseling the patient on stress-related problems (in $27 \%$ of the sessions).

The mean number of statements show that the therapists in our sample gave the most information on home exercise ( 7.7 informative statements per session) and advice about illness behavior ( 4.2 informative statements per session) . The last concerned advice on taking rest, correct posture or locomotion, wearing better shoes, etc.

The relatively large standard deviations indicate that great differences occurred in the number of statements per session. These differences between the sessions are set out in table 3.2. Graphs one to five in table 3.2 show how the information was distributed among all the sessions with the patients. (see next page) 
Table 3.2 Mean number of statements per theme in each session $(n=227)^{*}$

\section{Teaching about illness}

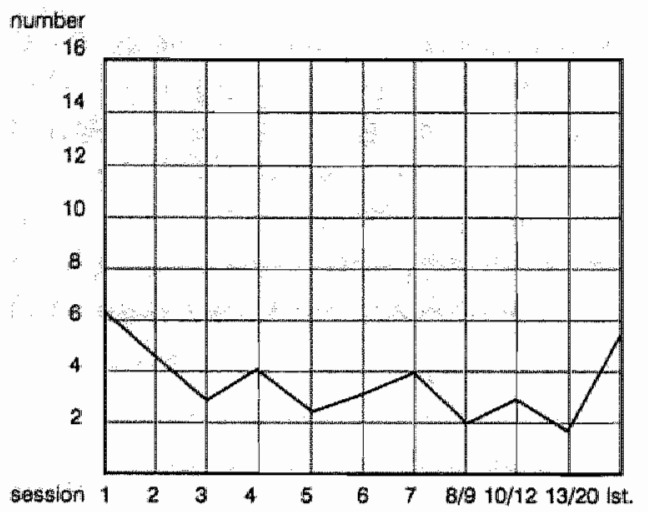

3. Advice and information

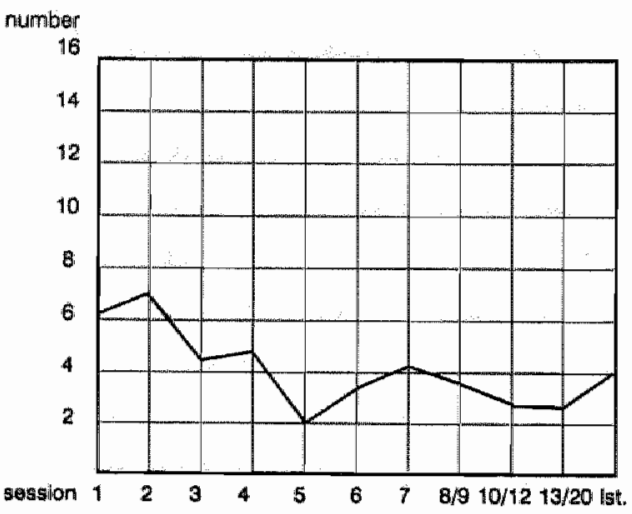

\section{Exercise instructions}

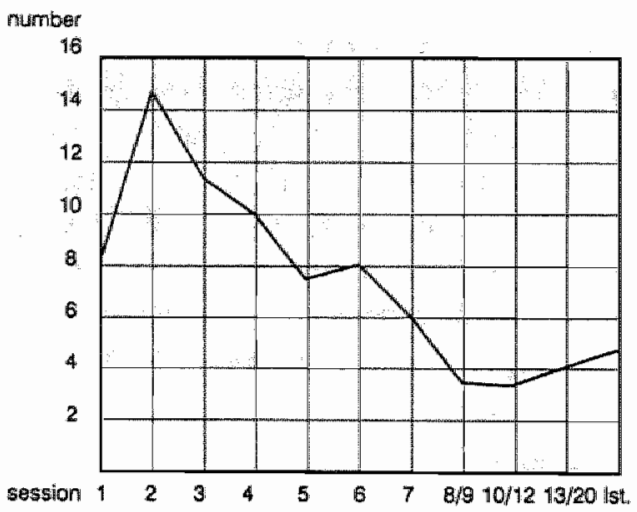

4. General heallth education

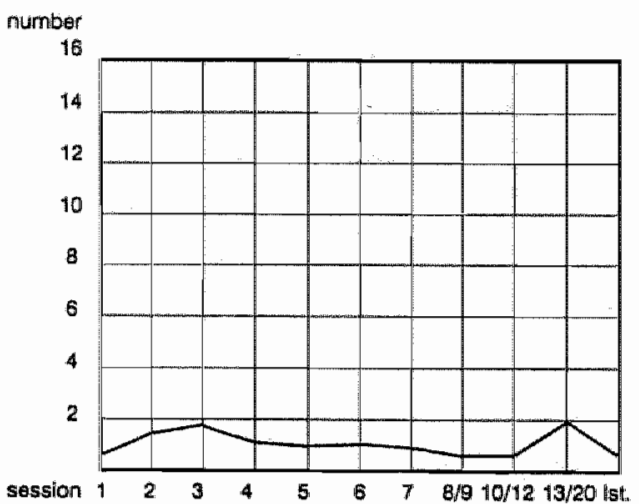

5. Stress-related counseling

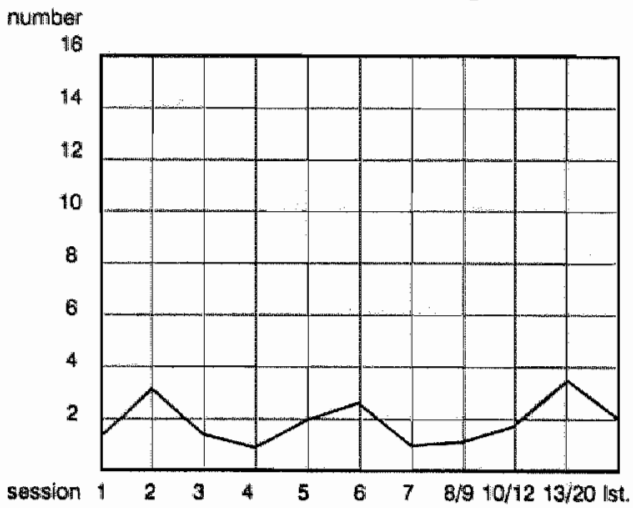

*) the flgures in graph 2 only relate to the sessions where home exercises were given. 
If we take graph 1 as an example; it concerns information about the diagnosis or illness, the cause, the prognosis and the significance of the symptoms. Physical therapists gave an average of nearly seven informative statements in the first session with the patient. In the second session this had fallen to four. In all following sessions the amount of information about the illness declined to two to four statements per session, however in the last session, it rose to six.

An entirely different pattern can be seen in graph 2 on home exercises. These instructions concern for example: the structure of the exercise programme; performance and the required frequency; tailoring exercises to every day activities; monitoring exercise performance and motivating the patient to exercise at home.

Here, most information was given during the second session with the patient. The patients received a mean number of nearly 15 informative statements in each second session. This number steadily decreased in the following sessions. Relatively few instructions on home exercises were given in sessions eight to twenty.

'Advice and information' and 'general health education' also reveal different patterns. 'Advice and information' is defined as informing the patient about the correct way to deal with illness or symptoms and about measures to prevent recurrence of the symptoms in the future. For example, advice on: taking rest, assuming a correct posture, making adjustments in work or sport, using aids, self-care, pain relieving measures etc.

'General health education' was defined as advice on a healthy life style, for example, information about fitness, weight reduction or smoking.

More fluctuations between sessions were seen in the number of statements concerning 'advice and information' when those were compared with "general health education". Physical therapists gave the most advice on illness behavior in the first four sessions. Although patients did not receive much advice about a healthy life style (as graph 4 shows), such advice did seem to be given regularly throughout the entire period of treatment.

'Counseling on stress-related problems" is defined as: explaining to patients the way in which their physical complaints may be connected to stress-related problems (that is, the mind-body connection) and giving patients care and support when they suffer discomfort, pain or handicap. As graph 5 shows, counseling displays virtually no regularity. However, it seems that therapists provided slightly more frequent counseling when they had treated the patients for a longer period of time.

We tested the significance of the differences between the sessions by means of an analysis of variance. As the results indicated that there were significant differences between the sessions ( $p .<.01$ ), a two-tailed $t$-test of significance was applied to further explore these differences. However, since only a restricted number of t-tests can be applied meaningfully, three groups of sessions were formed. These were the groups showing the greatest face value differences: all first and second sessions $(n=46)$, all 
final sessions $(n=19)$ and all the sessions in-between $(n=162)$. Table 3.3 presents the results.

Table 3.3 Mean amount of 'informative' and 'counseling statements" in three groups of sessions $(n=227)$

\begin{tabular}{|c|c|c|c|c|c|c|}
\hline & \multicolumn{2}{|c|}{$\begin{array}{l}\text { Group 1 } \\
(\text { sess } 1+2)\end{array}$} & \multicolumn{2}{|c|}{$\begin{array}{l}\text { Group II } \\
\text { (sess.3-19) }\end{array}$} & \multicolumn{2}{|c|}{$\begin{array}{l}\text { Group III } \\
\text { (final sess.) }\end{array}$} \\
\hline & mean & sd & mean & sd & mean & sd \\
\hline teaching about illness & $5.7^{\mathrm{a}}$ & $(4.3)$ & $3.0^{\mathrm{ac}}$ & (3.2) & $5.9^{c}$ & $(4.5)$ \\
\hline exercise instructions & $11.3^{\mathrm{ab}}$ & (9.1) & $7.2^{a}$ & $(6.9)$ & $4.7^{b}$ & $(3.5)$ \\
\hline advice and information & $6.6^{a}$ & $(6.4)$ & $3.5^{\mathrm{a}}$ & $(4.0)$ & 4.0 & $(4.4)$ \\
\hline general health education & 1.1 & $(3.0)$ & 1.2 & (2.4) & 0.7 & (1.3) \\
\hline $\begin{array}{l}\text { counseling about stress- } \\
\text { related problems }\end{array}$ & 2.4 & $(4.7)$ & 1.8 & $(5.1)$ & 2.2 & $(4.2)$ \\
\hline
\end{tabular}

a) significant difference between graup I and $\| 1 p<.05$

b) significant difference between group I and III $p<.05$

c) significant difference between group II and III $\mathrm{p}<.05$

As can be seen, three of the five educational themes show significant differences between the groups of sessions $(p<.05)$. The patients received nearly twice as much information in the first two sessions compared with the follow-up sessions: they received more information about their complaints, about home exercises and they also received more advice. In respect of the finall session, it is interesting to note that the patients received a relatively large amount of information about the illness and the complaints in this session, and not - as we had expected - more advice about coping with iliness in the future or about measures to prevent a recurrence of the symptoms.

In sum, the results of this analysis indicate that the physical therapists in our study did not program patient education throughaut the entire period of treatment. In fact, the amount of patient education declined significantly during the course of treatment. It was interesting to see that this decline did not apply to all the educational activities. We may conclude that the therapists used different patterns to program patient education over the course of treatment for the different educational activities.

Before turning to a discussion on the implications of these findings, we have selected one of the 25 case studies to exemplify the information-giving patterns described above. 
The patient is a woman of 50 . She was referred to the physical therapist by her general practitioner for 'cervical complaints caused by stress and lasting about three months'. The physical therapist's working diagnosis is that the complaints are localised in T2$3+$ T5-6-7 segments and are apparently caused by limited trunkal mobility with stress as a trigger. She had undergone a mamma-amputation about ten years previously. The physical therapist's treatment plan involves: increasing the range of motion, pain reduction and providing a clearer understanding of the complaints.

The physical therapist planned ten sessions with the patient, twice a week. After a total of 15 sessions, treatment was stopped.

The scheme below shows the type of information the physical therapist gave the patient in each of the 15 sessions.

Scheme 3.1 Number of informative and counseling statements in each of the fifteen sessions given to one patient

\begin{tabular}{|c|c|c|c|c|c|c|c|c|c|c|c|c|c|c|c|}
\hline session & 1 & 2 & 3 & 4 & 5 & 6 & 7 & 8 & 9 & 10 & $\| 1$ & 12 & 13 & 14 & 15 \\
\hline teaching about illness & 13 & 7 & 6 & 2 & 5 & 2 & 5 & 4 & & 1 & & 3 & 1 & 2 & 8 \\
\hline exercise instructions & & & 17 & 13 & 15 & 22 & 9 & 4 & & & & 2 & & 8 & 8 \\
\hline advice and information & 3 & & & 2 & & 1 & 1 & & & & & 5 & 1 & 2 & \\
\hline general health education & & 1 & & & 1 & & & & & & 5 & 1 & & & \\
\hline $\begin{array}{l}\text { counseling about } \\
\text { stress-related problems }\end{array}$ & & 3 & & & & 25 & & 1 & & & & & & & 6 \\
\hline total & 16 & 11 & 23 & 17 & 21 & 50 & 15 & 9 & - & 1 & 5 & 11 & 2 & 12 & 22 \\
\hline
\end{tabular}

A general decline in information occurs in this example as was the case in the total sample. The therapist made an average of 20 informative and counseling statements per session in the first eight sessions with the patient and an average of 8 statements in sessions nine through fifteen. It can also be seen that - broadly speaking - the same patterns emerged. The therapist gave the greatest amount of information about the illness and the complaints in the first session and also, quite a lot, relatively speaking, in the last session when treatment stopped. The instructions on home exercises started in the third session and showed a sharp decline following the sixth session. Other patient education activity does not show a great deal of regularity. 'Advice and information' on illness behavior was occasionally given; it involved pain-relieving selfcare in the first session, and correcting posture in the follow up sessions.

Health behavior was also discussed (smoking and losing weight). The physical therapist had a long counseling talk with the patient in the sixth session. The patient spoke about the mamma-amputation and the therapist gave her a sympathetic hearing, showing concern. The relation between stress and the current complaints was not extensively discussed. 
The total lack of information in the ninth session was caused by the therapist's treatment evaluation in this session. On the grounds of this evaluation, it was decided to continue treatment beyond the ten planned sessions. It is obvious that there is a sharp decline in information giving after this ninth session.

\section{Discussion}

The principal issue here is: How do physical therapists program patient education throughout the entire period of treatment?

The results show that the therapists gave significantly more information (nearly twice as much) in the first two sessions when compared with the follow-up sessions. This phenomenon involved three of the five educational activities: information about the illness and complaints, instructions on home exercise and advice about 'illness behavior". So, we must conclude that the therapists in our sample did not utilize the entire period of treatment to program the information they had to give.

A second result is the finding that the five educational activities did not show the same pattern of decline in the course of treatment: general health education - although infrequently given - did not decline in the course of treatment and that counseling the patient even seemed to increase in the course of time. The three other activities showed different patterns as well. The patients received the most information about the illness in the first and in the final session and the most exercise instructions in the second session. We will first discuss the implications of this for practice and then the suggestions for further research.

\section{Implications for practice}

The finding that the patients received so much information in the first two sessions should be examined. Ley ${ }^{12}$ found that the more information patients receive, the more they forget. In fact, patients appear to forget about half of the information they receive. They forget less when the information is adjusted to their particular demands and perceptions and when they are not embarrassed by worries or pain. This may have consequences for the initial sessions in physical therapy. At the start of treatment, many patients suffer from pain or are anxious about their complaints. They may be worried and feel insecure about the significance of the symptoms and the prognosis. Accordingly, they may focus on particular kinds of information (for example explanations about the symptoms, pain relief, reassurance) and be less receptive to other information (for example exercises, advice or counseling). Physical therapists should therefore first inquire about the concerns particular to each patient. This enables them to adjust the information they give to meet patient needs. It may mean that therapists should sometimes postpone educational activities to follow-up sessions, when patients are more susceptible to them. Fortunately - as physical therapists see their patients a number of times - they have the opportunity to program information and prevent patient overload. In short, adequate patient education requires the right balance between patient's wishes and the therapist's plans. 
The sharpest decline in information during the course of treatment involved instructions on home exercise: very few exercise instructions were given in sessions eight to twenty. Presumably patients then knew what they had to do; at least the physical therapist appeared to assume this. In this respect it would seem important to make a distinction between 'patients' management of the exercises" and "patient compliance with exercises". In the first few sessions the patients are usually instructed as to how to perform the exercises. Being able to perform the exercises, however, does not automatically imply that patients will exercise regularly at home. In fact, it appears that from one third to one half of the patients do not comply with exercise regimens ${ }^{16}$. It would seem important therefore, in the second phase of treatment - after the patients have learned the exercises - for therapists to shift their attention to patient compliance with the exercise programme. As physical therapists see their patients regularly, they have the opportunity to apply a number of compliance enhancing strategies that have proven to be effective ${ }^{17}$. For example, patient compliance can be carefully monitored to give the patients positive feedback about their progress and efforts. In addition, and most importantly, the therapists should carefully inquire into the problems and barriers to compliance. About one third of the patients report one or more barriers to their efforts to comply with exercise regimens ${ }^{18}$ : the problems most frequently mentioned were lack of time and pain or discomfort. The therapists should, together with the patient, search for solutions to these problems and barriers; for example, by tailoring the exercises to a patient's particular situation and daily routines. The follow-up sessions can be utilized to check whether the problems are being adequately resolved. In short, facilitating patient compliance should be a goal in the second phase of treatment.

'Giving advice and information about illness behavior' showed relatively high number of fluctuations throughout the course of treatment. Although this advice was most frequently given in the first two sessions with the patient, it was also frequently discussed in the follow-up sessions. Perhaps those fluctuations were caused by the different nature of the advice given in the different phases of treatment. In the example we gave, the physical therapist first gave advice about pain-relieving self-care and later, advice about correct posture. Thus far we do not know whether the physical therapist has an educational plan in the back of his mind. Perhaps some therapists do program advice carefully throughout the different phases of treatment. A logical sequence for such a programme might be: advice about pain relieving measures in the first sessions, advice on curative measures in the follow-up sessions, and, advice about measures to prevent recurrence of symptoms in the future in the subsequent sessions. In the Netherlands an experiment on this subject is currently being conducted. Physical therapy students are being taught to draw up an educational programme that must be entered on patients' record, just like the treatment plan. It is assumed that such an educational plan will make it easier for physical therapists to program patient education systematically throughout the entire course of treatment. Further research will reveal whether this is feasible. 
There is one final observation about an obvious finding in the example we described. After the planned ten sessions, there was a decline in educational activities in the additional sessions: As the physical therapist had planned his educational activities carefully over the original ten planned sessions, the patient may have received all the necessary information at that time. It may be, however, that the physical therapist was disappointed that the expected improvements did not occur or that the educational activities did not have the expected effects. As a consequence the physical therapist may have lost confidence in his treatment or educational activity and partly (or entirely) given up trying to change the patient's behavior. Since this could be detrimental to the ultimate effects of prolonged treatment, it deserves further exploration.

\section{Suggestions for further research}

As very little is known at present about actual patient education by physical therapists, a great deal of research is yet to be done. We should point out that our study was restricted to 25 patients and 6 physical therapists. So general conclusions cannot yet be drawn. It would be interesting for example, to investigate whether the kind and amount of patient education differs according to the disease involved. It may be assumed that acute diseases require different educational activities when compared with chronic illnesses and perhaps also another programme of education distribution. It would be interesting to compare experienced therapists with novice therapists in respect of their educational activities.

It would also seem relevant to investigate what information patients forget and what they remember in order to discover the right amount of information to give per session.

Further, it would seem very important to investigate patient compliance with exercise regimens and to investigate whether applying compliance enhancing strategies in the follow-up sessions contributes to patient compliance.

Finally, it would seem relevant to know what type of advice (pain relief, curative, preventive) is best in the various phases of treatment, that is to say, to discover the most adequate sequence of advice.

It is important to investigate whether an educational programme makes it easier for physical therapists to distribute the patient education systematically over the entire course of treatment. When more research has been done and we have more knowledge about the educational process in physical therapy, it may become possible to develop standards for the quality of 'educational care' in physical therapy. 


\section{Literature}

1 Lledekerken PC, Jonkers R, De Haes WFM, Kok GJ, Saan JAM.

Effectiveness of health education.

Assen: Van Gorcum, 1990.

2. Norton S.

Support for physiotherapists in health education.

Physiotherapy $72 ; 1986,1: 5-7$.

3 Leathley $M$.

Physiotherapists and health education: report of a survey.

Physiotherapy $74 ; 1988,5: 218-220$.

4 Hayne CR.

The preventive role of physiotherapy in the National Health Service and industry.

Physiotherapy $74 ; 1988,1: 2-3$.

5 Croft dJ.

Interviewing in physical therapy.

Physical Therapy 60; 1980, 8: 1033-1036.

6 Wagstaff GF.

A small dose of commonsense - communication, persuasion and physiotherapy.

Physlotherapy 68; 1982, 10: 327-329.

7 May BJ.

Teaching: a skill in clinical practice.

Physical Therapy 63; 1983, 10: 1627-1633.

8 Ice R.

Long-term compliance.

Physical Therapy 65; 1985, 12: 1832-1839.

9 Mayo NE.

Patient compllance: practical implications for physical therapists: a review of the literature.

Physical Therapy $58 ; 1978,9: 1083-1090$.

10 Lyne PA.

The professions allied to medicine: their potential contribution to health education.

Physiotherapy $72 ; 1986,1: 8-10$.

11 Hough A.

Communication in health care.

Physiotherapy $73 ; 1987,2: 56-59$.

12 Ley $\mathrm{Ph}$.

Giving information to patients. In: Eiser JR (ed.). Social psychology and behavioral science.

New York: John Wiley \& Sons, 1982: 339-373. 
13 DIMatteo MR, DINicola DD.

Achilewing patient compliance: the psychollogy of the medical practitioner's role.

New York: Pergamon Press, 1982.

14 Bartlett EE.

At last, a definition (editorial).

Patient Education and Counseling 7; 1985, 4: 323-324.

15 Slufs EM.

A checklist to assess patient education in physical therapy practice: development and reliability. Physical Therapy $71,1991,8: 561 / 17-569 / 25$.

16 Dishman RK

Exercise adherence: its impact on public health.

Champalgn: Human Kinetics Books, 1988.

17 Sluifs EM, Knibbe Jd.

Patient compliance with exercilse: different theoretical approaches to short-term and long-term compliance.

Patient Education and Counselling 17; 1991, 3: 191-204.

18 Sluijs EM, Hermans IMJ.

Problemen die patienten ervaren bil het doen van huiswerkoefeningen en bij het opvolgen van adviezen: een inventarisatie. (Problems that patients encounter in exercising and following advice) Nederlands Tijdschrift voor Fysiotherapie 100; 1990, 6: 175-179. 


\section{PATIENT EDUCATION IN PHYSICAL THERAPY AS RELATED TO THE PATIENT, THE ILLNESS AND THE KIND OF TREATMENT APPLIED}

E.M. Sluijs, G.J. Kok, J. van der Zee

Submitted.

\section{Abstract}

Improving patient education in physical therapy requires knowledge about the way physical therapists currently educate their patients.

In our study we assessed the kind, the quantity and quality of patient education actually given by physical therapists in private practices in the Netherlands. We investigated if the education was related to characteristics of the patient, the illness and the kind of treatment applied.

The material of the study consists of 1837 audiotaped treatment sessions, recorded by 84 physical therapists. Trained observers rated the audiotapes by means of a checklist.

The results show that in $97 \%$ of all the sessions some kind of education took place: the physical therapists informed the patients about their illness in $80 \%$ of the sessions; home exercises were given in $64 \%$; advice was given in $69 \%$ of the sessions; general health education and counseling both occurred in $23 \%$ of the sessions.

The amount of education was related to the kind of treatment: when massage was applied more counseling took place. Counseling also occurred more frequently when patients' complaints were perceived as psychosocial in nature. However, half of the patients with psychosocial complaints were not counseled. The amount of education was strongly related to the number of questions the patients asked. Younger patients and highly educated patients received more education than older ones and low educated ones. One quality aspect obviously is eligible for improvement: the therapists seldom if at all asked patients to tell their demands and perceptions. In addition, it may be concluded that the therapists' tasks on the subjects of counseling and health education are as yet unclear. 
This study describes the quantitative and quality aspects of patient education given by physical therapists in private practice. In physical therapy, a considerable part of treatment consists of giving patients information, advice and exercise instructions. Physical therapists, in fact, are continuously 'educating' patients about adequate behavior to cure or prevent illness or symptoms. These communicative aspects of treatment are enjoying increasing attention for at least two reasons.

Firstly, physical therapists are increasingly aware of the problem of non-compliance: research findings indicate that about half of the patients do not comply with exercise regimens, especially as time goes by ${ }^{1-3}$. Physical therapists themselves estimated that only one fifth of their patients are able to comply with prescribed exercises in the long run after treatment has stopped ${ }^{4}$. It may be assumed that non-compliance is related to the high recurrence rate of illness in physical therapy practice $e^{5,6}$.

Secondly, nowadays educational methods to enhance patient compliance are being discovered ${ }^{7-15}$. Attempts are being made to incorporate these methods in the physical therapy treatments ${ }^{16-22}$. Whether this may enhance compliance in physical therapy is as yet unknown. Moreover, very little is known about the way in which physical therapists actually educate their patients and about the strategies they use to obtain patients' compliance. If one wants to study and improve patient education in physical therapy one first has to know what actually goes on in practice.

In 'patient education' - "a planned learning experience using a combination of methods such as teaching, counseling and behavior modification techniques which influence patient's knowledge and health behavior" ${ }^{23}$ - three aspects deserve attention: the kind of education; the quantity of education and its quality. In physical therapy three kinds of education are inherently connected with treatment: 1 informing the patient about symptoms or illness, 2. advising him about correct posture and locomotion, 3. giving exercise instructions. Two other kinds of education are less self-evident: giving general health education and counseling the patient on stress-related problems. Whether or not physical therapists consider it their task to give general health education and counsel the patient and whether they actually practice it is not known. Some authors argue that physical therapists have the optimal setting for these activities because the patient is regularly seen over a long period of time $e^{2426}$.

The adequate kind and quantity of education per disease are not yet described in standards or norms. Physical therapists gear their education to the patient and his illness ${ }^{27}$, but whether this leads to great differences per patient is unknown. It might be, for example, that chronic patients, who already know much about their disease, need less information but perhaps more care and support than patients with acute diseases, such as sport injuries. The amount of education may be related to the characteristics of the patients: research indicates that more information is given to patients asking questions, to highly educated patients and to female patients and older patients ${ }^{28-30}$. 
Some studies found that the amount of education is also related to the stage of treatment: patients prove to receive more education during the first encounter than in follow-up encounters ${ }^{31,32}$. This study endeavors to describe the various factors that may influence the amount of education to enhance knowledge about the educational process in physical therapy.

The quality of patient education refers to the way in which the education is given: Research - unfortunately not concerning physical therapy - has resulted in many 'quality' aspects that can contribute to the patient's remembrance, satisfaction and compliance ${ }^{33-36}$. We mention the most important ones: the information should be understandable and be linked with the patient's expectations and perceptions ${ }^{37-4 \%}$; prescriptions should be tailored to the patient's situation and daily routines ${ }^{42-44}$; the patient should be given positive feedback and information about progress ${ }^{45-50}$. It also appears that the more general standards for giving care contribute to the effectiveness of patient education, for example an adequate relationship with the patient and a systematic planned treatment approach ${ }^{51-60}$. Research indicates that a multitude of these quality aspects is more effective in enhancing compliance than a single one ${ }^{61}$. It may be assumed that physical therapists already use some of the quality aspects in educating their patients: many of them appeared to be satisfied with their educational skills ${ }^{4}$. It thus seems important to investigate whether these skills are adlequate or are eligible for improvement.

\section{Research questions}

The basic aim of the study is to discover the main sources of variance in the education that patients receive. Five questions are formulated:

1 What are the kind, the quantity and the quality of patient education in normal physical therapy treatments?

2 Is the education related to the type of treatment and the stage of treatment?

3 Is the education related to the kind of illness and its characteristics?

4 Is the education related to characteristics of the patient?

5 What are the main sources of variance: the treatment, the illness, or the patient? The way in which physical therapists differ in educating their patients is the subject of a separate article (see Chapter 6).

\section{Methods}

A random sample of 300 physical therapists in non-institutional care were asked to make audiorecordings of their treatments and to complete a registration form. The sample was drawn from the Physical therapists Registration of the Netherlands Institute of Primary Health Care. Therapists working fewer than 2 days a week were excluded. Of the sample, 84 (28\%) participated. A non-response analysis (appendix 5 , page 210) revealed two differences between respondents and non-respondents. First, $37 \%$ of the male therapists participated (63 out of 170 ) as against $16 \%$ of the female therapists ( 21 
out of 130). Secondly, $68 \%$ of the respondents encountered problems in educating patients as against $42 \%$ of the non-respondents. Respondents and non-respondents did not differ in their attitudes to patient education.

The patients ( $n=1931)$ were unselected by the physical therapists." each therapist was asked to audiotape one treatment session of the first 25 patients whom he or she saw in a particular week. Patients coming twice a week were recorded only once. Of the patients, $95 \%$ gave informed consent for the treatments to be audiotaped. A total of 1837 audiorecordings were made (mean is 22 recordings per physical therapist). The therapist turned the recorder on and off; no observer was present. Because the recorder was fixed in one room; treatment elements applied elsewhere were not recorded.

\section{Measure the kind and quantity of education}

The 1837 audiotapes were judged by three trained observers; the tapes were randomly distributed among them. The kind and quantity of education were assessed by means of a checklist. The development and justification of the checklist are described in a previous publication ${ }^{62}$. The inter- and intra-rater reliability of the checklist (.71 through .90) appeared sufficient.

The checklist contained five kinds of education:

1 teaching and informing the patient about the illness;

2 instructing the patient to do home exercises;

3 giving advice and information about illness behavior;

4 giving general health education:

5 counseling the patient on stress-related problems.

The observers assessed which of the five educational themes was present on the audiotape and assessed the quantity of education per theme. The quantity was rated by counting all meaningful 'informative remarks' such as: "Your complaints are not caused by surgical treatment; overstrained muscles are causing the pain". This example is counted as two meaningful informative remarks.

Counseling on stress related problems was quantified by counting four relevant forms of behavior: exploring, listening, supporting and explaining. We call them 'counseling remarks'.

The 'informative remarks' and the 'counseling remarks' are together called 'educational remarks'.

\section{Measure the quality of education}

The quality of education was also assessed by means of the checklist. Three quality aspects were rated:

1 The therapist's attention to the patient's perception was measured by counting the number of times that the therapist asked the patient to tell of his or her ideas, demands and perceptions. The total number of such questions is used in the analysis.

2 The relationship between physical therapist and patient was scored by the 
observers on a five-item scale (Alpha .85) (appendix 7, page 214). The items contain the following topics: giving positive feedback; showing concern with pain; showing interest in the patient; showing involvement in treatment; and following a patient-centred approach.

3 A planned and systematic approach was indicated by the extent to which the physical therapists informed the patient about their treatment plan, about their findings and about their evaluation of treatment. We counted the total number of the physical therapists' remarks on these topics.

\section{Measure type of treatment and stage of treatment}

In the treatments, seven elements were distinguished: 1 . anamnesis and physical examination 2. exercise therapy 3. massage 4 . applying a modality 5 . conversation only 6. mixture of treatment elements 7. closing or evaluation of treatment. When a mixture of treatment elements occurred or we could not judge what actually went on, we marked the category 'mixture of treatment elements'. The different combinations of treatment elements are used in the analyses.

The stage of treatment is indicated by the sequential number of the session. The therapist noted this number on the registration form. We distinguished six groups of sessions that are used in the analyses: all first sessions, all second sessions, sessions 3 to 12 , sessions 13 to 24 , sessions 25 to 36 and all sessions above 36 . (In the Netherlands treatments usually consist of one or more series of twelve sessions.)

\section{Measure kind of illness and characteristics of illness}

The diagnosis was written on the registration form. These were classified according to the International Classification of Primary Care (ICPC) by an experienced judge with a medical background. On the basis of the ICPC codes, we distinguished six groups of diseases that are rather uniformly defined in physical therapy and a seventh group with 'other diseases'. Table 4.1 gives the groups of diseases.

Table 4.1 Number of recorded sessions per group of diseases $(n=1837)$

\begin{tabular}{|c|c|c|c|}
\hline & & number & $\%$ \\
\hline 1 & multiple pathology & 83 & $4.5 \%$ \\
\hline 2 & systemic diseases & 94 & $5.1 \%$ \\
\hline 3 & traumata and postoperation & 234 & $12.7 \%$ \\
\hline 4 & radiating back pain & 180 & $9.8 \%$ \\
\hline 5 & back pain without radiation & 312 & $17.0 \%$ \\
\hline 6 & neck/shoulder pain & 319 & $17.4 \%$ \\
\hline \multirow[t]{2}{*}{7} & other & 615 & $33.5 \%$ \\
\hline & total & 1837 & $100.0 \%$ \\
\hline
\end{tabular}


The first six groups of illnesses are mutually exclusive: for example, patients with systemic diseases do not also have radiating back pain; or patients with radiating back pain do not also have neck/shoulder pain.

The physical therapists noted five characteristics of the patient's illiness on the registration form (see appendix 2 page 192):

1 Recidivism. The physical therapist noted whether this was the patient's first treatment or whether he or she had been treated for the same illness before. Of the patients, $846(46 \%)$ had been treated for the same illness before.

2 Hindrance. The degree of hindrance was measured by the following question: "To what extent does the illness form a hindrance for the patient, compared with his/her normal activities?" The physical therapists noted their answer on a four-point scale. It ranged from 'no hindrance' (7\% of the patients) to 'very great hindrance' (17\% of the patients). The other answers lie in between.

3 Duration of illness. This was asked by the question: "How long has the patient been suffering from this illness?" The therapists marked one of six classes, ranging from: 'acute illness' to 'chronic illness'. We made two classes: 'lasting less than 3 months' (43\%) and 'more than three months' (55\%); (2\% were missing).

4 Prognosis. The prognosis of the illness was rated on a four-point scale: ranging from 'the illness will not return' to 'the illness will be permanently present'. The therapists expected $11 \%$ of the illnesses to disappear and $22 \%$ to remain; the others lie in between.

5 Psychosocial nature. The therapist was asked "Do you think that psychosocial aspects are influencing the complaints?" The answer could be marked in one of four classes ranging from "no influence' to 'very considerable influence'. 'No influence' was marked 667 times (36\%) and 'very considerable influence' 192 times $(11 \%)$. The other scores lie in between.

\section{Measure characteristics of the patient}

The patients' characteristics were noted by the therapist. Of the patients, $42 \%$ were men and $58 \%$ were women. Patients' mean age was 45.9 years: $18 \%$ were younger than 30 years; $23 \%$ were older than 60 years. Patients' level of education was noted in four classes: 280 patients (15\%) had 'primary education or less' and 238 of them (13\%) had had 'college education'.

The questions that patients asked were assessed from the audiotapes: the judges rated whether or not the patients asked for information and the number of questions that they asked. Besides these 'direct' questions, we noted the number of patients' 'probings': a 'probing' was scored when the patient himself initiated the discussion about an educational subject.

A mean number of 1.2 questions and 1.6 'probings' per session were scored. In the analyses we use the number of questions and probings concerning each of the five educational themes that we distinguished (for example questions about the diagnosis, questions about home exercises and so on). 
Firstly, the quantity and quality of the education per session and the variation between sessions will be described. Secondly, analyses of variance are used to investigate the proportion of the variance that can be explained by the type of treatment and the stage of treatment, by the disease and its characteristics, and by the characteristics of the patients. Thirdly, a multiple regression analysis is used to investigate which of these factors are most powerful in explaining the variation in patient education.

\section{Results}

\section{The kind, the quantity and the quality of education}

The first questions to be answered are: In how many sessions did the patients receive educational information? And, what is the mean number of educational remarks in each session? The results are set out in Table 4.2; the mean number of remarks is calculated including zeros.

Table 4.2 Number of treattment sessions with education and mean number of educational remarks per session $(n=1837)$

\begin{tabular}{|c|c|c|c|c|c|c|}
\hline & & $\begin{array}{l}\text { sessions with } \\
\text { education }\end{array}$ & $\%$ & $\begin{array}{c}\text { mean } \\
\text { number }\end{array}$ & sd & range \\
\hline 1 & teaching about illness & 1471 & 80.1 & 5.44 & 6.20 & 49 \\
\hline 2 & exercise instructions & 1178 & 64.1 & 6.09 & 8.01 & 82 \\
\hline 3 & advice and information & 1268 & 69.0 & 4.80 & 6.31 & 62 \\
\hline 4 & generall health education & 428 & 23.3 & 1.07 & 2.65 & 24 \\
\hline 5 & $\begin{array}{l}\text { counseling about stress- } \\
\text { related problems }\end{array}$ & 421 & 22.9 & 2,73 & 7.30 & 74 \\
\hline & total education & 1781 & 97.0 & 20.14 & 16.03 & 117 \\
\hline
\end{tabular}

In $97 \%$ of all the sessions, some kind of educational activity takes place. In $80 \%$ of the sessions, the physical therapists teach and inform the patient about the illness; this concerns the diagnosis, the cause of the illness and its prognosis. Giving 'general health education' and 'counseling on stress related problems' occurred much less (both 23\%).

The range (fifth column) indicates great differences between the sessions in the number of remarks per session: the range of 'teaching about illness' for example is 49 , indicating that there is at least one patient who received 49 'teaching' remarks about the illness during the treatment session, whereas $20 \%$ of the other patients got no teaching at all.

The figures on the quality aspects are set out in Table 4.3. 
- patient's perception: number of questions asked
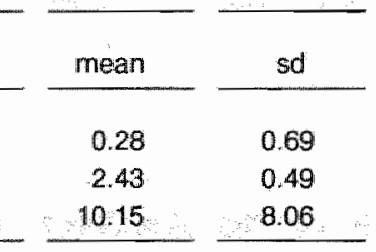

range

- relationship score on relationship scale (1-4)

- planned approach number of remarks

0.15

8.06

9

3

58

The therapists asked a mean number of 0.28 questions concerning patients' perceptions and demands per session. This means that in many sessions no such questions were asked: in $81 \%$ of the sessions no questions of that kind were asked, and only in $37 \%$ of all the first sessions did the therapists ask about patients' perceptions or demands. The relationship score of 2.43 is a rather neutral score. The therapists gave a mean number of 10.15 remarks about their treatmentplan, their findings and treatment evaluation: in the first two sessions, they made more such remarks than in a later stage of treatment.

The way in which these quality aspects are related to the quantity of the education is set out in Table 4.4 .

Table 4.4 Correlation coefficients between quality aspects and the number of educational remarks $(h=1837)$

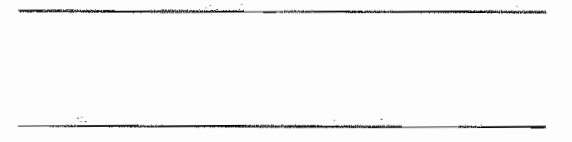

1 teaching about illness

2 exercise unstructions

3 advice and information

4 general health education

5 counseling about

stress-related problems

6 total amount of education
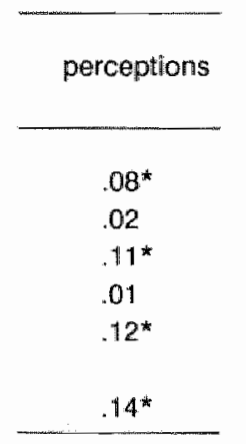

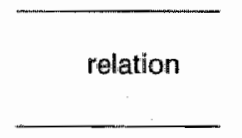

$16^{\star}$

$.32^{*}$

$.22^{*}$

$.07^{\star}$

$.15^{*}$

$.39^{*}$

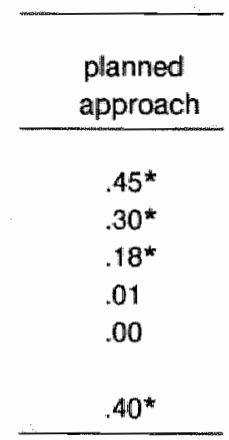

* $p<01$

A significant but weak relation between the quantitative and the quality aspects exists: giving more education goes together with a 'better' relationship between physical therapist and patient and with giving information about the treatment plan. 'General health education' is hardly related to the quality aspects.

The same pattern of correllations emerged, when all the first sessions were excluded from the analysis, which made us conclude that no artefact occurred.

On the whole, it must be stated that the quantity and quality of education are not strongly related: when therapists give more education it does not automatically imply that they also pay more attention to quality aspects of education. 


\section{Education related to type and stage of treatment}

The second question is: is the education related to the type of treatment applied and to the stage of treatment? Or, stated otherwise, when do therapists give education? The amount of education that the therapists gave during different types of treatments is set out in Table 4.5 .

Table 4.5 Number of treatment types and number of educational remarks in each type of treatment $(n=1837)$.

\begin{tabular}{|c|c|c|c|c|c|c|c|}
\hline & number & $\begin{array}{l}\text { inform } \\
\text { diagn }\end{array}$ & $\begin{array}{l}\text { home } \\
\text { exer }\end{array}$ & $\begin{array}{l}\text { advice } \\
\text { behav }\end{array}$ & $\begin{array}{l}\text { health } \\
\text { educ }\end{array}$ & $\begin{array}{l}\text { couns } \\
\text { eling }\end{array}$ & total \\
\hline exercise therapy & 403 & 5.8 & 10.9 & 4.8 & 0.7 & 1.9 & 24.0 \\
\hline massage & 295 & 5.2 & 1.5 & 3.7 & 1.3 & 4.1 & 15.8 \\
\hline applying modality & 136 & 5.0 & 1.0 & 5.5 & 1.1 & 1.7 & 14.3 \\
\hline exercise + massage & 306 & 5.5 & 9.1 & 5.1 & 11.3 & 2.9 & 24.0 \\
\hline exercise + modality & 152 & 5.1 & 7.9 & 4.7 & 1.1 & 1.2 & 20.0 \\
\hline massage + modality & 247 & 4.9 & 1.7 & 4.5 & 1.0 & 3.5 & 15.6 \\
\hline exerc + mass + mod & 162 & 5.9 & 9.7 & 5.6 & 1.1 & 2.7 & 25.0 \\
\hline other & 136 & 6.2 & 1.8 & 5.4 & 1.4 & 3.3 & 18.1 \\
\hline - significance $p<$ & & $\mathrm{ns}$ & .01 & ns & .05 & .01 & .01 \\
\hline - explained variance & & $0.3 \%$ & $25.8 \%$ & $0.6 \%$ & $0.9 \%$ & $1.4 \%$ & $5.9 \%$ \\
\hline
\end{tabular}

Table 4.5 must be read as follows: in 403 sessions, only exercise therapy was applied; in 295 sessions only massage was applied and in 306 sessions both exercise therapy and massage were applied. The amount of education is significantly related to the type of treatment applied. More or less as a matter of course, when therapists applied exercise therapy they gave the most instructions for home exercises, $25.8 \%$ of the variance being explained by it. Counseling occurs relatively more when massage is applied. It is interesting to see that the physical therapists utilized the massage time and perhaps the close contact with the patients - to counsel them about stress related problems. No significant relation is seen between the type of treatment applied and the degree of 'teaching about illness' and 'advice about illness behavior'. The relation between the type of treatment and the kind of illness will be analysed in the next section.

The quality aspects also differ significantly $(p<.01)$ per treatment type. When the therapists applied exercise therapy, they gave more information about their treatment approach (explained variance $8.2 \%$ ). Surprisingly, the relationship between therapist and patient was rated higher (better) when the therapists gave exercise therapy as compared with all other types of treatment (explained variance $8.4 \%$ ). The therapists asked slightly more questions concerning patients" demands and perceptions in the category 'other' types of treatment (explained variance 1.5\%). 
The way in which the amount of education differs between the different stages of treatment is set out in Table 4.6. Per group of sessions we calculated the mean number of educational remarks.

Table 4.6 Number of sessions per ireatment stage and mean number of educational remarks per session $(n=1800)^{*}$.

\begin{tabular}{|c|c|c|c|c|c|c|c|}
\hline & number & $\begin{array}{c}\text { inform } \\
\text { diagn }\end{array}$ & $\begin{array}{l}\text { home } \\
\text { exer }\end{array}$ & $\begin{array}{l}\text { adwice } \\
\text { behav }\end{array}$ & $\begin{array}{l}\text { health } \\
\text { educ }\end{array}$ & $\begin{array}{l}\text { couns } \\
\text { eling }\end{array}$ & total \\
\hline sessions number 1 & 140 & 9.1 & 5.1 & 6.6 & 0.7 & 2.4 & 23.9 \\
\hline sessions number 2 & 97 & 6.6 & 8.8 & 5.1 & 0.5 & 3.5 & 24.5 \\
\hline sessions 3 to 12 & 948 & 5.5 & 6.6 & 5.1 & 1.2 & 2.2 & 20.6 \\
\hline sessions 13 to 24 & 346 & 4.8 & 5.6 & 4.4 & 1.1 & 3.0 & 19.0 \\
\hline sessions 25 to 36 & 102 & 4.8 & 5.8 & 4.2 & .6 & 3.5 & 19.0 \\
\hline sessions $>36$ & 167 & 3.3 & 4.0 & 2.6 & 1.1 & 3.9 & 14.8 \\
\hline - significance $p<$ & & .01 & .01 & .01 & .05 & .05 & .01 \\
\hline - explained varlance & & $4.3 \%$ & $1.6 \%$ & $2.1 \%$ & $0.8 \%$ & $0.7 \%$ & $2.1 \%$ \\
\hline
\end{tabular}

* the session number is missing in 37 cases

The physical therapists gave more information about the illness in the first treatment sessions and more exercise instructions in the second sessions. This is in conformity with the findings of our preceding study ${ }^{32}$. It can be seen that the total amount of education gradually declines in the course of the treatment period. In particular, patients who have had more than 36 sessions - indicating a very long treatment period - received less information than patients with shorter treatment periods. However, it appears that these patients were counseled relatively more about stress-related problems. It seems that counseling increases with time and that informing the patient decreases with time. Whether patients with a very long treatment period are the ones with chronic diseases will be analysed in the next section.

On the quality aspects, the relationship between therapist and patient showed no significant difference between the different groups of sessions. In contrast, $11 \%$ variance in the information about the treatment approach was accounted for by the stage of treatment: the therapists gave twice as much information about their treatment approach and treatment plan in the first two sessions with the patient than in the sessions above number 36 . Particularly in the first session the most questions concerning patients' perceptions were asked (explained variance 2,5\%).

\section{Education related to the kind and characteristics of illness}

The third question is: are the kind and amount of education related to the illiness and its characteristics? Table 4.7 shows the mean amount of education in each group of illnesses. 


\begin{tabular}{|c|c|c|c|c|c|c|c|}
\hline & & $\begin{array}{l}\text { inform } \\
\text { diagn }\end{array}$ & $\begin{array}{l}\text { home } \\
\text { exer }\end{array}$ & $\begin{array}{l}\text { advice } \\
\text { behav }\end{array}$ & $\begin{array}{l}\text { health } \\
\text { educ }\end{array}$ & $\begin{array}{l}\text { couns } \\
\text { eling }\end{array}$ & $\begin{array}{l}\text { total } \\
\text { educ }\end{array}$ \\
\hline 1 & multiple pathology & 4.3 & 4.7 & 3.9 & .7 & 2.6 & 16.2 \\
\hline 2 & systemic diseases & 4.3 & 5.6 & 3.5 & 1.2 & 3.9 & 18.5 \\
\hline 3 & trauma/postoperation & 7.5 & 6.9 & 5.9 & 1.0 & 1.2 & 22.5 \\
\hline 4 & radiating back pain & 6.0 & 7.9 & 6.5 & 1.0 & 1.9 & 23.3 \\
\hline 5 & back pain, no radiation & 4.9 & 7.2 & 4.9 & 1.0 & 2.8 & 20.8 \\
\hline 6 & neck/shoulder pain & 5.1 & 4.9 & 3.8 & 1.0 & 3.1 & 17.9 \\
\hline 7 & other & 5.3 & 5.6 & 4.7 & 1.2 & 3.2 & 20.0 \\
\hline \multirow{2}{*}{\multicolumn{2}{|c|}{ - signiflicance $p<$}} & .01 & .01 & .01 & ns & .01 & .01 \\
\hline & & $2.0 \%$ & $1.6 \%$ & $2.0 \%$ & $0.2 \%$ & $1.0 \%$ & $1.4 \%$ \\
\hline
\end{tabular}

The amount of education depends on the kind of illness at hand, with the exception of general health education. The therapists gave the most education (last column) to patients suffering from radiating back pain and to patients with traumata or postoperation conditions. The least education was given to patients with multiple pathology. Patients with systemic diseases were more often counseled than other patients. It appeared that these patients had slightly more very long treatment periods: $20 \%$ of them had had 36 sessions or more compared to $8 \%$ of the patients with other diseases.

The analysis of variance, however, showed only one interaction effect between the stage of treatment and the kind of illness: it appeared that patients with traumata or postoperation conditions in particular got more pieces of advice in the first session than was predicted by the session number and the illness group $(p<.01)$.

Although the type of treatment was related to the kind of illness - for example, patients with traumata received more exercise therapy and less massage - there was no significant interaction effect between the kind of illness and the type of treatment.

The variance explained by the illness is rather small and does not exceed $2 \%$ (see the last row of Table 4.7).

The quality aspects also displayed minor differences between groups of illnesses, as an analysis of variance indicated. 
Table 4.8 Correlations between characteristics of the liness and number of educational remarks $(n=1547)^{* * *}$

\begin{tabular}{|c|c|c|c|c|c|c|}
\hline & $\begin{array}{l}\text { inform } \\
\text { diagn }\end{array}$ & $\begin{array}{l}\text { home } \\
\text { exer }\end{array}$ & $\begin{array}{l}\text { advice } \\
\text { behav }\end{array}$ & $\begin{array}{l}\text { health } \\
\text { educ }\end{array}$ & $\begin{array}{l}\text { couns } \\
\text { elling }\end{array}$ & $\begin{array}{l}\text { total } \\
\text { edicic }\end{array}$ \\
\hline recidivism & 0.12 & .07 & - & $\therefore$ & .07 & .07 \\
\hline hindrance & - & - & .07 & - & .08 & .06 \\
\hline duration of illness & $\ldots$ & - & -.07 & -. & .10 & -- \\
\hline prognosis & -.11 & - & -. & - & .11 & - \\
\hline psychosocial aspects & -.07 & - & - & - & .34 & .11 \\
\hline
\end{tabular}

* only coefficlents $p<.01$ are in the table

* missing values decreased the number of cases

The relations between the characteristics of the illness and education are on the whole rather weak. Nevertheless, the 'amount of counseling' appears to be related to the characteristics of the illness: when the therapists perceived patients' illness as influenced by (or connected with) psychosocial aspects, they counseled the patient more often. It appeared that psychosocial influences were not connected with specific diseases; the therapists attributed psychosocial influences to all kinds of diseases. The only exception was formed by the traumata and postoperation conditions: the therapists seldom considered traumata or postoperation conditions to be influenced by or connected with psychosocial aspects.

An analysis of variance revealed that $3.9 \%$ of the variance in the total amount of education can be explained by the characteristics of the illness. In particular, $10 \%$ of the variance in 'counseling' was explained by the 'psychosocial nature' of the illness. The interaction between the illness and the illness characteristics showed that patients with non-radiating back pain or neck-shoulder pain were more often counseled when their complaints were perceived as psychosocial in nature than patients with other complaints (interaction effect $p<.01$ ).

\section{Education related to the patient and his characteristics}

The relation between the characteristics of the patient and the amount of education received is expressed in a coefficient of correlation in Table 4.9. Note that the questions that the patient asked were broken down into 'questions about illness', 'questions about home exercises' and so on. 
Table 4.9 Correlation coefficients between characteristics of the patient and number of educational remarks $(n=1772)^{\text {*** }}$

\begin{tabular}{|c|c|c|c|c|c|c|}
\hline & $\begin{array}{l}\text { inform } \\
\text { diagn }\end{array}$ & $\begin{array}{l}\text { home } \\
\text { exer }\end{array}$ & $\begin{array}{l}\text { advice } \\
\text { behav }\end{array}$ & $\begin{array}{l}\text { health } \\
\text { educ }\end{array}$ & $\begin{array}{l}\text { couns } \\
\text { elling }\end{array}$ & $\begin{array}{l}\text { total } \\
\text { educ }\end{array}$ \\
\hline patient's sex & - & - & - & - & $.08^{* * * * * t}$ & -. \\
\hline patient"s age & -.06 &. .10 & .09 & $-\infty$ & - & .10 \\
\hline patient"s education & .13 & -- & - & - & - & - \\
\hline Illness questions & .53 & - & .08 & .09 & - & .27 \\
\hline illness probings & .33 & $\ldots$ & .09 & - & - & .17 \\
\hline exercise questions & .12 & .36 & .06 & - & - & .23 \\
\hline exercise probings & .08 & .30 & .10 & - & - & .23 \\
\hline advice questions & .16 & -- & .46 & - & - & .26 \\
\hline advice probings & .14 & - & .44 & - & .07 & .29 \\
\hline health education questions & .08 & -• & - & .46 & $=$ & .12 \\
\hline health education probings & - & - & - & .57 & .11 & .17 \\
\hline psychosocial questions & .07 & -- & - & - & .23 & .14 \\
\hline psychosocial probings & - & -- & -- & .07 & .57 & .29 \\
\hline total questions & .47 & .13 & .26 & .19 & -- & .39 \\
\hline total probings & .28 & .12 & .30 & .22 & .23 & .42 \\
\hline
\end{tabular}

* only coefficients $p<.01$ are in the table

** missing values decreased the number of cases

*** a t-test showed a significant difference, $p<.01$

The number of questions that patients asked and their 'probings' are significantly related to the total amount of education they received. This holds true for the total number of questions and probings (last rows) but even more strongly for the questions and probings per theme. The therapists in particular gave more information about the illness when patients asked more questions about the illness. Giving advice and general health education depended strongly on patients' questions and their probings. It is interesting to see that patients probings (more than there questions) display a relation to the amount of counseling on stress-related problems. Exercise instructions seemed to be relatively less influenced by patients" questions and probings. We return to this in the discussion.

The other relations, although sifnificant are weak. The amount of education is related to patients" age: patients older than 60 years received less information, fewer exercise instructions and less advice than patients below 60 years; patients younger than 30 years were given the most exercise instructions.

More female patients than male patients were counseled. It proved that women's complaints were also more often perceived as psychosocial in nature. This was not connected with women's age: in all age groups women's complaints were perceived as more psychosocial than men's.

A multiple regression analysis showed that, together, the characteristics of the patient 
explained $28 \%$ in the total amount of education (ranging from $20 \%$ of home exercises to $47 \%$ of general health education) and explained $4 \%$ to $12 \%$ of the differences in the quality of education. The quality aspects were rated slightly higher when patients showed more interest in treatment, as indicated by the number of questions and 'probings".

\section{Main sources of variance in education}

The main sources of variance in the education that the patients received was analysed by a step-wise multiple regression analysis. The eight types of treatments have been compressed to four types because only exercise therapy and massage were significantly related to the amount of education (see table 4.10).

The results are in line with the univariate analyses. Of the total amount of education, $33 \%$ of the variance is explained, mostly by the characteristics of the patient. In particular, patients who asked questions and showed interest in treatment by their 'probings' received more education. Teaching about the illness is most strongly related to patients' questions. In addition, in the first session more such teaching takes place than in sessions above number 36 . As a matter of course, exercise instructions are strongly related to the type of treatment applied. The amourt of advice and general health education seems to depend mostly on patients' questions and probings. In addition, counseling occurs particularly when patients initiate discussions about stressrelated problems - as is indicated by their probings. Therapists also give more counseling when they perceive patients' complaints as more psychosocial in nature. In general it appears that the amount of education is hardly related to the kind of patient"s disease and only slightly related to the characteristics of the disease and to the stage of treatment.

The quantity of education was predicted better (explained variance $33 \%$ to $46 \%$ ) than was the quality of education (explained variance $3 \%$ to $26 \%$ ). The degree in which therapists asked for patients' demands and perceptions is hardly related to the variables that we measured. The other two quality aspects showed some relations: the therapists gave more information about their treatment approach in the initial stage of treatment, when they applied exercise therapy instead of massage, and when the patients asked more questions. The relationship between therapist and patient was judged as better by the observers, when the therapists gave exercise therapy instead of massage or 'other' treatments and when the patients showed interest in treatment by their 'probings'.

We used the split-half method to detect possible artifacts. Two groups of therapists were formed, those giving less education and those giving more education (the median as separating point). Multiple regression analyses were done for each group separateIy. The results showed some minor deviations, only concerning very low Betas. The explained variance remained the same for both groups. We conclude that the relations we found were not caused by therapists giving much and therapists giving little education. 
Table 4.10 Step-wise multiple regression analysis of the quantity and the quality of education as dependents $(n=1500)$

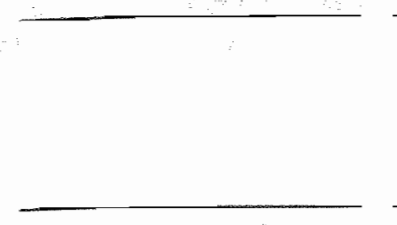

\begin{tabular}{|c|c|c|c|c|c|c|c|c|}
\hline \multicolumn{6}{|c|}{ NUMBER OF EDUCATIONAL REMARKS } & \multicolumn{3}{|c|}{ QUALITY ASPECTS } \\
\hline $\begin{array}{l}\text { Int } \\
\text { diag }\end{array}$ & $\begin{array}{l}\text { home } \\
\text { exer }\end{array}$ & $a d v$ & ghe & $\begin{array}{l}\text { coun } \\
\text { sel }\end{array}$ & $\begin{array}{l}\text { total } \\
\text { duc: }\end{array}$ & $\begin{array}{l}\text { per } \\
\text { cept }\end{array}$ & $\begin{array}{l}\text { rel } \\
\text { at }\end{array}$ & $\begin{array}{l}\text { plan- } \\
\text { ning }\end{array}$ \\
\hline Beta & Beta & Beta & Beta & Beta & Beta & Beta & Beta & Beta \\
\hline
\end{tabular}

\section{TYPE OF TREATMENT}

exercise ther

massage

exercise + mass (dummy)

other

$\begin{array}{ccccccccc}- & .05 & - & - & - & - & - & - & .07 \\ - & -.34 & -.07 & -- & .06 & -.18 & -. & -.25 & -.19 \\ - & -.27 & - & - & -. & -.13 & -. & -.20 & -.10\end{array}$

STAGE OF TREATMENT

session 1
session 2
sessions 3-12 (dum
sessions 13-24
sessions 25-36
session > 36
KIND OF ILLNESS
multiple path.
systemic dis.
traum/postop.
radiation backpain
back pain (dummy)
neck/shoulder pain
other

\begin{tabular}{|c|c|c|c|c|c|c|c|}
\hline-.05 & - & -.04 & .. & $\ldots$ & .14 & .07 & .26 \\
\hline- & - & $\ldots$ & -. & - & $\therefore$ & - & .09 \\
\hline-- & -- & - &.- & - & $\ldots$ & - & $\therefore$ \\
\hline- & $\cdots$ & $\therefore$ & $\therefore$ & - & -- & - & -- \\
\hline$-m$ & -.07 & -- & -. & -.07 & -.. & $\ldots$ & -.10 \\
\hline
\end{tabular}

ILLNESS CHARACTERISTICS recidivism

hindrance

duration

prognosis

psychosoclal

$\begin{array}{lllllllll}-.08 & - & - & - & - & -.07 & - & -.09 & -.08 \\ -- & -- & .05 & -- & - & -- & - & .05 & - \\ - & - & -- & - & - & -- & - & - & - \\ - & - & - & -- & - & - & -- & .08 & - \\ -- & -- & -- & - & .22 & .14 & .08 & - & \cdots\end{array}$

PATIENT CHARACTERISTICS

\begin{tabular}{|c|c|c|c|c|c|c|c|c|c|}
\hline $\operatorname{sex}$ & - & -- & $\ldots$ & -. & - & - & $-\infty$ & $\because 08$ & 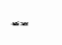 \\
\hline age & -.04 & -.07 & -.08 & - & $\therefore .05$ & -.10 & -.08 & -- & .07 \\
\hline education & .05 & -.05 & -- & - & - & - &.$- \cdot$ & -.- & -- \\
\hline questions** & .49 & .25 & .40 & .39 & .14 & .29 & $-\infty$ & $\cdots$ & .24 \\
\hline probings ** & .22 & .16 & .33 & .49 & .50 & .32 & - & .14 & .13 \\
\hline Multiple R & .62 & .60 & .59 & .68 & .63 & .58 & .17 & .34 & .52 \\
\hline Adjusted R2 & .39 & .36 & .34 & .46 & .39 & $\times 33$ & .03 & .11 & .26 \\
\hline
\end{tabular}

* missing values decreased the number of cases

** In the first five columns the number of patients' questions and probings are calculated per theme; in the sixth to ninth column, the total number of questions and probings is calculated 


\section{Discussion}

This article has described the physical therapist's educational activities in regular treatments and the main sources of variation in the education that patients received. Before the results are discussed, some methodological remarks must be made.

The choice of audio instead of videorecordings was made to lower the participation threshold for patients and therapists. The majority of the patients did in fact participate but many therapists considered making audiorecordings too much a burden or were afraid that recording would interfere with treatment. Such interference appeared to be minimum: after the first few minutes patient and therapists seemed to forget the recorder and therapists often forgot to turn the recorder off after the patient had left. Whether or not the therapists paid more attention than usual to education cannot be checked. One may assume, however, that it would be very difficult for therapists to maintain such a change of behavior during the more than twenty sessions that they recorded.

The results of the study confirm the fact that at least three kinds of patient education are inherently connected to physical therapy. In the majority of the sessions the therapists taught the patients about the illness and gave them exercise instructions and advice. Because exercises as well as advice were often aimed at preventing recurrence of symptoms in the future, secondary prevention appeared to be inherently connected to physical therapy treatment.

Primary prevention - promoting a healthy lifestyle - is much less a regular activity in physical therapy: it occurred in less than a quarter of the sessions. Perhaps the physical therapists did not consider it their task to give general health education: some therapists told us that they were reluctant to interfere with a patient's lifestyle and considered it the patient's own choice and responsibility. It was obvious however, that the patients themselves often started the conversation about general health matters. This might indicate that patients desire or appreciate information and advice on such subjects. In fact, this provides an opportunity for physical therapists to extend their preventive tasks, as some authors advocate. It may be concluded that these tasks are as yet unclear in physical therapy as they are in general practice ${ }^{63-68}$. It seems useful that the profession reaches consensus about the physical therapists' tasks on the subject of health education and primary prevention.

The study revealed that the therapists did counsel patients in aimost one fourth of the sessions: they gave the patients explanations of the way in which psychosocial distress could influence the complaints and they gave care and support when patients suffered from handicaps or distressing life events. The latter subjects were often initiated by the patient during massage time. Thus giving massage proved to have more than one function. It would be interesting to know whether applying massage does in fact facilitate such discussions. 
When a counseling conversation is indicated in physical therapy treatment is not clear. One might assume that this depends on the psychosocial nature of patients' complaints. Our results indeed showed that the therapists gave more counseling according to their perceiving more psychosocial influences. But this was not a 'one to one' relationship: only half of the patients with complaints perceived as "very much influenced by psychosocial aspects' were counseled, the others were not. We do not know what caused the difference. Perhaps the therapists or patients considered counseling the responsibility of other health care professionals. Perhaps some patients would not talk about psychosocial matters at all. Another explanation lay in the fact that physical therapists take the somatic complaints as the 'primary point of application', according to the directives in their task requirements. This does not, however ${ }_{n}$ explain the considerable differences between the physical therapists; some of them frequently counseled patients, whereas others did so hardly if at all. It seems important to develop some 'handholds' for physical therapists about the indications for counseling.

The quality of the education cannot be judged as 'good' or 'bad', because standards do not yet exist. The results showed that the therapists frequently informed the patients about their treatment approach and treatment plan. One thing, however, we consider calls for obvious improvement: the physical therapists seldom asked about patient's ideas, demands and perceptions. In more than three quarters of the sessions, no such questions were asked, and, more strikingly, in two third of the first sessions such questions were absent. Sometimes, this led to confused discussions and even to irritated patients. For example: the patient who was extensively advised to apply a "hot lamp' at home remarked with some irritation that he had already done so for a fortnight but that it had not helped. If the therapist had asked before what the patient had already done, such confusion would have been prevented. Another example: the patient who, after receiving lengthy exercise instructions, plucked up his courage to confess that he had had the same exercises before, but had never done them at home.

It may be clear that physical therapists can adjust their education and advice to the particular patients only when their view is known. It seems important to accentuate the importance of the patient's view in the vocational training because the patient's compliance partly depends on $\mathrm{it}^{38,69}$.

The main source of variance in the education that patients received appeared to be the patient himself: more questions and 'probings' provided for the therapist giving more education. The obvious explanation that 'questions give answers' is not the only one. The physical therapists also found it more rewarding to educate interested patients, as they told us. This mechanism has implications for practice. Firstly, it may be that patients asking no questions are wrongly perceived as uninterested, and thus are given less education. Knowing that highly educated patients asked twice as many questions as uneducated patients makes the latter 'a group at risk' for less education. Secondly, patients' question-asking depended on patient's characteristics but equally on the physical therapist: it appeared that the self-imposed information given by the 
physical therapists often elicited patients' questions. A reciprocal relation was seen: 'questions elicited information' and 'information elicited questions'. Thirdly, in practice, physical therapists can stimulate patients to ask questions by 'explicitly' inviting them to do so. We accentuate 'explicitly' because routinely asking "no further questions?" has hardly any effect at all. Besides, the patient can be asked to write down all his questions at home, to discuss and answer them in the next appointment. This method is now being experimented with in general practice. We shall conclude by saying that patient education in physical therapy is an important part of treatment and appeared to be influenced by the interaction between therapist and patient. This makes the communicative aspects of treatment of the utmost importance. 


\section{Literature}

1 Dishman RK.

Exercise adherence: its impact on public health.

Champaign: Human Kinetics Books, 1988.

2 Gerber KE.

Compliance in the chronically ill: an introduction to the problem. In: Gerber KE, Nehemkis AM

(eds.). Compliance: the dilemma of the chronically ill.

New York: Springer Publishing Company, 1986: 12-23.

3 Haynes RB, Taylor DW, Sackett DL (eds.).

Compliance in health care.

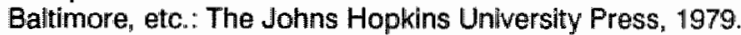

4 Sluijs EM, Kuijper EB

Problemen die fysiotherapeuten ervaren bij het geven van voorlichting aan patienten: een inventarlsatie. (Problems physical therapists encounter in educating patients.)

Nederlands Tijdschrift voor Fysiotheraple 100; 1990, 5: 128-132.

5 Knibbe JJ.

Fysiotherapie en secundaire preventle van lage rugklachten: literatuurstudie naar mogelijkheden en beperkingen. (Physlcal therapy and secondary prevention of low back pain.)

Nederlands Tijdschrift voor Fysiotherapie 97; 1987, 7/8: 175-183.

6 Simonds SK, Kanters HW.

Comparative analysis of patient education by four professions in the Netherlands and the United

States.

Patient Education and Counseling 15; 1990, 2: 151-167.

7 Bartlett EE.

Behavioral diagnosis: a practical approach to patient edlucation.

Patlent Counselling and Health Education 4; 1982, 1: 29-35.

8 Bartlett EE.

The contributions of behavioral science to patient education practice: a review. In: Ruffint JL. (ed.).

Advances in medical social science. Vol 2.

New York: Gordon and Breach Science Publishers, 1984: 1-43.

9 Epstein $\mathbf{L H}$, Cluss PA.

A behaviorall medicine perspective on adherence to lang-term medical regimens.

Journal of Consulting and Clinical Psychology 50; 1982, 6: 950-971.

10. DilMatteo MR, DiNicola DD.

Achieving patient compliance: the psychology of the medical practitioner's role.

New York: Pergamon Press, 1982.

11 Green LW.

Educational strategies to improve compliance with therapeutic and preventive regimens: the recent evidence. In: Haynes RB, Taylor DW, Sackett DL (eds.). Compllance in health care

Baltimore, etc.: The Johns Hopkins University Press, 1979: 157-173. 
Compllance with exercise in cardiac rehabilitation. In: Dishman RK (ed). Exercise adherence: its impact on public health.

Champaign: Human Kinetics Books, 1988: 283-304.

13 Pendleton D.

Dactor-patient communication: a revlew. In: Pendleton D and Hasler $J$ (eds.). Doctor-patient communication.

London "etc: Academic Press, 1983: 5-53.

14 Southam MA, Dunbar J.

Facllitating patient compliance with medical interventions. In: Holroyd KA, Creer ThL (eds.). Selfmanagement of chronic disease: handbook of clinical interventions and research.

Orlando, etc: Academic Press, 1986: 163-187.

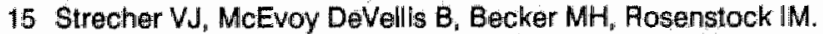

The role of self-efflcacy in achleving health behavior change.

Health Education Quarterly $13 ; 1986,1: 73-92$.

16 Dickson DA, Maxwell, M.

The interpersonal dimension of physiotherapy: implications for training.

Physiotherapy $71 ; 1985,7: 306-310$.

17 ICe R.

Long-term compliance.

Physical Therapy 65; 1985, 12: 1832-1839.

18 Linden HA van der.

Fysiotherapie en patiërtenvoorlichting. (Physical therapy and patient education.)

Nederlands Tijdschrift voor Fyslotheraple 97; 1987, 5: 106-112.

19 May BJ.

Teaching: a skill in clinilical practice.

Physical Therapy 63; 1983, 10: 1627-1633.

20 Mayo NE.

Patient compliance: practical implications for physical therapists: a review of the literature.

Physical Therapy 58; 1978, 9: 1083-1090.

21 Rheault WL.

Incorporating locus of control theories into patient education practices.

Physilotherapy Canada 34: 1982, 3: 152-156.

22 Wagstaff GF.

A small dose of commonsense - communication, persuasion and physiotherapy.

Physiotherapy $68 ; 1982,10: 327-329$.

23 Bartlett EE

At last, a definition (editorial).

Patlent Education and Counseling 7 ; 1985, 4: 323-324.

24 Hough A.

Communication in health care.

Physiotherapy 73; 1987, 2: 56-59.

25 Lyne PA.

The professions allied to medicine: their potential contribution to health education.

Physiotherapy 72; 1986, 1: 8-10.

26 Saunders $C$, Maxwell $M$.

The case for counselling in physiotherapy.

Physiotherapy 74; 1988, 11:592-596. 
27 Bertels $M$, Brummelen L ten, Dijkum CJ van, et al.

Tijd voor kwaliteit: evaluatie-onderzoek fysiotherapie in gezondheidscentra in Amsterdam. (Time for quality: evaluative research physical therapy in health centres.)

Amsterdam: Stichting Universitair Instituut voor Sociaal Wetenschappeli]k Onderzoek/Onderzoeksplatform in de Eerstelijns Dienstverlening in Amsterdam, 1985.

28 Hall JA, Roter DL, Katz NR.

Meta-analysis of correlates of provider behavior in medical encounters.

Medical Care 26; 1988, 7: 657-672.

29 Hooper EM, Comstock LM, Goodwin JM, Goodwin JS.

Patient characteristics that influence physican behavior.

Medical Care 20; 1982, 6* 630-638.

30 Waitzkin $\mathrm{H}$.

Information giving in medical care.

Journal of Health and Social Behavior 26; 1985, 2; 81-101.

31 Radecki SE, Mendenhall RC.

Patient counseling by primary care physicians: results of a nationwide survey.

Patient Education and Counseling 8; 1986, 2: 165-177.

32 Sluijs EM.

Patient education in physiotherapy: towards a planned approach.

Physiotherapy 77; 1991, 7: 503-508.

33 Bartlett EE.

Eight principles from patient education research.

Preventive Medicine 14; 1985: 667-669.

34 Blackwell B.

Counselling and compliance.

Patlent Counselling and Health Education 1; 1978, 2: 45-49.

35 Campen $C$ van, Sluijs EM.

Patient compllance: a survey of revlews (1979-1989).

Utrecht: Nivel, 1989. NIVEL-Bibliographies, 38.

36 Ley Ph.

Giving information to patients. In: Eiser JR (ed.). Social psychology and behavioral sclence.

New York: John Wiley \& Sons, 1982: 339-373.

37 Lazare $A_{n}$ Elsenthal S, Frank A, Stoeckle JD.

Studies on a negotiated approach to patienthood. In: Stoeckle JD (ed.) Encounters between patients and doctors: an anthology.

Cambridge, etc.: The MIT Press, 1987: 413-432.

38 Leventhal $\mathrm{H}$, Cameron $\mathrm{L}$.

Behavioral theories and the problem of compliance.

Patient Education and Counseling 10; 1987, 2: 117-138.

39 Leventhal $H$, Nerenz DR, Steele DJ.

Illness representations and coping with health threats. In: Baum A, Taylor SE, Singer JE (eds.).

Handbook of psychology and health. Vol IV: Social psychological aspects of health.

Hillsdale, New Yersey: Lawrence Erlbaum, 1984: 219-252

40. Leventhall $H$, Zimmerman R, Gutmann $M$.

Compliance: a self-regulation perspective. In: Gentry WD (ed.). Handboak of behavloral medicine New York, etc.: The Guifford Press, 1984: 369-436. 
41 Svarstad BL

Physiclan-patient communication and patient conformity with medical advice. In: Mechanic D. The growth of bureaucratic medicine: an inquiry into the dynamics of patient behavior and the organization of medical care.

New York: John Wiley and Sons, 1976: 220-238.

42 Lafrenlere JG.

The low back patient: procedures for treatment by physical therapy.

New York: Masson Publishing, 1979.

43 Posavac EJ, Sinacore $J M$, Brotherton SE, Heltord MC, Turpin RS.

Increasing compliance to medical treatment regimens: a meta-analysis of program.

Evaluation and the Health Professions 8; 1985, 1:7-22.

44 Spelman MR.

An exploratary study: the effects of a health education program on patient compliance to back exercises and alterations in activitles of daily living.

Detrolt, Michigan: Wayne State University, 1980. Dissertation.

45 Atklns C.J, Kaplan RM, Timms RM, Reinsch S, Lofback K.

Behavioral exercise programs in the management of chronic obstructive pulmonary disease.

Journal of Consulting Clinical Psychology $52 ; 1984,4: 591-603$.

46 Dunbar JM, Marshall GD, Hovell MF.

Behavioral strategies for improving compliance. In: Haynes RB, Taylor DW, Sackett DL (eds.).

Compllance in health care.

Baltimore, etc. The Johns Hopkins University Press, 1979: 174-190.

47 Knapp DN.

Behavioral management techniques and exercise promotion. In: Dishman RK (ed.). Exercise acherence: its impact on public health.

Champaign: Human Kinetics Books ${ }_{i i}$ 1988: 203-235.

48. Martin JE, Dubbert PM.

Exercise applications and promotion in behavioral medicine: current status and future directions. Journal of Consulting and Clinical Psychology 50; 1982, 6: 1004-1017.

49 Martin JE Dubbert PM, Katell AD, Thompson JK, Raczynski JR, Lake M, Smith PO, Webster JS.

Behavioral control of exercise in sedentary adults: studles 1 through 6 .

Journal of Consulting and Clinical Psychology 52; 1984, 5: 795-811.

50 Sackett $\mathrm{DL}$.

A compliance practicum for the busy practitioner. Im: Haynes RB, Taylor DW, Sackett DL (eds.).

Compliance in health care.

Baltimore, etc: The Johns Hopkins University Press, 1979: 286-294.

51 Becker $\mathrm{MH}$.

Patient adherence to prescribed therapies

Medical Care 23; 1985, 5: 539-555.

52 Carter WB, Inui TS, Kukull WA, Haigh VH.

Outcome-based doctor-patient interaction analysis (II): identifying effective provider and patient behavior.

Medical Care 20; 1982, 6: 550-566.

53 Croft Ju.

Intervlewing in physical therapy.

Physical Therapy 60; 1980, 8: 1033-1036.

54 Falvo D, Woehlke P, Deichmann J.

Relationship of physician behavior to patient compliance.

Patient Counselling and Health Education $2 ; 1980,4: 185 \times 188$. 
55 Feinberg J.

The effect of patient-practitioner interaction on compliance: a review of the literature and application In rheumatoid arthritis.

Patlent Education and Counseling 11; 1988, 3: 171-187.

56 Hanson RW.

Physician-patient communication and compliance. In: Gerber KE, Nehemkis AM (eds.). Compllance: the dilemma of the chronically ill.

New York: Springer Publishing Company, 1986: 182-212.

57 Pendleton $\mathrm{D}$.

Doctor-patient communication: a review. In: Pendleton D and Hasler J (eds.). Doctor-patient communication.

London, etc.: Academic Press, 1983: 5-53.

58 Rand $\mathrm{PH}$.

Evaluation of patient education programs.

Physical Therapy 58; 1978, 7: 851-856.

59 Stone GC.

Patient compliance and the role of the expert.

Journal of Social Issues $35 ; 1979,1: 35-59$.

60 Taylor SH, Gill SJ.

Professional disclosure in the counseling profession: a review of the literature.

Patient Education and Counseling $5 ; 1983,1: 35-40$.

61 Mullen PD, Green LW, Persinger GS.

Clinical trials of patient education for chronic conditions: a comparative meta-analysis of intervention types.

Preventive Medicine 14; 1985: 753-781.

62 Sluijs EM.

A checklist to assess patient education in physical therapy practice: development and reliability. Physical Therapy 71; 1991, 8: 561/17-569/25.

63 Cohen $\mathrm{Dl}$, Littenberg $\mathrm{B}$, Wetzel $\mathrm{C}$, Neuhauser DvB.

Improving physician compliance with preventive medicine guidelines.

Medical Care 20; 1982, 10: 1040-1045.

64 Ford AS, Ford WS.

Health education and the primary care physiclan: the practitioner's perspective.

Social Science and Medicine 17; 1983, 20: 1505-1512.

65 Freeman SH.

Health Promotion talk in family practice encounters.

Social Science and Medicine 25; 1987, 8: 961-966.

66 Horowitz MM, Byrd JC, Gruchow HW.

Attitudes of faculty members, residents, students, and community physicians toward health promotion.

Journal of Medical Education 62; 1987, 11: 931-934.

67 Sättertund Larsson U, Säljö R, Aronsson K.

Patient-doctor communication on smoking and drinking: Iffestyle in medical consultations.

Socilal Science and Medicine 25; 1987, 10: 1129-1137.

68 Spronk VRA, Warmenhoven NE.

Patient education in general practice: opinions of general practitioners.

Patient Education and Counseling 5; 1983, 2: 68-75.

69 Sluijs EM, Knibbe لJu.

Patient compliance with exercise: different theoretical approaches to short-term and long-term compliance. Patient Education and Counseling 17; 1991, 3: 191-204. 
48

28 


\title{
5 DIFFERENCES BETWEEN PHYSICAL THERAPISTS IN ATTENTION PAID TO PATIENT EDUCATION
}

\author{
E.M. Sluijs, J. van der Zee, G.J. Kok
}

Submitted.

\section{Abstract}

This article describes differences between physical therapists in their attention paid to patient education. The differences between therapists were analyzed by means of audiotaped treatment sessions of 1837 patients, recorded by physical therapists in non-institutional care in the Netherlands. Trained judges assessed the quantity and the quality of the education, by means of a checklist.

In addition, the therapists' opinion about patient education and their worksetting were asked by questionnaire. We investigated if these factors could explain the differences between physical therapists.

The results showed that the therapists differed strikingly in their opinions about patient compliance. They also differed in the number of exercise instructions given to their patients, in the degree of stress related counseling, and in their attention to the patient's demands and perceptions. There were only minor differences in the amount of general health education.

The differences could partly be explained by the therapists' opinions about effects of education and about patients' compliance. Therapists with high expectations about the effects of education and about patients' compliance gave more education than the others.

The results showed also that therapists who spent more time per session gave more education and they had a better relationship with their patients. It can be concluded that physical therapists hold different views on patient education and they differ considerably in practising educational tasks. It seems important that the profession tries to reach consensus about educational tasks and that standards for patient education in physical therapy become to be developed. 
In physical therapy, patient education has recently come to be embodied in the vocational training and in the job requirements ${ }^{1-6}$. Physical therapists generally support these developments ${ }^{7 \cdot 10}$. In practice, however, we discovered substantial differences in the kind and amount of education that patients received ${ }^{11}$. In this article, we shall describe to what extent physical therapists differ in educating patients. In addition we shall investigate whether these differences can be explained by the therapists' opinions about patient education. When we know which factors influence patient education in physical therapy directions for change and improvement may become more clear.

This study is part of a large-scale study on patient education in physical therapy. Audiotaped treatments of 1837 patients were analysed to assess the way in which physical therapists in private practices educate their patients during normal treatments. The main results described in an earlier publication ${ }^{11}$ - are as follows.

Three educational subjects were frequently discussed by the physical therapists: the patients were taught about the illness in $80 \%$ of the (1837) treatment sessions; in $69 \%$ of the sessions the therapists gave advice for example to rest or to correct posture or locomotion. In $64 \%$ of the sessions patients were instructed to exercise at home. Two educational activities occurred less frequently: giving general health education and counseling patients on stress-related problems both occurred in $23 \%$ of the sessions. Nearly $40 \%$ of the differences in the amount of education that patients received could be explained: more information was given to patients when exercise therapy was applied instead of massage or modalities, and when patients' complaints were more psychosocial in nature. In particular, more information was given to patients who asked more questions.

The greater part of the variance, however, remained unexplained. That is why we focus in this article on the differences between physical therapists.

Besides the kind and quantity of education, the manner in which the education is given is important. Several studies - unfortunately not concerning physical therapy have revealed that a number of 'quality aspects' can contribute to patient's satisfaction, remembrance and compliance ${ }^{12-18}$. We mention the most important ones. The information should be clear and understandable for the patient ${ }^{19-22}$; the information should be linked with the patient's demands and perceptions and regimens should be tailored to the patient's situation and daily routines ${ }^{23-28}$. In addition, the more general standards for giving care - an adequate relationship between therapist and patient and a systematic planning of treatment (a problem oriented approach) - can contribute to the effectiveness of education ${ }^{29-35}$. In our study three quality aspects were measured: the relationship between therapist and patient, a planned and systematic approach of treatment; the therapists' attention to patients' demands and perceptions.

The way in which physicall therapists differ in educating patients and possible explanations of that are not yet described in the literature. Assumptions about 'Why 
do physical therapists do what they do?' we thus derived from more general assumptions about human behavior: 'behavior will be influenced by perceived benefits and costs of behavior; while conditions that hinder or facilitate behavior can contribute to the benefits and costs'.

For physical therapists, several 'benefits' and 'costs' may be connected with educating patients.

Firstly, possible benefits of giving education. The possible effects yielded by educating patients can have rewarding value for the physical therapists: therapists who are convinced that their education can prevent recurrence of illness, and that it contributes to the patient's well being, may give more education than those who are more pessimistic about such effects ${ }^{36-36}$. In the same line of thought: therapists who perceive their education contributing to the patient's compliance may be more inclined to give education than therapists who do not perceive that. In short, we assume that perceiving more effects leads to more teaching about the illness, more exercise instructions and more pieces of advice and, in the case of psychosocial complaints, to more counseling.

Secondly, the 'costs' connected with education may consist of the extra time it demands ${ }^{39}$ and the effort it calls for to translate medical knowledge into commonplace words comprehensible to the patient. Besides, a therapist may perceive that education requires extra skills that he or she is lacking ${ }^{40}$. We consider in short, the barriers that the therapist perceives in educating patients to be 'costs'.

Thirdly, conditions that may facilitate or hinder patient education are more or less speculative. We assumed that three work setting factors may facilitate education. Firstly, having enough appointment time per patient may mean that the therapist has the time to educate ${ }^{41}$. Secondly, a working week that is not overloaded, so that the therapist can afford the effort to educate ${ }^{41}$. Thirdly, in the Netherlands working in health centres may facilitate education, because in such centres great attention is paid to prevention of illness ${ }^{30}$.

\section{Research questions}

1 What are the differences between physical therapists in the kind, the quantitative and quality aspects of patient education?

2 Can these differences be explained by

- perceived benefits and costs of giving education?

- conditions that hinder or facilitate patient education? 
The variables of the study are pictured below.

\begin{tabular}{|l|}
\hline perceived benefits \\
- preventive possiblitiles \\
- percelved effects \\
- patient compllance \\
perceived costs \\
- problems and barriers
\end{tabular}

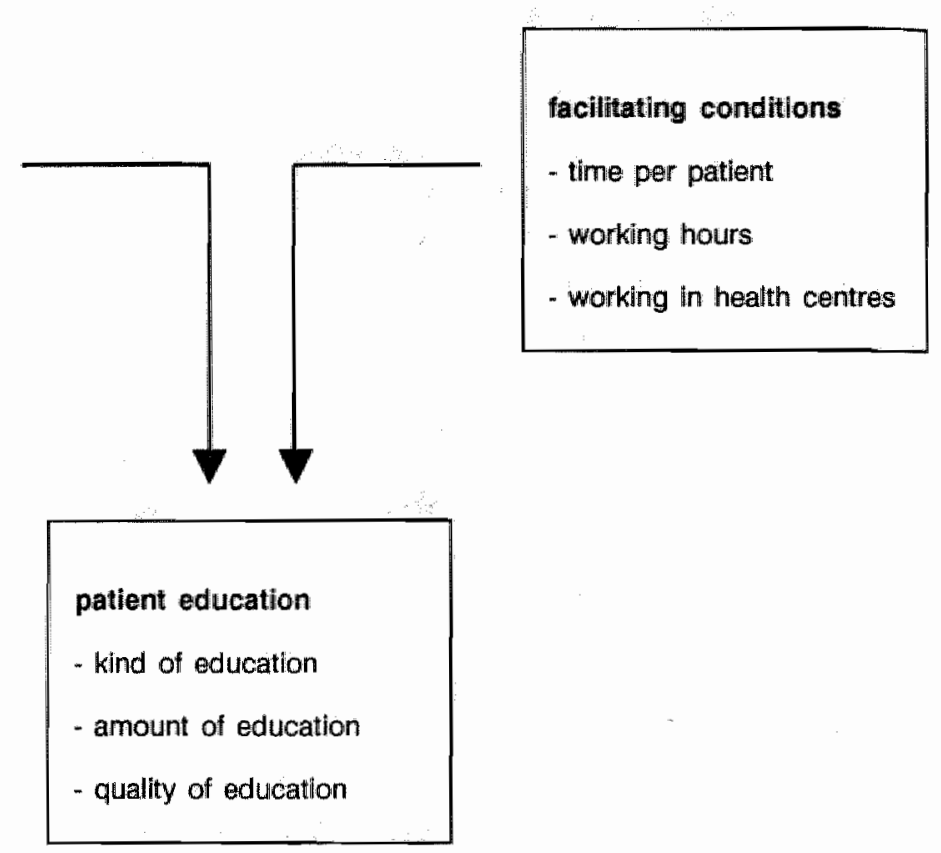

\section{Methods}

\section{Design and material}

Out of a random sample of 300 physical therapists in non-institutional care, 84 therapists $(28 \%)$ made audiorecordings of their treatments. In addition, their opinions about patient education were sought by questionnaire. A non-response analysis (appendix 5, page 210) revealed two differences between respondents and nonrespondents. First, $37 \%$ of the male therapists participated ( 63 out of 170 ) as against $16 \%$ of the fernale therapists ( 21 out of 130 ). Secondly, $68 \%$ of the respondents encountered problems in educating patients as against $42 \%$ of the non-respondents. Respondents and non-respondents did not differ in their attitudes to patient education.

The patients $(n=1931)$ were unselected chosen by the physical therapists: each therapist was asked to audiotape one treatment session of the first 25 patients treated in a particular week. Patients coming twice a week were recorded only once. Of the patients, $95 \%$ gave informed consent for the treatments to be audiotaped. A total of 1837 audiorecordings were made (mean is 22 recordings per therapist). The therapist turned the recorder on and off; no observer was present. Because the recorder was fixed in one room, treatment elements applied elsewhere were not recorded. 
The 1837 audiotapes were judged by three trained observers; the tapes were randomly distributed among them. The kind, quantity and quality of education were assessed by means of a checklist of sufficient reliability, described in an earlier publication ${ }^{42}$. The checklist contained five kinds of education:

- teaching and informing the patient about the illness

- instructing the patient to do home exercises

- giving advice and information about illness behavior

- giving general health education

- counseling the patient on stress-related problems.

The quantity of education was assessed by counting all meaningful 'informative remarks', such as 'Your complaints are not caused by surgical treatment; overstrained muscles are causing the pain". This example is counted as two informative remarks. The number of informative remarks was assessed for each kind of education. Counseling was quantified by counting four relevant forms of behavior: exploring. listening, supporting and explaining.

Three quality aspects were measured:

1 Patients' perceptions. Education appears to be more effective if it is linked with patient's perceptions ${ }^{14,17}$. The therapist's attention to these perceptions was measured by counting the number of times that the therapist asked the patient to tell of his or her ideas, demands and perceptions.

2 Relationship. An adequate relationship between therapist and patient appears to contribute to the patient's satisfaction and compliance ${ }^{14}$. The relationship was scored by means of a five-item scale (Alpha .85) (appendix 7, page 214). The items contained the following topics: giving positive feedback; showing concern with pain; showing interest in the patient; showing involvement in treatment; following a patient-centred approach.

3 A problem oriented approach. A planned and systematic approach of treatment was measured by counting the number of times that the therapists informed the patient about their treatment plan, their findings and their evaluation of treatment.

\section{Measure perceived benefits and costs}

The perceived 'benefits' and 'costs' were measured by questionnaire (appendix 4, page 199). The scales that we used are described in a report in detail ${ }^{43}$.

1 Preventive possibilities. The therapist's opinion about the possibilities of preventing recurrence of symptoms or illness in the future was measured by a scale (Alpha .71) (appendix 8, page 215). The items of the scale asked to what extent recurrence of eight commonly treated illnesses in physical therapy could be prevented. The mean score on the items is used in the analyses, ranging from 1 to 5 , 'prevention is impossible' and 'prevention is definitely possible' respectively.

2 Perceived effects. The perceived effects of patient education were measured by means of a 12-item scale (Alpha .75) (appendix 9, page 216). The therapists were asked whether they thought their education would contribute to: patient participa- 
tion, prevention of symptoms, patient's independence of health care, diminishing costs of health care and so on. The mean score on the items is used in the analyses. The possible scale values range from 1 to 5 , "education does not contribute to the effects mentioned' and 'education contributes very greatly to the effects mentioned" respectively.

3 Patient compliance. We asked the therapists: "How many of your patients do you expect to comply with the prescribed exercises?" Two estimates were asked for: one for short-term compliance and one for long-term compliance. Short-term was defined as two weeks during the treatment episode; long-term was defined as one year after the treatment episode. These estimates are expressed in a percentage indicating how many of all the patients are expected to comply with exercises.

The perceived barriers were asked for by means of an open question: "Do you encounter problems in educating patients and, if so, what kind of problems do you encounter?" Four main topics were mentioned and accordingly the problems were classified: a) the problems are caused by communication difficulties b) the problems are caused by patients' lack of knowledge or interest c) lack of time and material d) educational problems arise when patients' complaints are vague or psychosocial in nature ${ }^{44}$.

We assumed that physical therapists would counsel patients when they attributed considerable psychosocial influences to physical complaints. Hence, a scale was applied, measuring the degree of psychosocial influences in four commonly treated illnesses (Alpha .81) (appendix 10, page 218). The scale values range from 1 to 4 , "no psychosocial influence' to 'very great psychosocial influence' respectively. In addition we asked whether or not the therapists considered it their task to counsel patients.

\section{Measure work-setting factors}

Time per patient: the time that the therapist spent per session was automatically registered by the recorder. From this total time we subtracted the time spent on interruptions such as telephone calls and so on. In our analyses we use the 'pure' time during which the therapist and patient were actually in contact with each other. The time worked per week was registered by the therapists in the questionnaire. It was marked in one of five classes, ranging from 'work fewer than three days' to 'work six days or more'.

Whether the physical therapists worked in a health centre or in private practice was also registered in the questionnaire.

\section{Analysis}

The level of analysis is the physical therapist $(n=84)$. The independent variables stem from the questionnaires, the dependent variables from the audiorecordings. As a consequence the scores from the audio-tapes are aggregated to the physical therapist level. It means that for every dependent variable, an average score per physical therapist has been computed of all his or her recorded sessions. 
The relation between the therapists' opinions and the education that they gave on the audiotapes will be expressed in correlation coefficients. A multiple regression analysis has been made to discover the most powerful explanatory variables.

\section{Results}

\section{Differences between physical therapists in the kind, the quantity and quality aspects of education}

The mean number of remarks per session and the mean "quality scores' are set out in Table 5.1. The last column shows the differences between physical therapists expressed in a coefficient of variation (i.e. the standard deviation divided by the mean). The greater the coefficient of variation, the greater the differences between physical therapists.

Table 5.1 Mean number of educational remarks per session and mean scores on the quality aspects, all calculated per physical therapist $(n=84)$.

\begin{tabular}{|c|c|c|c|c|}
\hline & mean & lowest & highest & var.coeff. \\
\hline \multicolumn{5}{|l|}{ Number of educational remarks } \\
\hline - total educational remarks (per session) & 20.0 & 4.5 & 39.5 & .36 \\
\hline - teaching about illness & 5.4 & 1.4 & 11.3 & .43 \\
\hline - exercise instructions & 6.1 & 0.0 & 21.0 & 60 \\
\hline - advice and information & 4.7 & 0.5 & 16.2 & .56 \\
\hline - general health education & 1.1 & 0.0 & 3.4 & .64 \\
\hline - counseling about stress-related problems & 2.7 & 0.0 & 10.2 & .74 \\
\hline \multicolumn{5}{|l|}{ Quality aspects of education } \\
\hline $\begin{array}{l}\text { patient"s perceptions: mean number of } \\
\text { questions asked per session }\end{array}$ & 0.3 & 0.0 & 1.9 & 1.00 \\
\hline - relationship: score on relationship scale $(1-4)$ & 2.4 & 1.5 & 3.0 & .12 \\
\hline $\begin{array}{l}\text { - planned approach: mean number of remarks } \\
\text { about the treatment approach }\end{array}$ & 10.1 & 2.5 & 20.6 & .38 \\
\hline
\end{tabular}

The physical therapists gave an average of 20 educational remarks per session. The 'least' educating therapist gave an average of four remarks per session, whereas the 'most' educating therapist gave an average of 39 remarks per session. Most remarks concerned the instructions for home exercises. The greatest difference between the therapists in the amount of education that they gave is seen with counseling on stress related problems, as indicated by the coefficient of variation. Some therapists paid great attention to the psychosocial aspects of the complaints and tried to explain how distress can influence physical complaints, while others seemed to disregard psychosocial influences. The therapists also differed substantially in the amount of exercise instructions that they gave and in the number of pieces of advice. Some therapists tried hard to make the patient correct his posture, adjust his place of work or change his daily activities, whereas others discussed such subjects occasionally. 
Of the quality aspects, the judgements about the relationship between therapist and patient did not show much variance. The therapists also differed little in the information that they gave the patients about their treatment plan. Asking for patients' perceptions, however, differed greatly per therapist. Though generally the patients were seldom asked to tell of their demands and perceptions (only in $19 \%$ of the sessions were such questions asked), some therapists asked regularly, whereas others never asked such questions at all.

Table 5.2 Correlation coefficients between the dependent variables $(n=84)$

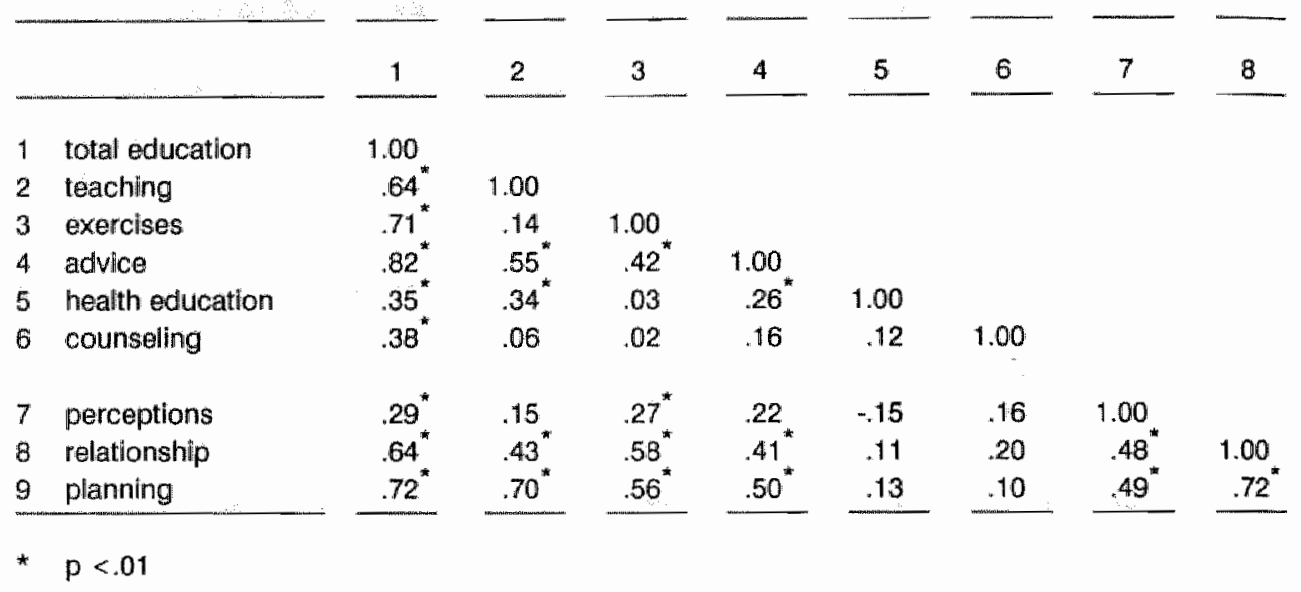

The total amount of education, being composed of all the educational activities, is of course strongly related to each of them. Less self-evident is the finding that the quality aspects of education are strongly related to the amount of education. It means that those physical therapists who give much information, instructions and advice are also the ones who follow a systematic treatment approach and who have a good relationship with their patients (as judged by the observers). These two quality aspects appear to be strongly interrelated.

The correlations between the quantitative aspects of education show that physical therapists who give many exercise instructions are also the ones who give many pieces of advice. It is interesting to see that 'teaching about the illness' is in particular related to giving advice and not to exercise instructions.

Counseling the patient is the only activity that is neither related to the other educational activities nor to the quality aspects of education.

\section{Benefits and costs of education and work-setting factors}

The physical therapist's opinions about patient education, as measured by questionnaire, are set out in Table 5.3. The possible values of the scales are noted in the first column: a low value means a more negative attitude, a high value a more positive one. 


\begin{tabular}{|c|c|c|c|c|c|}
\hline 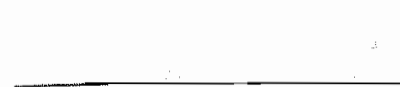 & $\begin{array}{l}\text { possible } \\
\text { values }\end{array}$ & $\begin{array}{l}\text { mean } \\
\text { score }\end{array}$ & $\begin{array}{l}\text { lowest } \\
\text { score }\end{array}$ & $\begin{array}{l}\text { highest } \\
\text { score }\end{array}$ & $\begin{array}{l}\text { var } \\
\text { coef }\end{array}$ \\
\hline $\begin{array}{l}\text { preventive possibilities } \\
\text { (= score on scale) }\end{array}$ & $1-5$ & 3.3 & 2.1 & 5.0 & .17 \\
\hline $\begin{array}{l}\text { perceived effects of education } \\
(=\text { score on scalle) }\end{array}$ & $1-5$ & 3.2 & 2.2 & 4.3 & $: 13$ \\
\hline estimated compliance: & & & & & \\
\hline - short-term compliance $(\%)$ & $0-100$ & $63.0 \%$ & $0 \%$ & $90 \%$ & .29 \\
\hline - long-term compliance (\%) & $0-100$ & $21.0 \%$ & $0 \%$ & $50 \%$ & .59 \\
\hline
\end{tabular}

The meaning of the figures in Table 5.3 is as follows. The minimum score of 2.1 on the scale about "preventive possibilities' indicates that the most pessimistic physical therapist thinks it is hardly possible to prevent the recurrence of commonly treated illnesses such as "frozen shoulder", "back pain" or "ankle distortion"; whereas a colleague considers it quite feasible to prevent such recurrences (score 5).

The estimates of patient compliance with exercise regimens are striking. One physical therapist expected none of his patients to comply with short-term exercise regimen, whereas 22 therapists were as optimistic as to expect that $80 \%$ or $90 \%$ of their patients would comply. The coefficient of variation indicates that the therapists differed most about long-term compliance: 28 therapists estimated that $10 \%$ of their patients would comply in the long term, whereas 5 therapists expected that $50 \%$ of their patients would maintain long-term compliance (defined as one year after the treatment period). The median score for short-term compliance is $70 \%$ and for long-term compliance $20 \%$ indicating that the therapists are clearly aware that long-term compliance is far more difficult to attain than short-term compliance.

The problems that therapists encountered in educating patients are described in Table 5.4. More than one problem was mentioned by 44 therapists (mean $=2.4$ ). 
Table 5.4 Number of therapists perceiving problems in educating patients and kind of problems mentioned $(n=84)$

therapists perceiving no problems

therapists percelving problems

kind of problems:

- communication problemis

- problems attributed to the patients

- lack of time and material

- vague or psychosocial complaints

- other problems

- total number of problems
27

57

46

42

22

15

9

134
$32 \%$

$68 \%$

$34 \%$

$31 \%$

$17 \%$

$11 \%$

$7 \%$

$100 \%$

Of the therapists, $68 \%$ encountered problems in educating patients. Most mentioned were 'communication problems'. The therapists wrote for example that it is difficult to educate in simple language understandable by the patient, that it is difficult to adjust regimens to patients' circumstances or that motivating patients to change their habits or lifestyle is not easy. The problems attributed to the patient were for example patients' lack of knowledge, their lack of interest in education, their different views on health and illness, and so on. Less often the therapists remarked that lack of time and 'educational material' hindered them in educating patients. Finally, some therapists found it difficult to educate patients with vague or psychosocial complaints. A more detailed description of the problems can be found in an earlier article ${ }^{43}$.

The three work-setting factors display the following distribution.

The average time per session was 24.4 minutes (sd 4.2). Note that this is the time without interruptions. The range, minimum is 12.2 minutes, maximum is 32.3 minutes, indicates that the therapists differed in the amount of time spent on the patient.

Of the therapists, $58 \%$ worked full-time or longer and $42 \%$ worked less than full-time. The majority of the physical therapists $(94 \%)$ worked in private practices, whereas $6 \%$ of our sample worked in health centres. 


\begin{tabular}{|c|c|c|c|c|c|c|c|c|}
\hline & : & 1 & 2 & $3 a$ & $3 b$ & 4 & 5 & 6 \\
\hline 1 & preventive possibilities & 1.00 & & & & & & \\
\hline 2 & perceived effects & $33^{* k}$ & 1.00 & & & & & \\
\hline $3 a$ & short-term compliance & .00 & .07 & 1.00 & & & & \\
\hline $3 b$ & long-term compliance & .17 & $.30^{\star *}$ & $.50^{\star \star}$ & 1.00 & & & \\
\hline 4 & problems/barriers & .02 & .17 & .10 & .05 & 1.00 & & \\
\hline 5 & session time & .04 & .00 &. .03 & -.07 & .16 & 1.00 & \\
\hline 6 & working hours & -.03 & -.05 & .05 & -.03 &. .10 &. .18 & 1.00 \\
\hline 7 & work-setting & .07 & $18^{*}$ & -.12 & .10 & .15 & .05 & $-.21 *$ \\
\hline
\end{tabular}

It appears that therapists who perceive more effects of education have more optimistic views about the preventive possibilities of treatment and are more optimistic about long-term compliance. A rather strong relation exists between short-term and longterm compliance. The therapists' opinions about compliance seem to be unrelated to the problems they encountered in educating patients. In general, the therapists' opinions about the 'benefits' and 'costs' of education are hardly related to the worksetting factors. Of the latter it appears that therapists in private practice work longer than therapists in health centres. In general, the interrelations between the work-setting factors are rather weak.

Finally, we present the therapists' opinions about counseling.

Of the therapists, $46 \%$ considered 'counseling being subsidiary to physical therapy' and $51 \%$ consider 'counseling an essential part of physical therapy treatment". Therapists holding the latter view also perceived more psychosocial influences on somatic illinesses, as measured by the 'psychosocial influence scale': the correlation between 'counseling tasks' and 'psychosocial influence' is .26 $(p<.01)$.

\section{The quantity and quality of education related to the 'benefits" and "costs' of education}

The relation between the therapists' perceptions of the 'benefits' and 'costs' of education and the education that they actually gave on the audiorecordings is set out in Table 5.6, expressed in a Pearson correlation coefficient (only significant coefficients noted). 
Table 5.6 Percenved 'benefits' and "costs" of education related to the kind, amount and quality of education $(n=84)$

\begin{tabular}{|c|c|c|c|c|c|c|c|c|}
\hline & $\begin{array}{l}\text { prev } \\
\text { poss }\end{array}$ & $\begin{array}{l}\text { perc } \\
\text { eff }\end{array}$ & $\begin{array}{l}\text { short } \\
\text { comp }\end{array}$ & $\begin{array}{l}\text { long } \\
\text { comp }\end{array}$ & $\begin{array}{l}\text { pro } \\
\text { blems }\end{array}$ & $\begin{array}{l}\text { time } \\
\text { sess }\end{array}$ & $\begin{array}{l}\text { work } \\
\text { time }\end{array}$ & $\begin{array}{l}\text { set } \\
\text { ting }\end{array}$ \\
\hline Amount of education & & & & & & & & \\
\hline total education & - & $.26^{* *}$ & $.20^{*}$ & $-\dot{x}$ & $.25^{*}$ & $27^{* *}$ & - & - \\
\hline teaching about illness & -- & $.21 *$ & $\cdots$ & - & $.26^{* *}$ & $30^{* *}$ & - & $.18^{*}$ \\
\hline exercise instructions & - & -- & $.34^{* *}$ & $.21^{*}$ & $\ldots$ & -. & - & - \\
\hline advice and information & - & $.22^{*}$ & - & - & $.23^{*}$ & $26^{* \star *}$ & - & - \\
\hline general health education & - & $\infty$ & - & - & - & -.. & -- & - \\
\hline $\begin{array}{l}\text { counselling about stress- } \\
\text { related problems: }\end{array}$ & - & $.29^{* *}$ & - & $\cdots$ & -- & - & - & - \\
\hline \multicolumn{9}{|l|}{ Quality aspects } \\
\hline asking pt. perceptions & $-\infty$ & $.19^{*}$ & - & $\propto$ & - & - & $-.26^{\star \star \star}$ & $.35^{* *}$ \\
\hline relationship ther-pt & - & - & $.19^{\star}$ & $\cdots$ & $.23^{*}$ & $.35^{\star \star}$ & $-.21^{\star}$ & - \\
\hline planned approach & - & $.19^{*}$ & $.20^{*}$ & - & + & $.20^{\star}$ & - & $.31^{* \pi}$ \\
\hline
\end{tabular}

* $p<.05$

*** $p<.01$

The perceived 'benefits' of education appeared to be related to the quantity and the quality of education: therapists holding the view that their education contributes to effects such as 'patients becoming more interested in treatment', 'patients becoming more satisfied", 'a quicker recovery from illness' and so on, gave more and 'better' education than those who thought that their education would not yield such effects. Therapists who were more optimistic about their patients' compliance gave more instructions for home exercises and followed a more 'problem-oriented' approach. In addition, therapists who held the view that their patients generally did comply with prescribed exercises appeared to have a better relationship with their patients, as rated by the observers.

The problems that therapists encountered were not related to the number of exercise instructions. They were related to teaching and advising, but in the reverse direction to what we assumed: it appeared that the therapists who encountered no problems did not give more but less education than those who did encounter problems. Taking a closer look, it appeared that the kind of problems did matter: therapists who said that they lacked time and material did in fact give less education, whereas the therapists who experienced problems with the patient and communication gave more education. Perhaps giving more education makes the therapist discover more problems in educating patients. We shall return to this in the discussion.

As regards the work situation, the session time is significantly related to the amount and the quality of education. Therapists who spend on average more time on their patients give more information and advice, they follow a more systematic treatment 
approach and they seem to have a better relationship with their patients. The weekly work time is negatively related to the quality aspects of education: It is obvious that therapists who work (too) long less often ask their patients to tell of their demands and ideas and the relationship with the patients is judged less good. The therapists who work in health centres paid more attention to the quality aspects of education.

As expected, the therapists' opinions about counseling tasks and about psychosocial influences were related to the counseling actually given. In particular, therapists who considered counseling an essential part of physical therapy gave more counseling than their colleagues who did not think so (correlation .21, $p<.05$ ).

To discover which of the variables have the most explanatory value, a multiple regression analysis was performed. The worksetting is omitted because in the sample only five therapists worked in health centres.

Table 5.7 Multiple regression analyses relating dependent and independent variables expressed in Betas $(n=84)^{*}$

\begin{tabular}{|c|c|c|c|c|c|c|c|c|c|}
\hline & amo & t of e & cation & & & & qualit & & \\
\hline & tot & inf & exer & $\mathrm{adv}$ & ghe & psy & pat & rel & plan \\
\hline preventive possibilities & - & - & - & -.. & -- & $m$ & - & - & -. \\
\hline perceived effects & .26 & .21 & -. & .22 & $\ldots$ & .29 & -. & - & -. \\
\hline compliance (short) & - & -- & .34 & - & -- & $=$ & - & $-\cdots$ & - \\
\hline compllance (long) & - & - & - & $\therefore$ & -- & - & -- & - & $\cdots$ \\
\hline problems encountered & -- & - & - & - & -- & $-\ldots$ & - & -. & - \\
\hline session time & .27 & .31 & - & .27 & $\ldots$ & - & $\ldots$ & .35 & - \\
\hline working hours & - & - & - & -- & -- & -. & -.27 & -- & $-\cdots$ \\
\hline multiple $\mathrm{R}$ & .38 & .37 & .34 & .35 & $\therefore$ & .29 & .27 & .35 & $*$ \\
\hline adjusted R2 & .12 & .12 & .10 & .10 & - & .07 & .06 & .11 & - \\
\hline
\end{tabular}

* only significant Beta's are in the table $p<.05$

The results are in line with the earlier analyses. The perceived effects of education and the time spent on the patient do have the main predictive value in explaining the differences between physical therapists. The differences between therapists in the number of exercise instructions can partly be explained by their expectations about patients' compliance. It is interesting to see that therapists who spend more time per patient have a better relationship with their patients than therapists who spend less time. The therapists" opinions about the possibilities of preventing recurrence of illness were unrelated to the education that they gave. There is also no significant relationship with the problems that physical therapists encounter in educating patients.

The therapists' sex and age - although not included in our model - showed some 
interesting relations to the education they gave. Firstly, it appeared that female therapists appeared slightly more often to counsel their patients than male therapists (p. <.05). Their opinions about 'counseling tasks' however, did not differ significantly from those of male therapists. Secondlly, we found no differences between younger and older therapists, with one exception: younger therapists gave less information about 'general health education' than older therapists (significant $p<.05$ ). The implications of this finding will be discussed next.

\section{Discussion}

The first aim of the study was to describe the differences between physical therapists in attention paid to educational activities. As a second aim, we tried to explain these differences by the therapists' opinions about patient education.

The results showed that the therapists differed significantly in almost all aspects of patient education, some of them giving considerable information and advice, whereas others did so less frequently; some of them counseled their patients about stress related problems, whereas others did not so and did not consider it their task to give counseling; most therapists never asked about patients' perceptions, while a minority of them frequently asked the patients to tell of their demands and ideas.

It was interesting to see that the quality aspects of education were strongly related to the amount of education. The cause of it being unknown. It may be for example that giving much information to patients of itself provides for a better relationship with them. Another explanation can be that some therapists pay much attention to all the aspects of education because they set great value to influencing patient's behavior, while others are less inclined to do so. Perhaps the latter attached more value to the technical aspect of treatment, which is an interesting question for future research.

The differences between physical therapists were hardly surprising. Earlier research at our institute had revealed that physical therapists differed in many respects of their work ${ }^{45}$. This diversity may be partly due to the diffuse complaints without clear causes or diagnoses with which physical therapists are often confronted. Partly, however, the lack of standards or protocols in physical therapy provides for great degrees of freedom in applying treatments. The development of protocols seems to be a necessary step forward to more uniformity in physical therapy. Patient education should conscientiously be integrated into such protocols. It is obvious that protocols are important to future research; for daily practice, protocols can be valuable instruments in peer review activities and quality assessment.

We hypothesized that the differences in patient education, could be explained by the 'benefits' and 'costs' that the therapists perceived in educating patients. Part of this hypothesis was confirmed: it proved that therapists holding the view that education yields many effects gave more education than therapists who were more pessimistic about such effects. This does not mean that giving more education is caused by the therapists' opinions, as is assumed by attribution theories. Our study, being correla- 
tional, does not permit of such conclusions. Perhaps the therapists simply made their opinions consonant with their behavior, as would be predicted by the theory of cognitive dissonance.

From a theoretical point of view, this remains an interesting question for future research. From a practical point of view, however, such considerations do not give much of a handhold for change or improvement.

We consider the problem of non-compliance more relevant to daily practice. The therapists' expectations about patients' compliance give food for thought. Why do some therapists see patients as non-compliant, whereas others see patients as very good compliers? Are their expectations based on reality or are they personal views? This question - besides being puzzling - has great relevance. If a therapist sees patients as non-compliant, he appeared to give less exercise instruction. One therapist even gave hardly any home exercises at all, because he considered patients to be unable to maintain exercising " as he told us.

Because much is still unknown about patient compliance in physical therapy, specific research is needed. It seems particularly worthwhile to discover feasible and effective methods for enhancing patients' compliance in physical therapy. Currently, tailoring exercises to patients' situation and integrating the exercises into patients' daily activities seems to be one of the most promising methods.

The time that the therapists spent on the patient was significantly related to the relationship with the patient (more time implied a better relationship) and to the amount of information and advice they gave. This may be a 'chicken and egg' problem, because perhaps spending more time provides more opportunities for education, but the reverse may also be true: giving education implies spending more time. More interesting is the finding that counseling the patient was unrelated to the treatment time. This is in contrast with the situation in medical practice, in which counseling the patient generally is strongly related to the time allotted to consultation. An explanation may be that the physical therapists utilized the time they applied massage to discuss stressrelated problems with the, patient. Our earlier research findings suggested such a mechanism".

Therapists who encountered problems in educating patients did not gave less education, as we had expected, but slightly more education. Two explanations are possible. Firstly, it may be that the problems therapists encountered were not perceived as 'costs' but perhaps as 'challenges', making them try harder to educate their patients. The second explanation we have already touched on: it seems plausible that paying more attention to education leads to the discovery of more difficulties. This explanation is partly supported by the kind of communication problems mentioned by the therapists. For example: "It is difficult to teach in simple words and common language" or, "It is difficult to tailor advice to the patient's situation", or, "You cannot give too much information because patients will forget parts of it". Such remarks indicate the therapists' awareness of the extra effort and skills that education requires. 
For practice, it seems important that specific educational skills are taught in the vocational training or in follow-up courses. The skills to be taught should correspond to the practical problems experienced by the therapists; in fact they should be tailored to the therapists' needs.

Finally, we found one tendency deserving of further attention. Although, in general, the physical therapists infrequently discussed general health education, older therapists did so slightly more than younger ones. Perhaps older people are more aware of the risks of unhealthy lifestyles. Perhaps, however, younger therapists may be less inclined to interfere with patients' lifestyle, because they do not consider it their task or take the view that it is the patients' own choice and responsibility. We do not yet know. Such a tendency, however, would undermine intended extensions of the physical therapists' role in health education. Although the physical therapy treatment is considered to be the optimal setting for health education, the tasks in the field of health education are as yet unclear. 


\section{Literature}

1 Dickson DA, Maxwell, $M$.

The interpersonal dimension of physiotherapy: Implications for training.

Physiotherapy $71 ; 1985,7: 306-310$.

2. Huhn RR, Volski RV.

Primary prevention programs for business indiustry: role of physical therapists.

Physical Therapy 65; 1985, 12: 1840-1844.

3 Norton S.

Support for physiotherapists in health education.

Physiotherapy 72; 1986, 1:5-7.

4 Saunders C, Maxwell M.

The case for counselling in physiotherapy.

Physilotherapy $74 ; 1988,11: 592-596$.

5 Schultz $\mathrm{CL}$, Wellard $\mathrm{R}$, Swerissen $\mathrm{H}_{n}$

Communication and interpersonal helping skills: an essential component in physiotherapy educathion?

The Australian Journal of Physiotherapy 34; 1988, 2: 75-80.

6 Simonds SK, Kanters HW.

Comparative analysis of patient education by four profiesslons in the Netherlands and the United

States.

Patient Education and Counseling 15; 1990, 2: 151-167.

7 Kok J, Bouter LM.

Patiënterwoorlichting door fysiotherapeuten in de eerste lijn. (Patient education by physical therapists in primary care).

Nederlands Tijdschrift voor Fyslotherapie 100; 1990, 2: 59-63.

8 Leathley M.

Physiotherapists and health education: report of a survey.

Physiotherapy 74; 1988, 5: 218-220.

9 Lyne PA.

The professions allied to medicine: their potential contribution to health education.

Physiotherapy $72 ; 1986,1: 8-10$.

10 May BJ.

Teaching: a skill in clinical practice.

Physical Therapy 63; 1983, 10: 1627-1633.

11 Sluijs EM, Kok GJ, Zee J van der.

Patient education in physical therapy as related to the patient "the illness and the kind of treatment applied.

Submitted. 
12 Bartett $E E$

The contributions of behavioral science to patient education practice: a review. In: Ruffinl $J L$ (ed.).

Advances in medical social science. Vol 2.

New York: Gordon and Breach Science Publishers, 1984: 1-43.

13 Campen $\mathrm{C}$ van, Sluils EM.

Patient compliance: a survey of reviews (1979-1989).

Utrecht: Nivel, 1989. NIVEL-Bibliographies, 38.

14 DiMatteo MR, DiNicola DD.

Achieving patient compliance: the psychology of the medical practitioner's role.

New York: Pergamon Press, 1982.

15 Dishman RK.

Exercise adherence: its impact on public health:

Champaign: Human Kinetics Books, 1988.

16 Haynes RB, Taylor DW, Sackett DL (eds.).

Compliance in health care.

Baltimore, etc.: The Johns Hopkins University Press, 1979.

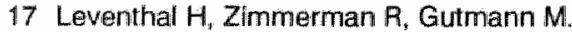

Compliance: a self-regulation perspective. In: Gentry WD (ed.). Handbook of behavioral medicine.

New York, etc: The Guillord Press, 1984: 369-436.

18 Mullen PD, Green LW. Persinger GS.

Clinical trials of patient education for chronic conditions: a comparative meta-analysis of intervention types.

Preventive Medicine 14; 1985: 753-781.

19 Pendleton D.

Doctor-patient communication: a review. In: Pendleton D and Hasler J (eds.). Doctor-patient communication.

London, etc.: Academic Press, 1983: 5-53.

20 Green LW.

Educational strategies to improve compliance with therapeutic and preventive regimens: the recent evidence. In: Haynes RB, Taylor DW, Sackett DL (eds.). Compliance in health care

Baltimore, etc.: The Johns Hopkins University Press, 1979: 157-173.

21 Ley Ph.

Giving information to patients. in: Eiser JR (ed.). Social psychology and behavioral science.

Now York: John Wiley \& Sons, 1982: 339-373.

22 Swarstad BL

Physician patient communication and patient conformity with medical advice. In: Mechanic D. The growth of bureaucratic medicine: an inquiry into the dynamics of patient behavior and the organization of medical care.

New York John Wiley and Sons, 1976: 220-238.

23 Hanson RW.

Physician-patient communication and compliance. In: Gerber KE, Nehemkis AM (eds.). Compllance: the dilernma of the chronically ill.

New York: Springer Publishing Company, 1986: 182-212.

24 Lazare A, Eisenthal S, Frank A, Stoeckle JD.

Studies on a negotiated approach to patienthood. Im; Stoeckle JD (ed.) Encounters between patients and doctors: an anthology.

Cambridge, etc: The MIT Press, 1987: 413 432.

25 Lafrenière JG.

The low back patient: procedures for treatment by physical therapy.

New York: Masson Publishing, 1979. 
Behavioral theories and the problem of compliance.

Patient Education and Counseling 10; 1987, 2" 117-138.

27 Oldridge NB.

Compliance with exerclse in cardiac rehabilitation. In: Dishman RK (ed.). Exercise adherence: its impact on public health.

Champaign: Human Kinetics Books, 1988: 283-304.

28. Spelman MR.

An exploratory study: the effects of a health education program on patient compliance to back exercises and alterations in activities of daily living.

Detroit, Michigan: Wayne State University, 1980. Dissertation.

29 Becker MH.

Patient adherence to prescribed therapies.

Medical Care 23; 1985, 5: 539-555.

30 Bertels $M$, Brummelen L ten, Dijkum CJ van, et al.

Tijd voor kwaliteit: evaluatie-onderzoek fysiotherapie in gezondheldscentra in Amsterdam. (Time for quality: evaluative research physical therapy in health centres.)

Amsterdam: Stichting Universitair Instituut voor Sociaal Wetenschappelijk Onderzoek/Onderzoeksplatform in de Eerstelijns Dienstwerlening in Amsterdam, 1985.

31 Carter WB, Inui TS, Kukull WA, Haigh VH.

Outcome-based doctor-patient interaction analysis (ili): identifying effective provider and patient behavior.

Medical Care 20; 1982, 6: 550-566.

32. Croft JJ.

Interviewing in physical therapy.

Physical Therapy 60; 1980, 8: 1033-1036.

33. Feinberg $\mathrm{J}$.

The effect of patient-practitioner interaction on compliance: a revlew of the literature and application in rheumatoid arthritis.

Patient Education and Counseling 11; 1988; 3: 171-187.

34 Green LW.

What is quality in patient education and how do we assess it? In: Squlyres WD (ed.). Patient education.

New York: Springer Publishing Company, 1980: 137-156.

35 Rand $\mathrm{PH}$.

Evaluation of patient education programs.

Physical Therapy 58; $1978,7: 851-856$.

36 Deyo RA.

Compliance with therapeutic regimens in arthritis: issues, current status, and a future agenda.

Seminars in Arthritis and Rheumatism 12; 1982, 2: 233-244.

37 Rosen MA, Logisdon DN, Demak MM.

Prevention and health promotion in primary care: baseline results on physicians from the INSURE project on lifecycle preventive health services.

Preventive Medicine 13; 1984: 535-548.

38 Wechsler H, Lewine S, Idelson RK, Rohman M, Taylor JO.

The physician's rolle in health promotion: a survey of primary-care practitioners.

The NNew England Journal of Medicine 308; 1983, 2: 97-100.

39 Lyne PA, Phillipson $\mathrm{C}$.

The barriers to health education.

Physiotherapy $72 ; 1986,1: 10-12$. 
40 McClellan W.

Current perspectives: patient education in medical practice: the physician and patient education: a revlew:

Patient Education and Counseling 8; 1996, 2: 151-163.

41 Waitzkin H.

Information giving in medical care.

Journal of Health and Social Behavior 26; 1985; $2: 81-101$.

42 Slujis EM.

A checklist to assess patient education in physical therapy practice: development and reliability.

Physlcal Therapy $71 ; 1991,8: 561 / 17-569 / 25$.

43 Sluils EM.

Patient education in physical therapy.

Utrecht: Nivel, 1991. Dissertation.

44 Sluils EM, Kullper EB.

Problemen die fysiotherapeuten envaren bij het geven van voorlichting aan patienten: een inventarlsatie. (Problems physical therapists encounter in educating patients.)

Nederlands Tildschrift voor Fysiotherapie 100; 1990, 5: 128-132.

45 Curfs EC, Kerssens JU.

Fysiotherapie in de Nederlandse Gezondheidszorg (Physical Therapy in the Netherlands).

In press. 


\title{
6 PATIENTS' COMPLIANCE IN PHYSICAL THERAPY AS RELATED TO PATIENTS' ATTITUDES AND THERAPISTS' BEHAVIOR
}

\author{
E.M. Sluijs, G.J. Kok, J. van der Zee
}

Submitted.

\section{Abstract}

This article describes factors that are related to patient compliance with exercise regimens during physical therapy treatments. We investigated if patient compliance was related to characteristics of the patient and the illiness, to patients' attitudes and to the physical therapist's behavior.

Material of the study are 1931 patient questionnaires and 1837 audiorecorded sessions of real physical therapy treatment sessions.

The results show that the three main factors that are related to non-compliance are: 1) the barriers patients perceive; 2) the lack of positive feedback; 3) the degree of helplessness. The barriers patients perceive and encounter is the most powerful factor in explaining non-compliance. The results also show that non-compliance is not related to the illness per se but to the characteristics of the illness: a bad prognosis is negatively related to compliance and much hindrance of the complaints is positively related to compliance. There is no difference between man and women but low educated patients are slightly more compliant than high educated patients.

For physical therapy practice it seems important that physical therapists carefully explore which problems patients encounter in their efforts to comply and that solutions are sought in mutual cooperation with the patient. 
This article describes factors that are related to patients' compliance in physical therapy. Patients' compliance is of considerable importance in physical therapy because treatment effects partly depend on it. There are, however, indications that non-compliance with exercise regimens is as great as non-compliance with other medical regimens ${ }^{\prime}$. The development of methods for improving patients' compliance first of all requires insight into the causes of patients' non-compliance.

Research on patients' compliance with exercises mostly concerns cardiacrehabilitation programs, preventive fitness programs, or backschools. These studies report different figures on exercise compliance: it appears that one third to two thirds of the patients are found to be non-compliant with exercises ${ }^{2-7}$. The degree of patients' compliance with exercises prescribed during regular physical therapy treatments is unknown. Physical therapists themselves estimate that two third of their patients comply with short-term exercise regimens, and that only one fifth of them persevere with exercising in the long run ${ }^{8}$. Whether these estimates are realistic is unknown: a 'true' assessment of patients' compliance is difficult for providers (and still more for researchers) ${ }^{8-10}$. Firstly, patients hardly dare to admit non-compliance or are inclined to give the answers desired of them; although patients' negative answers (admitting non-compliance) are reliable, positive answers can be doubted ${ }^{11 \cdot 12}$. Secondly, compliance usually is not a matter of 'all or nothing' but has many gradations. These gradations provide for different definitions of 'compliance', which often makes it impossible to compare research findings ${ }^{13}$.

The literature on compliance research gives over 200 factors that may be related to patients' compliance. These factors concern characteristics of the patients and their illiness and, characteristics of the prescribed regimen and of the provider (see surveys $^{14 \cdot 15}$ ). Because many research findings are weak or contradictory ${ }^{16}$, we mention only the most consistent results.

Generally it appears that non-compliance is hardly related to characteristics of the patients such as patient's sex, age, race or social status ${ }^{15}$. Patients' beliefs and attitudes, however, certainly are related to compliance ${ }^{18-19}$. Patients with an 'external locus of control" - believing that health and illness hardly depend on their own behavior - appear to be less compliant than those with an internal locus of control. The problems that patients perceive in being compliant are a strong factor in non-compliance. These problems - called 'costs' in the Decision Theories and 'perceived barriers' in the Health Belief Mode ${ }^{20-21}$ - play a role in both illness behavior and health behavior ${ }^{22}$. Finally, lack of social support is sometimes related to patients' non-compliance ${ }^{23}$.

Some characteristics of the illness are also related to compliance: when the illness causes more disabilities and handicaps and patients perceive the illness as very serious, they appear to be more compliant than patients with less serious illnesses ${ }^{17}$. Patients with chronic illnesses, however, seem to be less compliant than patients with acute illnesses: the expected recovery from acute illnesses may motivate patients to 
comply.

Characteristics of the prescribed regimen are related to compliance, as is the behavior of the health care provider ${ }^{24}$. Complex regimens cause more non-compliance than simple regimens ${ }^{25}$, as does the inconvenience of the regimen ${ }^{26-28}$. In particular it appears that compliance is less likely when the regimen is not tailored to patients" situation or their daily routines ${ }^{29-30}$.

The health care provider plays a role in compliance. Firstly, and most importantly, 'prolonged supervision" is a strong factor in compliance ${ }^{31-33}$ : patients whose compliance is being monitored and, particularly, who get positive feedback about their efforts and progress do comply better than patients without supervision ${ }^{34-37}$. As has been mentioned, physical therapists estimate that $63 \%$ of their patients are compliant during the (supervised) treatment period and only $21 \%$ thereafter. Secondly, when providers give unclear instructions and fail to explain the reason behind the instructions, unintended non-compliance can arise from forgetting or misinterpretations ${ }^{38-39}$. Thirdly, when the provider does not link up the prescribed regimen with patients' own ideas and perceptions about health and illness, non-compliance is more likely ${ }^{40-43}$.

Finally, the relationship between patient and provider appears to be important: a better relationship leads to more satisfaction and more compliance ${ }^{44-50}$.

Which of these factors are related to patients' compliance in physical therapy is the subject of this study. It is part of a large-scale study on patient education by physical therapists. In previous publications we focused on the way in which physical therapists educate their patients ${ }^{8,54-52}$; in this study we focus on patients' compliance.

\section{Research questions}

Subject of the study is patients' compliance with exercise regimens during regular physical therapy treatments. The main research question is: Is patients' compliance with the exercises related to characteristics of the patient and the illness, to patients' attitudes, and to the therapists' behavior?

From previous studies, we derived the following assumptions:

1 Patients' compliance will presumably be unrelated to patients' sex, age and education.

2 Patients will be more compliant if the illness is acute, more serious and causes more disabilities.

3 Patients will be more compliant when they believe exercising contributes to recovery and when they perceive no barriers in being compliant.

4 Patients will be more compliant when they are adequately instructed by the physical therapists and when they have a good relationship with them.

\section{Methods}

\section{Design and material}

Subject of the study are physical therapists in non-institutional care in the Netherlands. Out of a random sample of 300 physical therapists, 84 therapists ( $28 \%$ ) participated. They made audiorecordings of their treatment sessions and completed registration 
forms of these sessions. A non-response analysis (appendix 5, page 210) revealed two differences between respondents and non-respondents. First, $37 \%$ of the male therapists participated (63 out of 170 ) as against $16 \%$ of the female therapists (21 out of 130 ). Secondly, $68 \%$ of the respondents encountered problems in educating patients as against $42 \%$ of the non-respondents. Respondents and non-respondents did not differ in their attitudes to patient education.

A total of 1837 recordings were made (mean is 22 recordings per therapist). The therapists turned the recorder on and off, no observer was present.

The patients were unselected by the physical therapists: each therapist was instructed to audiotape one treatment session of the first 25 patients that they treated in a particular week. Patients coming twice a week or more were recorded only once. Of the 1931 patients who were asked to participate, 1837 (95\%) gave informed consent for the treatments to be audiotaped.

The therapists also asked the patients to complete a questionnaire. They gave this questionnaire after the (audiotaped) session and asked the patient to complete it immediately upon returning home. The patients knew that the therapist would not see the answers because the patients sent the questionnaire directly to our institute. Of the 1837 patients, $1681(92 \%)$ returned the questionnaire.

\section{Measuring patients' compliance}

The patients were instructed to answer two questions about home exercises in the questionnaire. Firstly they were asked whether or not they had to exercise at home and secondly their degree of compliance was asked for. We asked for their compliance of the last week because that would be remembered better than a more distant period of time.

Of the 1681 patients who completed the questionnaire, 1206 patients (72\%) filled in that they were supposed to exercise at home. They answered the following question about exercising:

"Did you manage to exercise regularly last week?" The answers were marked in classes: 270 (22\%) patients said they exercised 'not or a little' and 425 (35\%) patients said they exercised 'very regularly'; 499 (41\%) patients answered in between ("exercised rather regularly"). The latter patients can be considered to be moderately or partly compliant ( $1 \%$ were missing).

In our analyses we compare non-compliant and compliant patients. Together they form a subsample of 695 patients: the 'partly' compliant patients are excluded from the analyses because the exact degree of compliance is unknown and this could confuse the analyses.

\section{Measuring characteristics of patient and illness}

Patient's sex, age and education were noted on the registration form by the physical therapist. Education was divided into four classes, ranging from 'primary education or less" to 'college education'.

The diagnosis was written on the registration form. These diagnoses were classified 
according to the International Classification of Primary Care (ICPC) by an experienced judge with medical background. On the basis of the ICPC codes, we distinguished six mutually exclusive groups of diseases and a seventh group with 'other diseases" 51 . Table 6.1 shows the groups of diseases in the total sample and in the subsample that we analysed. There are no significant differences between the subsample and the total sample.

Table 6.1 Number of patients per group of diseases in the total sample $(N=1931)$ and in the subsample $(n=695)$.

\begin{tabular}{|c|c|c|c|c|c|}
\hline & & total s & ple & subs: & \\
\hline & & number & $\%$ & number & $\%$ \\
\hline 1 & multiple pathology & 87 & $4 \%$ & 32 & $5 \%$ \\
\hline 2 & systemic diseases & 98 & $5 \%$ & 33 & $5 \%$ \\
\hline 3 & traumata and post operation & 244 & $13 \%$ & 93 & $13 \%$ \\
\hline 4 & radiating back pain & 187 & $10 \%$ & 78 & $11 \%$ \\
\hline 5 & back pain without radiation & 327 & $17 \%$ & 107 & $15 \%$ \\
\hline 6 & neclk/shoulder pain & 336 & $17 \%$ & 123 & $18 \%$ \\
\hline 7 & other & 652 & $34 \%$ & 229 & $33 \%$ \\
\hline
\end{tabular}

The patients noted five characteristics of the illness in the questionnaire:

1 the degree of pain caused by the illness;

2 the seriousness of the illiness;

3 the degree of disability caused by the illness;

4 the prognosis of the illness;

5 the degree of psychosacial influences on the illness.

The patients marked their answer in one of four classes ranging from positive answers (for example: no pain, not serious, good prognosis) to negative answers (very much pain, very serious, bad prognosis). We use the dichotomized answers in the analyses: scale values 1 and 2 (not or little) against 3 and 4 (much or very much).

\section{Measuring patients' attitudes}

The barriers that patients perceived and their confidence in exercises were measured by twelve items. The items were scored on a four-point scale ranging from 'agree' to 'disagree'. The content of the items is - in summarized form - described in Table 6.2, together with the results of the factor analysis. 
Table 6.2 Factor loadings on twelve items concerning patients" opinions about exercising (oblique rotation).

\begin{tabular}{|c|c|c|c|c|c|}
\hline & & 1 & 2 & 3 & 4 \\
\hline 1 & I get tired from exercising & .78 & .05 & .06 & -.07 \\
\hline 2 & the exercises are difficult & .74 & .11 & -.04 & .06 \\
\hline 3 & the exercises are painful: & 64 & -.06 & .08 & .11 \\
\hline 4 & I have too little time & .02 & .77 & -.15 & .06 \\
\hline 5 & ex do not fit dally routines & .35 & .70 & -.11 & .00 \\
\hline 6 & 1 aften forget to exercise & -.15 & .64 & .11 & .01 \\
\hline 7 & I cannot afford to exercise & .01 & 52 & 52 & -.17 \\
\hline 8 & exercising will not help much & .03 & .01 & 81 & .02 \\
\hline 9 & I can do little by myself & .06 &. .15 & 64 & .13 \\
\hline 10 & recovery depends on the therapist & .14 & .06 & -.08 & .80 \\
\hline 11 & the therapist is more important & .08 & -.03 & .31 & .64 \\
\hline 12 & $\begin{array}{l}\text { my complaints will disappear } \\
\text { without exercising }\end{array}$ & -.33 & .28 & .01 & .47 \\
\hline & explained variance & $18.5 \%$ & $14.7 \%$ & $13.3 \%$ & $8.7 \%$ \\
\hline
\end{tabular}

The four factors explain $55 \%$ of the variance. The first factor indicates the degree of pain and fatigue caused by exercising; we will call this factor 'discomfort'. The 'barriers' that patients perceive are expressed in the second factor: lack of time and the fact that exercises are not tailored to patients' daily routines form the main components. The third factor denotes patients' lack of confidence in (their) exercising, called 'helplessness'. Patients' 'dependence' on the therapist is expressed in the fourth factor. Only the latter two factors are weakly interrelated (corr .17). The factor scores on the four dimensions will be used in our analyses.

To get more insight into the kind of problems that patients encounter in exercising, we asked the following open question: "Do you encounter problems in doing home exercises?" and, if so, "what kind of problems do you encounter?" The patients wrote down the problems in their own words. The answers are described in the results section to illustrate what kind of problems patients encounter.

\section{Measure behavior of the physical therapist}

The physical therapist's behavior was assessed from the audiotaped treatments. Trained judges rated the audiotapes by means of a checklist. The checklist, its reliability and the methods used are described in detail in an earlier publications ${ }^{53}$. In this article we use four variables that are supposed to be related to compliance: the extensiveness of the instructions, the therapist's attention to patient's demands, the relationship between therapist and patient and the degree of positive feedback.

1 Extensiveness of instructions. The judges counted the therapist's number of remarks about home exercises. For example "it is very important to exercise at home", "you should exercise at least twice a day", "you must stop when exercising gets painful" and so on. The total number of such remarks that the therapist made 
in the audiotaped session is used in the analyses. It indicates how extensively the therapists give their instructions for home exercises.

2 Patient's demands. The judges counted the number of times that the therapist asked the patients to tell of their demands and ideas. For example "Have you any idea about what causes your complaints?", "Do you think the exercises are helpful?". The total number of such questions is used in the analyses, indicating the therapists' attention to patients' demands and ideas.

3 Therapist-patient relationship. The relationship between therapist and patient was scored by the judges on a five-item scale (Alpha .81). Subject of the items are for example 'the degree of interest shown by the therapists', 'the therapists' concern for pain' and so on. The scores on the scale are used in the analyses. They indicate the judges' opinion of the relationship.

4 Positive feedback. The positive feedback that the patients received was noted by the patients themselves in the questionnaire. We asked: "Is the therapist satisfied with your exercising at home?" If the patients did not know whether or not the therapist appreciated their efforts, they marked "I do not know". When they knew the therapists' opinion they marked one of four classes ranging from 'not satisfied' to "very satisfied". These answers are used in the analyses.

\section{Analyses}

Compliant patients and non-compliant patients form the dichotomous dependent variable. To investigate whether non-compliant patients differ from compliant patients on the independent variables, chi-square tests and t-tests are used (for the dichotomous and continuous variables respectively). To analyse which of the independent variables has the greater power to explain compliance or non-compliance, a discriminant analysis with all variables has been done. SPSS software was used.

\section{Results}

\section{Compliance related to characteristics of the patients}

The first question is: is patients' compliance related to characteristics of the patient? In Table 6.3, non-compliant patients and compliant patients are compared. One should compare the column percentages to see whether (for example) more men than women are compliant (the row percentages always add up to $100 \%$ ). The first column gives the total number of cases in each class. 
Table 6.3 Patients'sex, age and education as related to non-compliance and compliance.

\begin{tabular}{|c|c|c|c|c|c|c|c|}
\hline & $\begin{array}{l}\text { total } \\
\text { number }\end{array}$ & non-c & $\begin{array}{c}\text { opliance } \\
39 \%\end{array}$ & comp & $61 \%$ & $\begin{array}{l}\text { chi2 } \\
\text { p.value }\end{array}$ & \\
\hline \multicolumn{8}{|l|}{ Sex } \\
\hline men & 277 & 111 & $40 \%$ & 166 & $60 \%$ & $\times 2$ & .31 \\
\hline women & 414 & 156 & $38 \%$ & 258 & $62 \%$ & & ns \\
\hline \multicolumn{8}{|l|}{ Age } \\
\hline age $<30$ years & 141 & 65 & $46 \%$ & 76 & $54 \%$ & & \\
\hline age $30-45$ years & 203 & 88 & $43 \%$ & 115 & $57 \%$ & & \\
\hline age 45 - 60 years & 178 & 62 & $35 \%$ & 116 & $65 \%$ & $\times 2$ & 10.1 \\
\hline age $>60$ years & 169 & 53 & $31 \%$ & 116 & $69 \%$ & $\mathrm{p}<$ & .05 \\
\hline \multicolumn{8}{|l|}{ Education } \\
\hline low education & 352 & 120 & $34 \%$ & 232 & $66 \%$ & $x_{2}$ & 7.5 \\
\hline high education & 320 & 143 & $45 \%$ & 177 & $55 \%$ & $\mathrm{p}<$ & .01 \\
\hline
\end{tabular}

* the expected frequencles for each row are $39 \%$ and $61 \%$ for each class of independent varlable

Men and women hardly differ in being compliant: of the men, $60 \%$ are compliant and of the women $62 \%$. Compliance seems to increase with age: more older than younger patients report doing their exercises regularly.

Contrary to our expectations, patients' education is significantly related to compliance: highly educated patients are less compliant with home exercises than are low-educated patients. Combining sex, age and education yields some interesting results. Noncompliance occurs most among highly educated women younger than 45 years: $54 \%$ of these women are non-compliant compared with $36 \%$ of the low-educated women in the same age group (p.<.01). Among men, compliance is not related to their education: highly educated and low educated young men are equally compliant. Whether these differences in compliance are related to the different illnesses or complaints among groups of patients will be analyzed next.

\section{Compliance related to the illmess and its characteristics}

The second question is: is patients' compliance related to the illness and its characteristics? Whether compliance differs per (groups of) illness can be seen in Table 6.4. 
Table 6.4 Non-compliant and compliant patients per group of iliness $(n=695)$.

\begin{tabular}{|c|c|c|c|c|c|c|}
\hline & $\begin{array}{l}\text { total } \\
\text { number }\end{array}$ & non-c & $\begin{array}{c}\text { oplance } \\
39 \% *\end{array}$ & compl & $\begin{array}{l}\text { nce } \\
61 \%\end{array}$ & chi2 \\
\hline multiple pathology & 32 & 14 & $44 \%$ & 18 & $56 \%$ & .16 \\
\hline systemic diseases & 33 & 10 & $30 \%$ & 23 & $70 \%$ & .72 \\
\hline traumata/post-operative & 93 & 29 & $31 \%$ & 64 & $69 \%$ & 2.30 \\
\hline radiating back pain & 78 & 28 & $36 \%$ & 50 & $64 \%$ & .20 \\
\hline back pain without radiation & 107 & 46 & $43 \%$ & 61 & $57 \%$ & .72 \\
\hline neck/shoulder pain & 123 & 50 & $41 \%$ & 73 & $59 \%$ & .12 \\
\hline other & 229 & 93 & $41 \%$ & 136 & $59 \%$ & .34 \\
\hline
\end{tabular}

* expected frequencies in each row are $39 \%$ and $61 \%$ for each group of illness

None of the Chi-square values reaches the significance level of $p .<.05$. This means that patients with one kind of illness are no more likely to exercise at home than patients with another kind of illness. There is however, the tendency that patients with traumata or post-operative conditions comply slightly better than patients with other kinds of illness.

As might be expected, the kind of illness is significantly related to patients' age: older patients have more multiple pathology and neck/shoulder complaints, whereas younger patients have more traumata and, especially in the age group 30 to 45 years more radiating back pain occurs. The difference in compliance between highly and loweducated women, however, cannot be explained by differences in the kind of illness because no differences were seen.

It can be concluded that the illness itself appears to be unrelated to compliance. The characteristics of the illness, however, are certainly related to compliance, as can be seen in Table 6.5. 
Tabile 6.5 Relation between the characteristics of the liness and patients" compliance.

\begin{tabular}{|c|c|c|c|c|c|c|c|}
\hline & $\begin{array}{l}\text { lotal } \\
\text { number }\end{array}$ & non-c & $\begin{array}{c}3 p \text { liance } \\
39 \%\end{array}$ & comp & $\begin{array}{l}\text { ce } \\
61 \%\end{array}$ & $\begin{array}{l}\text { chi2 } \\
\text { p.value }\end{array}$ & \\
\hline \multicolumn{8}{|l|}{ Pain } \\
\hline little or no pain & 280 & 121 & $43 \%$ & 159 & $57 \%$ & $\times 2$ & 3.75 \\
\hline (very) much pain & 402 & 143 & $36 \%$ & 259 & $64 \%$ & $p<$ & .05 \\
\hline \multicolumn{8}{|l|}{ Seriousness } \\
\hline little/not serious & 269 & 121 & $45 \%$ & 148 & $55 \%$ & $\times 2$ & 6.79 \\
\hline (very) serlous & 420 & 146 & $35 \%$ & 274 & $65 \%$ & $p<$ & .01 \\
\hline \multicolumn{8}{|l|}{ Disabilities } \\
\hline Ittle/no disab. & 242 & 119 & $49 \%$ & 123 & $51 \%$ & $\times 2$ & 15.5 \\
\hline (very) much disab. & 450 & 151 & $34 \%$ & 299 & $66 \%$ & $p<$ & .01 \\
\hline \multicolumn{8}{|l|}{ Prognosis } \\
\hline illness will disappear & 203 & 61 & $30 \%$ & 142 & $70 \%$ & $\times 2$ & 7.72 \\
\hline Alness will remain & 452 & 189 & $42 \%$ & 263 & $58 \%$ & $p<$ & .01 \\
\hline \multicolumn{8}{|l|}{ Psychosocial Influence } \\
\hline no/little influence & 484 & 179 & $37 \%$ & 305 & $63 \%$ & $\times 2$ & 3.34 \\
\hline (very) much influence & 158 & 72 & $46 \%$ & 86 & $54 \%$ & $\mathrm{p}<$ & .10 \\
\hline
\end{tabular}

* the expected frequencles in each row are $39 \%$ and $61 \%$ for each independent variable

The degree of disability shows the strongest relation with compliance: patients whose illness causes more disabilities comply better with home exercises than patients with less hindrance from the illness. The disabilities are strongly related to the degree of pain and the seriousness of the disease (corr. .47 and .55 respectively) and accordingly patients' compliance is also related to the perceived seriousness and pain. However the prognosis is inversely related to compliance: patients who think that their illness will remain exercise less than patients who think that their complaints will disappear. Patients are also less inclined to comply when they perceive their complaints as more psychosocial in nature.

We investigated whether these characteristics of the illness were connected with particular kinds of illnesses. The disabilities were not significantly related to any of the illnesses but the pain was: patients with radiating back pain and with neck/shoulder complaints report significantly more pain than patients with systemic disease or with traumata and post-operative conditions. Systemic diseases were perceived as the most serious ones. Traumata and post-operative conditions had the best prognosis of all diseases and little or no psychosocial influence was attributed to them. Although significant relations between these characteristics and the kind of illness exist, we must conclude that it is the characteristics of the illness that influence patients' compliance and not the kind of illness per se. 
The relation between patients' beliefs and attitudes and compliance

As the third question, we investigated whether patients' attitudes are related to compliance. By means of a t-test we analysed whether non-compliant patients have higher 'factor scores' on the following four dimensions: discomfort, barriers, helplessness and dependency (see Table 6.6).

Table 6.6 Factor scores of non-compliant and compliant patients $(n=581)^{*}$

\begin{tabular}{|c|c|c|c|}
\hline & $\begin{array}{c}\text { non-compl. } \\
(n=224)\end{array}$ & $\begin{array}{c}\text { compl. } \\
(n=357)\end{array}$ & $\mathrm{p}$-value \\
\hline Degree of discomfont & +.11 & -.04 & $p<.10$ \\
\hline Percelved barriers & +.95 & -.59 & $p<.01$ \\
\hline Degree of helplessness & +.28 &.$\| 1$ & $p<.01$ \\
\hline Degree of dependency & .00 & +.02 & $n s$ \\
\hline
\end{tabular}

* 1114 cases had missing values on one of the items and were excluded

The perceived barriers and the degree of helplessness are significantly related to compliance: exercising occurs less when patients think that exercising will not help much, and in particular when patients perceive many barriers to exercising. The 'degree of dependency', i.e. perceiving the physical therapist as more important than exercising does not seem to be related to compliance.

The kind of problems that patients encountered in doing home exercises were written down by the patients ${ }^{54}$. Of the non-compliant patients, $60 \%$ reported one or more problems, whereas $13 \%$ of the compliant patients did. A total of 272 problems were noted; they are described in Table 6.7.

Table 6.7 Number and kind of problems reported by non-compliant and compliant patients $(n=695)$

\begin{tabular}{|c|c|c|c|c|}
\hline & $\begin{array}{l}\text { non-compl. } \\
n=270\end{array}$ & $\begin{array}{l}\text { compl. } \\
n=425\end{array}$ & $\begin{array}{l}\text { total } \\
n=695\end{array}$ & $\%$ \\
\hline lack of time to exercise & 73 & 13 & 86 & $31 \%$ \\
\hline exercising causes pain or discomfort & 30 & 29 & 59 & $22 \%$ \\
\hline one forgets to exercise & 47 & 3 & 50 & $18 \%$ \\
\hline lack of motivation to exercise & 35 & 5 & 40 & $15 \%$ \\
\hline the exercises do not help & 7 & $i$ & 8 & $3 \%$ \\
\hline other problems mentioned & 19 & 10 & 29 & $11 \%$ \\
\hline total & 211 & 64 & 272 & $100 \%$ \\
\hline
\end{tabular}


The non-compliant patients reported all kinds of problems significantly more often than the compliant patients, with the exception of the 'pain problem'. Most frequently patients who did not comply wrote that they lacked the time to exercise or that the exercises did not fit into their daily routines. The pain or discomfort caused by exercising formed another problem in exercising and was mentioned both by patients who did and who did not exercise. On the other hand, forgetting to exercise and lack of motivation to exercise were especially mentioned by non-compliant patients. All but one of the problems (i.e. pain) are significantly related to the factor 'barriers' (correlations .17 to $.46, p<.01)$. The pain problem is significantly related to the factor 'discomfort' (corr. .25, $p<01$ ), which supports the validity of the factor measures.

\section{Compliance related to the physical therapists' behavior}

The fourth question is: Is patients' compliance related to the physical therapists' behavior, as assessed from the audiotapes? In particular we investigated whether compliance was related to: the number of exercise instructions given by the therapist; the number of times the therapist asked the patient to tell his or her demands and ideas; the relation with the patient as judged by the observers; and, the positive feedback that patients received as perceived by the patients themselves. Table 6.8 shows the results of the t-tests.

Table 6.8. Mean scores of physical therapist behavior with non-compliant and compliant patients $(n=680)$

number of exercise instructions
(number per session)
asking patients' demands
(number of questions asked)
therapist-patient relationship
(score on relationship scale)
positive feedback
(patients" questionnalre)

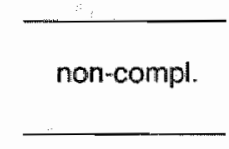

$\begin{array}{r}7.47 \\ .28 \\ 2.45 \\ 2.23 \\ \hline\end{array}$

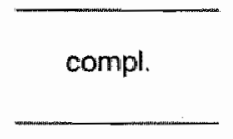

6.94

.29

2.51

3.57 p-value

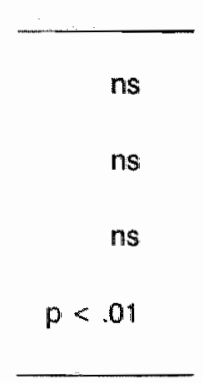

Compliance is significantly related to the positive feedback that patients received: particularly, patients who said that the therapist was (very) satisfied with their exercising are more compliant than patients who did not know whether the therapist appreciated their exercising. The other forms of behavior show no significant relation with compliance, at least not a direct relation.

There was, however, a difference between two groups of therapists, those with relatively more compliant patients and those with relatively more non-compliant patients. It appeared that therapists whose patients are more compliant more frequently asked patients to tell their demands and ideas $(p<.05)$ and that they more often 'monitored' patients' performance and more frequently motivated patients to exercise at home $(p<.01)$. It can be concluded, however, that the positive feedback 
is a more important factor in patients' compliance.

\section{Multivariate analysis between the independent variables and patients' compliance}

To investigate which of the factors are most powerful in explaining compliance and non-compliance, we used the discriminant analysis statistic. All the independent variables were included in the analysis:

- patients' sex, age and education (three measures)

- the kind of illness (seven groups) and the characteristics of the illness (five measures)

- patients' attitudes concerning discomfort, barriers, helplessness and dependency (four measures)

- the physical therapists' behavior (four measures).

Table 6.9 Results of the discriminant analysis (stepwise) relating all independent variables to the criterion non-compliance versus compliance $(n=537)^{\star}$.

\begin{tabular}{|c|c|c|c|}
\hline & & Wilks Lambdia & Canonic corr. \\
\hline 1 & Perceived barriers (factor 2 ) & .53 & .69 \\
\hline 2 & Positive feedback & .49 & .71 \\
\hline 3 & Degree of helplessness (factor 3 ) & .47 & .73 \\
\hline 4 & Degree of disability & 47 & .73 \\
\hline 5 & Prognosis of the disease & .46 & .73 \\
\hline 6 & Perceived seriousness & .46 & .73 \\
\hline 7 & Multiple patholagy & .46 & .73 \\
\hline B & Systemic diseases & 46 & .73 \\
\hline 9 & Degree of pain & .46 & .73 \\
\hline
\end{tabular}

* cases with missing values on one of the variables were excluded.

With these nine variables, $86 \%$ of the cases are carrectly classified: of the noncompliant patients, $73 \%$ are predicted correctly (prior probability $38 \%$ ) and of the compliant patients $94 \%$ are predicted correctly (prior probability $62 \%$ ). It appears that particularly the barriers that patients perceive strongly predict patients' non-compliance. The positive feedback that patients receive is the second important factor in patients' compliance, and the degree of helplessness the third one. The other factors are significantly related to compliance but they do not seem to enhance the total correlation coefficient.

\section{Discussion}

This study was intended to discover factors that are related to patients' compliance with exercise regimens in physical therapy.

It must be noted in advance that we studied short-term 'supervised' compliance. As a consequence the results cannot be generalized to long-term 'non-supervised' 
compliance: both types of compliance are different in nature, as we have argued elsewhere 1 . We shall discuss the main results, the implications for practice and future research questions.

The degree of patients' compliance in physical therapy can be considered optimistically and pessimistically: pessimistically viewed, only $35 \%$ of the patients fully comply with exercise regimens, while this figure rises to $76 \%$ when one adds the patients who "partly" comply. Partial compliance may or may not be sufficient: a therapist may prescribe more exercises than necessary, assuming that patients will cut down the number; or patients may find that exercising four times is as effective as seven times. From our study we can conclude that patients compliance in physical therapy is unsatisfactory. Sound conclusions about the exact degree of non-compliance, however, cannot yet be drawn. This is partly due to two problems. Firstly, noncompliance in physical therapy is hardly, if ever, investigated, which makes it impossible to compare our findings with other results. Secondly, and related to it, there is a lack of measurement tools to assess patients' compliance with exercises and advice on physical therapy. Although a 'true" assessment of compliance is at least very difficult, it is obvious that reliable measurement tools should be developed. In our study we asked rather broad questions about patients" compliance, but more knowledge about the degree of compliance and about the reliability of patients" answers is needed. We consider this topic a high priority for future research.

The three main causes of non-compliance are the barriers that patients perceive, the lack of positive feedback and the perceived helplessness.

The first one, the barriers that patients perceive, is the strongest factor in noncompliance. Most frequently patients mentioned that exercising required too much extra time, that the exercises were not adjusted to their particular situation or that they do not fit into their daily routines. Patients also mentioned that they forget to exercise. Some patients wrote that exercising caused pain and some of them lacked the motivation to exercise. Some examples: "my full-time job makes it impossible to exercise three times a day" "with three little children little time remains" "after a busy" day I am too tired to exercise" "I ought to swim but I hate cold water" "it is deadly dull to exercise", "exercising provokes pain" "I intend to exercise but seem to forget it".

One could consider all these problems as easy excuses for not exercising. However, in that case one wrongly overlooks the real problems that people encounter when they try to change their habits or life style.

For physical therapists at lleast two things seem to be important. Firstly, the problems that patients encounter cannot be resolved if they are unknown to the therapists. Thus therapists should carefully inquire about the kind of problems that each patient encounters. One should not beforehand assume that one knows the reason for noncompliance, as Bartlett has emphasized ${ }^{55}$, because patients' problems differ in nature, as our results have shown.

The second step is to try to resolve these problems. This may be facilitated by the principle of 'tailoring', as is supported by research findings. This means that the 
physical therapist should search for appropriate circumstances in patients" daily activities that provide the opportunity to exercise. This prevents the prescribing of exercise programs that are infeasible for the patient, and provides an opportunity to adjust the program to the patients' particular situation. Tailoring also implies the search for cues in patients' daily routines that can function as reminders. When exercising becomes connected with other daily routines it may become a habit for the patient. It should be stressed that this will not succeed without a patient-centred approach to treatment. It is obvious that only the patients themselves know their daily routines, thus their good rapport, and mutual cooperation with the patient is needed. In conclusion, discussing the problems that patients encounter and trying to resolve them may be a first step towards facilitating patients' compliance.

A second factor in non-compliance is the lack of positive feedback, as our results showed. The importance of positive feedback is supported by many research findings. It is also firmly grounded in learning theories in which it is assumed that human behavior is greatly influenced by the positive consequences that it yields.

We measured only one form of positive feedback, namely the appreciation that the therapist showed for patients" progress or efforts. This kind of positive feedback can easily be given by physical therapists because the patient is regularly seen over a longer period of time. However, it requires a positive attitude on the part of the physical therapists. What we mean is that one can only sincerely give positive feedback when one focuses on successes, even if they are small ones, and not on failures. It may be helpful to set goals that are within easy reach of the patient and progress step by step. Such a positive attitude towards small successes is more likely when one realizes how difficult it is to change habits or life style, and when one takes the patients' problems seriously. Physical therapists with such an attitude may become creative in inventing other forms of positive feedback than the one we measured.

A third factor in non-compliance appears to be the 'degree of helplessness'. Patients who think that they can do little by themselves and that exercising will not help much are less inclined to exercise. On this subject more research is needed. Two interpreta: tions are possible. Firstly, some patients may lack confidence in the exercises per se and think that the exercises will not contribute to recovery or health; this explanation fits within the locus of control theory. In such cases compliance could be facilitated by giving more explanation about the benefits of exercising. Although currently the effects of all types of exercises are as yet not clear ${ }^{56}$, there is a general consensus about the health benefits of exercising ${ }^{2,57}$. Secondly, patients may lack confidence in their own ability to exercise and may think that they themselves are unable to maintain exercising; this explanation fits within the self efficacy theory. When patients think the exercises are helpful but find themselves unable to exercise - the second case - one should search for methods of enhancing patients" confidence in their own abilities. Which of these two explanations is valid remains an interesting and relevant question for future research. 
As a fourth result the study revealed that non-compliance was not related to the kind of illness per se but to the characteristics of the illness. This is particularly relevant for physical therapists because they focus on the consequences of diseases, such as disabilities or handicaps. The characteristics showing the strongest relation with noncompliance are the prognosis of the illness and the degree of hindrance caused by the illness.

The prognosis is negatively related to compliance: when - in the patient's opinion the complaints will remain in the future, less compliance occurs. One can easily understand that patients who think that recovery is unlikely or impossible are less motivated to maintain exercising. In such cases, to deal adequately with illness competes with many other priorities in life, as is clearly described in "Compliance, the dilemma of the chronically ill" 27 .

What physical therapists can do is to adjust their prescriptions as much as possible to patients' perceptions and their preferences; they may stimulate the patients themselves to discover and select adequate forms of behavior that suit them. Such a 'self-regulation approach' is extensively described by Leventhal ${ }^{41}$. We have worked it cut for the situation in physical therapy'.

It is also conceivable that patients with little hindrance from the complaints are less compliant than those with great hindrance. Such hindrance may continuously remind patients to exercise, and the prospect of surmounting it may be a strong motivation to comply. This mechanism facilitates compliance with curative measures but not with preventive measures. Compliance with preventive measures appears to be very difficult to attain, and the majority of the patients seem to be unable to maintain long-term compliance with preventive measures. This implies that physical therapists are faced with considderable difficulties when they try to attain patients" long-term compliance with exercise programs that are aimed at preventing recurrence of the complaints. It is obvious that this problem remains a very relevant topic for future research.

\section{Conclusions}

\section{Implications for practice}

Our research reveals that the main factors that are related to non-compliance in physical therapy are the barriers that patients perceive and the lack of positive feedback. From this it may be assumed that efforts to resolve these barriers and to provide for positive feedback may enhance patients' compliance with exercises. Hence, it seems important that physical therapists proceed to pay particular attention to the following aspects of patient education. The relevance of these aspects is supported by many results of patients' compliance research.

Firstly, physical therapists should carefully explore to what extent the patient complies with the prescribed exercises. When non-threatening questions are asked, reliable answers are mare likely.

Secondly, when patients are non-compliant, the reasons for this must be known and the problems encountered by the patient should be taken seriously. One should not assume that one knows these problems betorehand, since they appear to differ 
considerably per patient.

Thirdly, solutions for the problems should be sought in cooperation with the patient. The principle of tailoring exercises to patients' specific situation and daily routines seems to be particularly relevant in physical therapy.

Fourthly, positive feedback appears to facilitate compliance and many forms of it exist. One of the things that physical therapists can do is to show sincere interest in and appreciation of patients' efforts and progress. It may be obvious that one can express such appreciation only when one has a positive attitude towards patients' efforts and when one realizes how difficult it is for people to change habits or life style.

Table 6.10 Implications for practice

1 Physical therapists should carefuly explore to what extent patients comply with the prescribed exercises and advice.

2. One should explore the reasons for non-compliance and not at forehand assume one knows the reasons for non-compliance.

3. The problems patients encounter in their efforts to comply should be taken seriously.

4 Solutions for the problems should be sought in cooperation with the patient.

5 Patients should receive positive feedback for their efforts and progress.

\section{Implications for research}

Because our research project is one of the first concerning non-compliance in physical therapy, it is abvious that much work needs to be done ${ }^{58}$. Firstly, however, we must mention one important finding. Our results indicate that patients' non-compliance in physical therapy is influenced by a number of factors that are also related to noncompliance with medical regimens. It indicates that physical therapists can benefit from and build on the knowledge yielded by the great many research projects in medical practice.

From our research findings we can derive the following priorities for future research. Firstly, research on patient compliance in physical therapy requires a reliable and valid measurement tool to assess the degree of patients' compliance both with exercises and with the great number of pieces of advice that patients receive. Because compliance in physical therapy is not a matter of all or nothing but of many gradations, particular attention should be paid to the degree of compliance.

Secondly, it seems highly relevant to investigate whether patients' compliance can be facilitated by applying a number of compliance-enhancing strategies. Some of these strategies are described in this article, others can be derived from other research on patients' compliance. In this respect it seems useful first to concentrate on strategies that can easily be applied in physical therapy practice and do not require complex extra skills from the therapists. Simply stated, one should focus on the major 
gains that can be attained with the least effort.

Thirdly, little knowledge if any exists about long-term compliance in physical therapy. It should be noted that our research related to short-term supervised compliance. Long-term non-supervised compliance (i.e. when treatment has stopped) is totally different in nature and far more difficult to attain, as we have argued elsewhere ${ }^{1}$. In addition, long-term compliance in physical therapy is often aimed at primary or secondary prevention, and research has shown that the majority of the patients are unable to maintain compliance with preventive measures. Research on this topic is highly relevant. It may be obvious that both physical therapists and patients will benefit from knowledge about factors that facilitate compliance with long-term preventive measures. 


\section{Literature}

1 Slutijs EM, Knibbe JU.

Patient compliance with exercise: different theoretical approaches to short-term and long-term compliance.

Patient Education and Counseling 17; 1991 , 3: 191-204.

2 Dishman RK.

Exercise adherence: its impact on public health.

Champaign: Human Kinetics Books, 1988.

3 Dubbert $\mathrm{PM}_{1}$ Martin JE, Epstein LH.

Exercise. In: Hollroyd KA, Creer TL (eds.). Self-management of chronic disease: handbook of

clinical interventions and research.

Orlando, etc.: Academic Press, 1986: 127-161.

4. Härkäpää $K$, Järvikoski $A$, Mellin $G$, Hurri $H$.

A controlled study on the outcome of inpatient and outpatient treatment of low back paim. Part I.

Pain, disability, compliance, and reported treatment benefits three months after treatment.

Scandinavian Journal of Rehabilitation Medicine 21; 1989: 81-89.

5. Ice R.

Long-term compliance.

Physical Therapy 65; 1985, 12: 1832-1839.

6 Martin JE Dubbert PM.

Exercise applications and promotion in behavioral medicine: current status and future directions.

Journal of Consulting and Clinical Psychology 50; 1982, 6: 1004-1017.

7 Dishman RK.

Compllance/Adherence in health-related exercise.

Health Psychology 1; 1982, 3: 237-267.

a Sluijs EM, Kuijper EB.

Problemen die fysiotherapeuten ervaren bij het geven van voorlichting aan patienten: een inventarisatie. (Problems physical therapists encounter in educating patients.)

Nederlands Tijdschrift voor Fysiotheraplie 100; 1990, 5: 128-132.

9 Feinstein AR.

"Compliance bias" and the interpretation of therapeutic trials. In: Haynes RB, Taylor DW, Sackett DL (eds.). Compliance in thealth care.

Baltimore, etc.: The Johns Hopkins University Press, 1979: 309-322.

10 Gordis L.

Conceptual and methodologic problems in measuring patient compliance. In: Haynes RB, Taylor DW, Sackett DL (eds.). Compliance in health care.

Baltimore, etc.: The Johns Hopkins University Press, 1979: 23-45.

11 Deyo RA.

Compliance with therapeutic regimens in arthritis: issues, current status, and a future agenda.

Seminars in Arthritis and Riheumatism 12; 1982, 2: 233-244. 
12 Foth HP.

Measurement of compliance

Patlent Education and Counseling 10;1987,2:107-116.

13 Perkins KA, Epstein LH.

Methodology in exercise adherence research. In: Dishman RK (ed.). Exercise adherence: its impact on public health.

Champaign: Human Kinetics Books, 1988: 399-416.

14. Campen C van, Siujis EM.

Patient compliance: a survey of reviews (1979-1989).

Utrecht: Nivel, 1989. NIVEL-Bibliographies, 38.

15. Haynes RB, Taylor DW, Sackett DL (eds).

Compliance in thealth care.

Baltimore, etc: The Johns Hopkins University Press, 1979.

16 Cohen S.J.

New metaphors for old problems. In: Cohen SJ (ed.). New directions in patient compliance.

Toronto etc., s.in.: 1979: 153-163.

17 Spellman MR.

An exploratary study: the effects of a health education program on patient compliance to back exercises and alterations in activities of daily living.

Detroit, Michligan: Wayne State University, 1980. Dissertation.

18 Ferguson $\mathrm{K}_{\mathrm{B}}$ Bole $\mathrm{GG}$.

Family support, health beliefs, and therapeutic compliance in patients with rheumatoid arthritis.

Patient Counselling and Health Education 1; 1979, 3: 101-105.

19 Helby EM, Carlson JG.

The health compliance model.

The Journal of Compliance in Health Care 1; 1986, 2 : 135-152.

20 Janz NK, Becker MH.

The Health Bellief Model: a decade later.

Health Education Quarterly 11; 1984, 1: 1-47.

21 Sonstroem RJ.

Psychological models. In: Dishman FK (ed.). Exercise adherence: its Impact on public health.

Champaign: Human Kinetics Books, 1988: 125-153.

22 Sallis JF, Haskell WL, Fortmann SP, Vranizan KM, Taylor CB, Solomon DS.

Predictors of adoption and maintenance of physical activity in a community sample.

Preventlve Medicine 15; 1986: 331-341.

23 LeVy RL.

Social support and compliance: selective review and critique of treatment integrity and outcome measurement.

Soclall Sclence and Medicine 17; 1983, 18: 1329-1338.

24 Dolan-Mullen PD. Green LW, Persinger GS.

Clinical trlals of patient education for chronlc conditions: a comparative meta-analysis of interventon types.

Preventlwe Medicine 14; 1985: 753-781.

25 Becker MH.

Patient adherence to prescribed therapies.

Medical Care $23 ; 1985,5$ : 539-555.

26 Haynes RB.

Determinants of compliance: the disease and the mechanics of treatment. In: Haynes RB, Taylor

DW, Sackett DL (eds.). Compliance in health care.

Baltimore, etc: The Johns Hopkins University Press, 1979: 49-62. 
Compliance in the chronically ill: an introduction to the problem. In: Geiber KE, Nethemikis AM (eds.). Compliance: the dilemma of the chronically III.

New York: Springer Publishing Company, 1986: 12-23.

Compliance and exercise in primary and secondary prevention of coronary heart disease: a veview.

Preventive Medicine 11; 1982: 56-70.

29 Bartlett EE.

Behavioral diagnosis: a practical approach to patient education.

Patlent Counselling and Health Education 4; 1982, 1: 29-35.

30 Posavac E $\mathbb{J}$, Sinacore JM, Brotherton SE, Helford MC, Turpin RS.

Increasing compliance to medical treatment regimens: a meta-analysis of program.

Evaluation and the Health Professions $8 ; 1985,1: 7-22$.

31 Blackwell $B$.

Counselling and compllance.

Patient Counselling and Health Education 1; 1978, 2: 45-49.

32 Haynes RB, Wang $E$, Da Mota Gomes $M$.

A critical review of interventions to improve compliance with prescribed medications.

Patient Education and Counseling 10; 1987, 3: 155-166.

33 Sackett $\mathrm{DL}$

A compliance practicum for the busy practitioner. In: Haynes RB, Taylor DW, Sackett DL (eds.).

Compliance in health carre.

Baltimore, etc:: The Johns Hopkins University Press, 1979: 286-294.

34 Dunbar JM, Marshall GD, Hovell MF.

Behavioral strategles for improving compliance. In: Haynes RB, Taylor DW, Sackett DL (eds.).

Compliance in health care.

Baltimore, etc. The Johns Hopkins University Press, 1979: 174-190.

35 Epstein $\mathrm{LH}_{\text {, Cluss PA. }}$

$A$ behavioral mediche perspective on adherence to long-term medical regimens.

Journal of Consulting and Clinical Psychology 50; 1982, 6: 950-971.

36 Knapp DN.

Behavioral management techniques and exercise promotion. In: Dishman RK (ed.). Exercise adherence: its impact on public health.

Champaign: Human Kinetics Books, 1988: 203-235.

37 Martin JE, Dubbert PM, Katell AD, Thompson JK, Raczynski JR, Lake M, Smith PO, Webster JS.

Behavioral control of exercise in sedentary adults: studies 1 through 6 .

Journal of Consulting and Clinical Psychology 52; 1984, 5: 795-811.

38. Ley Ph.

Patients" understanding and recall in clinical communication fallure. In: Pendleton $\mathrm{D}$ and Hasler $\mathrm{J}$

(eds.). Doctor-patient communication.

London, etc.: Academic Press, 1983: 89-107.

39 Svarstad BL.

Physician-patient communication and patient conformity with medical advice. In: Mechanic D. The growth of bureaucratic medicine: an inquiry into the dynamics of patient behavior and the organization of medical care.

New York: John Wiley and Sons, 1976: 220-238.

40 Lazare A, Elsenthal $S_{f}$ Frank A, Stoeckle JD.

Studies on a negotiated approach to patienthood. In: Stoeckle JD (ed.) Encounters between

patients and doctors: an anthology.

Cambridge, etc.: The MIT Press, 1987: 413-432. 
41 Leventhal $H_{i}$ Cameron $L$.

Behaviorat theories and the problem of compllance.

Patient Education and Counseling 10; 1987, 2: 117-138.

42. Oldridge NE.

Compliance with exercise in cardiac rehabilitation. In: Dishman RK (ed.). Exercilse adherence: its impact on public health.

Champalign: Human Kinetics Books, 1988: 283-304.

43 Turk DC, Salovey P, Litt MD.

Adherence: a cognitive-behavioral perspective. In: Gerber $K E_{\text {; }}$ Nehemkis AM (eds.). Compliance: the dilemma of the chronically ill.

New York: Springer Publishing Company. 1986: 44-72.

44. Carter WB, Inui TS, Kukull WA, Haigh VH.

Outcome-based doctor-patient interaction analysis (Il): identifying effective provider and patient behavior.

Medical Care 20; 1982, 6: 550-566.

45 DiMatteo MR, DiNicola DD.

Achieving patient compliance: the psychology of the medical practitioner's role.

New York: Pergamon Press, 1982.

46 Falvo D, Woehlke P, Delchmann J.

Pelationship of physician behavior to patlent compliance.

Patient Counselling and Health Education 2; 1980, 4: 185-188.

47 Feinberg $\mathrm{J}$.

The effect of patient-practitioner interaction on compliance: a review of the literature and application in theumatoid arthritis.

Patient Education and Counseling 11; 1988, 3: 171-187.

48 Hanson RW.

Physiclan-patient communication and compliance. In: Gerber KE, Nehemkis AM (eds.). Compliance: the dilemma of the chronically lll.

New York: Springer Publishing Company, 1986: 182-212.

49 Pendleton D.

Doctor-patient communication: a review. In: Pendleton D and Hasler $J\left(e d s_{n}\right.$ ). Doctor-patient communication.

London, etc.: Academic Press, 1983: 5-53.

50 Stone GC.

Patient compliance and the role of the expert.

Journal of Soctal Issures $35 ; 1979,1: 35-59$.

61 Sluijs EM, Kok GJ, Zee J van der.

Patient education in physical therapy as related to the patient, the illness and the kind of treatment applied.

Submitted.

52 Stuils EM, Zee J van der, Kok G.

Differences between physical therapists in attention paid to educational activities.

Submitted.

53 Sluilis EM.

A checklist to assess patient education in physical therapy practice: development and reliability. Physical Therapy $71 ; 1991,8: 561 / 17-569 / 25$.

54 Sluijs EM, Hermans IMJ.

Problemen die patiërten ervaren bij het doen van huiswerkoefeningen en bij het opvolgen van adviezen: een inventarisatie. (Problems that patients encounter in exercising and following advice) Nederlands Tijdschrift voor Fysiotherapie 100; 1990, 6: 175-179. 
55 Bartlett EE, Higginbotham JC, Cohen-Cole S, Bird J.

How do primary care residents manage patient non-adherence?

Patient Education and Counseling $16 ; 1990,1: 53-60$.

56 Koes BW, Bouter LM, Beckerman H, Heijden GJMG van der, Knipschild PG.

Physiotherapy exercises and back pain: a blinded review.

British Medical Journal, 302; 1991, 6792: 1572-1576.

57 Bouchard C, Shephard RJ, Stephens T, Sutton JR, McPherson BD (eds.)

Exercise, fitness and health. A consensus of current knowledge.

Champaign: Human Kinetics Books, 1988.

58. Dishman RK.

Epilogue and future directions. In: Dishman RK (ed.). Exercise adherence: its impact on public health.

Champaign: Human Kinetics Books, 1988: 417-426. 



\title{
7 PATIENT COMPLIANCE WITH EXERCISES: DIFFERENT THEORETICAL APPROACHES TO SHORT-TERM AND LONG-TERM COMPLIANCE
}

\author{
E.M. Sluijs, J.J. Knibbe
}

Published in Patient Education and Counseling; 17, 1991, 3: 191-204.

\section{Abstract}

Compliance with exercise regimens is difficult to obtain as is compliance with other medical regimens. In analyzing non-compliance, two problems exist: 1 . current theories only partly explain patients' non-compliance; 2 . health care providers seldom act according to the recommendations derived from research findings.

These problems may be due in part to great differences in types of compliance behavior. A significant difference exists between short-term supervised compliance and long term non-supervised compliance. Therefore different theoretical and practical approaches may be needed, depending on the specific compliance behavior in question.

Analysis of compliance with exercise regimens indicates that interventions based on behavioral theory are adequate for short-term compliance, whereas a self-regulation approach can be useful in long-term compliance. As a logical consequence, the health care provider should be able to act differently, according to the type of compliance needed. The practical implications for exercise regimens in physical therapy practice are discussed in detail. 
A multitude of research papers on patient compliance has provided us with valuable insights into the complicated nature of compliance. In the past few decades several important theoretical models concerning compliance emerged, proposing solutions for the compliance problem ${ }^{1-2}$ and research has resulted in the discovery of over 200 factors related to compliance ${ }^{3}$. Nevertheless, it appears that these separate theories and models only partly account for the differences in compliance. The explained difference is often small and the correlations weak or even contradictory ${ }^{1-4}$. Compliance problems differ in nature, however ${ }^{5-6}$. As a consequence, different theoretical approaches may be appropriate for different types of (compliance) behavior.

Besides the theoretical problem, a practical problem exists. It is disappointing that health care providers seldom act according to valuable recommendations derived from research ${ }^{7.8}$. As Bartlett states: "There is a 15-year lag between theory and practice." Although research advances rapidly, practice patterns are registering only modest improvements ${ }^{9}$. This discrepancy could be related to the inconsistency of research findings. Health care providers are often confronted with recommendations from researchers that seem ad hoc, or diverse and fragmentary ${ }^{10}$. Providers need guidelines tailored to the specific compliance behavior desired in their health care setting. Providing the health professional with insight into the mechanisms underlying the recommendlations and selecting the most powerful, yet simply applicable strategies may facilitate acceptance and practice of the recommendations.

We will argue that it is essential to specify the characteristics of the desired type of compliance. This enables an optimal choice of a theoretical model or combination of theories. From this selection practical recommendations for the health care provider can be deduced, which theoretically speaking, have a maximum potential for attaining compliance.

First compliance behavior will be analyzed. An important way in which compliance behaviors differ is the length of the period in which compliance needs to be maintained. The distinction between long-term and short-term compliance has implications for the choice of a theoretical approach. It is also meaningful to distinguish between compliance with curative regimens and compliance with preventive measures. Distinguishing different forms of compliance has been done by various authors and researchers ${ }^{1-3}$. Studies focus on compliance behavior in specific diseases, specific groups of patients or different treatment regimens ${ }^{11}$. Distinguishing short-term compliance from long-term compliance has also been done ${ }^{12-14}$, mostly resulting in the conclusion that long-term compliance is far more difficult to obtain than short-term compliance ${ }^{13,15 \cdot 16}$. Although a search for new theories is proposed ${ }^{17}$, it may be promising to take selective advantage of existing theories based on a clear distinction between short-term and long-term compliance. 
Secondly, we will argue that short-term compliance is best achieved by using the basic principles of a behavioral approach, whereas the self-regulation perspective could be useful in achieving long-term compliance, with different stresses depending on the curative or preventive orientation. These propositions will be supported by logical and empirical evidence.

Finally, we will explain how these different theoretical approaches implicate a selective use of the various recommendations given a specific health care setting. As an example we will work out the three steps for compliance with exercise regimens in physical therapy (fig. 7.1), as compliance is a relevant topic in physical therapy ${ }^{18-21}$.

Fig. 7.1 Three-step approach for compliance

$\begin{array}{lll}\text { COMPLIIANCE BEHAVIOR } & \begin{array}{l}\text { THEORETICAL APPROACH } \\ \text { FOR PROVIDER }\end{array} & \text { IMPLICATIONS } \\ \begin{array}{l}\text { SHORT-TERM COMPLIANCE } \\ \text { Curative - preventive }\end{array} & \text { BEHAVIORAL APPROACH } & \text { RECOMMENDATIONS } \\ \begin{array}{l}\text { LONG-TERM COMPLIANCE } \\ \text { Curative - preventive }\end{array} & \text { SELF-REGULATION MODEL } & \text { RECOMMENDATIONS }\end{array}$

\section{Exercise compliance in physical therapy}

In the Netherlands over $10 \%$ of the population is treated yearly by physical therapists ${ }^{22-}$ ${ }^{23}$. Most disorders concern impairments and handicaps of the locomotor system; neck-, shoulder-and back-pain account for $50 \%$. Around $30 \%$ of the disorders appears to be chronic and there is a high recurrence rate ${ }^{22-24}$. An essential part of physical therapy is instructing patients in how to do exercises at home and advising them of the right behavior in order to recover ${ }^{20}$. This is particularly true because definitive cure is frequently impossible, and secondary prevention often involves behavioral change ${ }^{23}$ 25.27

The exact amount of patient compliance with these regimens is not known. It is remarkable that measures of patient compliance are frequently absent in research reports on exercise-programs, although program effects may depend largely on the amount of patient compliance ${ }^{28-32}$. In addition, differences in the definition of compliance and in the observed follow-up period render the interpretation of result difficult. Nevertheless, some conclusions can be drawn. Compliance with exercise regimens ranges from $30-57 \%{ }^{33-40}$ and rates of compliance drop as time passes ${ }^{27.41-44}$. The greatest drop is associated with the moment of discharge. Physical therapists are aware of this drop in compliance. They estimate that on average $64 \%$ of their patients 
complied with exercise prescription during the treatment period, while only $23 \%$ continued to do so after treatment had stopped ${ }^{45}$. Thus, physical therapists do not seem to overestimate their patients' compliance level, as physicians appear to do ${ }^{46}$. Based on these findings it seems worth while to enhance compliance in physical therapy.

\section{Analyzing compliance behavior in physical therapy}

The initial step in approaching compliance problems is to define clearly the type of compliance behavior involved. Several components of treatment which require compliance can be distinguished such as, entering treatment, keeping appointments and behavioral change. The last of them is the main issue in physical therapy and, thus, is the focus of this article.

Physical therapy involves changing behavior in at least three different respects: first, physical therapists instruct people to perform and master certain motor skills or techniques of movement. Examples of motor skills are muscle-strengthening exercises, exercises to change one's posture, or breathing techniques. The second step is to integrate this movement-behavior into daily life ${ }^{21,47-48}$. Some exercise programs are only effective if performed dailly and patients need to maintain the regimens after symptoms have disappeared in order to prevent recurrence of the illness ${ }^{20,48}$. Besides teaching exercises, physical therapists thirdly offer their patients other kinds of health advice with curative or preventive purposes ${ }^{45}$, for instance, changing one's mattress, wearing better shoes, or taking more time to relax. In all these instances success of treatment and prevention of further problems largely depend on patient compliance ${ }^{49-51}$.

\section{Short-term supervised and long-term non-supervised compliance}

The current definitions of short-term compliance and long-term compliance, only based on a certain period of time are confusing. A same period can have different significance in different situations. For example, long-term compliance, measured two year after the cessation of a program has other significance than a two year followup measure taken immediately after cessation of a two year lasting program, because supervision is an essential element in compliance ${ }^{33,52-54}$.

Therefore, our definitions of short-term and long-term compliance differ from the quantitative measures. We define short-term compliance as compliance with the regimen within the period of treatment, which is usually a short and limited period. It can also be called supervised compliance, because contact with the health care provider within this period is an important component. It means that the provider has more or less direct perception, influence and control over the process. If short-term compliance is required, physical therapists can optimally employ the favorable conditions the therapy setting offers ${ }^{26,55-57}$. In the Netherlands the treatment procedure usually consists of frequent (twice a week) personal contacts for 20 to 30 minutes, spread over a relatively long period of time (six weeks on average) ${ }^{58}$. This means that the treatment program can be built up gradually, step by step ${ }^{21,56,59}$.

We define long-term compliance as compliance after the treatment period. From the 
moment treatment is stopped, the influence of the health care provider is minimal or absent. Indeed, in this phase compliance behavior must literally be self-regulatory in nature in order to be maintained ${ }^{60}$. This is often necessary in treatments with a preventive orientation, which brings us to the second subdivision of compliance behavior: the curative or preventive orientation of treatment ${ }^{61}$.

\section{Curative and preventive orientation of physical therapy}

As long as the distinction between curative and preventive treatment is simply seen as a question of two clear definitions, there is a considerable amount of overlap. For example, advice to sit with a straight back facing a computer monitor at the right height is both a curative and a preventive piece of advice. Nevertheless, significant differences exist.

Curative measures aim at success in the shortest time possible. When the goal is reached, namely the absence of certain symptoms or signs, curative treatment can be stopped. The product of curative physical therapy is clear, namely recovery, and it can be evaluated likewise, both by the patient and by the provider. If treatment is continued, its aims can be oriented or reoriented towards prevention ${ }^{20}$. Prevention, in its most ideal form, is directed at infinity, meaning the product itself is in fact never reached and its goal is in essence a process instead of a product. The clear evaluation of success or failure of curative treatment contrasts with the more subtle evaluation of preventive measures. Neilther the provider, nor the patient can in any stage be confident about whether the chosen course of prevention is the ultimate and most successful one. Preventive measures may even be a success when the symptoms recur at a slower rate. This can be confusing to patients and could influence compliance behavior"

These differences both in the orientation in time and in the possibility of evaluating success or failure have implications for the way compliance can be reached with curative measures, on the one hand, and preventive measures on the other.

On the basis of these distinctions in compliance behavior we will analyze why the behavioral approach seems to be particularly useful in short-term compliance, with different accents in curative and preventive measures. After that, the same procedure will be followed for long-term compliance. For the sake of clarity the differences between the approaches are stressed.

\section{The behavioral approach in short-term compliance}

\section{Introduction}

The contemporary behavioral approach fits within social learning theory, but its main principles are derived from operant learning theory ${ }^{62-63}$. Conventional learning theory is based on the assumption that behavior is determined by its antecedents and its consequences. This means that behavior is influenced by stimuli that elicit behavior, and by feedback or positive consequences that reinforce behavior. Stimuli are objects or situations that elicit a respons. For example, seeing my sportshoes reminds me of 
jogging; the onset of a headache reminds me of doing relaxation exercises. Stimuli act as a kind of reminder that draws the individual's attention to his or her behavior. Any kind of environmental or social condition can serve such a cueing function. So, if behavior change is desired, one has to seek conditions that support the desired behavior and change or avoid conditions evoking undesired behavior.

According to the theory, stimuli are necessary but not sufficient conditions for behavior change: the reinforcements or rewards that follow the behavior make that behavior will be repeated and sustained. For example, the fine feeling after jogging motivates me to jog again; the disappearance of my headache make me sustain the relaxation exercises. If reinforcements are withdrawn, the behavior gradually disappears, or, in terms of the theory, is extinguished:

This latter principle is the reason why a behavioral theory is often successful in attaining short-term compliance - as is convincingly demonstrated by research findings ${ }^{64}$ - but usually fails to achieve long-term compliance ${ }^{65}$. As long as the intervention continues and the provider can stimulate or reinforce desired behavior, compliance is likely to occur. When the provider stops the regular treatment, and its associated reinforcing feedback, behavior is likely to drop to the pre-treatment level. This is exactly what the theory predicts.

This behavioral approach can be criticized in two ways. Many authors point at the limitations of behavioral theory because of its failure to attain long-term compliance ${ }^{66}$. However, they tend to overlook that the majority of medical treatments require only short-term compliance. In all such cases a behavioral approach appears to be adequate.

The second kind of criticism concerns resistance against a rather mechanistic view of behavior in the original learning theory, denying cognitive processes in learning ${ }^{67}$. This was certainly true for the original applications of the theory, mainly based on animal experiments, but does not apply to the contemporary adaptations derived from social learning theory. Nowadays it is acknowledged that it is the individual's interpretation and perception of behavior-sequences that is crucial. Only individuals themselves can detect which objects or situations in their daily living can be meaningful reminders. The same holds true for reinforcements: identical rewards may motivate one person but be meaningless for someone else. So, a behavioral approach can not succeed without active patient participation, nor without a treatment that is tailored for the patient's situation and preferences.

\section{Behavioral approach in physical therapy practice}

Applying the behavioral approach in physical therapy does not mean applying a form of psychotherapy. We will concentrate on simple, yet powerful principles of behavior change ${ }^{6,64}$ requiring a minimum of extra skills or time ${ }^{13,68 \cdot 69}$. If physical therapists wish patients to act according to instructions and advice given, three topics deserve attention: behavior, stimuli and reinforcements. 
Firstly, physical therapists instruct the patient in what to do and how to exercise. Usually they supply their instructions with modeling and guided performance to make patients acquire the necessary skills to exercise. If a complex behavior is involved, as is often the case, the behavioral principle of shaping can be used, which means that skills are acquired step by step and divided into less complex units ${ }^{70-71}$.

Secondly, if the patient knows and accepts what to do and thus has the basic intention to comply, the next step implies the search for the most appropriate circumstances or cues in the patient's daily routine that can function as reminders. This enables the behavior to become part of daily routines ${ }^{67,71-72}$. For example, patients can put a sticker on the telephone that reminds them of doing pelvic-floor exercises each time the telephone rings. Or, one can make it a custom to do the neck-shoulder exercises at the bathroom, as one therapist advised his patients; entering the bathroom became a cue for the patient to exercise. Patients should understand and accept the function of reminders. Therapists must explain that they are aids in performing the desired behavior $^{60}$. The discovery of adequate reminders depends on active participation by the patients because they know their daily routines and personal lifestyle best. Physical therapists can assist the patient in discovering and using cues as aide-mémoires.

Thirdlly, there is a need to reinforce desired behavior, for which there are several options $\mathrm{s}^{20,73}$. The physical therapist can give attention or positive feedback on progress, show appreciation of the patient's efforts and explain that treatment success depends on it. Therapists can also praise the actual smooth performance of the exercises ${ }^{20,74}$. Fortunately, some exercises can be intrinsically rewarding: stretching exercises may instantly relief backpain; intense exercising may give a satisfied relaxed feeling afterwards. Finally, support from relatives can be rewarding as well. Attending patients to rewarding effects can enhance short-term compliance ${ }^{34,74-75}$.

In order to reward adequately the provider has to know if the patient has actually performed the desired behavior ${ }^{21,39,44}$. Physical therapists have two ways of assessing patients' compliance. First, they can simply ask the patients whether or not they have complied. Becker states that non-threatening questioning makes reliable answers most likely ${ }^{11}$. In addition, physical therapists can request performance of the exercises and judge the progress and performance ${ }^{75}$.

If the patient is considered non-compliant, one can, according to the theory, intervene in all three steps: behavior, stimuli and reinforcements.

If performance of the behavior itself causes difficulties to the patient, substituting a more tailored behavior may remove the barriers ${ }^{71,76}$. It may be sufficient to proceed at a slower pace or to take a small step back in the treatment process if symptoms or pain limit compliance.

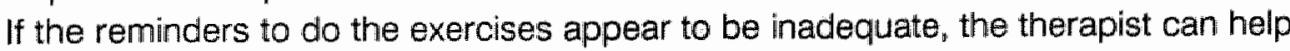
the patient to seek other reminders. If the rewards are not sufficiently appealing, one can explain that positive results are not always immediately visible, or one can search for more motivating alternatives. 
In this search the information gathered from the patient's perspective is essential ${ }^{77}$. Therefore, there is a need for a good relationship and an open dialogue with the patient ${ }^{38,78-80}$.

\section{Differences between curative and preventive measures}

The behavioral approach slightly differs in curative and preventive measures. In curative treatment symptoms and pain may facilitate the behavioral approach because they can act as reminders while relief of symptoms and pain can be rewards, as was noted.

When symptoms are absent, as in the case of preventive measures, other rewarding sources can be found. An example of short-term compliance in a pre-operative breathing exercise program which is aimed at preventing post-operative respiratory distress may illustrate this. Although symptoms are absent, progress in mastering the technique can be visualised on a chart or the patients can learn to experience and evaluate their own progress ${ }^{74}$. The progress can give them a sense of active control over their health, which could be rewarding when facing major chest surgery.

\section{Self-regulation theory in long-term compliance}

These direct options, relying mainly on the supervising role of the provider and on the presence of rewarding effects, are often lacking when long-term compliance is necessary. The provider is absent along with the positive feedback and when recovery has set in, the intrinsic rewards of pain relief dissappear and symptoms no longer trigger the exercises. An additional problem emerges because relapse into the previous behavior pattern often does not provoke any symptoms. The possibility of prolongating the effect through regular recall visits or continued supervision or support ${ }^{41}$ could be helpful, but dependence on health care is the consequence. In some cases totally different solutions can be found, such as ergonomic adaptations, not requiring longterm compliance ${ }^{81-82 \text { a }}$. However, self-regulation of the behavior is often the optimum goal, indicating that a different theoretical approach is required.

\section{The main principles of the self-regulation theory}

Because long-term compliance is hard to attain without prolonged supervision ${ }^{14}$, Leventhal proposed a new approach ${ }^{66}$. He constructed the theory of self-regulation or self-control, in which he integrates effective concepts from other theories that have proved their efficacy ${ }^{66,83}$. Such concepts are derived from the health bellief mode ${ }^{84}$, self-efficacy ${ }^{85}$, self-management ${ }^{57}$, and also the behavioral approach.

Self-regulation theory reflects a common sense way of dealing with health and illness: patients are considered active agents, choosing their own goals, which are mainly determined by their perceptions of the illness. They select responses or behavior to reach those goals and evaluate their progress in goal-attainment. An everyday example may illustrate this basic mechanism: John has a low back pain. In his perception it is caused by a cold draught and the wet autumn weather, although at the back of his mind he knows that stress caused by his work could also influence it. His aim is to be 
free of back pain, so he wears an extra sweater, takes hot showers and avoids a draught. If the back pain disappears, he decides that his perception and way of dealing with the problem have been correct. If there is not any improvement, he may change his perception to the stress-perspective, he may change his coping strategy, or he may change both. To utilize and enhance this mechanism - according to Leventhal - three aspects deserve attention: 1) perception or representation of the illness, 2) coping with the illness, and 3) appraisal of the outcomes.

Representation of the illness. Experiencing symptoms or illnesses, people seek labels or diagnoses to explain and understand them. This perception of the illness is based on current symptoms, on earlier experiences with illness and on personal views of health and illness originating from social and cultural influences. Altogether these elements form the patient's representation of the illness, which can be highly individual. Research on the health belief model stresses the importance of these individual perceptions ${ }^{37}$. Knowing these representations is very important to the provider because the way patients cope, depends on them.

Coping with the illness. In coping with an illness, patients will take those actions they personally consider to be adequate. Patients have their own expectations, preferences and goals, mainly based on earlier experiences. If the treatment plan and prescriptions do not fit into this existing scheme, long-term compliance is unlikely ${ }^{86}$. Coping also depends on the patients' repertoire of behavior skills and sense of effectiveness. The latter is essential in the phase of appraisal.

Appraisal. Self regulation theory implies that patients learn to evaluate the sequence of representation, coping and outcome. Essential in the theory is the fact that evaluation occurs in such a way that it enhances the patients" feelings of self-esteem or sense of effectance ${ }^{85}$ : disappointing outcomes should not be seen as failures but as signs to distinguish ineffective from effective coping tactics. For example, when Johns backpain remains after hot showers and warm clothes, he assumes that not the draught but distress was the cause and, according to it, he changes his coping. In doing so, he perceives himself as being able to distinguish suitable from unsuitable representations and adequate from inadequate coping. According to the self-regulation theory, patients should get a view of themselves as observers or experimenters whose goal is to test and accept or reject specific acting.

The main principles described above merely concern the cognitive level of dealing with illness. The theory states that a parallel and equally important process can be seen at an emotional level ${ }^{85}$. The embarrassment or worries caused by the onset of symptoms may distort patients' perception of the identity and cause of the illness. Symptoms may even be ignored because they are too threatening to face. In the second fase of coping with illness, feelings of frustration or even guilt may arise: health behavior may require changes in lifestyle and conflicting goals can exist between health behavior and other priorities in life like social engagements or ambitious jobs. In the 
third fase of appraisal the outcomes may be disappointing and may cause anxiety and anger ${ }^{87}$. Furthermore, if coping fails, the patient may encounter feelings of hopelessness or ineffectiveness and such feelings in inhibit further trials ${ }^{85}$. These processes are closely interrelated to the cognitive one and long-term compliance is determined by both, indicating intervention ar both levels must be taken into consideration.

Before turning to the practical implications of this approach for health care providers, one remark has to be made. Strictly speaking, the term compliance is not correct in the view of self-regulation theory. Instead of following the exact prescriptions of the providers, patients seek, discover and select coping behaviors that suit them ${ }^{88}$. The role of the provider is to support and stimulate the patients, teaching them the necessary skills, and transmitting knowledge as an expert enabling patients to choose their own appropriate solutions ${ }^{89-91}$.

\section{Self-regulation principles in physical therapy practice}

Although self-regulation theory is not clearly made operational for use in health care delivery, its significance is recognised for the field of exercise adherence. We will try to make these elaborations for long-term compliance in physical therapy.

Representation. To adjust treatment to the patient's frame of reference the therapist must explore the patient's representation of the illness. If patients $s^{z}$ perceptions and ideas conflict with medical knowledge, it is necessary to correct them. For example, the patient who said "My back is crooked, I often feel it cracking" must be explained that, as a rule cracking sounds are harmless and not alarming. Patients who focus on minor deviations on the X-ray and think their back is "burned up", should be told that minor deviations are very common and often without any clinical significance, to restore patients' confidence in their own back and health. Changing patients' ideas is not always easy and may require extensive explanations and clarifications. The physical therapist should pay attention to patient's doubts and feelings of anxiety by listening to the patient ${ }^{78}$, and by giving realistic information or reassurance.

Coping. Points of attention in coping are the patients' behavioral repertoire and sense of effectance. More specifically, the physical therapist can ask the patient what he or she already has done to obtain relief. The answer reveals the kind of behavior the patient considers adequate and enables the physical therapist to adjust instructions and advice to already existing coping patterns or ideas, which are more likely to be sustained because they are independent of provider behavior ${ }^{19,34,72}$. For example, if a patient is used to take hot showers for pain relief, the therapist can suggest he or she takes the showers just before doing the exercises, because this may facilitate performance.

An other recommendation is teaching the patient to generalise desired behavior. This implies an activity at different levels. First and more traditional in patient education, the patient is supplied with information about the illness and how to cope with it. Apart from this the patient obtains information and guidelines at a meta-level, about the operating 
mechanisms behind the information itself. Using this knowledge the patient can then be stimulated to discover substituting behaviors containing the same mechanism, which perhaps fit better into present or future ways of living. For example, in training the patients the right way of lifting, they should understand why an object should be lifted as close to the body as possible. Then, patients will be stimulated to apply this principle and come up with simple solutions, tailored to their own situation.

Generalising is particularly relevant to the type of problems physical therapy patients face. Daily fluctuations in symptom levels, like in rheumatoid arthritis, may even require that patients adjust their behavior accordingly ${ }^{92-93}$. Besides, it is virtually impossible to instruct patients in how to face every situation that may occur, because the variation in situations is enormous and often unforeseeable by the physical therapist.

Both using existing coping patterns, and enabling the patient to discover and generalize adequate behavior may enhance patients' feelings of competence and self-effectance, which is also the aim in the appraisal phase.

Appraisal. The physical therapist's contribution is teaching the patient how to interpret outcomes of compliance and explaining their relation to the coping behavior. It is important to help the patient in understanding that negative outcomes can be useful, rather than regarding them as signs of failure. Negative outcomes indicate that the specific coping behavior is inadequate or unsuitable for the patient's life-style and alternatives must be found. For example, when patients cannot afford to swim three times a week, ane should encourage the patients to discover an other way of exercising that suits them better instead of blaming them for non-compliance. In doing so feelings of inadequacy or failure can be avoided.

\section{Differences in curative and preventive measures}

The distinguishing factors between curative and preventive treatment noted before orientation in time and clear ability to evaluate success and failure - have consequences for the self-regulatory approach. Leventhal points to the tendency of patients (and perhaps also physical therapists) to think, and subsequently act, in terms of a "disease model". This tendency may be responsible for failure to achieve long-term compliance with preventive measures ${ }^{83}$. In acute disease thinking, the presence of symptoms, the short term nature of the illness and the possibility of curing the underlying disease process play an important part. These three aspects of the representation of the illness are all strongly related to curative treatment, but inversely related to preventive treatment. For preventive treatment to be successful, Leventhal argues, attention must be paid to changing such acute disease thinking into thinking in terms of maintaining health or avoiding risks ${ }^{66}$. So other targets must be found, for example, becoming a sportsman, feeling fit and healthy, looking supple and exercised, being autonomous and able to cope with life. The personal value of such targets may motivate the patient to comply.

At the same time this refers to a fundamental change from a medical model - with absence of disease as criterion for health - to a health model, where the capacity of the person to maintain his own health at an acceptable level is the ultimate goal ${ }^{70}$. 
The latter way of thinking can promote a patient's involvement in taking preventive measures to stay healthy.

\section{Conclusion}

The essence of our argument has been that different theoretical approaches are needed because compliance behaviors differ in nature. Analyzing short-term and longterm compliance one can see that there is a significant difference between the two as far as the degree of supervision is concerned. In the case of short-term compliance the patient is seen frequently by the physical therapist over a short period of time. After that period supervision lacks; patients must rely on their own recources to maintain the regimen. So, in physical therapy one can distinguish short-term supervised compliance and long-term non-supervised compliance.

A second distinction concerns the curative or preventive orientation of treatment. In curative treatment, compliance behavior is directed at recovery from illness and can be evaluated likewise, whereas in preventive treatment the goals are less tangible, thus making evaluation of the regimens success more difficult.

Because of these distinctions we argued that in short-term supervised compliance a behavioral approach offers the best perspective, whereas the self-regulation model is of greater use in achieving long-term non-supervised compliance.

Choice of the behavioral approach rests on its known effectiveness in enhancing short-term compliance and its easy applicability in the physical therapy setting. The self-regulation model is considered suitable for long-term compliance due to its emphasis on patients regulating their own behaviors without supervision.

The behavioral and the self-regulation models have similarities and differences. An important difference concerns the therapist-patient relationship. The behavioral approach implies a'guidance-cooperation' relationship between therapistand provider. The self-regulation model is characterized by a 'mutual-participation' relationship ${ }^{70,91}$. The latter approach implicates a necessary change in professional attitude: from a guiding expert to a supporting one, who respects the patient's choices and allocates successes to the patient.

Besides these differences there are many similarities, because both models fit in the social learning theory framework. Social learning theory assumes that only individuals' perceptions and interpretations of events make them significant. In the behavioral approach this implies that patients must discover both cues and reinforcements meaningful to them and ways to integrate behavior in their daily routines. It is obvious in the self-regulation approach that the patient's perspective is of equal importance.

In deriving practical recommendations for physical therapists we based them on two considerations. First, the simplest and most powerful recommendations should be derived from the theories and, second, they should be performable with minimal extra 
effort.

As a starting point the physical therapist should determine whether short-term or longterm compliance is the goal and subsequently derive from it a careful plan about the goal and strategy concerning the patient's compliance. Unplanned interventions are most likely to fail.

If short-term compliance is the purpose of treatment, all regular contacts can be utilized to apply a behavioral approach. The most powerful element appears to be reinforcement. A second element consists of discovering appropriate cues or situations for each individual patient taking into account the desired behavior.

Applying these basic principles requires little extra skill or time. The effort will lie in making them a habit, which can be promoted by integrating their acquisition into physical therapists' vocational training.

Stimulating long-term compliance by applying the principles of the self-regulation model does require extra skills and effort from the physical therapist. To develop an intervention based on the selfregulation model, all the patient's ideas and perceptions about the illness should be explored first, in order to adjust the prescribed regimen to existing coping patterns. Secondly, it is important to teach patients to generalise underlying principles to enable them to choose and cope adequately in the future. The final point is teaching the patient how to appraise performances and outcomes in such a way that feelings of competence and self-efficacy are intensified.

Some final remarks should be made. The principle of this article is that compliance behaviors differ in nature and that, as a consequence, different theoretical approaches have to be indicated. We have made a general distinction in only two respects: shortterm versus long-term compliance, and curative versus preventive measures. It seems worthwhile to continue this line of thought by making further specifications of compliance behaviors. For example, it could be significant to make further distinctions between high and low frequencies of desired behavior, or between regimens asking patients to unlearn bad habits versus learning new habits. In physical therapy it seems promising to continue analysis of compliance behaviors for different diseases or for different subgroups of patients. Such a further analysis of compliance behaviors may provide detailed guidelines for the practice.

The essence of this approach is that it should not be restricted to physical therapy, but that it can also be useful in other health care settings. Hopefully professionals in these fields will be inspired to undertake the same exercise for the types of compliance they encounter.

\section{NOTES}

a. Recognising the difficulty of reaching long-ferm, compliance, it must be stated that there are other options avallable, especially in physical therapy ${ }^{25}$, by avoiding the compllance problem altogether. Simpler and even permanent solutions may not require behavioral change, such as is suggested for example by Haynes ${ }^{81}$. He proposes to invest in the search for medication which is convenient to take and, once taken, has long lasting effects. 
In physical therapy such simple solutions are often avalable. Reducing the physical laad on the patient, for example through ergonomic adaptations at home, instead of training his muscle power, could have a permanent preventive effect. ${ }^{82}$. This requires minimal effort from the side of the patient and it certainly avoids the question of reaching compliance with an exercise program for the rest of his life. Besides, it promotes patients' independence of health care.

The value of acting along this preventive route seems to be underestimated by physical therapists ${ }^{25}$.

Fig. 7.2 Implications for practice

Make a treatment plan according to the type of compliance required:

- short-term compliance (untill treatment is over), or,

- long-term compliance (beyond treatment).

\section{SHORT TERM COMPLIANCE}

1 Cues: together with the patients tallor exercises to patients' daily routines and find cues that can remind to exercising.

2 Rewards: attend patients to rewarding effects like pain rellef or progress and reward patients' efforts by giving them positive feedback.

3 Evaluation monitor patients' compliance continuesly in an open atmosphere to solve problems or to adjust cues and rewards if necessary.

\section{LONG TERM COMPLIANCE}

1 Patients' perception: check patients' ideas about health and illness and, If necessary, correct thern.

\section{Coping:}

- analyze patients' existing coping patterns and if possible, utilize them.

- explain the principles underlying the desired behavior and teach patients to generalise these principles.

- motivate patients to discover adequate behaviors, tailored to their specific preference and lifestyle.

3 Appraisal: teach patients how to appraise outcomes: try to enhance patients" feelings of competence and self-efficacy by appraising outcomes in a positive way.

4 Emotions: pay careful attention to feelings and emotions that coping with illness brings along.

5 Spread the treatment sessions over a relatively long period to allow patients to regulate and appraise their coping behavior by themselves. 


\section{Literature}

1 Campen C van, Sluijs EM.

Patient compliance: a survey of reviews (1979-1989).

Utrecht: Nivel, 1989. NIVEL-Bibliographies, 38.

2 Dishman RK, Dunn AL.

Exercise adherence in children and youth: Implications for adulthood: In: Disimman RK (ed.).

Exercise adherence: its impact on public health.

Champaign: Human Kinetics Books, 1988: 155-200.

3 Haynes RB, Taylor DW, Sackett DL (eds.).

Compliance in health care.

Baltimore, etc.: The Johns Hopkins University Press, 1979.

4 Cohen SJ.

New metaphors for old problems. In: Cohen SJ (ed.). New directions in patient compliance.

Toronto etc.. s.n.: 1979: 153-163.

5 Cameron $\mathrm{R}_{\text {, Best JA. }}$

Promoting adherence to health behavior change Interventions: recent findings from behavloral research.

Patient Education and Counseling 10; 1987, 2: 139-154.

6 Knapp DN.

Behavioral management techniques and exercise promotion. In: Dishman AK (ed.). Exercise adherence: its impact on public health.

Champaign: Human Kinetics Books, 1988: 203-235.

7 Dolan-Mullen PD, Green LW, Persinger GS.

Clinical trials of patient education for chronic conditions: a comparalive meta-analysis of intervention types.

Preventive Medicine 14; 1985: 753-781.

8 Leventhal $H$.

The role of theory in the study of adherence to treatment and doctor-patient interactions.

Medical Care 23:" 1985, 5: 556-563.

9 Bartlett EE.

Two year update.

Patient Education and Counseling 9; 1987, 1: 1-3.

10 Kok GJ.

Research in order to support health education in practice. In: First European Conference on effectiveness of health education.

Utrecht: Dutch Health Education Centre, 1989: 9-14.

11 Becker $\mathrm{MH}$.

Patient adlinerence to prescribed therapies.

Medical Care 23; 1985, 5: 539-555. 
12 Oldridge NB.

Compliance with exercise in cardiac rehabilitation. In: Dishman RK (ed.). Exercise adherence: its impact on public health.

Champaign: Human Kinetics Books ${ }_{i}$ 1988: 283-304.

13 Green CA.

What can patient health education coordinators learn from ten years of compliance research?

Patient Educiation and Counseling 10; 1987, 2: 167-174.

14 Haynes RB, Wang $E_{i}$ Da Mota Gomes $M$.

A critical review of interventions to improve compliance with prescribed medications.

Patient Education and Counseling 10; 1987, 3: 155-166.

15 Mazucca SA.

Does patlent education in chronic disease have therapeutic value? Journal of Chronic Diseases $35 ; 1982: 521-529$.

16. Turk DC, Salovey P, Litt MD.

Adherence: a cognitive-behavioral perspective. In: Gerber KE, Nehemkis AM (eds.). Compliance: the dilemma of the chronically ill.

New York: Springer Publishing Company. 1986: 44-72.

17 Helby EM, Carlson JG.

The health compllance model.

The Journal of Compliance in Health Care 1; 1986, 2: 135-152.

18 Dubbert PM, Martin JE, Epstein LH.

Exercise. In: Holroyd KA, Creer TL (eds.). Self-management of chronic disease: handbook of clinical interventions and research.

Orlando, etc.: Academic Press, 1986: 127-161.

19 Ice R.

Long-term compliance.

Physical Therapy $65 ; 1985,12: 1832-1839$.

20 Lafrenière $\mathrm{JG}$.

The low back patient: procedures for treatment by physical therapy.

New York: Masson Publishing, 1979.

21 Mayo NE.

Patient compliance: practical implications for physical therapists: a review of the literature.

Physical Therapy 58; 1978, 9: 1083-1090.

22 Kerssens JJ, Groenewegen PP.

Referrals to physiotherapy: the relation between the number of referrals, the indication for referral and the inclination to refer.

Social Science and Medicine 30; 1990, 7: 797-804.

23 Ministerie van Welzilin, Volksgezondheid en Cultuur.

Notitie ontwikkeling van de fysiotherapeutische hulpverlening. (Developments in physical therapeutic care)

s-Gravenhage: SDU Uitgeveri]. 1989. Kamerstuk 20 800, no. 164.

24 Groenewegen PP.

Fysiotherapeut. (The physical therapist) in: Overzichtsstudie onderzoek eerstelijn. Sluijs EM,

Dopheide JP, Zee J wan der (eds.).

Utrecht: Nivel, 1985: 145-175.

25 Hayne $\mathrm{CR}$.

The preventlve role of physiotherapy in the National Health Service and industry.

Physiotherapy $74 ; 1988,4: 2-3$. 
26 Knibbe J J.

Fysiotherapie en secundaire preventie van lage rugklachten: literatuurstudie naar mogelijkheden en beperkingen. (Physical therapy and secondary prevention of low back pain.)

Nederlands Tijdschrift voor Fyslotherapie 97; 1987, 7/8: 175-183.

27 Bertels $\mathrm{M}_{s}$ Brummelen L ten, Dijkum CJ van, et al.

Tijd voor kwaliteit: evaluatie-onderzoek fysiotherapie in gezondheldscentra in Ainsterdam. (Time fior quality: evaluative research physical therapy in health centres.)

Amsterdam: Stichting Universitair Instituut voor Soclaal Wetenschappelijk Onderzoek/Onderzoeksplatform in de Eerstelijns Dienstwerlening in Amsterdam, 1985.

28 Belcon MC, Haynes RB, Tugwell $P$.

A critical review of compliance studies in rheumatoid anthritls.

Arthritis and Rheumatism 27; 1984, 11: 1227-1233.

29 Evans $C_{\text {, }}$ Gilbert JR, Taylor W, Hildebrand A.

A randomized controlled trial of flexion exercises, education, and bed rest for patients with acute low back pain.

Physiotherapy Canada 39; 1987, 2: 96-101.

30 Lindequist $S$, Lundberg $B$, Wikmark $R$, Bergstad $B$, Lööf $G$, Ottermark $A C$.

Information and regime at low back pain.

Scandinavian Journal of Rehabilitation Medicine 16; 1984: 113-116.

31 Mellin $G$, Järvikoski $A$, Verkasalo $M$.

Treatment of patients with chronic low back pain: comparison between rehabilitation centre and outpatient care.

Scandinavian Journal of Rehabilitation Medicine 16; 1984: 77-84,

32 Snooks $\mathrm{SH}$.

Comparison of different approaches for the prevention of low back pain: ergonomic interventians to prevent musculosceletal injurles in industry.

Michigan: Lewis Publishers, 1987: 57-72. Industrial Hygiene Science Series, II.

33 Dishman RK.

Compliance/Adherence in health-related exercise.

Health Psychology 1; 1982, 3: 237-267.

34 Sikorski JM.

A rationalized approach to physiotherapy for low back pain.

Spine 10; 1985, 6: 571-579.

35 Deyo RA, Tsui-Wu YJ.

Descriptive epiderniology of low-back pain and its related medical care In the United States.

Spine 12; 1987, 3: 264-268.

36 Feinberg $\mathrm{J}$.

The effect of patient-practitioner interaction on compliance: a review of the literature and application in rheumatoid arthritis.

Patient Education and Counseling 11; 1988, 3: 171-187.

37 Ferguson $\mathrm{K}$, Bole GG.

Family support, health beliefs, and therapeutic compliance in patients with rheumatoid arthritis.

Patient Counselling and Health Education 1; 1979, 3: 101-105.

38 Lankhorst GJ, Stadt RJ van de. Vogelaar TW Korst JK van der, Prevo AJH.

The effect of the Swedisch back school in chronic idiopathic low back pain.

Scandinavian Journal of Rehabilitation Medicine 15; 1983: 141.145.

39 Spelman MR.

Back pain: how health education affects patient compliance with treatment.

Occupational Health Nursing 32 ; 1984: 649-651. 
40: Berwick DM, Budman S. Feldstein M.

No clinical effect of back schools in an HMO: a randomized prospectrve trial.

Spine 14; 1989, 3: 338-344.

41 Oldridge NB, Jones NL.

Preventive use of exercise rehabilitation after myocardial infarction. In: Astrand PO, Grimby G (eds.). Physical activity in health and disease.

Stockholm: Almquist \& Wiksell International ${ }_{n}$ 1986: 123-129. Acta Medica Scandinavica Symposium Serles; 2.

42. Treusch JW, Krusen FH

Physical therapy applied at home for arthritis.

Archives of Internal Medicine 72; 1943; 231-238.

43 Beekman CE, Axtell L.

Ambulation, activity level and pain, outcomes of a program for spinal pain.

Physical Therapy 65; 1985, 11: 1649-1657.

44 Deyo RA.

Compliance with therapeutic regimens in arthritis: issues, current status, and a future agenda.

Seminars in Arthritts and Rheumatism 12; 1982, 2: 233-244.

45 Sluijs EM.

A checklist to assess patient education in physical therapy practice: development and reliability.

Physical Therapy 71; $1991,8: 561 / 17-569 / 25$.

46 Gillum RF, Barsky AJ.

Diagnosis and management of patlent noncompliance.

Journal of American Medical Association 228: 1974, 12: 1563-1567.

47 Czerniawski L.

Exercise therapy: the role of physical therapy. In: Stanton-Hicks M, Boas RA (eds.). Chronic low back pain.

New York: Raven Press, 1982.

48 Huhn RR, Volski RV.

Primary prevention programs for business industry: role of physical therapists.

Physical Therapy 65; 1985, 12: 1840-1844.

49 Leathley $M$.

Physiotherapists and health education: report of a survey.

Physiotherapy $74 ; 1988,5: 218-220$.

50 May BJ.

Teaching: a skill in clinical practice.

Physical Therapy 63; 1983, 10: 1627-1633.

51 Norton S.

Support for physiotherapists in health education.

Physiotherapy $72 ; 1986,1: 5-7$.

52 Dishman RK.

Epilogue and future directions. In: Dishman RK (ed.). Exercise adherence: its impact on public health.

Champaign: Human Kinetics Books, $1988:$ 4117-426.

53 Haynes RB.

Determinants of compliance: the disease and the mechanics of treatment. In: Haynes RB, Taylor DW, Sackett DL (eds.). Compllance in health care.

Baltimore, etc.: The Johns Hopkins University Press, 1979: 49-62. 
54 Southam MA, Dunbar J.

Facilitating patient compliance with medical interventions, in: Holroyd KA $\mathrm{Creer}_{\mathrm{i}} \mathrm{ThL}$ (eds.). Selfmanagement of chronic disease: handbook of clinical interventions and research.

Orlando, etc.: Academic Press, 1986: 163-187.

55. Hough A.

Communication in health care.

Physiotherapy $73 ; 1987,2: 56-59$.

56 Lyne PA.

The professions allied to medicine: their potentlial contribution to health education.

Physiotherapy 72; 1986, 1: 8-10.

57 Saunders $C$, Maxwell M.

The case for counselling in physiotherapy.

Physiotherapy $74 ; 1988,11: 592-596$.

58 Curfs EC, Groenewegen PP.

Physiotherapy in the Netherlands: an overview.

Physiotherapy Practice 2; 1986: 132-137.

59 Knibbe JJ.

Integration of secondary prevention of low back pain in physical therapy treatment: a literature review. In: Profession in action: 100 years of physiotherapy in Holland; Congress june $13-16,1989$, the Hague.

The Hague: Dutch Society for Physiotherapy, 1989.

60 Kok GJ!.

Health motivation: health education from a soclal psychological point of vlew. In: Maes S, Splelm berger CD, Defares PB, Sarason IG (edls.). Topics in thealth psychology.

New York, etc.: John Wiley \& Sons, 1988: 295-300.

51 Posavac EJ.

Evaluatlons of patient education programs: a meta-analysis.

Evaluation and the Health Professions $3 ; 1980,1: 47-62$.

62 Karoly P.

Operant Methods. In: Kanfer FH, Goldstein AP (eds.). Helping people change: a textbook of methods; 2nd. ed.

New York, etc.: Pergamon Press, 1980: 210-247.

63 Levy RL.

Socilal support and compliance: a selective review and critique of treatment integrity and outcome measurement.

Social Science and Medicine 17; 1983, 18: 1329-1338.

64 Dunbar JM, Marshall GD, Hovell MF.

Behavioral strategies for improving compliance. In: Haynes RB, Taylor DW, Sackett DL (eds.).

Compliance in health care.

Baltimore, etc. The Johns Hopkins University Press, 1979: 174-190.

65 Linden HA van der.

Fysiotherapie en patiërtenvoorlichting. (Physical therapy and pattent education.)

Nederlands Tijdschrift voor Fysiotherapie 97; 1987, 5: 106-112.

66 Leventhal $\mathrm{H}$, Cameron $\mathrm{L}$.

Behavioral theories and the problem of compliance.

Patient Education and Counseling 10; 1987, 2: 117-138.

67 Tobin DL, Reynolds RVC, Holroyd KA, Creer ThL.

Self-management and social learning theory. In: Holroyd KA, Creer ThL (eds.). Self-management of chronic disease: handbook of clinical interventions and research.

Orlando, etc.: Academic Press, 1986: 29-55. 
68 Martin JE Dubbert PM.

Exercise applications and promotion in behavioral medicine: current status and future directions. Journal of Consulting and Clinical Psychology 50; 1982, 6: 1004-1017.

69 Sackett DL.

A compliance practicum for the busy practitioner. In: Haynes RB, Taylor DW, Sackett DL (eds).

Compliance in health care.

Baltimore, etc: The Johns Hopkins University Press, 1979: 286-294.

70 Bartlett EE.

The medical and educational models of health care under prospective pricing.

Pattent Education and Counseling $6 ; 1984,2 ; 57-61$.

71 Green LW.

Educational strategles to improve compliance with therapeutic and preventive regimens: the recent evidence. In: Haynes $\mathrm{RB}_{\mathrm{s}}$ Taylor DW, Sackett DL (eds.). Compliance in health care

Baltimore, etc: The Johns Hopkins University Press, 1979: 157-173.

72 Boczkowski JA, Zelchner A.

Medication compliance and the elderly.

Clinical Gerontologist $4 ; 1985,1: 3-15$.

73 Kanters HW:

Effectiviteit van patientenvoorlichting: een literatuuronderzoek. (Effectiveness of patient education: a literature review)

Utrecht: Landelijk Centrum Dienstverlening GVO, 1986.

74 Calrns D, Thomas L, Mooney V, Blair Pace J.

A comprehensive treatment approach to chronic low back pain.

Pain 2; 1976: 301-308.

75 Rand $\mathrm{PH}$.

Evaluation of patient education programs.

Physical Therapy $58 ; 1978,7: 851856$.

76 Bartlett EE.

Behavioral diagnosis: a practical approach to patient education.

Patient Counselling and Health Education $4 ; 1982,1: 29-35$.

77 Hanson RW.

Physician-patient communication and compliance. In: Gerber KE, Nehemkis AM (eds.). Compliance: the dilemma of the chronically ill.

New York: Springer Publishing Company, 1986: 182-21.

78 Croft Jl.

Interviewing in physical therapy.

Physlcal Therapy 60; 1980, 8: 1033-1036.

79 Ley Ph.

Gwing information to patients. In: Eiser JR (ed.). Social psychology and behavioral science.

New York: John Wiley \& Sons, 1982:" 339-373.

80 Wagstalt GF.

A small dose of commonsense - communication, persuasion and physiotherapy.

Physiotherapy $68 * 1982,10: 327-329$.

81 Haynes RB.

Patient compliance then and now.

Patient Education and Counseling 10; 1987, 2: 103-105.

82 Snook SH:

Approaches to the control of back pain in industry: job design, job placement and education/.

training.

Occupational Medicine: State of the Art Reviews 3; 1988: 45-61. 
83 Leventhal $\mathrm{H}$, Zimmerman $\mathrm{R}$, Gutmann $\mathrm{M}$.

Compliance: a self-regulation perspective. In: Gentry WD (ed.). Handbook of behavioral medicine.

New York, etc: The Guilford Press, 1984: 369-436.

84. Janz NK, Becker MH.

The Health Bellef Model: a decade later.

Health Education Quarterly 11; 1984, 1: 1-47.

85 Bandura A.

Self-efficacy: toward a unifying theory of behavior change.

Psychological Review 84; 1977, 2: 191-215.

86 Simonds SK.

Individual health counselling and education: emerging directions from current theory, research, and practice.

Patient Counselling and Health Education 4; 1983, 4: 175-181.

87 Gerber KE.

Compliance in the chronically ill: an introduction to the problem. In: Gerber KE, Nehemkis AM

(eds.). Compllance: the dilemma of the chronically ill.

New York: Springer Publishing Company, 1986: 12-23.

88 Trostle JA.

Medical compliance as an ideology.

Social Science and Medicine 27; 1988, 12: 1299-1308.

89 Steele D., Blackwell B, Gutmann MC, Jackson TC.

The activated patient: diogma, dream or desideratum? Beyond advocacy: a review of the active patient concept.

Patlent Education and Counseling 10; $1987,1: 3-23$.

90 Stone GC.

Patient compliance and the role of the expert.

Journal of Sociall Issues 35; 1979, 1: 35-59.

91 Szasz TS, Hollender MH.

A contribution to the philosophy of medicine: the basic model of the doctor-patlent relationship. In: Stoeckle JD (ed.). Encounters between patients and doctors.

Massachusetts: The MIT Press, 1987: 165-177.

92 Mahowald ML, Steveken ME, Young M, Ytterberg SR.

The Minnesota Arthritis-Training Program: emphasis on self-management, not compliance.

Patient Education and Counseling 11; 1988, 3: 235-241.

93 Lorig $K_{n}$ Konkol L, Gonzalez V.

Arthritis patlent education: a review of the literature.

Patient Education and Counseling 10; 1987, 3; 207-252. 



\section{Summary}

\section{Introduction}

The way in which physical therapists in primary care give patient education was the subject of this three-year investigation subsidized by the Prevention Fund.

The relevance of patient education in physical therapy is threefold. Firstly, the professional group of physical therapists endeavors to develop the preventive aspects of the treatment further and to expand preventive tasks. Patient education is an important instrument in this. Secondly, the universal problem of non-compliance with instructions plays a part in physical therapy too. The proper provision of education can partly solve this problem. Thirdly, physical therapists prove to experience problems with educating patients, among other things because educational skills are as yet hardly taught explicitly in the vocational training of physical therapists.

As it is not known how physical therapists give education, in this investigation the present situation has been mapped with the aim of tracking down possibilities of improving the quality of patient education in physical therapy.

\section{Research questions}

The investigation was performed by means of the following questions:

1 What is the nature, the extent and the quality of patient education in physical therapy?

2 Is the education given bound up with the nature of the complaints, the characteristics of the patient and the type of treatment?

3 How do physical therapists differ from one another in the education that they give, and can these differences be explained by views regarding patient education?

4 What is the extent of non-compliance in physical therapy and what factors are connected with non-compliance?

These four questions have been investigated with the aid of empirical material. The results are described in Chapters 4 to 6 . In addition a theoretical analysis has been made of the consequences that different forms of compliance have for education in 
physical therapy (Chapter 7 ). The instruments required for measuring this were developed in a preliminary investigation (Chapters 2 and 3 ).

\section{Method}

\section{Material}

The investigation has been performed by means of audio recordings of physical therapy treatment sessions. Audio recordings were opted for (instead of video) to protect the privacy of patients as much as possible. In addition patients and physical therapists completed questionnaires and registration forms (see appendices 1-4). In concrete terms the study material consists of:

1931 registration forms completed by the physical therapist 1837 audio recordings of physical therapy treatment sessions 1681 questionnaires completed by patients 222 questionnaires completed by physical therapists.

\section{Sample and respondents}

From the Nivel Register of Physical Therapists a representative sample was taken of 300 physical therapists with as criterion working at least 3 days a week.

The physical therapists were asked to make audio recordings of treatment sessions and to complete a registration form for each session. In addition they were asked to complete a once-only questionnaire on their views with regard to patient education.

The questionnaire was returned by 222 physical therapists (response $74 \%$ ). The audio recordings were made by 84 physical therapists (response $28 \%$ ). A non-response analysis showed two differences between respondents and non-respondents. First, $37 \%$ of the male physical therapists participated ( 63 of the 170 ) as against $16 \%$ of the female physical therapists (21 of the 130). The cause of this is unknown. Secondly, the respondents encountered more problems in educating patients than the nonrespondents (respectively $68 \%$ and $42 \%$ ). Perhaps this was one of the reasons to participate. There are however no reasons to assume that this has drastically influenced the results because: the differences between male and female therapists in educating patients are small and there is only a weak relationship between educating patients and the problems encountered (Chapter 5).

The patients were unselected by the physical therapist: the latter was requested to involve in the investigation the first 25 patients whom he or she saw in a certain week. The physical therapists completed a registration form on 1931 patients and asked permission to make an audio recording; 1837 patients gave permission for the recording (response 95\%). If the patient refused, no recording was made. The average number of recordings per physical therapist is 22 . The physical therapist operated the recorder personally; there was no researcher present. 
Upon completion of the session the patients were given a questionnaire by the physical therapist with the request to complete this immediately upon returning home. The patients returned the questionnaire direct to Nivel and knew that the physical therapist would not see the answers. Of the 1837 patients, 1681 returned the questionnaire (response 92\%).

It was possible to compare the data of the questionnaire with those of the audio tape by assigning a code number.

\section{Procedure}

The audio tapes were assessed by three trained observers: a physical therapist, a hygienist and a psychologist; the tapes were divided among them at random. The assessment was performed by means of a checklist with a reliability expressed in Cramer's $V$ from .71 to .90 (Chapter 2). The checklist contains three parts: the nature of the education, the amount of education and the quality of the education.

\section{Results}

\section{What is the nature, the extent and the quality of patient education in physical therapy? (Chapter 4)}

\section{Nature and extent of the education}

The results show that in $97 \%$ of the 1837 physical therapy sessions information, instructions and advice are given to the patient. This confirms that patient education is an essential part of every physical therapy treatment and is indissolubly bound up with the latter.

Most education given pertains to the diagnosis and complaints: in $80 \%$ of the sessions the physical therapists give an explanation of the diagnosis, the significance of the symptoms and the cause or prognosis of the complaints.

In $69 \%$ of the sessions patients are given advice on dealing with the complaints, for instance resting, correcting posture, lifting in a different way, wearing better shoes etc. This advice serves a curative purpose but is often directed at the same time towards secondary prevention (avoiding recurrence of the complaints).

In $64 \%$ of all sessions the physical therapists give instructions on home exercises: these instructions relate to learning the exercises, explanation of the manner and the frequency of exercising and motivating the patient to do the exercises at home.

Two education themes are of less frequent occurrence: general health education and psychosocial counseling. in $23 \%$ of the sessions general health education is given. This is education on the importance of movement or sport, avoiding overweight or the risks of smoking. This education is aimed at a healthy life style and thus at primary prevention.

Likewise in $23 \%$ of the sessions, physical therapists give the patient psychosocial counseling. This embraces both giving insight into the relation between problems or 
stress and physical complaints and helping the patient to cope with handicaps or giving support and consolation in the case of pain.

In conclusion, we may state that in the majority of the sessions information, instructions and advice are given, whereas general health education and psychosocial counseling occur less frequently.

\section{Quality aspects}

In the investigation three quality aspects have been assessed: working methodically (planned and goal directed), concurring with the ideas and wishes of the patient, and the relation between physical therapist and patient.

Two findings are interesting. Firstly, two of these quality aspects prove to be significantly connected with the amount of education that is given: working methodically and the physical therapist-patient relationship. According as more education is given, more attention is devoted to these aspects. This relationship is much stronger at the level of the physical therapist than at the level of the patient: the correlation between education and working methodically, for instance, is .40 at patient level and .72 at physical therapist level. This means that physical therapists who give considerable education by and large also devote considerable attention to the quality aspects, while this is not reflected in every individual patient.

A second result is the finding that physical therapists seldom ask patients explicitly about their ideas and wishes: in $81 \%$ of the sessions it was not asked what the patient himself or herself thought of the complaints, what he or she had already tried for themselves or what was expected of the treatment. This sometimes gave rise to misunderstandings or irritation, for instance because the physical therapist advised measures that the patient had already tried but which had not helped. It may be concluded that there are possibilities for improvement here. For it emerges from the literature that education has more effect if it ties in with the perceptions and ideas of the patient.

Is the education given connected with the kind of treatment, the phase of the treatment, the type of complaint or the characteristics of the patient? (Chapter 4)

\section{Kind of treatment}

The kind of treatment that the physical therapist applies can be broadly divided into massage, exercise therapy and applying modalities and the various combinations that are possible here. The results show that the education given is significantly connected with the kind of treatment applied by the physical therapist. Firstly - and obviously - it is found that during exercise therapy above all the instructions for home exercises are given. Secondly, it emerges that during massage significantly more psychosocial counseling of the patient takes place compared with exercise therapy and applying modalities. The physical therapists prove to use the massage time - and probably also 
the intimate contact with the patient - to conduct psychosocial conversations. Such conversations often relate to stress or stressful events in the patient's life, and to the way in which these are connected with the complaints. The physical therapists also regularly give counseling and aid regarding the impediments or handicaps that the patient undergoes as a result of the complaints.

It is striking that quality aspects are also bound up with the kind of treatment, notably with exercise therapy: in exercise therapy a methodical procedure is more frequently followed and the relationship between physical therapist and patient is assessed as better compared with treatments in which massage or modalities are used. Perhaps the active cooperation between patient and physical therapist in exercise therapy leads to a better relationship.

In conclusion, the education given is bound up with the kind of treatment that the physical therapist applies.

\section{Phase of the treatment}

The education is also connected with the phase of the treatment. The results show that most education is given in the first two sessions with the patient: in the first session that is above all an explanation of the diagnosis and the complaints; in the second session it is above all instructions for home exercises. It proves that less and less education is given according as the patient undergoes treatment longer; in particular relatively little information is given on the home exercises in the second half of the treatment (see also Chapter 3). An exception is formed by the psychosocial counseling of the patient: according as the patient receives treatment longer, relatively somewhat more conversation about psychosocial aspects take place.

As regards the quality aspects, it is found that methodical working in particular occurs more often in the first session with the patient than in the remaining sessions. Physical therapists also inquire somewhat more often, relatively speaking, about the perceptions of the patient in the first session.

In conclusion, we may say that the giving of education is not uniformly spread over the treatment but takes place above all in the first phase of the treatment.

\section{Nature and characteristics of the complaints}

The results show that the amount of education that physical therapists give is not significantly connected with the type of complaint of the patient. Patients with back complaints, for instance, get just as much education as patients with neck/shoulder complaints or with traumas.

Conversely, the education is significantly connected with the characteristics of the complaints. Patients with recurrent complaints, who have been treated for the same complaints before by physical therapy, receive relatively less education.

The psychosocial character of the complaints also plays a part: if the physical therapist considers the complaints more psychosocial in nature, psychosocial counseling is given considerably more often. It is, however, striking that for half of the patients with psychosocial complaints no psychosocial counseling takes place. Finally, psychosocial counseling proves to occur relatively somewhat more frequently among patients 
with chronic complaints.

Summarizing, the amount of education is in fact connected with the characteristics of the complaint, but not with the complaint in itself. We should remark that the concrete content of the education in this investigation has not been measured. It goes without saying that the content of the education differs per complaint.

\section{Characteristics of the patient}

The most important finding is that the education that physical therapists give is closely connected with the questions and the initiatives of the patient (initiatives are defined as bringing up a new subject). The correlations between the questions and the initiatives of the patient and the amount of education that is given vary from .23 to .57 . The number of questions that the patient asks is connected above all with giving an explanation of the diagnosis and complaints, whereas the giving of general health education and psychosocial counseling is bound up above all with the patient's initiatives. This explains a considerable part of the differences in education. On the one hand this relation is self-evident, he who asks usually gets a reply, on the other hand the relationship also proves to be the other way round: giving information often proves to be the reason for the patient to ask further questions. For instance, an explanation of the diagnosis often elicits questions such as: 'How serious is this? What causes it? Can it be cured? Will it get worse?' and so forth. In conclusion, we may say that the education is closely bound up with the patient's questions and is not one-way traffic. It is a characteristic of the interaction between physical therapist and patient.

A weak but significant correlation proves to exist between giving education and the patient's age: younger patients get more education than older ones. Physical therapists also prove to give somewhat more information on the diagnosis and the complaints to highly educated patients compared with patients with a lower level of education. The sole difference between male and female patients is that physical therapists more often assess the complaints of women as psychosocial than the complaints of male patients. Although significant, the connection between education and characteristics of the patient is a good deal weaker than the connection between education and the questions and initiatives of the patient.

\section{In what way do physical therapists differ among themselves in the education that they give, and can these differences be explained by views regarding patient education? (Chapter 5)}

\section{Differences in giving education}

Between physical therapists great differences exist in their educational activities. These differences concern all aspects of patient education but are the greatest with regard to the extent to which patients are given psychosocial counseling, with regard to general health education and with regard to the extent to which instructions are given for home exercises. For instance, some physical therapists devote considerable attention to discussing the relationship between stress and complaints, whereas other 
physical therapists rarely or never discuss this. Some physical therapists give nearly every patient instructions for home exercises, while others seldom do so. The same applies to the attention that is devoted to the perceptions and the ideas of the patient. The investigation shows that female physical therapists give somewhat more psychosocial counseling than males and that older physical therapists give somewhat more general health education than younger ones. However, these differences are fairly small ones.

\section{Differences in views}

The same differences are encountered in the views of physical therapists about patient education. The most striking difference here is the extent to which patients are thought to be conscientious about performing the therapy. On average the physical therapists estimate that $64 \%$ of their patients do in fact perform the exercises at home and that $36 \%$ do not. There is great pessimism about continued compliance with the therapy in the long term: the physical therapists estimate that only $23 \%$ of their patients continue to do the prescribed home exercises once the treatment has ended. Some physical therapists think that not a single patient perseveres with the exercises in the long term, whereas other physical therapists are of the opinion that $50 \%$ of their patients carry on exercising in the long term. Interestingly, patients' self reported degree of compliance is not statistically significant related to the therapist's pessimistic or optimistic view. This deserves further research.

A second striking difference concerns the psychosocial counseling of the patient: $46 \%$ of the physical therapists regard giving psychosocial counseling as subordinate to the physical therapy treatment, whereas $51 \%$ regard it as an essential part of the physical therapy treatment.

Finally, it proves that $57(68 \%)$ of the 84 physical therapists experience problems with giving education to patients and $27(32 \%)$ do not. The problems most commonly mentioned are 'communication problems' and problems 'with the patient'. Summarizing, the physical therapists are found to differ most in their views on compliance and on psychosocial counseling, whilst in addition two thirds have problems with educating patients and one third do not.

\section{Explanation of differences}

By and large there is a rather weak relationship between the views of the physical therapists on patient education and the education that they actually give on the tapes. Nevertheless, these views explain part of the differences. It is notably the perceived effects of education that are significantly connected with giving education: physical therapists who are of the opinion that the education that they give contributes to effects like 'more rapid recovery', 'better cooperation by the patient', 'reduction of costs in health care" etc. devote more attention to patient education than physicall therapists who do not expect such effects. In addition it proves that physical therapists who are optimistic about patient compliance devote more attention to the home exercises than physical therapists who are pessimistic about this. 
A second explanation of the differences is formed by factors relating to the work setting of the physical therapists. There is a significant correlation between the time devoted to the patient and the amount of education given. Here we encounter the familiar chicken and egg problem because we do not know what causes what: does one devote more time so as to be able to give more education or does one give more education because one devotes more time? An interesting finding is the fact that the psychosocial counseling that the physical therapist gives is not connected with the length of time. This contrasts with the situation in general practice, where these two factors are usually closely connected. Probably this is caused by the fact that this psychosocial counseling is often given during massage. As a result it is not necessary to invest much extra time because two things are combined.

There is a significant connection between the quality aspects and work setting factors: firstly the relationship between physical therapist and patient is found to be better if the physical therapist devotes more time to the patient. Secondly, the length of the working week proves to have an effect: according as one works longer, the ideas and wishes of the patients are enquired after relatively less frequently. Perhaps fatigue or pressure of time plays a part here. Thirdly, it proves that physical therapists employed in health centres spend more time working methodically and ask about the ideas and wishes of the patients more than the other physical therapists.

Summarizing, it may be concluded that the differences between physical therapists in the quantity and quality of the education can be explained in part by the effects expected from it and by factors relating to the work setting.

\section{What is the extent of non-compliance in physical therapy and which factors are connected with non-compliance? (Chapter 6).}

\section{Compliance with home exercises}

In the patient survey $22 \%$ of the patients state that they barely perform the prescribed exercises, if at all, whereas $35 \%$ of the patients say that they exercise 'very regularly'. The remaining $41 \%$ of the patients are in between and say that they do the exercises 'fairly regularly'. This group may be regarded as partly compliant. Compliance with home exercises is therefore not a matter of all or nothing but has different levels. It may be concluded that - just as in medical practice - non-compliance is a problem in physical therapy practice. It must be remarked that 'short-term compliance' is involved here, i.e. compliance during the period that the patient is receiving treatment.

\section{Differences between patients}

The analyses show that there is no difference in compliance between men and women. There is, however, a connection with the age and educational level of the patient. Firstly, it emerges that older patients exercise more often than younger patients. A second finding is that patients of a higher educational level are less conscientious about adhering to the therapy than patients of a lower educational level: above all highly educated women younger than 45 years state that they exercise less than 
women of a low educational level in the same age group. Summarizing, non-compliance occurs more often among younger and highly educated patients.

\section{Differences between complaints}

The type of complaint proves not to be connected with compliance or non-compliance: there is for instance no significant difference between patients with back complaints and patients with neck/shoulder complaints.

Conversely, the characteristics of the complaints are significantly connected with compliance: according as patients experience more nuisance and hindrance from the complaints, they adhere to the therapy more faithfully. This connection - which was found quite often - is understandable because overcoming the hindrance can have a motivating effect. The opposite holds for the chronicity of the complaints. The results show that patients with chronic complaints, that is to say patients who think that their complaints will never go away exercise less frequently than patients who think that their complaints will disappear.

This result is also found in the compliance literature. In conclusion, it is not the complaints in themselves that are connected with compliance but the nuisance and the chronicity of the complaints.

\section{Explanations for non-compliance}

Three factors form the principal explanation for non-compliance: the barriers that patients experience, the absence of positive feedback, and the feeling of 'helplessness'. With these three factors $86 \%$ of the cases are correctly predicted in a discriminant analysis.

By far the most important factor is formed by the 'barriers' that patients experience, that is to say the problems that patients encounter in their attempts to follow the physical therapist's instructions. The barriers or problems that patients mention most frequently are: lack of time, the fact that the exercises do not fit into the daily routines, the fact that exercising causes pain, the fact that patients forget to exercise, and lack of motivation to exercise. in fact one can distinguish two dimensions in these prablems: on the one hand there are motivational problems and on the other there are situational problems, that is to say the circumstances form an obstacle in the way of regularly doing exercises.

A second explanation for non-compliance is the absence of positive feedback. The appreciation that the physical therapist shows for the efforts that the patient makes is positively connected with compliance: patients who say that the physical therapist is satisfied with the exercises that they do at home are more compliant than patients who state that they do not know whether the physical therapist appreciates their efforts or state that the physical therapist is not satisfied. This is in conformity with the general compliance literature, in which the giving of positive feedback is usually significantly connected with compliance.

Finally, as a third factor it emerges that patients exercise less if they are of the opinion that exercise will not help. This relation is self-evident. The question is only whether one 
thinks that exercise will not help or whether one has personally experienced that exercise does not help.

Summarizing, the barriers that patients experience prove to be the principal cause of non-compliance, while in addition positive feedback and 'helplessness' play a part.

\section{Conclusions and recommendations}

\section{Conclusions and recommendations with regard to the practice of patient education in physical therapy}

The investigation has clearly demonstrated that patient education is an essential part of every physical therapy treatment. In the majority of the sessions attention is devoted to information on the complaints, the instructions for home exercises and to curative and/or preventive advice. The interaction between giving education and the patient's questions and initiatives implies that the communication between physical therapist and patient is of the greatest importance.

Two educational activities are of less frequent occurrence: general health education and psychosocial counseling.

General health education is often provided on the patient's initiative. We derive from this that patients appreciate such information. In fact physical therapists have a good opportunity for expanding their preventive tasks in this way. It moreover seems important to develop standards or guidelines for general health education in physical therapy, the more so as patients also ask questions that fall outside the expertise of the physical therapist. Such standards can further define physical therapy tasks in the field of health education.

On the strength of the results we conclude that there is a lack of clarity about the tasks regarding the psychosocial counseling of patients. Half of the physical therapists consider this an essential part of the physical therapy treatment, while the other half are of the opinion that it is a subordinate aspect of the treatment. In practice, too, there are differences: although psychosocial counseling is given more often according as the physical therapist considers the complaints of the patient more psychosocial in nature, it also proves that in the case of half of the patients with psychosocial complaints no discussion about the psychosocial aspects takes place. On the basis of these findings it seems important to define in more concrete terms the indications for psychosocial counseling and the tasks in this field.

The investigation demonstrates that in physical therapy little use is made as yet of general principles of education theory. This offers the possibility of raising the quality of the education, assuming that physical therapists share some responsibility in patient compliance by prescribing feasible regimens and by facilitating patient compliance. On the strength of the results it seems important to give priority to the following three matters: working by means of an educational plan, solving compliance problems and applying 'compliance-raising strategies'. We shall explain them in succession. 
Firstly, it seems important that physical therapists make an educational plan parallel to and integrated into the treatment plan, so that the education can be spread out uniformly over the treatment. The investigation shows that the information decreases according as the patient undergoes treatment longer and that in the second phase of the treatment less attention is devoted to the home exercises. This offers the possibility - after the exercises have been learnt in the first phase of the treatment - of directing attention in the second phase explicitly towards patient compliance. Both aspects can be included in the educational plan. In addition, it is self-evident to construct the plan in accordance with the logical order of the instructions and advice in physical therapy: palliative, curative and preventive measures. Such a systematic and rational planning of the education makes it easier to devote attention to all education aspects, makes it possible to spread the information uniformly over all sessions so that the whole treatment period is utilized optimally, and facilitates evaluation of the education.

Secondly, the most important explanation of non-compliance is formed by the barriers and problems that patients experience. Prevention and solution of these problems seems of the greatest importance. Two matters deserve attention here. Firstly, one can try to obviate such problems by applying the tailoring principle. This means that the exercises and advice are adapted to the specific situation of the patient or fitted into his or her daily routines. It means that together with the patient it is examined what possibilities he or she has of exercising and that the exercise program is adjusted as well as possible to this situation. Next, efforts can be made to link the exercises as much as possible to other routines that are also performed daily so that the patient is reminded of these exercises. For instance, doing pelvic floor exercises in the bus to work or every time the telephone rings, neck/shoulder exercises after showering or while listening to favorite music etc. This tailoring principle can obviate the prescribing of measures that are not feasible in the patient's situation and facilitates habit-forming. In addition, it will have to be regularly discussed with the patient what other problems he or she encounters. Careful questioning is necessary here because the problems differ considerably per patient. Alternatives or solutions can then be sought together with the patient. In fact this means that the instructions are always viewed from the patient's situation.

Summarizing, it seems important to adapt the instructions to the specific situation of the patient and together with the patient to seek alternatives or solutions for compliance problems.

Thirdly, the investigation shows that positive feedback is significantly bound up with compliance. Physical therapists can utilize this to stimulate the patients to apply the therapy faithfully. For instance, every improvement can be made manifest or emphasized and appreciation shown for the efforts that the patient makes. This requires a positive attitude on the part of the physical therapist; it means that one looks above all at what has proved successful and does not concentrate too much on what has not (yet) succeeded. 
The fact that positive feedback and tailoring, broadly speaking, increase compliance with therapy is theoretically explicable (Chapter 7 ). In fact the two most important principles from learning theories are then used, namely the finding of 'cues and reminders' that recall the behavior and 'reinforcements' to stimulate the behavior. This approach proves by and large effective in the short term, during the period that the patient is undergoing treatment.

Compliance with therapy in the long term, after the treatment has ended, is in general much more difficult to bring about, research shows. Leventhal's self-regulation theory offers starting-points for stimulation of compliance with therapy in the long term. It seems important to examine how this theory could be used in physical therapy. An initial impetus may be found in Chapter 7 .

The use of strategies to encourage patients to comply has consequences for the traditional structure of physical therapy treatment, in which patients are generally seen twice a week. Since supervision plays such an important part in compliance, it may be useful to spread the sessions out over a longer period. Patients then have more opportunity to experiment with the advice that they are given, as a result of which the problems also become more apparent. It may also be necessary to introduce followup contacts to support the patient or to add a number of sessions particularly aimed at prevention. Summarizing, it seems important that physical therapists examine the situations in which it is advisable to spread the treatment out over a longer period so as in that way to stimulate compliance of patients with the therapy.

In conclusion, it goes without saying that compliance by patients can contribute to the effects of physical therapy treatment. On the basis of this it is important to integrate the above-mentioned principles of education theory into the training. The psychology and communication subjects offer an opportunity for that, but explicit training in these skills in the practical lessons increases the possibility of their actually being used in practice. From that point of view it may be relevant that the practical and trainee teachers master these skills, because they serve as 'models' for the future physical therapists.

In addition, it seems important to integrate education principles into the regular refresher and continuation courses for physical therapists. This seems more effective than devising special education courses, firstly because education is inextricably bound up with treatment and secondly because it has been found that physical therapists currently have little interest in specific courses in patient education. Finally, in peer review, notes can be compared on a basis of practical experience on the strategies used to stimulate compliance with therapy and above all the solutions that have been found for the patient's problems. This series of measures can make a major contribution to the quality of patient education in physical therapy.

\section{Conclusions and recommendations with regard to theoretical or scientific aspects}

On the basis of theoretical and practical considerations it is important further to analyze and define the various kinds of compliance with therapy. The usual distinction between short-and long-term compliance - defined only as period of time - makes no allowance 
for an essential element in compliance, namely the presence or absence of supervision. This leads to confusion, because for instance a compliance period of three months while intervention is still going on differs essentially from an identical period after intervention has ended. This confusion may have contributed to the often contradictory results in compliance research. It therefore seems important to make a distinction in physical therapy between "supervised short-term compliance" (during the treatment period) and "unsupervised long-term compliance" (upon completion of the treatment). This distinction contributes to the comparability of research data and moreover has theoretical and practical consequences for patient education in physical therapy.

In the case of short-term compliance during treatment the physical therapist can use the principles of learning theory to stimulate adherence to the therapy by patients. Finding cues or reminders that recall the behavior and ensuring positive feedback are essential in this. This influence of the physical therapist is absent in long-term compliance, after conclusion of the treatment. For that reason Leventhal's selfregulation seems more suitable for attaining long-term compliance. The theory assumes that the way in which people manage their complaints is determined by their perceptions of the complaints, by their behavioral possibilities and by the way in which they assess the results of the behavior. The health care professional can take advantage of these three aspects by subscribing as much as possible to the patient's perceptions, by expanding the patient's behavioral possibilities and by teaching the patient to assess the results of the behavior in an adequate manner. It seems important to try out the possible applications of this model in physical therapy in an experimental way.

Following on the above distinction is the difference between compliance with curative measures and compliance with preventive measures. Besides the difference in supervision, curative measures have a number of characteristics that are absent from preventive measures. Curative measures are aimed at recovery in the shortest possible time, and this offers physical therapist and patient the possibility of evaluating whether the aim has been achieved (absence of symptoms). The symptoms often function as cues that recall exercises or advice, and in addition the expected recovery can be a strong motivation for compliance. These factors are absent from preventive measures. Often the latter must be permanently kept up, and it is difficult to evaluate whether the aim has been achieved: symptoms may return despite preventive measures, and it is difficult to establish whether the failure of symptoms to recur has in fact been caused by the preventive measures. In addition, prevention lacks the motivating factor of recovery and there are no symptoms that recall the behavior. These factors make adherence to therapy with preventive measures difficult.

In conclusion, we may say that analyzing the different kinds of compliance can contribute to a better understanding of the differences in compliance and moreover give an idea of the theoretical and practical consequences that follow from the differences. 


\section{Further research}

In our opinion three research themes deserve priority in further research; 1) research into the effects of strategies stimulating compliance with therapy, 2) the development of instruments for measuring compliance, 3) further analysis of the significance of problems with compliance. We shall briefly explain these themes.

Firstly, research into the effects of measures that may facilitate or encourage compliance with therapy by patients is of great relevance to the practice of physical therapy. It is important to investigate not only whether certain strategies have an effect but also which strategies are effective with different kinds of compliance. For instance with compliance during as against after treatment, compliance with curative as against preventive measures, compliance with home exercises as against various kinds of advice etc. Such research is theoretically relevant and can contribute to the effect of physical therapy.

Secondly, research into the effects of the education requires the development of reliable measuring instruments to establish the compliance with therapy by patients. In the present investigation a rather broad indication has been used for compliance. However, if it is desired to compare effects of different strategies, there is a need for more detailed measurement that gives an idea of the various levels in compliance with therapy. This is not simple, above all with regard to the advice that patients are given. Firstly, advice is given spread out over the whole treatment period and secondly it is of a diverse nature (palliative, curative, preventive). In addition, allowance must be made for the fact that 'acting in the spirit of the advice' may be just as important as 'literally following the advice'. Although this complexity makes it difficult to measure compliance, it can reveal which compliance enhancing strategies are effective in physical therapy.

Moreover, assessing patient compliance can enhance the knowledge about exercise therapy as such. Research on the effects of exercise therapy has found contradictory results: some studies show positive effects, whereas other studies show no effect. It is as yet unclear if this lack of effect is caused by patient's non-compliance with the exercises or that some forms of exercise therapy are more effective than other ones. Therefore, it is important to assess patient compliance uniformly in future research to make research findings comparable and to enhance the knowledge about exercise therapy.

Thirdly; further investigation is necessary into the barriers and problems that patients experience. They form the principal explanation of non-compliance, and this makes it important to gain more insight into the way in which these barriers and problems hamper compliance. Apart from its practical importance to the practice of physical therapy, this research is theoretically relevant because 'barriers' play a part in many theories. Our investigation shows that the broad concept 'barriers' can assume different forms and meanings. Firstly, there are great differences in the kind of barriers that patients encounter: there are motivational barriers and situation-bound barriers 
(the circumstances make it impossible to follow the advice). In addition there is the problem of the behavioral change itself, that is to say the difficulty in throwing off a habit or changing a life style. Secondly, there is the difference between 'perceived barriers" and 'actually encountered barriers': is compliance affected above all by the patient's ideas or by his concrete experience, and what does this mean for the way in which compliance can be influenced? Summarizing, we may conclude that it is practically and theoretically relevant to gain more insight into the problems that patients experience in their attempts to follow the prescribed instructions. 
s

स्स

क्ष

$\therefore \quad \because \quad \therefore$

\%

$\ddots$

$\therefore$

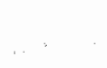

$\therefore$

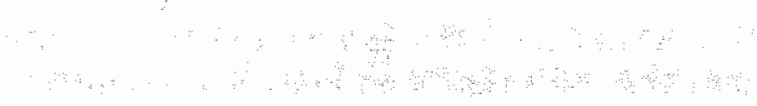




\section{Samenvatting}

\section{Inleiding}

De wijze waarop eerstelijns fysiotherapeuten patiëntenvoorlichting geven is onderwerp van dit driejarig onderzoek dat door het Praeventiefonds gesubsidieerd is.

De relevantie van patiëntenvoorlichting in de fysiotherapie is drieledig. Ten eerste streven fysiotherapeuten ernaar de preventieve aspecten van de behandeling verder te ontwikkelen en preventieve taken uit te breiden. Voorlichting is daarbij een belangrijk instrument. Ten tweede, speelt het universele probleem van non-compliance (het niet opvolgen van voorschriften) ook in de fysiotherapie een rol. Een goede wijze van voorlichten kan dit probleem voor een deel oplossen. Ten derde blijkt dat fysiotherapeuten problemen ervaren bij het voorlichten van patiënten, onder andere omdat voorlichtingsvaardigheden nog nauwelijks expliciet in de opleiding geleerd worden. In dit onderzoek is de huidige situatie in kaart gebracht met als doel mogelijkheden op te sporen om de kwaliteit van de voorlichting in de fysiotherapie te verbeteren.

\section{Onderzoeksvragen}

Het onderzoek is verricht aan de hand van de volgende vragen:

1 Wat is de aard, de omvang en de kwaliteit van patiëntenvoorlichting in de fysiotherapie?

2 Hangt de gegeven voorlichting samen met: de aard van de klachten, de kenmerken van de patiënt en het type behandeling?

3 Op welke wijze verschillen fysiotherapeuten onderling in de voorlichting die zij geven en kunnen deze verschillen verklaard worden door opvattingen ten aanzien van patiëntenvoorlichting?

4 Wat is de omvang van non-compliance in de fysiotherapie en welke factoren hangen samen met non-compliance?

De resultaten zijn beschreven in hoofdstuk 4 tot en met 6 . Daarnaast is op theoretische gronden geanalyseerd welke consequenties verschillende vormen van compliance hebben voor de voorlichting in de fysiotherapie (hoofdstuk 7). De benodigde meetinstrumenten zijn in een vooronderzoek ontwikkeld (hoofdstuk 2 en 3). Terwille van de overzichtelijkheid laten we het vooronderzoek in deze samenvatting buiten beschouwing. 


\section{Materiaal}

Het onderzoek is verricht aan de hand van geluidsopnamen van fysiotherapiebehandelingen. Er is gekozen voor geluidsopnamen (in plaats van video) om de privacy van patiënten zoveel mogelijk te beschermen. Daarnaast hebben patiënten en fysiotherapeuten vragenijsten en registratieformulieren ingevuld (zie bijlagen $1 \mathrm{t} / \mathrm{m}$ 4). Concreet bestaat het materiaal van de studie uit:

1931 registratieformullieren ingevuld door 84 fysiotherapeuten

1837 geluidsopnamen van fysiotherapie behandelingen

1681 enquâtes ingevuld door patiënten

222 enquâtes ingevuld door fysiotherapeuten

\section{Steekproef en respondenten}

Uit de Fysiotherapeuten Registratie van het Nivel werd een representatieve steekproef van 300 fysiotherapeuten getrokken met als criterium dat men minimaal 3 dagen per week werkzaam was. De fysiotherapeuten werd gevraagd geluidsopnamen van behandelingen te maken en van elke behandeling een registratieformulier in te vullen. Daarnaast werden zij verzocht eenmalig een enquête in te vullen over hun opvattingen ten aanzien van patiëntenvoorlichting.

De enquête werd geretourneerd door 222 fysiotherapeuten (respons $74 \%$ ). De geluidsopnamen werden gemaakt door 84 fysiotherapeuten (respons $28 \%$ ). Een nonrespons analyse (bijlage 5) toonde twee verschillen tussen respondenten en nonrespondenten: $37 \%$ van de mannelijke fysiotherapeuten participeerde (63 van de 170 ) tegenover $16 \%$ van de vrouwelijke fysiotherapeuten (21 van de 130). De oorzaak hiervan is onbekend. Ten tweede, de respondenten ervaarden meer problemen bij het geven van voorlichting $(68 \%)$ dan de non-respondenten $(42 \%)$. Wellicht was dat een van de redenen om aan het onderzoek mee te doen. Wij achten echter geen gronden aanwezig voor een al te grote selectiviteit van de resultaten, omdat mannelijke en vrouwelijke fysiotherapeuten slechts weinig verschillen in het geven van voorlichting en omdat de relatie tussen het geven van voorlichting en het ervaren van problemen zwak is (hoofdstuk 5).

De patiënten werden a-select gekozen door de fysiotherapeut: de fysiotherapeut werd verzocht de eerste 25 patiënten die hij of zij in een bepaalde week zag in het onderzoek te betrekken. De fysiotherapeuten vulden van 1931 patiënten een registratieformulier in en vroegen toestemming voor het maken van de geluidsopname; 1837 patiënten gaven toestemming voor de opname (respons 95\%). Als de patiënt geen toestemming gaf, werd geen opname gemaakt. Het gemiddelde aantal opnamen per fysiotherapeut is 22 . De fysiotherapeut bediende zelf de recorder, er was geen onderzoeker aanwezig.

De patiënten ontvingen na afloop van de zitting een enquête van de fysiotherapeut 
met het verzoek deze direct thuis in te vullen. De patiênten zonden de enquête rechtstreeks terug naar het Nivel en wisten dat de fysiotherapeut de gegevens niet zou zien. Van de 1837 patiënten retourneerden 1681 patiënten de enquête (respons $92 \%)$.

De gegevens van de enquête konden worden vergeleken met die van de geluidsband door het toekennen van een codenummer.

\section{Procedure}

De geluidsbanden werden beoordeeld door drie getrainde observatoren een fysiotherapeute, een gezondheidskundige en een psychologe; de banden waren op toevalsbasis over hen verdeeld. De beoordeling geschiedde aan de hand van een checklist met een betrouwbaarheid uitgedrukt in Cramer's V van . 71 tot .90 (hoofdstuk 2). De checklist bevat drie onderdelen: de aard van de voorlichting, de hoeveelheid voorlichting en de kwaliteit van de voorlichting.

\section{Resultaten}

Wat is de aard, de omvang en de kwaliteit van patiëntenvoorlichting in de fysiotherapie? (hoofdstuk 4)

\section{Aard en omvang van de voorlichting}

Uit de resultaten blijkt dat in $97 \%$ van de 1837 fysiotherapie-zittingen voorlichting aan de patiënt wordt gegeven. Dit betekent dat het geven van voorlichting een wezenlijk onderdeel is van elke fysiotherapie behandeling en daar onlosmakelijk mee verbonden is.

De meeste voorlichting betreft informatie over de diagnose en klachten: in $80 \%$ van de zittingen geven de fysiotherapeuten uitleg over de diagnose, de betekenis van de symptomen, de oorzaak of de prognose van de klachten.

In $69 \%$ van de zittingen krijgen patiënten adviezen over het omgaan met de klachten, bijvoorbeeld rust nemen, de houding corrigeren, anders gaan tillen, betere schoenen dragen, etc. Deze adviezen hebben een curatief doel maar zijn vaak tegelijkertijd gericht op secundaire preventie (het voorkómen dat de klachten opnieuw optreden). In $64 \%$ van alle zittingen geven de fysiotherapeuten instructies over huiswerkoefeningen: deze instructies betreffen het aanleren van de oefeningen, uitleg over de wijze en de frequentie van oefenen en het motiveren van de patiënt om de oefeningen thuis te doen.

Twee voorlichtingsthema"s komen minder vaak voor: algemene gezondheidsvoorlichting en -opvoeding en psychosociale begeleiding. In $23 \%$ van de zittingen wordt algemene gezondheidsvoorlichting en -opvoeding gegeven. Dit betreft voorlichting over het belang van bewegen of sport, het vermijden van overgewicht of de risico's van roken. Deze voorlichting is gericht op een gezonde leefstijl en daarmee op primaire preventie.

Eveneens in $23 \%$ van de zittingen geven fysiotherapeuten de patiënt psychosociale 
begeleiding. Dit behelst zowel inzicht geven in de relatie tussen problemen of stress en lichamelijke klachten als de patiënt helpen bij de verwerking van handicaps of steun en troost bieden bij pijn.

Concluderend kunnen we stellen dat in de meerderheid van de zittingen informatie, instructies en adviezen worden gegeven terwijl algemene gezondheidsvoorlichting en opvoeding en psychosociale begeleiding minder frequent voorkomen.

\section{Kwaliteitsaspecten}

In het onderzoek zijn drie kwaliteitsaspecten beoordeeld: 1) Methodisch Werken, 2) aansluiten bij de ideeén en wensen van de patiënt en, 3) de relatie tussen fysiotherapeut en patient. Twee bevindingen zijn interessant. Ten eerste blijkt het Methodisch Werken en cle fysiotherapeut-patiënt relatie significant samen te hangen met de hoeveelheid voorlichting die gegeven wordt. Dit betekent dat fysiotherapeuten die in zijn algemeenheid veel voorlichting geven ook veel aandacht besteden aan Methodisch Werken en aan de relatie met de patiënt. Deze samenhang komt niet bij elke individuele patiënt tot uiting maar is meer een algemeen kenmerk van de werkwijze van de fysiotherapeut. Bijvoorbeeld de correlatie tussen het Methodisch Werken en de hoeveelheid voorlichting die gegeven wordt is op het niveaul van de fysiotherapeut 72 maar op het niveau van de patiënt 40 . Concluderend wordt de samenhang tussen de kwaliteit en de kwantiteit van de voorlichting beter zichtbaar op fysiotherapeut-niveau dan op patiënt-niveau.

Een tweede resultaat is de bevinding dat fysiotherapeuten zelden expliciet naar de ideeën en wensen van de patiënt vragen: in $81 \%$ van de zittingen werd niet expliciet gevraagd wat de patiënt zelf van de klachten dacht, wat hij of zij zelf al geprobeerd had of wat men van de behandeling verwachtte. Soms gaf dit aanleiding tot misverstanden of irritaties, bijvoorbeeld omdat de fysiotherapeut maatregelen adviseerde die patiënt al geprobeerd had maar die niet hadden geholpen. Geconcludeerd kan worden dat hier mogelijkheden voor verbetering liggen. Uit de literatuur blijkt immers dat voorlichting meer effect heeft als deze aansluit bij de percepties en idleeën van de patiënt.

Hangt de gegeven voorlichting samen met: het soort behandeling, de fase van de behandeling, het type klacht of de kenmerken van de patiënt? (hoofdstuk 4)

\section{Soort behandeling}

Het soort behandeling dat de fysiotherapeut toepast kan globaal ingedeeld worden in massage, oefentherapie en fysiotechniek en de diverse combinaties die daarbij mogelijk zijn. Uit de resultaten blijkt dat de voorlichting die gegeven wordt significant samenhangt met het soort behandeling dat de fysiotherapeut toepast. Ten eerste en voor de hand liggend - blijkt dat tijdens oefentherapie vooral de instructies voor huiswerk- oefeningen worden gegeven. Ten tweede blijkt dat tijdens massage significant meer psychosociale begeleiding van de patiënt plaatsvindt vergeleken met oefentherapie en fysiotechniek. De fysiotherapeuten blijken de massagetijd - en vermoedelijk ook het intieme contact met de patiënt - te benutten om psychosociale 
gesprekken te voeren. Dergelijke gesprekken hebben vaak betrekking op stress of stressvolle gebeurtenissen in het leven van de patiënt en op de wijze waarop deze met de klachten samenhangen. Ook geven de fysiotherapeuten regelmatig begeleiding en steun bij de belemmeringen of handicaps die de patiënt ten gevolge van de klachten ondervindt.

Opvaliend is dat ook kwaliteitsaspecten met het soort behandeling samenhangen, metname met oefentherapie: bij oefentherapie wordt vaker een methodische werkwijze gevolgd én wordt de relatie tussen fysiotherapeut en patiënt als beter beoordeeld vergeleken met behandelingen waarin massage of fysiotechniek worden toegepast. Misschien leidt de actieve samenwerking tussen patiënt en fysiotherapie bij oefentherapie tot een betere relatie. Concluderend hangt de voorlichting samen met het soort behandeling dat de fysiotherapeut toepast.

\section{Fase van de behandeling}

De voorlichting hangt eveneens samen met de fase van de behandeling. Uit de resultaten blijkt dat de meeste voorlichting in de eerste twee zittingen met de patiënt wordt gegeven: in de eerste zitting is dat vooral uitleg over de diagnose en de klachten, in de tweede zitting zijn dat vooral instructies voor huiswerkoefeningen. Het blijkt dat steeds minder voorlichting gegeven wordt naarmate de patiënt langer in behandeling is; met name wordt relatief weinig informatie over de huiswerkoefeningen gegeven in de tweede helft van de behandeling (zie ook hoofdstuk 3). Een uitzondering vormt de psychosociale begeleiding van de patiënt: naarmate de patiënt langer in behandeling is vinden naar verhouding wat meer gesprekken over psychosociale aspecten plaats.

De kwaliteitsaspecten hangen eveneens samen met de fase van de behandeling. Methodisch Werken komt vaker voor in de eerste zitting met de patiënt vergeleken met de overige zittingen. Ook vragen fysiotherapeuten relatief wat vaker naar de ideeën en wensen van de patiënt in de eerste zitting.

Concluderend kunnen we stellen dat de voorlichting niet gelijkmatig over de behandeling gespreid is maar vooral plaatsvindt in de eerste fase van de behandeling.

\section{Aard en kenmerken van de klachten}

Uit de resultaten blijkt dat de hoeveelheid voorlichting die fysiotherapeuten geven niet duidelijk samenhangt met het type klacht van de patiënt. Patiënten met rugklachten krijgen bijvoorbeeld evenveel voorlichting als patiënten met nek/schouderklachten of met traumata. Daarentegen hangt de voorlichting wel significant samen met de kenmerken van de klachten. Patiënten met recidiverende klachten, die al eerder voor dezelfde klachten fysiotherapeutisch behandeld zijn, krijgen naar verhouding minder voorlichting. Ook het psychosociale karakter van de klachten speelt een rol: als de fysiotherapeut de klachten meer psychosociaal van aard acht wordt beduidend vaker psychosociale begeleiding gegeven. Opvallend is echter dat bij de helft van de patiënten met psychosociale klachten geen psychosociale begeleiding plaatsvindt. Tot slot blijkt dat psychosociale begeleiding relatief wat vaker plaatsvindt bij patiënten met chronische klachten. 
Samenvattend hangt de hoeveelheid voorlichting wel samen met de kenmerken van de klacht, maar niet met de klacht op zich. We merken op dat de concrete inhoud van de voorlichting in dit onderzoek niet gemeten is. Het ligt voor de hand dat de inhoud van de voorlichting wel per klacht verschilt.

\section{Kenmerken van de patiënt}

De belangrijkste bevinding is dat de voorlichting die fysiotherapeuten geven sterk samenhangt met de vragen en de initiatieven van de patiênt (initiatieven zijn gedefinieerd als het aansnijden van een nieuw onderwerp). De correlaties tussen de vragen en initiatieven van de patiënt en de hoeveelheid voorlichting die gegeven wordt variëren van .23 tot .57. Het aantal vragen dat de patient stelt hangt vooral samen met het geven van uitleg over de diagnose en klachten, terwijl het geven van algemene gezondheidsvoorlichting en psychosociale begeleiding vooral samenhangt met de initiatieven van de patiënt. Een aanzienlijk deel van de verschillen in voorlichting wordt hiermee verklaard. Enerzijds ligt deze relatie voor de hand, wie vraagt krijgt doorgaans antwoord, anderzijds blijkt de relatie ook andersom te liggen: het geven van voorlichting blijkt vaak voor de patiënt de aanleiding te zlijn om verdere vragen te stellen. Bijvoorbeeld uitleg over de diagnose lokt vaak vragen uit als: "Hoe ernstig is dit? Waar komt het door? Kan het genezen? Wordt het erger?" enzovoorts. Concluderend kunner we stellen dat de voorlichting sterk samenhangt met de vragen van de patiënt, vragen die mede uitgelokt worden door de voorlichting die de fysiotherapeut geeft. Voorlichting is dus geen eenrichtingsverkeer, het is een kenmerk van de interactie tussen fysiotherapeut en patiènt.

Er blijkt een zwakke maar significante correlatie te bestaan tussen het geven van voorlichting en de leeftijd van de patiënt: jongere patiënten krijgen meer voorlichting dan oudere patiënten. Ook blijken fysiotherapeuten wat meer informatie over de diagnose en de klachten te geven aan hoog opgeleide patiënten vergeleken met laag opgeleide patiënten. Het enige verschil tussen mannelijke en vrouwelijke patiënten is dat fysiotherapeuten de klachten van vrouwen vaker als psychosociaal beoordelen dan de klachten van mannelijke patiënten. Hoewel significant, is het verband tussen voorlichting en kenmerken van de patiënt veel zwakker dan het verband tussen voorlichting en de vragen en initiatieven van de patiënt.

Op welke wijze verschillen fysiotherapeuten onderling in de voorlichting die zij geven en kunnen deze verschillen verklaard worden door opvattingen ten aanzien van patiëntenvoorlichting? (hoofdstuk 5)

\section{Verschillen in het geven van voorlichting}

Tussen fysiotherapeuten onderling bestaan grote verschillen in het geven van voorlichting. Deze verschillen betreffen alle aspecten van patiëntenvoorlichting maar zijn het grootst ten aanzien van de mate waarin men patiënten psychosociale begeleiding geeft, ten aanzien van algemene gezondheidsvoorlichting en -opvoeding en ten aanzien van de mate waarin men huiswerkinstructies geeft. Bijvoorbeeld, 
sommige fysiotherapeuten besteden veel aandacht aan het bespreken van de relatie tussen stress en klachten, terwijl andere fysiotherapeuten dit zelden of nooit ter sprake brengen. Sommige fysiotherapeuten geven aan bijna elke patient huiswerkoefeningen mee, terwijl andere fysiotherapeuten dat slechts zelden doen. Hetzelfde geldt voor de aandacht die men besteedt aan de percepties en de ideeën van de patiënt. Uit het onderzoek blijkt dat vrouwelijke fysiotherapeuten wat meer psychosociale begeleiding geven dan mannelijke fysiotherapeuten en dat oudere fysiotherapeuten wat meer algemene gezondheidsvoorlichting geven vergeleken met jongere fysiotherapeuten. Deze verschillen zijn echter vrij gering.

\section{Verschillen in opvattingen}

Dezelfde verschillen treft men aan in de opvattingen van fysiotherapeuten over patiëntenvoorlichting. Het meest opvallende verschil is hier de mate waarin men denkt dat patiënten therapietrouw zijn. Gemiddeld schatten de fysiotherapeuten dat $64 \%$ van hun patiënten de opgegeven huiswerkoefeningen ook inderdaad thuis doet en dat $35 \%$ dat niet doet. Over therapietrouw op de lange termijn is men zeer pessimistisch: de fysiotherapeuten schatten dat slechts $23 \%$ van hun patiënten de opgegeven huiswerkcefeningen blijt doen als de behandeling afgelopen is. Sommige fysiotherapeuten denken dat geen enkele patiënt het volhoudt om op de lange termijn te blijven oefenen, terwijl andere fysiotherapeuten van mening zijn dat $50 \%$ van hun patiënten op de lange termijn blijft oefenen. Interessant is dat de compliance die patiënten zelf rapporteren niet duidelijk samenhangt met deze opvattingen van de fysiatherapeuten. Er is geen significante correlatie tussen de mate waarin patiënten zeggen hun huiswerkoefeningen te doen en de pessimistische of optimistische opvattingen die de fysiatherapeut daarover heeft.

Een tweede opvallend verschil betreft de psychosociale begeleiding van de patiënt: $46 \%$ van de fysiotherapeuten acht het geven van psychosociale begeleiding ondergeschikt aan de fysiotherapeutische behandeling terwijl $51 \%$ het een wezenlijk onderdeel van de fysiotherapeutische behandeling acht.

Tot slot blijkt dat $57(68 \%)$ van de 84 fysiotherapeuten problemen ervaren bij het voorlichten van patiênten en $27(32 \%)$ niet. De meest genoemde problemen zijn 'communicatieproblemen' en problemen 'met de patiënt'. Samenvattend blijken de fysiotherapeuten het meest te verschillen in hun opvattingen over compliance en over psychosociale begeleiding terwill daarnaast tweederde wel en eenderde geen problemen heeft met het voorlichten van patiënten.

\section{Verklaring van verschillen}

In zijn algemeenheid is er een vrij zwakke relatie tussen de opvattingen van de fysiotherapeut over patiëntenvoorlichting en de voorlichting die zij daadwerkelijk op de banden geven. Desondanks verklaren deze opvattingen een deel van de verschillen. Het zijn met name de gepercipieerde effecten van voorlichting die significant samenhangen met het geven van voorlichting: fysiotherapeuten die van mening zijn dat de voorlichting die zii geven bijdraagt aan effecten als 'sneller herstel', "betere medewerking van de patiënt', "kostenvermindering in de gezondheidszorg' etcetera, 
besteden meer aandacht aan het geven van voorlichting dan fysiotherapeuten die dergelike effecten niet verwachten. Daarnaast blijkt dat fysiotherapeuten die optimistisch zijn over de compliance van patiënten meer instructies aangaandle de huiswerkoefeningen geven dan fysiotherapeuten die daar pessimistisch over zijn.

Een tweede verklaring voor de verschillen vormen factoren met betrekking tot de werksetting van de fysiotherapeuten. Er is een duidelijk verband tussen de tijd die men aan de patiënt besteedt (gemeten als de tijd die men in elkaars aanwezigheid doorbrengt) en de hoeveelheid voorlichting die men geeft. Hier stuiten we op het bekende kip-ei probleem omdat we niet weten wat wat veroorzaakt: besteedt men meer tijd om meer voorlichting te kunnen geven, of geeft men meer voorlichting omdat men meer tijd besteedt? Een interessante bevinding is het feit dat de psychosociale begeleiding die de fysiotherapeut geeft niet samenhangt met de tijdsduur van de zitting. Dit is tegengesteld aan de situatie in de huisartsgeneeskunde. In de huisartsgeneeskunde hangt het geven van psychosociale begeleiding doorgaans sterk samen met de tijdsduur van het consult. Waarschijnlijk wordt het ontbreken van deze samenhang in de fysiatherapie veroorzaakt door het feit dat psychosociale begeleiding vaak wordt gegeven tijdens massage. Hierdoor hoeft men weinig extra tijd te investeren omdat men twee zaken combineert.

Er is een significante samenhang tussen de kwaliteitsaspecten en werksettingfactoren: Ten eerste blijkt de relatie tussen fysiotherapeut en patiënt beter te zijn als de fysiotherapeut meer tijd aan de patiënt besteedt, clat wil zeggen meer tijd in aanwezigheid van de patiënt doorbrengt. Ten tweede blijkt de lengte van de werkweek van invloed: naarmate men langer werkt wordt in verhouding minder vaak naar de ideeën en wensen van de patiënten gevraagd. Misschien dat vermoeidheid of tijdsdruk hierbij een rol speelt. Ten derde blijkt dat fysiotherapeuten die werkzaam zijn in gezondheidscentra meer Methodisch Werken en vaker naar de ideeën en wensen van de patiënt vragen vergeleken met de overige fysiotherapeuten.

Samenvattend kan geconcludeerd worden dat de verschillen tussen fysiotherapeuten in de kwantiteit en de kwaliteit van de voorlichting voor een deel verklaard worden door de effecten die men ervan verwacht en door factoren met betrekking tot de werksetting.

\section{Wat is de omvang van non-compliance in de fysiotherapie en welke factoren hangen samen met non-compliance? (hoofdstuk 6).}

\section{Compliance met huiswerkoefeningen}

In de patiëntenenquête geeft $22 \%$ van de patiënten aan de opgegeven huiswerkaefeningen niet of nauwelijks te doen terwijl $35 \%$ van de patiënten zegt 'zeer regelmatig' te oefenen. De overige $41 \%$ van de patiènten ligt daar tussenin en zegt de oefeningen 'vrij regelmatig' te doen. Deze groep kan beschouwd worden als gedeeltelijk compliant. Compliance met huiswerkoefeningen is dus niet een zaak van alles of niets maar kent gradaties. Geconcludeerd kan worden dat - net als in de medische 
praktijk - non-compliance een probleem is in de fysiotherapeutische praktijk. Hierbij moet opgemerkt worden dat het hier gaat om "korte termijn compliance" dat wil zeggen, compliance gedurende de periode dat de patient in behandeling is.

\section{Verschillen tussen patiënten}

Uit de analyses blijkt dat er geen verschil in compliance is tussen mannen en vrouwen. Er is wel een relatie met de leeftijd en het opleidingsniveau van de patiênt. Ten eerste blijkt dat oudere patiënten vaker oefenen dan jongere patiènten. Een tweede bevinding is dat hoger opgeleide patiënten minder therapietrouw zijn dan patiënten met een lagere opleiding: vooral hoog opgeleide vrouwen jonger dan 45 jaar geven aan minder vaak te oefenen dan laag opgeleide vrouwen in dezelfde leeftijdsgroep. Samenvattend komt non-compliance vaker voor bij jongere en hoog opgeleide patiënten.

\section{Verschillen tussen klachten}

Het type klacht blijkt niet duidelijk samen te hangen met compliance of noncompliance: er is bijvoorbeeld geen significant verschil tussen patiënten met rugklachten en patiënten met nek/schouder klachten.

De kenmerken van de klachten daarentegen hangen wel significant samen met compliance: naarmate patiënten meer hinder en belemmeringen van de klachten ondervinden zijn zij meer therapietrouw. Dit verband - dat vaker wordt gevonden - is begrijpelijk omdat het overkómen van de belemmeringen motiverend kan werken. Het omgekeerde geldt voor de chroniciteil van de klachten. Uit de resultaten blijkt dat patiënten met chronische klachten, dat wil zeggen, patiënten die denken dat hun klachten niet meer over zullen gaan, minder vaak oefenen dan patiënten die denken dat hun klachten weer verdwijnen. Ook dit resultaat vindt men in de compliance literatuur terug. Concluderend is het niet de aard van de klacht op zich die samenhangt met compliance maar de hinder en de chroniciteit van de klachten.

\section{Verklaringen voor non-compliance}

Drie factoren vormen de belangrijkste verklaring voor non-compliance: de barrières die patiènten ervaren, het ontbreken van positieve feedback, en het gevoel van 'hulpeloosheid'. Met deze drie factoren kan men in $86 \%$ van de gevallen correct voorspellen of patiënten hun huiswerkoefeningen al dan niet doen.

Verreweg de belangrijkste factor wordt gevormal door de 'barrières' die patiënten ervaren, dat wil zeggen de problemen die patiënten tegenkomen in hun pogingen de instructies van de fysiotherapeut op te volgen. De barrières of problemen die patiënten het meest frequent noemen zijn: gebrek aan tijd, het feit dat de oefeningen niet passen in de dagelijkse routines, het feit dat oefenen pijn veroorzaakt, het feit dat men vergeet te oefenen, en, gebrek aan motivatie om te oefenen. In feite kan men in deze problemen twee dimensies onderscheiden: enerzijds zijn er motivationele problemen en anderzijds zijn er situationele problemen, dat wil zeggen de omstandigheden belemmeren het regelmatig doen van oefeningen.

Een tweede verklaring voor non-compliance is het ontbreken van positieve feedback. De waardering die de fysiotherapeut toont voor de inspanningen die de patiënt zich 
getroost hangt positief samen met compliance: patiënten die zeggen dalt de fysiotherapeut tevreden is over de oefeningen die zij thuis doen zijn meer compliant zijn dan patiênten die aangeven dat zij niet weten of de fysiotherapeut hun inspanningen waardeert of aangeven dat de fysiotherapeut niet tevreden is. Dit is conform de algemene compliance literatuur waarin het geven van positieve feedback doorgaans significant samenhangt met compliance.

Als derde factor tenslotte blijkt dat patiënten minder oefenen als zij van mening zijn dat oefenen niet zal helpen. Deze relatie ligt voor de hand. De vraag is alleen of men dénkt dat oefenen niet zal helpen of dat men erváren heeft dat oefenen niet helpt.

Samenvattend blijken de barrières die patiënten ervaren de belangrijkste 'oorzaak' van non-compliance te zijn, terwijl daarnaast het gebrek aan positieve feedback en 'hulpeloosheid' een rol spelen.

\section{Conclusies en aanbevelingen}

Conclusies en aanbevelingen ten aanzien van de praktijk van de voorlichting in de fysiotherapie

Het onderzoek heeft duidelijk aangetoond dat voorlichting een wezenlijk onderdeel van elke fysiotherapeutische behandeling is. In de meerderheid van de zittingen wordt aandacht besteed aan voorlichting over de klachten, aan huiswerkinstructies en aan curatieve en/of preventieve adviezen. De wisselwerking tussen het geven van voorlichting en de vragen en initiatieven van de patiënt impliceert dat de communicatie tussen fysiotherapeut en patiënt van het grootste bellang is.

Twee voorlichtingsactiviteiten komen minder vaak voor: algemene gezondheidsvoorlichting en -opvoeding en psychosociale begeleiding. Algemene gezondheidsvoorlichting vindt vaak plaats op initiatief van de patiënt. Wij leiden thieruit af dat patiënten dergelijke voorlichting op prijs stellen. In feite hebben fysiotherapeuten hiermee een goede gelegenheid om hun preventieve taken uit te breiden. Het is daarbij belangrijk om standaarden of richtlijnen te ontwikkelen voor algemene gezondheidsvoorlichting in de fysiotherapie temeer daar patiënten ook vragen stellen die buiten de deskundigheid van de fysiotherapeut vallen. Door middel van dergellijke standaarden kunnen de fysiotherapeutische taken op het gebied van algemene gezondheidsvoorlichting en -opvoeding nader worden gedefinieerd.

Op grond van de resultaten concluderen we dat er onduidelijkheid bestaat over de taken ten aanzien van de psychosociale begeleiding van patiënten. De helft van de fysiotherapeuten acht dit een essentieel onderdeel van de fysiotherapeutische behandeling, terwijl de andere helft van mening is dat het een ondergeschikt aspect van de behandeling is. Ook in de praktijk blijken verschillen: hoewel psychosociale begeleiding vaker wordt gegeven naarmate de fysiotherapeut de klachten van de patiënt meer psychosociaal van aard vindt, blijkt ook dat bij de helft van de patiënten met psychosociale klachten geen gesprek over depsychosociale aspecten plaatsvindt. Op grond van deze bevindingen lijkt het belangrijk de indicaties voor psychosociale 
begeleiding en de taken op dit gebied concreter te definiëren.

Uit het onderzoek blijkt dat in de fysiotherapie nog weinig gebruikt wordt gemaakt van algemene voorlichtingskundige principes en van strategieên om de therapietrouw van patiënten te vergroten. Dit biedt de mogelijkheid de kwaliteit van de voorlichting in de fysiotherapie te verhogen, mits men het een taak acht om therapietrouw van patiënten te stimuleren. In het onderzoek is dit laatste niet gemeten maar uit gesprekken met fysiotherapeuten blijkt dat men van mening verschilt over de mate waarin ffysiotherapeuten mede-verantwoordelijk zijn voor de therapietrouw van patiènten. Het kan zijn dat deze verschillen bijgedragen hebben aan de grote verschillen tussen fysiotherapeuten in hun opvattingen over compliance. Dit vereist nader onderzoek. Als men zich als fysiotherapeut echter medeverantwoordelijk acht voor de therapietrouw van patiënten, dan bieden de resultaten van het onderzoek aanknopingspunten voor verbetering van de voorlichting. Het lijkt daarbij belangrijk om prioriteit te geven aan de volgende drie zaken: het werken aan de hand van een voorlichtingsplan, het oplossen van compliance problemen en, het toepassen van 'compliance verhogende strategieën'. We lichten ze achtereenvolgens toe.

Ten eerste, is het belangri.jk dat fysiotherapeuten een voorlichtingsplan maken parallel aan en geïntegreerd in het behandelplan, zodat de voorlichting op een evenwichtige manier over de behandeling uitgespreid kan worden. Uit het onderzoek blijkt dat de voorlichting afneemt naarmate de patiënt langer in behandeling is en dat in de tweede fase van de behandeling minder aandacht aan de huiswerkoefeningen wordt besteed. Dit biedt de mogelijkheid om - nadat de oefeningen aangeleerd zijn in de eerste fase van de behandeling - de aandacht in de tweede fase van de behandeling expliciet te richten op de compliance van de patiënt. Beide aspecten kunnen in het voorlichtingsplan opgenomen worden. Daarnaast ligt het voor de hand om het voorlichtingsplan op te bouwen volgens de logische volgorde van de instructies en adviezen in de fysiotherapie: palliatieve, curatieve en preventieve maatregelen. Een dergelijke systematische en rationele planning van de voorlichting maakt het gemakkelijker om aan alle voorlichtingsaspecten aandacht te besteden, maakt het mogelijk de voor lichting evenwichtig over alle zittingen te spreiden zodat de gehele behandelperiode optimaal benut wordt en vergemakkelijkt de evaluatie van de voorlichting.

Ten tweede, de belangrijkste verklaring voor non-compliance zijn de barrières en problemen die patiënten ervaren. Het voorkómen en oplassen van deze problemen lijkt van het grootste belang. Twee zaken verdienen daarbij de aandacht. Ten eerste kan men proberen dergelijke problemen te voorkómen door het principe van "tailoring" toe te passen. Dit houdt in dat de oefeningen en adviezen aangepast worden aan de specifieke situatie van de patiènt of ingepast worden in zijn of haar dagelijkse routines. Het betekent dat samen met de patiënt gekeken wordt welke mogelijkheden hij of zij heeft om te oefenen en dat het oefenprogramma zo goed mogelijk aan deze situatie wordt aangepast. Vervolgens kan geprobeerd worden de oefeningen zoveel mogelijk te koppelen aan andere routines die ook dagelijks verricht worden zodat de patiënt 
eraan herinnerd wordt. Bijvoorbeeld houdingscorrecties doen in de bus naar het werk of steeds als de telefoon gaat. Nek/schouderoefeningen doen na het douchen of bij het luisteren naar favoriete muziek enzovoorts. Dit principe van tailoring kan voorkómen dat maatregelen worden voorgeschreven die in de situatie van de patiënt niet haalbaar zijn en vergemakkelijkt gewoontevorming.

Daarnaast zal regelmatig met de patiënt besproken moeten worden weike overige problemen hij of zij tegenkomt. Zorgvuldig uitvragen is daarbij nodig omdat de problemen aanzienlijk verschillen per patiënt. Samen met de patiënt kan vervolgens gezocht worden naar alternatieven of oplossingen. In feite betekent dit dat men de voorschriften steeds beziet vanuit de situatie van de patiënt.

Samenvattend is thet belangrijk de voorschriften aan te passen aan de specifieke situatie van de patiënt en samen met de patiënt te zoeken naar alternatieven of oplossingen voor compliance problemen.

Ten derde, uit het onderzoek blijkt dat "positieve feedback" significant samenhangt met compliance. Fysiotherapeuten kunnen dit benutten om de therapietrouw van patiënten te stimuleren. Men kan bijvoorbeeld elke vooruitgang zichtbaar maken of benadrukken en waardering tonen voor de inspanningen die de patiënt zich getroost. Dit vereist een positieve instelling van de fysiotherapeut; kijkt naar wat wél gelukt is en zich niet blind staart op wat (nog) niet gelukt is.

Het feit dat positieve feedback en tailoring in zijn algemeenheid therapietrouw verhogen, is theoretisch verklaarbaar (hoofdstuk 7). In feite gebruikt men dan de twee belangrijkste principes uit de leertheorieën namelijk het vinden van geheugensteuntjes die aan het gedrag herinneren (cues en reminders) en zorgen dat het gedrag positieve consequenties heeft (reinforcements) om het gedrag te stimuleren. Deze aanpak blijkt in zijn algemeenheid effectief op de korte termijn, gedurende de periode dat de patiënt in behandeling is.

Therapietrouw op de lange termijn, nadat de behandeling afgelopen is, is over het algemeen veel moeilijker te realiseren, zo blijkt uit onderzoek. De zelfregulatietheorie van Leventhai biedt aanknopingspunten voor het stimuleren voor therapietrouw op de lange termijn. Het lijkt belangrijk te onderzoeken op welke wijze deze theorie in de fysiotherapie benut zou kunnen worden. Een eerste aanzet daartoe is in hoofdstuk 7 te vinden.

Het toepassen van strategieën om de therapietrouw van patiënten te stimuleren heeft consequenties voor de traditionele opbouw van de fysiotherapiebehandeling, waarbij patiënten doorgaans twee keer per week gezien worden. Omdat supervisie zo'n belangrijke rol speelt in compliance kan het nuttig zijn de zittingen over een langere tijd uit te spreiden. Patiënten hebben dan meer gelegentheid om te experimenteren met de gekregen adviezen waardoor ook de problemen beter zichtbaar worden. Ook kan het nodig zijn follow-up contacten in te lassen ter ondersteuning van de patiênt of een aantal zittingen toe te voegen, speciaal gericht op preventie. Samenvattend is het belangrijk dat fysiotherapeuten onderzoeken in welke situaties het zinvol is de behandeling over langere tijd uit te spreiden om op die wijze de therapietrouw van 
Tot slot. Het ligt voor de hand dat therapietrouw van patiënten kan bijdragen aan de effecten van de fysiotherapeutische behandeling. Op grond daarvan is het belangrijk de hiervoor genoemde voorlichtingskundige principes in de opleiding te integreren. De psychologie- en communicatievakken bieden daartoe gelegenheid maar expliciete training van deze vaardigheden in de praktijklessen verhoogt de kans dat ze inderdaad in de praktijk gebruikt worden. Uit dat oogpunt kan het relevant zijn dat de praktijk-en stagedocenten zich deze vaardigheden eigen maken omdat $z$ il' als 'model' fungeren voor de aankomende fysiotherapeuten.

Daarnaast lijkt het belangrijk om voorlichtingsprincipes te integreren in de reguliere na- en bijscholingscursussen voor fysiotherapeuten. Dit lijkt effectiever dan het ontwerpen van speciale voorlichtingscursussen, ten eerste omdat voorlichting onlosmakelijk met de behandeling verweven is en ten tweede omdat gebleken is dat fysiotherapeuten tot nu toe althans weinig belangstelling hebben voor specifieke cursussen patiëntenvoorlichting. Tot slat kan men in onderlinge toetsing ervaringen uitwisselen over de strategieën die men gebruikt om therapietrouw te stimuleren en vooral ervaringen uitwisselen aangaande de oplossingen die men heeft gevonden voor de problemen van de patiënt. Deze reeks maatregelen kunnen in belangrijke mate bijdragen aan de kwaliteit van de voorlichting in de fysiotherapie.

\section{Conclusies en aanbevelingen met betrekking tot theoretische of wetenschappelijke aspecten}

Op grond van theoretische en praktische overwegingen is het belangrijk om de verschillende soorten therapietrouw nader te analyseren en te definiëren. Het gebruikelijke onderscheid in korte- en lange-termijn compliance - alleen gedefinieerd als tijdsperiode - houdt geen rekening met een essentieel element in compliance namelijk de aan- of afwezigheid van supervisie. Dit geeft verwarring omdat bijvoorbeeld een compliance-periode van 3 maanden terwijl een interventie nog voortduurt wezenlijk verschilt van eenzelfde periode na afloop van de interventie. Deze verwarring kan hebben bijgedragen aan de vaak tegenstrijdige resultaten in compliance onderzoek. Het lijkt daarom belangrijk om in de fysiotherapie een onderscheid te maken in 'gesuperviseerde korte-termijn compliance' (gedurende de behandelperiode) en 'ongesuperviseerde lange-termijn compliance' (na afioop van de behandeling). Dit onderscheid draagt bij aan de vergelijkbaarheid van onderzoeksgegevens en heeft bovendien theoretisch en praktische consequenties voor de voorlichting in de fysiotherapie.

Bij korte-termijn compliance tijdens de behandeling kan de fysiotherapeut de principes uit de leertheorieën gebruiken om de therapietrouw van patiênten te stimuleren. Het vinden van cues of reminders die aan het gedrag herinneren en het zorgen voor positieve feedback zijn daarbij essentieel. Deze invloed van de fysiotherapeut is afwezig bij lange-termijn compliance, na afloop van de behandeling.

Bij lange termijn compliance lijkt de Zelfregulatietheorie van Leventhal beter geschikt, omdat deze theorie ernaar streeft de patiënt meer controle over eigen gedrag te geven 
en het vertrouwen in de eigen mogelijkheden te vergroten. De theorie gaat ervan uit: dat de wijze waarop mensen met hun klachten omgaan bepaald wordt door a) de percepties van de klachten, b) de gedragsmogelijkheden en c) de wijze waarop de uitkomsten van het gedrag beoordeeld worden. De hulpverlener zou zaveel mogelijk op deze drie aspecten in moeten spelen. Dit betekent bijvoorbeeld zo goed mogelijk aansluiten bi] de percepties van de patiènt en deze percepties corrigeren als ze uit medisch oogpunt onjuist zijn. Daarnaast zal de patiënt geleerd moeten worden om allerlei adviezen over het omgaan met de klachten te vertalen naar nieuwe toekomstige situaties. Dit vereist dat men een goed inzicht krijgt in de principes die aan de adviezen ten grondslag liggen. Tot slot moet de patiênt een middel in handen krijgen om te beoordelen of zi.jn/haar gedrag het beoogde resultaat heeft. Men leert dus de uitkomsten van het gedrag op een adequate wijze te beoordelen. Het lijkt belangrijk de toepassingsmogelijkheden van dit model in de fysiotherapie op experimentele wijze te toetsen.

In het verlengde van bovengenoemd onderscheid tussen korte- en lange termijncompliance ligt het verschil tussen compliance met curatieve maatregelen versus compliance met preventieve maatregelen. Behalve het verschil in supervisie hebben curatieve maatregelen een aantal kenmerken die afwezig zijn bij preventieve maatregelen. Curatieve maatregelen zijn gericht op herstel in de kortst mogelijke tijd en dit biedt fysiotherapeut en patiënt de mogelijkheid te evalueren of het doel bereikt is (afwezigheid van symptomen). De symptomen functioneren vaak als cues die aan oefeningen of adviezen herinneren en daarnaast kan het verwachte herstel een sterke motivatie zijn voor therapietrouw. Deze factoren zijn afwezig bij preventieve maatregelen. Vaak moeten deze blijvend volgehouden worden en of het doel bereikt wordt is moeilijk te evalueren: symptomen kunnen terugkeren ondanks preventieve maatregelen en het is moeilijk vast te stellen of het uitblijven van symptomen inderdaad door de preventieve maatregelen bewerkstelligd is. Daarnaast ontbreekt bij preventie de motiverende factor van herstel en zijn er geen symptomen die aan het gedrag herinneren. Deze factoren bemoeilijken therapietrouw met preventieve maatregelen. Concluderend kunnen we stellen dat het analyseren van de verschillende soorten compliance kan bijdragen aan een beter begrip van de verschillen in compliance en bovendien zicht geeft op de theoretische en praktische consequenties die uit de verschillen voortvloeien.

\section{Verder onderzoek}

Naar onze mening verdienen drie onderzoeksthema's prioriteit in verder onderzoek: 1) onderzoek naar de effecten van therapietrouw stimulerende strategieën, 2) het ontwikkelen van instrumenten om therapietrouw te meten, 3) het nader analyseren van de betekenis van therapietrouw-problemen. We lichten ze kort toe.

Ten eerste, onderzoek naar de effecten van maatregelen die therapietrouw van patiënten kunnen vergemakkelijken of stimuleren heeft grote relevantie voor de fysiotherapiepraktijk. Daarbij is het niet alleen belangrijk om te onderzoeken óf 
bepaalde strategieën effect hebben maar ook, welke strategieën effectief zijn bij verschillende soorten compliance. Bijvoorbeeld bij compliance tijdens versus ha de behandeling, compliance bij curatieve versus preventieve maatregelen, compliance met huiswerkoefeningen versus diverse soorten adviezen, enzovoorts. Dergeijk onderzoek is theoretische relevant en kan bijdragen aan de effecten van het fysiotherapeutisch handelen.

Ten tweede, onderzoek naar de effecten van de voorlichting vereist de ontwikkeling van betrouwbare meetinstrumenten om de therapietrouw van patiënten vast te stellen. In het huidige onderzoek is een tamelijk globale indicatie voor therapietrouw gebruikt. Als men echter effecten van verschillende strategieën wil gaan vergelijken, is een meer gedetailleerde meting nodig, die zicht geeft op de verschillende gradaties in therapietrouw. Dit is niet eenvoudig, vooral niet ten aanzien van de adviezen die patiënten krijgen. Ten eerste worden adviezen verspreid over de gehele behandelperiode gegeven en ten tweede zijn ze divers van karakter (palliatief, curatief, preventief). Daarnaast moet rekening gehouden worden met het feit dat 'handelen in de geest van de adviezen' even belangrijk kan zijn als het 'letterlijk opvolgen van de adviezen'. Hoewel deze complexiteit het moeilijk maakt om therapietrouw te meten is dit nodig om vast te kunnen stellen welke wijze van voorlichten het meest effect heeft. Bovendien draagt het meten (en registreren) van therapietrouw bij aan de fysiotherapeutische kennis van oefentherapie op zich. Effectonderzoek toont niet altijd eenduidige resultaten maar het is vooralsnog onduidelijk in hoeverre de mate van therapietrouw daarin een rol speelt. Het op een uniforme wijze vaststellen van de therapietrouw van patiënten maakt onderzoek beter vergelijkbaar en draagt bij aan de fysiotherapeutische kennis over de effecten van oefentherapie.

Ten derde is nader onderzoek nodig naar de barrières en problemen die patiënten ervaren. Zij zijn de voornaamste verklaring voor non-compliance en dit maakt het belangrijk om meer inzicht te krijgen in de wijze waarop deze barrières en problemen therapietrouw belemmeren. Behalve hetpraktische belang voor de fysiotherapiepraktijk is dit onderzoek theoretisch relevant omdat 'barrières' in veel theorieën een rol spelen. Uit ons onderzoek blijkt dat het globale begrip 'barrières' verschillende vormen en betekenissen kan hebben. Ten eerste zijn er grote verschillen in het soort barrières dat patiënten ondervinden: er zijn motivationele problemen en situatie gebonden problemen (de omstandigheden maken het onmogelijk de adviezen op te volgen). Daarnaast is er het probleem van de gedragsverandering zelf, dat will zeggen de moeilijkheid om een gewoonte af te leren of een leetstijl te veranderen. Ten tweede, is er het verschil tussen 'gepercipieerde barrières' en 'werkelijk ondervonden barrières': wordt therapietrouw vooral beïnvloed door de ideeën van de patiënt of door diens concrete ervaringen en wat betekent dat voor de wijze waarop therapietrouw beïnvloed kan worden? Samenvattend kunnen we concluderen dat het praktische en theoretische relevantie heeft om meer inzicht te krijgen in de problemen die patiënten ervaren bij hun pogingen de gegeven voorschriften op te volgen. 


\section{Literature}

\section{Agresti A.}

Analysis of ordinal categorical data.

New York, etc.: John Wiley \& Sons, 1984.

Atkins C., Kaplan PM, Timms AM, Reinsch S, Lofback K.

Behavioral exercise programs in the management of chronic obstructive pulmonary disease.

Journal of Consulting Clinical Psychology 52; 1984, 4:591-603.

\section{Bandura $\mathrm{A}$.}

Self-efficacy: toward a unifying theory of behavior change.

Psychological Review 84; 1977, 2: 191-215.

\section{Bartlett EE.}

At last, a definition (editorial).

Patient Education and Counseling 7; 1985, 4: 323-324.

\section{Bartlett EE.}

Behavioral diagnosis: a practical approach to patient education.

Patient Counselling and Health Education 4; 1982, 1: 29-35.

\section{Bartlett EE.}

The contributions of behavioral science to patient education practice: a review. In: Ruffini $\mathrm{JL}$ (ed.). Advances in medical social science. Vol 2.

New York: Gordon and Breach Science Publishers, 1984: 1-43.

\section{Bartlett EE}

Eight principles from patient education research.

Preventive Medicine 14; 1985: 667-669.

Bartlett EE, Higginbotham JC, Cohen-Cole S, Bird J.

How do primary care residents manage patlent non-adherence?

Patient Education and Counseling 16; 1990, 1: 53-60.

\section{Bartlett EE.}

The medical and educational models of health care under prospective pricing.

Patient Education and Counseling 6; 1984, 2: 57-61.

\section{Bartlett EE}

Two year update.

Patient Education and Counseling 9; 1987, 1:1-3.

\section{Becker MH.}

Patient adherence to prescribed therapies.

Medical Care 23; 1985, 5: 539-555.

\section{Beekman CE, Axtell L.}

Ambulation, activity level and pain, outcomes of a program for spinal pain.

Physical Therapy $65 ; 1985,11: 1649-1657$. 
Belcon MC, Haynes RB, Tugwell P.

A critical review of compliance studies in rheumatoid arthritis.

Arthritis and Rheumatism 27;1984, $11: 1227-1233$.

Bensing JM.

Doctor-Patient communication and the quality of care: an observationall study of instrumental and affective behavior into general practice.

Utrecht: Nivel, 1991. Dissertation.

Beroepsomschiljwing fysiotherapeut. (Nocational requirements in physical therapy)

Fysiovisie 2: $1986,2: 2-6$

Bertels M. Brummelen $L$ ten, Dijkum CJ van, et al.

Tijd voor kwaliteit: evaluatie-onderzoek fysiotherapie in gezondheidscentra in Amsterdam. (Time for quality: evaluative research physical therapy in health centres.)

Amsterdam: Stichting Universitail Instituut voor Sociaal Wetenschappelijk Onderzoek/Onderzoeksplatform in de Eerstelijirs Dienstvertening in Amsterdam, 1985.

Berwick DM, Budman S, Feldstein $M$.

No clinical effect of back schools in an HMO: a randomized prospective trial.

Spine $14 ; 1989$, 3: 338-344.

Blackwell B.

Counselling and compliance.

Patient Counselling and Health Education $1 ; 1978,2: 45-49$.

Boczkowski JA, Zelchner A.

Medication compliance and the elderly.

Clinical Gerontologist $4 ; 1985,1: 3-15$.

Bouchard C, Shephard RJ, Stephens T, Sutton JR, McPherson BD (eds.)

Exercise, fitness and health. A consensus of current knowledge.

Champaign: Human Kinetics Books, 1988.

Cairns D, Thomas L, Mooney V, Blair Pace J.

A comprehensive treatment approach to chronic low back pain.

Pain 2; 1976: 301-308.

Cameron R, Best JA.

Promoting adherence to health behavior change interventions: recent findings from behavioral research.

Patient Education and Counseling 10; 1987، 2: 139-154.

Campen C van, Sluijs EM.

Patlent compllance: a survey of reviews (1979-1989).

Utrecht:" Nivel, 1989. NIVEL-Bibliographies, 38.

Carter WB, Inul TS, Kukull WA, Haigh VH.

Outcome-based doctor-patient interaction analysis (II) : identifying effective provider and patient behavior.

Medical Care 20; $1982,6: 550-566$.

Gohen DI, Littenberg B, Wetzel C, Neuhauser DvB.

Improving physician compllance with preventive medicine guidelines.

Medical Care 20; 1982, 10: 1040-1045.

Cohen SJ.

New metaphors for old problems. In: Cohen SJ (ed.). New directions in patient compliance.

Toronto etc., s.n.: 1979: 153-163.

Chroft Ju,

Interviewing in physical therapy.

Physical Therapy 60" 1980, 8: 1033-1036. 
Curts EC Kerssens JJ.

Fysiotheraple in de Nederlandse Gezondheidszorg (Physical Therapy in the Netherlands).
ln press.

Curfs EC, Groenewegen PP.

Physiotherapy in the Netherlands: an overview.

Physiotherapy Practice 2; 1986: 132-137.

Czerniawski L.

Exercise therapy: the role of physical therapy. In: Stanton-Hicks M, Boas RA (eds). Chronic low back pain.

New York: Raven Press, 1982.

Deyo RA.

Compliance with therapeutic regimens in arthritis: issues, current status, and a future agenda.

Seminars in Arthritis and Rheumatism 12; 1982, 2: 233-244.

Deyo RA, Tsui-Wu YJ.

Descriptive epidemiology of low-back pain and its related medical care in the United States.

Spine 12; 1987, 3: 264-268.

Dickson DA, Maxwell, $M$

The interpersonal dimension of physlotherapy: implications for training.

Physiotherapy $71 ; 1985,7: 306-310$.

DiMatteo MR, DiNicola DD.

Achieving patient compliance: the psychology of the medical practitioner's role.

New York: Pergamon Press, 1982.

Dishuman RK.

Compliance/Adherence in health-related exercise.

Health Psychology 1; 1982, 3: 237-267.

Dishman RK.

Epllogue and future directions. In: Dishman RK (ed.). Exercise adherence: Its Impact on public health.

Champaign: Human Kinetics Books, 1988: 417-426.

Dishman RK, Dunn AL.

Exercise adherence in children and youth: implications for adjulthood. In: Dishman RK (ed.). Exercise adherence: its impact on public health.

Champaign: Human Kinetics Books, 1988: 155-200.

Dishman RKK.

Exercise adherence: its impact on public health.

Champalgn: Human Kinetics Books, 1988.

Dolan-Mullen PD, Green LW. Persinger GS.

Clinical trials of patient education for chronic conditions: a comparative meta-analysis of intervention types.

Preventive Medicine 14: 1985: 753-781.

Dubbert PM, Martin JE, Epstein LH.

Exercise. In: Holroyd KA, Creer TL (eds.). Self-management of chronic dlisease: handbook of clinical interventions and research.

Orlando, etc.: Academic Press, 1986: $127-161$.

Dunbar JM, Marshall GD, Hovell MF.

Bellawioral strategies for improving compliance. In: Haynes RB, Taylor DW, Sackett DL (eds.). Compliance in health care.

Baltimore, etc. The Johns. Hopkins University Press, 1979: 174-190.

Epstein LH, Cluss PA.

A behavioral medicine perspective on adherence to long-term medical regimens.

Journal of Consulting and Clinical Psychology 50; 1982, 6; $950-971$. 
Evans $C$, Gilbert ،R, Taylor W, Hildebrand A.

A randomized controlled trial of flexion exercises, education, and bed rest for patients with acute low back pain.

Physiotherapy Canada 39; 1987, 2: 96-101.

Falvo $D$, Woehike P, Deichmann J.

Relationship of physician behavior to patient compliance.

Patient Counseling and Health Education 2; 1980, 4: 185-188.

Feinberg $J$.

The effect of patient-practitioner interaction on compliance: a review of the literature and application in rheumatoid arthritis.

Patient Education and Counseling 11; 1988, 3: 171-187.

Feinstein AR,

"Compliance blas" and the interpretation of therapeutic trials. In: Haynes RB, Taylor DW, Sackett DL (eds.). Compliance in health care.

Baltimore, etc.: The Johns Hopkins University Press, 1979: 309-322.

Ferguson K, Bole GG.

Family support, health beliefs, and therapeutic compliance in patients with rheumatoid arthritis.

Patient Counselling and Health Education 1; 1979, 3: 101-105.

Ford AS, Ford WS.

Health education and the primary care physician: the practitioner's perspective.

Social Science and Medicine 17; 1983, 20: 1505-1512.

Freeman SH.

Health Promotion talk in family practice encounters.

Social Science and Medicine 25; 1987, 8: 961-966.

Gerber KE.

Compllance in the chronically ill: an introduction to the problem. In: Gerber KE, Nehemkis AM (eds.).

Compllance: the dilemma of the chronically ill.

New York: Springer Publishing Company, 1986: 12-23.

Gillum RF, Barsky AJ.

Diagnosis and management of patient noncompliance.

Journal of American Medical Association 228: 1974, 12: 1563-1567.

Glynn Owen OG, Goodge P.

Physiotherapists talking to patients.

Patient Counselling and Health Education $3 ; 1981,3$ : 100-102.

Gordis L.

Conceptual and methodologic problems in measuring patient compliance. In: Haynes RB, Taylor DW, Sackett DL (eds.). Compliance in health care.

Baltimore $e_{1}$ etc: The Johns Hopkins University Press, 1979: 23-45.

Green CA.

What can patient health education coordinators learn from ten years of compliance research?

Patient Education and Counselling 10; 1987, 2: 167-174.

Green LW.

Educational strategies to improve compliance with therapeutic and preventive regimens: the recent evidence. In: Haynes RB, Taylor DW, Sackett DL (eds.). Compliance in health care

Baltimore, etc.: The Johns Hopkins University Press, 1979: 157-173.

Green LW.

What is quality in patlent education and how do we assess it? Im: Squyres WD (ed.). Patient education. Now York: Springer Publishing Company, 1980: 137-156. 


\section{Groenewegen PP.}

Fysiotherapeut. (The physical therapist) In: Overzichtsstudie onderzoek eerstelijn. Slutis EM; Dopheide JP, Zee J van der (eds.).

Utrecht: Nivel, 1985: 145-175.

Hall JA, Roter DL, Katz NR.

Meta-analysis of correlates of provider behavior in medical encounters.

Medical Care 26; 1988, 7: 657-672.

Hamilton-Duckett $P$, Kidd $L$.

Counselling skills and the physiotherapist.

Physiotherapy $71 ; 1985,4: 179-180$.

Hanson RW.

Physician-patient communication and compliance. In: Gerber KE, Nehemkis AM (eds). Compltance: the dilemma of the chronically ill.

New York: Springer Publishing Company, 1986: 182-212.

Härkäpää $K$, Järvikoski $A_{1}$ Mellin $G_{n}$ Hurri $H$.

A controlled study on the outcome of inpatient and outpatient treatment of low back pain. Part I. Pain, disability, compliance, and reported treatment benefits three months after treatment.

Scandinavian Journal of Rehabilitation Medicine 21; 1989: 81-89.

Hayne CR.

The preventive role of physiotherapy in the National Health Service and industry.

Physiotherapy $74 ; 1988,1: 2-3$.

Haynes RB, Taylor DW. Sackett DL (eds.).

Compliance in health care.

Baltimore, etc.: The Johns Hopkins University Press, 1979.

Haynes RB.

Determinants of compliance: the disease and the mechanics of treatment. In: Hayres RB, Taylor DW,

Sackett DL (eds.). Compliance in health care.

Baltimore, etc.: The Johns Hopkins University Press, 1979: 49-62.

Haynes RB.

Patient compliance then and now.

Patient Education and Counseling 10; 1987, 2: 103-105.

Haynes RB, Wang $E_{*}$ Da Mota Gomes $M$.

A critical review of interventions to improve compliance with prescribed medications.

Patient Education and Counseling 10; 1987, 3: 155-166.

Heiby EM, Carlison JG.

The health compliance model.

The Journal of Compliance in Health Care 1; 1986, 2: 135-152.

Hooper EM, Comstock LM, Goodwin JM, Goodwin JS.

Patient characteristics that influence physican behawior.

Medical Care 20; 1982, 6: 630-638.

Horowitz MM, Byrd JC, Gruchow HW.

Attitudes of faculty members, residents, students, and community physicians toward health promotion. Journal of Medical Education 62; 1987, 11: $931-934$.

Hough A.

Communication in health care.

Physiotherapy $73 ; 1987,2: 56-59$

Huhn RR, Volski RV.

Primary prevention programs for business industry: role of physical therapists

Physical Therapy 65; 1985, 12: 1840-1844. 
Ice $\mathrm{R}$.

Long-term compliance.

Physical Therapy 65; 1985, 12: 1832-1839.

Janz NK, Becker MH.

The Health Belief Model: a decade later.

Health Education Quarterly 11; 1984, 1: 1-47.

Jensen $G M$, Shepard $K_{\text {, }}$ Hack LM.

The novice versuls the experienced clinician: insights into the work of the physical therapist.

Physical Therapy $70 ; 1990,5: 314-323$ :

Kanters HW.

Effectiviteit van patientenvoorlichting: een literatuuronderzoek: (Effectiveness of patient education: a literafure review)

Utrecht: Landelijk Centrum Dienstverlening GVO, 1986.

Karoly $\mathrm{P}$

Operant Methods. In: Kanfer FH, Goldstein AP (eds.). Helping people change: a textbook of methods; 2nd. ed.

New York, etc.: Pergamon Press, 1980: 210-247.

Kerssens $\mathrm{J} \mathrm{J}_{\mathrm{a}}$ Groenewegen PP.

Referrals to physiotherapy: the relation between the number of referrals, the indication for referral and the inclination to refer.

Soclal Science and Medicine 30; 1990, 7: 797-804.

Kindelan $\mathrm{K}$, Kent $\mathrm{G}$.

Patients" preferences for information.

Journal of the Royall College of General Practitioners $36 ; 1986,291: 461-463$.

Krapp DN.

Behavloral management techniques and exercise promotion: In: Dishman RK (ed.). Exercise adherence:

its impact on public health

Champaign: Human Kinetics Books, 1988: 203-235.

Knibbe $J J$

Fysiotherapie en secundaire preventie van lage rugklachten: literatuurstudie naar mogelijkheden en beperkingen. (Physilcal therapy and secondary prevention of low back pain.)

Nederlands Tijdschrift voor Fyslotherapie 97; 1987, 7/8: 175-183.

Knibbe JJ

Integration of secondary prevention of low back pain in physical therapy treatment: a literature review. In: Professlon in actlon: 100 years of physiotherapy in Holland; Congress, June 13-16, 1989, the Hague. The Hague: Dutch Society for Physlotherapy, 1989.

Koes BW, Bouter LM, Beckerman H, Heijden GJMG wan der, Knipschild PG.

Physiotherapy exercises and back pain: a blinded review.

Britlsh Medical Journal, 302; 1991, 6792: 1572-1576.

Kok Gلd.

Gedragsmodellen in patiëntenwoorlichting. (Behavioral models in patient education) In: Damoiseaux $V$ en Visser APh (eds.). Paltiënten- voorlichting: een interdisciplinaire benadering.

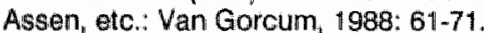

Kok GJ.

Health motivation: health education from a social psychological point of view. In: Maes $S$, Spielberger CD, Defares PB, Sarason IG (eds.). Topics in health psychalogy.

Now York, etc: John Wiley \& Sons, 1988: 295-300.

Kok J, Bouter LM.

Patlëntenvoorlichting door fyslotherapeuten in de eerste lijn. (Patient education by physical therapists in primary care).

Nederlands Tildschrift voor Fysiotherapie 100; 1990, 2: 59-63. 
Kok GJ.

Research in order to support health education in practice. In: First European Conference on effectiveness off health education.

Utrecht: Dutch Health Education Centre, 1989: 9-14.

Lafremière JG.

The low back patient: procedures for treatment by physical therapy.

New York: Masson Publishing, 1979.

Lankhorst GJ, Stadt RJ van de, Vogelaar TW, Korst JK van der; Prevo AJH:

The effect of the Swedisch back school in chronic idiopathic low back pain.

Scandinavian Journal of Rehabilitation Medicine 15; 1983: 141-145.

Lazare A, Eisenthal $S$, Frank $A$, Stoecklle JD.

Studies on a negotiated approach to patienthood. In: Stoeckle JD (ed.) Encounters between patients and doctors: an anthology.

Cambridge, etc.: The MIT Press, 1987: 413-432.

Leathley $M$.

Physiotherapists and health education: report of a survey.

Physiotherapy $74 ; 1988,5: 218-220$.

\section{Leventhal $H$, Cameron $L$}

Behavioral theories and the problem of compliance.

Patient Education and Counseling 10; 1987, 2: 117-138.

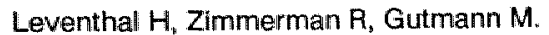

Compliance: a self-regulation perspective. In: Gentry WD (ed.). Handbook of behavioral medicine.

New York, etc.: The Guilford Press, 1984: 369-436.

Leventhal $H_{1}$ Nerenz DR, Steelle DJ.

Illness representations and coping with health threats. In: Baum A, Taylor SE, Singer JE (edis.). Handbook of psychology and health. Vol IV: Social psychological aspects of health.

Hillsdale, New Yersey: Lawrence Erlbaum, 1984: 219-252

Leventhal $\mathrm{H}$.

The role of theory in the study of adherence to treatment and doctor-patient interactions.

Medical Care 23; 1985, 5: 556-563.

Levy RL.

Social support and compliance: a selective review and critique of treatment integrity and outcome measurement.

Social Science and Medicine 17; 1983, 18: 1329-1338.

Ley $\mathrm{Ph}$.

Giving information to patients. In: Elser JR (ed.). Soclal psychology and behavloral science.

New York: John Wiley \& Sons, 1982: 339-373.

Ley Ph.

Patients' understanding and recall in clinical communication failure. In: Pendleton D and Hasler $J$ (eds.).

Doctor-patient communication.

London, etc: Academic Press, 1983: 89-107.

Liedekerken PC, Jonkers R, De Haes WFM, Kok GJ, Saan JAM.

Effectiveness of thealth ediucation.

Assen: Van Gorcum, 1990.

Linden HA van der.

Fysiotheraple en patientenvoorlichting. (Physical therapy and patient education.)

Nederlands Tijdschrift voor Fysiotheraple 97; 1987, 5: 106-112.

Lindequist $S$, Lundberg $B$, Wikmark $R$, Bergstad $B$, Lööf $G$, Ottermark AC.

Information and regime at low back pain.

Scandinavian Journal of Rehabilitation Medicine 16; 1984: 113-116. 
Lorig K Konkol L, Gonzalez V.

Arthritis patient education: a review of the literature.

Patlent Education and Counseling 10; 1987, 3: 207-252.

Lyne $\mathrm{PA}_{\mathrm{b}}$ Phillipson $\mathrm{C}$.

The barriers to health education,

Physilotherapy $72: 1986,1: 10-12$.

Lyne PA.

The professions allied to medicine: their potential contribution to health education.

Physlotherapy $72 ; 1986,1 ; 8-10$.

Mahowald ML., Steweken ME, Young $M$, Ytterberg SR.

The Minnesota Arthritis-Training Program: emphasis on self-management, not compliance.

Patlent Education and Counseling 11; 1988, 3: 235-241.

Martin JE, Dubbert PM, Katell AD, Thompson JK, Raczynski JR, Lake M, Smith PO, Webster JS.

Behavioral control of exercise in sedentary adults. studies 1 through 6.

Journal of Consulting and Clinical Psychology 52; 1984, 5: 795-811.

Martin JE, Dubbert PM.

Exercise applications and promotion in behavioral medicine: current status and future directions. Journal of Consulting and Clinical Psychology 50; 1982, 6: 1004-1017.

May BJ.

Teaching: a skill in clinical practice.

Physical Therapy 63; 1983, 10: 1627-1633.

Mayo NE.

Patient compliance: practical implications for physical therapists: a review of the literature.

Physical Therapy 58; 1978, 9: 1083-1090.

Mazucca SA.

Does patient education in chronic disease have therapeutic value?

Journal of Chronic Diseases $35 ; 1982: 521-529$.

McClellan W.

Current perspectives: patient education in medical practice: the physician and patient education: a review.

Patient Education and Counseling 8; 1986, 2: 151-163.

Mellin $G$, Järvikoski $A_{0}$ Verkasalo $M$.

Treatment of patients with chronic low back pain: comparison between rehabilitation centre and outpatient care.

Scandinavian Journal of Rehabilitation Medicine 16;1984: 77-84.

Ministerle van Welzijin Volksgezondheid en Cultuur.

Notitie ontwikkeling van de fysiotherapeutische hulpverlening. (Developments in physical therapeutic care)

's-Gravenhage: SDU Uitgeveri], 1989. Kamerstuk 20 800, no. 164.

Mullen $P D_{n}$ Green LW, Persinger GS.

Clinical trials of patient education for chronic conditions: a comparative meta-analysis of intervention types.

Preventive Medicine 14; 1985: 753-781.

Norton S.

Support for physiotherapists in health education.

Physlotherapy $72 ; 1986,1: 5-7$.

Oldridge NB.

Compliance and exercise in primary and secondary prevention of coronary heart disease: a review.

Preventive Medicine 11; 1982: 56-70. 
Oldridge $\mathbb{N B}$.

Compliance with exercise in cardiac rehabilitation: In: Dishman RK (ed). Exercise adherence: its impact on public health.

Champaign: Human Kinetics Books, 1988: 283-304.

Oldridge NB, Jones NL.

Preventive use of exercise rehabilitation after myocardial infarction. In: Astrand PO, Grimby G (eds.). Physical activity in health and disease.

Stockholm: Almquist \& Wiksell International, 1986: 123-129. Acta Medica Scandinavica Symposium Series, 2.

Pendleton D.

Doctor-patient communication: a review. In: Pendleton D and Hasler J (eds.). Doctor-patient communication.

London, etc.: Academic Press, 1983: 5-53.

Perkins KA, Epstein LH.

Methodology in exercise adherence research. In: Dishman RK (ed.). Exercise adherence: its impact on public health.

Champaign: Human Kinetics Books, 1988: 399-416.

Posavac EJ.

Evaluations of patient education programs: a meta-analysis.

Evaluation and the Health Professions $3 ; 1980,1: 47-62$.

Posavac EJ, Sinacore JM, Brotherton SE, Helford MC, Turpin RS.

Increasing complliance to medical treatment regimens: a meta-analysis of program.

Evaluation and the Health Professions 8; 1985, 1:7-22.

Radecki SE, Mendenhall RC.

Patient counseling by primary care physicians: results of a nationwide survey.

Patient Education and Counseling 8; 1986, 2: 165-177.

Rand $\mathbb{P H}$.

Evaluation of patient education programs.

Physical Therapy 58; $1978,7: 851-856$.

Rheault WL.

Incorporating locus of control theories into patient education practices.

Physiotherapy Canada 34: 1982, 3: 152-156.

Rijken $\mathrm{H}$.

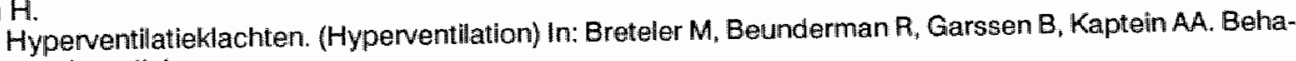
vioral medicine.

Leiden: Rijks Universiteit Leiden, 1989: 75-85.

Rosen MA, Logsdon DN, Demak MM.

Prevention and health promotion in primary care: baseline results on physicians from the INSURE project on lifecycle preventive health services.

Preventive Medicine 13; 1984: 535-548.

Rath HP.

Measurement of compliance

Patient Education and Counseling 10; 1987, 2: 107-116.

Sackett $D L$.

A compliance practicum for the busy practitioner. In. Haynes RB. Taylor DW, Sackett DL (eds.). Compliance in health care.

Baltimore $_{n}$ etc.: The Johns Hopkins University Press, 1979: 286-294.

Sallis JF, Haskell WL, Fortmann SP, Vranizan KM, Taylor CB, Solomon DS.

Predictors of adoption and maintenance of physical activity in a community sample.

Preventive Medicine 15; 1986: 331-341. 
Satterlund Larsson $U_{n}$ Saljo $R_{\text {, Aronsson } K}$

Patient-doctor communication on smoking and drinking: lifestyle in medical consultations.

Social Science and Medicine 25; 1987, 10: 1129-1137.

Saunders C, Maxwell M.

The case for counselling in physiotherapy.

Physiotherapy $74,1988,11: 592-596$.

Sohultz CL, Wellard R, Swerissen H.

Communication and lnterpersonal helping skills an essential component in physiotherapy education?

The Australlan لJoumal of Physiotherapy $34 ; 1988,2: 75-80$.

Sikorski JM.

A rationalized approach to physilotherapy for low back pain.

Spine 10: 1985, 6: 571-579.

Simonds SK, Kanters HW.

Comparative anallys is of patient education by four professions in the Netherlands and the United States.

Patient Education and Counseling 15; 1990, 2: 1511-167.

Simonds SK.

Individual health counselling and education: emerging directions from current theory, research, and practice.

Patient Counselling and Health Ediucation 4; 1983, 4: 175-181.

Siluijs EM.

A checklist to assess patlent education in physicall therapy practice: development and rellability.

Physical Therapy $71 ; 1991,8: 561 / 17-569 / 25$.

Sluils EM, Zee J van der, Kok GJ.

Differences between physical therapists in attention paid to educational activities.

Submitted.

Sluiljs EM, Leden J van der.

Methodisch werken: de ontwikkelingen sinds 1976. (Working methodically: developments since 1976)

Huisarts en Praktijk 31; 1988, 12:3-7. De kleren van de keizer: supplement bij Hulsarts en Wetenschap $31 ; 1988,11$.

Sluijs EM, Knibbe لd.

Patient compliance with exercise: different theoretical approaches to short-term and long-term compliance.

Patient Educationi and Counseling 17; 1991, 3: 191-204.

Siluils EM.

Patlent education in physiotherapy: towards a planned approach.

Physlotherapy $77 ;$, 1991, 7: 503-508.

Sluijs EM, Kok GJ, Zee J van der.

Patlent education in physical therapy as related to the patient the iliness and the kind of treatment applled.

Submitted.

Sluils EM.

Patiëntenvoorlichting door fyslotherapeuten (1): ontwikkeling van het observatleprotocol. (Patient oducation in physical therapy: development of the observation form)

Utrecht: Nivel, 1988.

Siluijs EM, Kuijper EB.

Problemen die fysiotherapeuten ervaren bif het geven van voorlichting aan patienten: een Inventarisatie. (Problems physical therapists encounter in educating patients.)

Nederlands Tijdschrift voor Fysiotherapie 100; 1990, 5: 128-132. 
Sluifis EM, Hermans IMJ.

Problemen die patiënten envaren bij het doen van huiswerkoefeningen en bil het opwolgen van adviezen: een inventarisatie. (Problems that patients encounter in exercising and following advice)

Nederlands Tijdschrift voor Fysiotherapie 100; 1990, 6: 175-179:

Sluilis EM.

Patient education in physical therapy.

Utrecht: Nivel, 1991. Dissertation.

Snook SH.

Approaches to the control of back pain in industry: job design, job placement and education/training.

Occupational Medicine: State of the Art Reviews $3 ; 1988: 45-61$.

Snook SH.

Comparison of different approaches for the prevention of low back pain: ergonomic interventions to prevent musculosceletal injuries in industry.

Michigan: Lewis Publishers, 1987: 57-72. Industrial Hyglene Science Serles, II

Sonstroem RJ.

Psychological models. In: Dishman RK (ed.). Exercise adherence: its impact on public health.

Champaign: Human Kinetics Books, 1988: 125-153.

Southam MA, Dunbar d.

Facilitating patient compliance with medical interventions. In: Holroyd KA, Creer ThL (eds.). Selfmanagement of chronic disease: handbook of clinical interventions and research.

Orlando, etc.: Academic Press, 1986: 163-187.

Spelman MR.

Back pain: how health education affects patient compliance with treatment.

Occupational Health Nursing 32; 1984: 649-651.

Spelman MR.

An exploratory study: the effects of a health education program on patient complliance to back exercises and alterations in activities of daily living.

Detroit, Michigan: Wayne State University, 1980. Dissertation:

Spenkelink G, Stelt L val, Oostendorp R.

TAB 2 duizend: Twentse aanpak bedrijfsfysiotherapie 2000. (Physical therapy in industry in 2000)

Fysiovisie 1991, febr.: 4-8.

Spronk VRA, Warmenhoven NE.

Patient education in general practice: opinions of general practitioners.

Patient Education and Counseling $5 ; 1983 ; 2: 68-75$.

Steele D.J, Blackwell B, Gutmann MC, Jackson TC.

The activated patient: dogma, dream, or desideratum? Beyond advocacy: a review of the active patient concept:

Patient Education and Counseling 10; 1987, 1: 3-23.

Stone GC.

Patient compllance and the role of the expert

Journal of Social Issues $35 ; 1979,1: 35-59$

Strecher Vul.

Improving physician-patient interactions: a review.

Patient Counselling and Health Education $4 ; 1983,3: 129-136$

Strecher VJ, McEvoy DeVellis B, Becker MH, Rosenstock IM.

The role of self-efficacy in achieving health behavior change

Health Education Quarterly $13 ; 1986,1: 73-92$. 
Svarstad BL.

Physician-patient communication and patient conformity with medical advice. In: Mechanic D. The growth of bureaucratic medicine: an inquiry into the dynamics of patient behavior and the organization of medical care.

New York: John Wlley and Sons, 1976: 220-238.

Szasz TS, Hollender MH.

A contribution to the philosophy of medicine: the basic model of the doctor-patient relationship. n: Stoeckle JD (ed). Encounters between patients and doctors.

Massachusetts: The MUT Press, 1987: 165-177.

Taylor SH, Gill SJ.

Professional disclosure in the couriseling profession. a rewiew of the literature.

Patient Education and Counseling $5: 1983,1$; $35-40$.

Tobin DL, Reynolds AVC, Holroyd KA, Creer ThL.

Self-management and social learning theory. In: Holroyd $K A_{s}$ Creer ThL (eds.). Self-management of chronic disease: handbook of clinical interventions and research.

Orlanido, etc: Academic Press, 1986: 29-55.

Treusch JV, Krusen FH.

Physical therapy applled at home for arthritis.

Archives of Internal Medicine 72; 1943: 231-238.

Trostle JA.

Medical compliance as an ideology.

Social Science and Medicine 27; 1988, 12: 1299-1308.

Turk DC, Salovey P, Litt MD.

Adherence: a cognitive-behavioral perspective. In: Gerber KE, Nehemkis AM (eds.). Compliance: the dilemma of the chronically ill.

New York: Springer Publishing Company. 1986: 44-72.

Verbrugge LM.

Gender and health: an update on hypotheses and evidence.

Journal of Health and Social Behavior 26; 1985, 3: 156-182.

Verhaak PFM.

Detection of psychologic complaints by general practitioners.

Medical Care 26; 1988, 10: 1009-1020.

Wagstaff GF.

A small dose of commonsense - communication, persuasion and physiotherapy.

Physiotherapy 68; 1982, 10:327-329.

Waltzkin $\mathrm{H}$.

Information giving in medical care.

Journal of Health and Social Behavior 26; 1985, 2: 81-101.

Wechsler $H_{i}$ Levine S, Idelson RK, Rohman M, Taylor JO.

The physiclan's role in health promotion: a survey of primary-care practitioners.

The New England Journal of Medicine 308; 1983, 2: 97-100.

Weiss Su.

Consensual norms regarding patient inwolvement.

Social Science and Medicine 22; 1986, 4: 489-496.

White KL.

The task of medicine: dialogue at Wickenburg.

Menlo Park, California: The Henry d. Kaiser Family Foundation, 1988. 


\section{Appendix}

1 Observation form patient education by physical therapists 189

2 Registration by physical therapist 192

$3 \quad$ Patients' questionnaire 193

4 Questionnaire for physical therapists on patient information 199

5 Respondents and non-respondents compared 210

6 Number of sessions with information per item $\quad 212$

7 Scale 1: Therapist-patient relationship 214

8 Scale 2: Preventive possibilities $\quad 215$

9 Scale 3: Perceived effects 216

10 Scale 4: Psychosocial influence 218 


\section{Appendix 1}

Observation form patient education by physical therapists

Date

Observer:

No. tape .............

patient $M / F$

No. physical therapist ......

date of birth

counter ........ to t...

No. patient $\ldots \ldots \ldots \ldots \ldots$

complaints

time .................

No. session

questionnaire $O$ yes $O$ no

interruptions ..... to ....

nettime

\begin{tabular}{|c|c|c|c|c|c|c|c|c|c|c|c|c|}
\hline \multirow{2}{*}{\multicolumn{2}{|c|}{ phases }} & \multicolumn{2}{|c|}{ counter } & \multicolumn{2}{|c|}{$\begin{array}{l}\text { mark } \\
\text { no yes }\end{array}$} & \multicolumn{2}{|c|}{ counter } & \multicolumn{2}{|c|}{$\begin{array}{l}\text { mark } \\
\text { no yes }\end{array}$} & \multirow[t]{2}{*}{ time } & \multicolumn{2}{|c|}{$\begin{array}{l}\text { complete } \\
\text { no yes }\end{array}$} \\
\hline & & begin & end & & & begin & end & & & & & \\
\hline 1 & $=$ beginning & …........... & $-\ldots \ldots+\ldots+n$ & - & & $\ldots \ldots \ldots . . .$. & $=. . . \ldots \ldots \ldots$ & - & & & 0 & 0 \\
\hline 2 & $=$ verbal examination & $\ldots \ldots \ldots \ldots \ldots$. & $-\ldots \ldots \ldots . . .0$ & 0 & 0 & $\ldots \ldots \ldots \ldots$ & $-\ldots \ldots \ldots . . .$. & 0 & 0 & $\ldots \ldots \ldots \ldots \ldots \ldots$ & $\mathrm{O}$ & 0 \\
\hline 3 & $=$ physical examination & $\ldots \ldots \ldots \ldots$ & $-\ldots \ldots \ldots . .$. & 0 & 0 & $\ldots \ldots \ldots \ldots$ & $-\ldots \ldots \ldots . . .$. & 0 & 0 & $\ldots \ldots \ldots+\ldots+\ldots \ldots$ & 0 & 0 \\
\hline 4 & $=$ massage & $\ldots \ldots \ldots \ldots$ & $-\ldots \ldots \ldots$ & 0 & 0 & $\ldots \ldots \ldots \ldots \ldots$ & $-\ldots \ldots \ldots \ldots$ & 0 & 0 & $\ldots \ldots \ldots, \ldots, \ldots, \ldots$ & 0 & 0 \\
\hline 5 & $=$ exercise therapy & no.t. & $-\ldots \ldots \ldots . .$. & 0 & 0 & $\ldots \ldots \ldots+\cdots$ & $-\ldots \ldots \ldots \ldots$ & 0 & 0 & ...........n. & 0 & 0 \\
\hline 6 & $=$ modality & $\ldots \ldots \ldots \ldots$ & $-\ldots \ldots \ldots$ & 0 & 0 & $\ldots \ldots \ldots . .$. & $-\ldots \ldots \ldots \ldots$ & 0 & 0 & …, & 0 & 0 \\
\hline 7 & $=$ conversation & $\ldots \ldots+n+\ldots$ & $-\ldots \ldots \ldots \ldots$. & $\mathrm{O}$ & 0 & $\ldots \ldots \ldots$ & $-\ldots \ldots \ldots \ldots$ & 0 & 0 & $\ldots \ldots \ldots \ldots$ & 0 & 0 \\
\hline 8 & = other & . & $-\ldots \ldots \ldots$ & 0 & 0 & $\ldots \ldots \ldots$ & $-\ldots \ldots \ldots \ldots$ & 0 & 0 & , .................... & 0 & 0 \\
\hline 9 & $=$ evaluation & $\ldots \ldots \ldots \ldots$ & $-\ldots \ldots \ldots \ldots$ & 0 & 0 & $\ldots \ldots \ldots \ldots$ & $-\ldots \ldots \ldots \ldots$ & 0 & 0 & $\ldots \ldots+\ldots \ldots \ldots \ldots \ldots$ & 0 & 0 \\
\hline
\end{tabular}

60 unintelligible

no yes patient questions/ probings

number of remarks per phase

Asking patient's demands and perceptions:

61 exploring demands and expectations

00

62 exploring idieas and perceptions.

00

63 exploring self-care activities

00

64 checking patient's understanding

00

Therapist-patient relationship:

65 reinforcing patient's performance

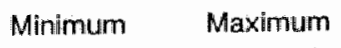

$\begin{array}{llll}1 \quad 2 & 3 & 4\end{array}$

number

\begin{tabular}{l}
$1 \quad 2 \quad 3 \quad 3 \quad 4$ \\
\hline
\end{tabular}

number

66 showing concern for pain

67 showing interest in the patient

68 showing involvement in treatment

69 facilitating patient participation

\begin{tabular}{llll}
1 & 2 & 3 & 4 \\
\hline 1 & 2 & 3 & 4 \\
\hline 1 & 2 & 3 & 4
\end{tabular}

70 patient's interest in treatment

$\begin{array}{r}1 \quad 2 \quad 3 \quad 4 \\ \hline\end{array}$




$\begin{array}{lll}\text { na. no yes } & \\ & & \\ 0 & 0 & 0 \\ 0 & 0 & 0 \\ 0 & 0 & 0 \\ 0 & 0 & 0 \\ 0 & 0 & 0\end{array}$

patient questions/ probings

1 expl. treatmient session

2 expl. follow-up treatment(s)

3 expl. duration of treatment.

4 evaluating the couirse of treatm.

5 miscell, or remaining toples

$$
\text { probings }
$$

number of remarks per phase

Planning: Information about the treatment applied

\author{
6 expl aim of physical examination \\ 7 expl. aim of exercise therapy \\ 8 expl. aim of massage \\ 9 expl. aim of a physical agent \\ 10 expi: possible side effects of treatm. \\ 11 miscell. or remaining topics:
}

$\begin{array}{lll}0 & 0 & 0 \\ 0 & 0 & 0 \\ 0 & 0 & 0 \\ 0 & 0 & 0 \\ 0 & 0 & 0 \\ 0 & 0 & 0\end{array}$

Planning: information about findings

12 communic. findings from history taking

13 communic findings of the phys. exam. (s)

14. communic findings of therapy

15 miscell. or remaining topics
O
0
00
0
0
0
0
0
0
0
O

Teaching and providing information about illmess

16. about diagnosis and complaints

17 about the cause of the illness

18 about the prognasis

19 illustrative material to clarify inform.

20 milscell. or remaining topies

$\begin{array}{lll}0 & 0 & 0 \\ 0 & 0 & 0 \\ 0 & 0 & 0 \\ 0 & 0 & 0 \\ 0 & 0 & 0\end{array}$

O
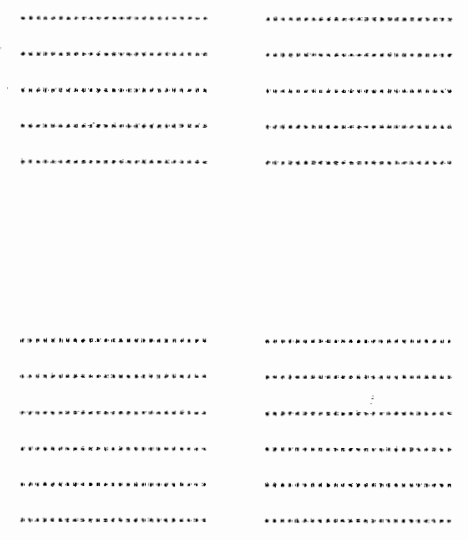

Instructions for home exercises

21 explaining home exercises

22 frequency of each exercise

23 number of sessions per day

24 exerclse instructions

25 the build-up of the exercise program

26 the build-up of each exercise

27 exercise leaflet

28 instructions written by the therapist

29 integrating exercises to dally activities

$\begin{array}{lll}0 & 0 & 0 \\ 0 & 0 & 0 \\ 0 & 0 & 0 \\ 0 & 0 & 0 \\ 0 & 0 & 0 \\ 0 & 0 & 0 \\ 0 & 0 & 0 \\ 0 & 0 & 0 \\ 0 & 0 & 0 \\ 0 & 0 & 0 \\ 0 & 0 & 0 \\ 0 & 0 & 0 \\ 0 & 0 & 0\end{array}$

30 molivating the patient to comply

31 monitoring patient's compliance

32 resolving compliance problems.

33 miscellaneous or remaining toplcs. 
34 on laking rest

35 on correct posture and movement

36 on work, sports or hobbles

37 on daily activities

38 on self care and domestic medicines

39 on adiaptations

40 on aids and appliances

41 on health services

42 on family physicians or specialists

43. motivating the patient to comply

44 moniloring patient's compliance

45 resolving compliance problems

46 miscellaneous or remaining topics

General health education

47 an sports or exercise

48 on weight control or nutrition

49 on smoking, alcohol or drugs intake

50 on painkillers or medicine

51 on health and lliness in general

52 motivating the patient to comply

53 monitoring patient's compliance

54 resolving compliance problems

55 miscellaneous or remaining topics questions/ probings

number of

remarks

per phase

ad- spe- per-

vice cific sua

sive

pq1 pq2 pqu

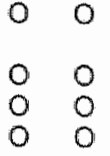

yn yn $y n$

$y$ in $y$ n $y$ in

yn yn yn

$y n y n$ y $n$

00

0

0

yn y $n$ yn

y $n$ y $n$ y $n$

$y \rightarrow y n y n$

y $n$ y $n$ y

00

yn y $n$ y $n$

yn yn yn

$y n$ y $n$ y

y $n$ y $n$ yn

$y n$ y $n$ y

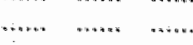

…...

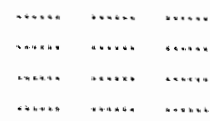

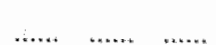

00

00

00

.
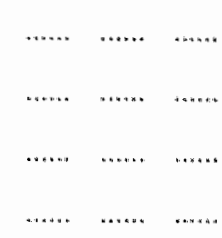

$y n$ yn yn

yn $y n$ y

$0 \quad 0$

00

y n y $n$ y

y $n$ y $n$ y $n$

00

yn yn $y n$

$y n$ y $n$ y $n$

$y n$ y $n$ y $n$

yn y $n$ y $n$

y n y $n$ y $n$

a b $\quad G \quad d$

56 explaining mind-body relations

57 exploring stress-related problems

58 supportive care with handicaps

59 supportive care with personal distress

60 miscellaneous or remaining topics

* follow-up pages were used when more than one advice per item was given pq1 = patient's questionnaire: the patient wrote down this particular advice in the questionnaire pq2 = patient's questionnaire: the patient wrote down this advice in more general terms $\mathrm{pq} 3$ = patient's questionnaire: the patient wrote down an advice that was not heard on the audiotape
$a=$ listening
$\mathrm{b}=$ understanding and support
$c=$ exploring
$\mathrm{d}=$ explaining 


\section{Appendix 2}

Registration by physical therapist

PATIENT NO.

Phys. ther no.

patient $\mathrm{O}$ M OF

year of birth .........

educational level

prim./sec./higher treatment. rir.

same complaint before yes

also phys the treatmentyes

other phys.th: treatment

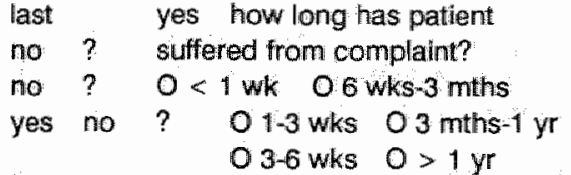

last 3-6 wks $0>1 \mathrm{yr}$

1. Patient's complaint:

2. Your working diagnosis:

3. Referral indication:

4. Seriousness: how serious do you find these complaints?
1. not serious
2. somewhat serious
3. rather serious
4. wery serious

5. Hindrance: to what extent do the complaints according to you form a hindrance for the patient compared with his/her nomal activities?
1. no hindrance
2. some hindrance
3. vather considerable hindrance
4. very considerable hindrance

6. Psychosocial: do you think that psychosocial aspects influence the complaints?
1. no influence
2. some intluence
3. vather considerable intluence
4. very considerable influence

7. Course: do you think that the complaints of this patient in the course of the next two years:

1. will fairly certainly not return

2. will probably not return

3. will probably return

4. will be permanently present

8. Gooperation: do you think that the patient is motivated to cooperate himself/herself actively on his/her health?

1. not or hardly motivated

2. somewhat motivated

3. rather motivated

4. very motivated
The following questions are applicable only if the patients must perform home exercises

9. Short-term: do you think that the patient will get round to home exercises regularly on the next two weeks?
1. certainly not
2. probably not
3. probably
4. certainly

10. Importance: do you find it important that the patient continues to do these hame exercises in the long run too?

1. not important

2. somewhat important

3. rather important

4. very important

11. Long-term: do you think that the patient will succeed in keeping up the home exercises for a year?

1. certainly not

2. probably not

3. probably

4. certainly

(Space for remarks)
Nederlands instituut voor onderzoek van de eerstelijnsgezondheidszorg (Nivel) 


\section{Appendix 3}

Patilents' questionnaire

No. . .

Please tick the answer that is most applicable to you.

Do not think too long about the answers but tick what occurs to you.

There are no right of wrong answers; what matters is your personal opinion.

1. I am: 0 man $\quad 0$ a woman my year of binth is

2. Can you briefly indicate the complaints of disorder for which you are recelving physical therapeutic treatment?

3. How serious do you find these complaints?

0 not serious

o somewhat serious

0 rather serious

0 very serious

4. How much of a handicap do these complaints form for you compared with your normall activitles?

0 no handicap

0 some handicap

0 a rather considerable handicap

0 a very considerable handicap

5. How much pain do you suffer from the complaints?

0 no pain

o some pain

0 rather considerable pain

0 very considerable pain

6. Did you have to do exercises at home during the past week?

0 no, then please continue with question 31 on page 5 .

0 yes "then please continue with the following questions. 
Each statement is followed by the figures 1 to 4 .

These mean:

1 = yes, that is so

$2=$ yes, that is stightly so

$3=$ that is hardly $\mathrm{so}$

$4=$ no $_{\text {, that is not }} \mathrm{so}$

Please circle the figure that is most applicable to you for each statement.

7. I get very tired from exercising

8. The exercises are difficult to fit into my dally life

9. Exerclsing is a dally habit for me

10. The exercises that i have to do are difficult ones

11. I can't make the effort to exercise regularty

12. It depends above all on the physical therapist whether I get better

13. I can do little myself about my complaints

14. Exercises will not help much with my complaints

15. The exerclses are painful to do

16. I have too little time to exercise

17. I often forget to exercise

18. What the physical therapist does is more important than exercising

19. My complaints will go away without exercising yes slightly hardly no
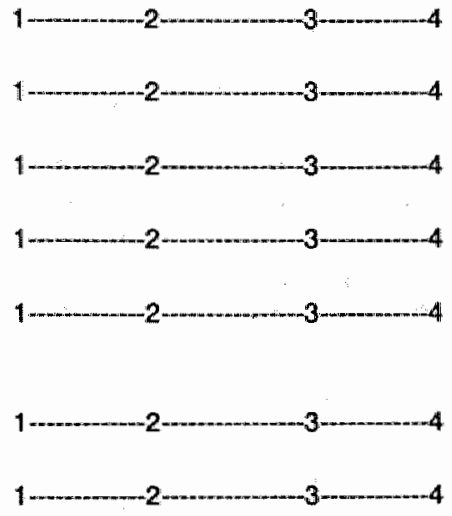

$1+2-3$
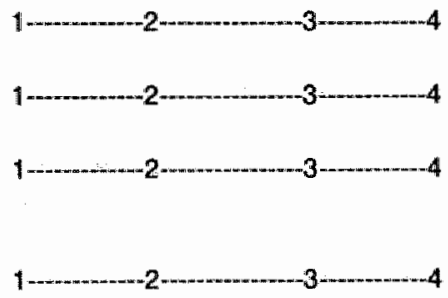

$1-2-3$ 
20. Please write down below in your own words what the problems are for you with doing home exercises regularly. (If you have no problems just put 'no problems).

21. Do you think you'll succeed in exercising regularly in the coming two weeks?

0 no, definitely not

0 probably not

0 probably

0 certainly

22. Is it important for your complaints that you continue doing home exerclses in the long term too?

0 that is not important

0 that is somewhat important

0 that is rather important

0 that is very important

23. Do you think you'll succeed in exercising regularly for a year?

0 no, certainly not

0 probably not

0 probably

0 certainly

24. Did you get manage to exercise regularly at home in the past week?
o no or hardly
D somewhat
0 rather reguiarly
0 very regularly

25. Did you get round to exercising yesterday?
o no
0 yes, .......... times 
Thils page relates to your last visit to the physical therapist.

Perhaps on that last occasion the physical therapist spoke to you about the subjects that are mentioned in the following questions.

Please try to answer these questions.

26. Did the physical therapist ask you last time how the exercising was going?

0 I don't remember

0 no, that wasn't discussed

a yes, that was briefly discussed

0 yes, that was discussed at length

27. Did the physical therapist provide you with written instructions last time?

0 yes

o no, not this time but a previous time

o no, never

28. Did the physical therapist tell you last time exactly how many times a day you ought to exercise?

0 I don't remember

0 no, that wasn't discussed

0 yes. ........ times a day

0 yes, I may determine for myself how many times I exerclse

29. Did the physical therapist tell you last time exactly how long during a day you ought to exercise?

0 I don't remember

0 no, that wasn't discussed

0 yes $s_{n}$........ minutes a day

(or each exercise ......... times)

0 yes ${ }_{\mathrm{i}}$ I may dettermine for myself how long I exercise

30. Is the physicall therapist satisfied about the exercises that you do at home?
01 don't know
0 not so satislied
0 somewhat satisfied
0 rather satisfied
0 very satisfied 
This page relates to advice that you received iduring the last visit to the plyysical therapist. This may be advice on for instance beds, shoes, chairs or on work, spont, posture, rest, caring for yourself etc. (we therefore do not mean the exercises).

31. Did you receive advice from the physical therapist last time?

0 I don't remember (please go on to questions 37)

0 no, not this time (please go on to question 37)

0 yes (please go on to the following questions)

32. Please write down below the advice that you received last time from the physical theraplist

33. What are for you the problems in following this advice? (if there are no problems you can write "no problems")

34. Do you think that this advice contributes to a reduction of your complaints?
o not very much
a perhaps
0 probably
0 certainly

35. Do you think that you will succeed in following this advice during the next two weeks?
0 no, certainly not
o probably not
0 probably
o certainly

36. Do you think that you will succeed in following this advice for a year?
0 no, certainly not
0 probably not
a probably
0 certainly 


\section{LAST QUESTIONS}

37. Have you in recent times had much worry, stress or grief in your life?
o no
o no more than usual
o more than usual
o much more than usual

38. Do you think that this worry. stress or grief has an effect on your complaints?
0 no effect
0 some effect
0 rather large effect
0 very large effect

39. If you think about the future, do you then think that in the next two years your complaints will return?
O fairly certailnly will not return
a probably will not return
o probably will return
a probably will be perrnanently present

40. Some people have already tried to do something themselves about their complaints before going to the GP of physical therapist. Please write down what you had tried yourself before going to the physical therapist.

41. Has the physical therapist occasionally asked what you had already tried yourselr?
01 don't remember
0 no, that was not discussed
0 yes, that was occasionally discussed
0 yes, that was discussed at length

Date of conpiletion:

Thank you very much for completing this questionnaire.

Emmy Slulis 


\section{Appendix 4}

\section{Questionnaire for physical therapists on patient information}

\section{Explanation:}

- Please tick the answer that comes closest to your opinion.

- Do not think too long about the questions but tick the first answer that comes to mind.

- You can return the questionnaire in the reply envelope; a stamp is not necessary.

Information: Mrs. E. Sluljs $\mathbf{s}_{\sharp}$ 030-319946

Netherlands Institute of Primary Health Carre (NIVEL), P.O. Box 1568, 3500 BN Utrecht, tel, 030319946 
1. What is your date of binth?

2. What is your sex?

O female

O male

3. Which academy did you attend and in which year did you gain the diploma?

Name of academy: at

Diploma gained in the year

4. For how many years have you been actively working as a physical therapist? years

5. How many shifts do you work per week on average as a physical therapist? (a shift Is a morning or an afternoon or an evening)
O 5 shifts or fewer
O 10 or 11 shifts
06 or 7 shifts
O 12 or more shifts

O 8 or 9 shifts

6. How much time do you usually reserve in your diary for treatment of a patient?
O 15 minutes
O 20 minutes
025 minutes
O 30 minutes
$0>30$ minutes

7. Do your treatments occasionally last longer than planned?
O seldom or never
O sometimes
O often
O very often 
8. How often do you have the feeling that you are running out of time in a treatment?

O seldom or never

O sometimes

O often

$O$ very aften

9. In what way are you active as a physical therapist?

O physical therapist with a contract of employment in a freely established practice

O physical therapist on a billing basis with payment of social security contributions

O physical therapist in the paid employment of a thealth centre

O physical therapist in the paid employment of a foundation or PLC other than a health centre

O observer

O other, viz

10. How many physical therapists work in total, i.e. including yourself, in the practice or health centre? (do not count trainees and incidental observers)

(number of physical therapists)

11. How often do you consult (on work or patients) the following aid workers? We mean both formal and informal consultation.

$\begin{array}{lllll} & \text { never } & \text { sometimes } & \text { often } & \text { very often } \\ \text { (fellow) physical therapists } & 0 & 0 & 0 & 0 \\ \text { general practitioners } & 0 & 0 & 0 & 0 \\ \text { specialists } & 0 & 0 & 0 & 0 \\ \text { district nurses } & 0 & 0 & 0 & 0 \\ \text { home nursing } & 0 & 0 & 0 & 0 \\ \text { social workers } & 0 & 0 & 0 & 0 \\ \text { psychologist or psychiatrist } & 0 & 0 & 0 & 0 \\ \text { other, viz ........................... } & 0 & 0 & 0 & 0\end{array}$


12. How useftu do you find (or would you find) consultation with the following aid workers?

\begin{tabular}{|c|c|}
\hline $\begin{array}{l}\text { mot } \\
\text { useful }\end{array}$ & $\begin{array}{l}\text { somewhall } \\
\text { useftul }\end{array}$ \\
\hline
\end{tabular}

(fellow) physical therapists

$\begin{array}{llll}0 & 0 & 0 & 0 \\ 0 & 0 & 0 & 0 \\ 0 & 0 & 0 & 0 \\ 0 & 0 & 0 & 0 \\ 0 & 0 & 0 & 0 \\ 0 & 0 & 0 & 0 \\ 0 & 0 & 0 & 0 \\ 0 & 0 & 0 & 0\end{array}$

13. Have you since your physical therapy training attended supplementary courses or training (or are you still doing so)?

Please thck the number of course days that the whole course or training covers. Do not include homework or home study.

name of course:

$$
\text { actual number of course days }
$$

campleted

\begin{tabular}{|c|c|c|c|c|}
\hline $\begin{array}{l}1.5 \\
\text { days }\end{array}$ & $\begin{array}{l}6-10 \\
\text { days }\end{array}$ & $\begin{array}{l}11-20 \\
\text { days }\end{array}$ & $\begin{array}{l}>20 \\
\text { days }\end{array}$ & - yes \\
\hline
\end{tabular}

1.

$\begin{array}{llllll}0 & 0 & 0 & 0 & 0 & 0\end{array}$

2 .

0

0

0

$0 \quad 0$

3.

$0 \quad 0$

0

0

0

4.

$0 \quad 0$

0

0

0

0

5.

6.

0

0

0

0

$0 \quad 0$

7.

0

0

0

0

0

0

3.

0

0

0

0

$0 \quad 0$ 
The following statements concern the relation between physical therapist and patient: For each statement please tick the answer that appeals to you the most Don't think too long about it.

$\begin{array}{llll}\begin{array}{l}\text { definitely don't } \\ \text { don't }\end{array} & \begin{array}{l}\text { partly } \\ \text { agree }\end{array} & \begin{array}{l}\text { agree, } \\ \text { partly } \\ \text { agree }\end{array} & \\ & & \begin{array}{l}\text { don't } \\ \text { agree }\end{array} & \text { agree } \\ & & \end{array}$

14. Patients can at all times require of their physical therapist that they are fully informed about their complaints

15. A successful treatment often depends more on the confidence that the patients has in the physical therapist than on a good explanation

O

0

o

0

$\mathbf{O}$

16. In the application of physiotechnology the physical therapist should always explain exactly and in detail what the purpose and effect of it is.

17. There is mothing against patients looking up to their physical therapist a little

18. Even if the physical therapist is uncertain about the correct form of treatment he/she should tell the patient that

0

0

o

0

0

19. A physical therapist should always explain to the patients. what he/she reports back to the GP or specialist

0

0

O

O

0

20. It is difficult to take some patients seriously, in view of the way in which they handle their complaints

21. With a number of patients there is little point in giving an explanation because they wouldn't understand it anyway

22. It is better to give information on the prognosis of the complaints only if patients ask for it

0
0

0

0

23. The physical therapist should always discuss with the patients what concrete treatment goal will be aimed at

24. Patients who do not actively cooperate in the treatment are also entitled to a good treatment

0

0

0

0

0 
25. Below 13 subjects are mentioned that lie in the field of health promotion and prevention. Physical therapists may bring up such subjects if there is a causal relation with the complaints.

The question is now: do you consider it a task of physical therapists to give information and advice on these subjects it there is no direct connection with the complaints?

Does informing or advising on these

subjects form part of the task of

the physical therapist?

- ergonomic design of the workplace

(If there is no connection with the complaints)

- avoidance of overwelight

(if there is no connection with the complaints)

- stopping smoking

(if there is no connection with the complaints)

- wearing good footwear

(if there is ne connection with the complaints)

- taking sufficient exercise

(if there is no connection with the complaints)

- moderate consumption of alcohol

(if there is no connection with the complaints)

- warming-up before sport

(if there is no connection with the complaints)

- slleeping on a good mattress

(if there is no connection with the complaints)

- dealing properly with stress

(if there is no connection with the complaints)

- paying attention to a good posture

(if there is no connection with the complaints)

- attending to a good nutritional pattern

(ifi there is no connection with the complaints)

- lifting In the correct manner

(If there is no connection with the complaints)

- responsible use ol medicine

(if there is no connection with the complaints) definite- hardly some- largely fully ly not

what

0

0

0

0

0

$0 \quad 0$

0

0

0

o

0

0

o

0

0

0

0

0

0

0

0

0

0

0

0

o

0

0

0

0

0

0

0

0

0

0

0

0

0

0

0

0

0

0

o

0

0

0

0

0

0

0

0

0

0

0

0

0

0

0 
26. Physical therapy is directed both towards increasing the ability to bear burdens and to limiting the burden on a patient.

Please tick where you by and large try to lay the stress.

equal stress on

both aspects

more stress on

limiting the burden

$0 \quad 0$

0

0

0

o

more stress on

increasing the ability to bear burdens

The following statements are concerned with advantages and disadvantages that can play a part for you personally in giving information or not.

By information we mean everything that you consciously impart to the patient to bring about greater knowledge or a change in behavior among patients.

Please tick for each statement the answer that appeals to you the most. Don't think too long about it.

$\begin{array}{llll}\text { definitely don't } & \text { partly agree } & \text { fully } \\ \text { don't } & \text { agree } & \begin{array}{l}\text { agree, } \\ \text { partly } \\ \text { don't } \\ \text { agree }\end{array} & \\ & & & \\ & & & \end{array}$

27. The information that I give contributes towards patients becoming more independent

0

28. My information ensures that even uninterested passive patients proceed to cooperate actively in the treatment.

0

0

0

0

0

29. I consider that I possess sufficient skills to give good information

0

0

0

O

0

30. Through the information that I give patients are much sooner free of complaints

0

0

0

0

0

31. My information has considerable effect on the extent to which pattients feel responisible for their own health

0

0

o

0

0

32. If I devoted considerable attention to information, thave more pleasure in my work

0

0

0

0

0 


$\begin{array}{llll}\text { definitely dontt } & \text { partly } \\ \text { don't } & \text { agree } & \text { agree } & \text { fully } \\ \text { agree } & & \begin{array}{l}\text { partly } \\ \text { don't } \\ \text { agree }\end{array} & \\ & & & \\ & & \end{array}$

33. Whether patients faithfully do their home exercises depends above all on my Intormation

34. Through the information that I give patients can make better decisions about their own health

35. The quality of my work as a physiotherapist is determined above all by the information that I give

0

0

0

0

36. As a result of good information: rarely see patients again with the same complaints

0

$0 \quad 0$

0

37. Giving information is for me a way of showing the patlent that I take him/her serlously

38. Giving good information costs me considerable energy

39. Patients nowadias expect that I glve extensive information

40. If I devote little attention to information I do not consider myself a good physical therapist

$0 \quad 0$

$0 \quad 0$

41. Through information it is often possible to change the behavior of patients permanently

o

$0 \quad 0$

o

O

42. If find it a disadvantage that giving extensive information is at the expense of treatment time

$0 \quad 0$

$0 \quad 0$

0

43. || consider that I am not entitled to concern myself with unhealthy life. styles of patients

0

$0 \quad 0$

0

0

44. Through the information that I give 1 contribute to cost-cutting in health care

0

$\mathrm{O}$

0

0

0

45. The satisfaction of patients does not depend on the information that I give

$0 \quad 0$

0

0

0 
46. Through the nature of the disorder avoidance of the necessity of physical therapeutic treatment being required again for the same complaints is possible for some complaints.

To what extent do you regard this as possible for the following 12 complaints.

avoidance of the complaints requiring treatment again is:

$\begin{array}{lllll}\text { not } & \text { some } & \text { reaso } & \text { quite } & \text { highly } \\ \text { possibie } & \text { what } & \text { nably } & \text { posibible } & \text { possi- } \\ & \text { possible } & \text { possible } & & \text { ble }\end{array}$

complaints in connection with

- frozen shoulder

$\begin{array}{lllll}0 & 0 & 0 & 0 & 0 \\ 0 & 0 & 0 & 0 & 0 \\ 0 & 0 & 0 & 0 & 0\end{array}$

- tennis elbow

- chronic non-specific lung disease

$0 \quad 0$

- arthrosis of the knee

$0 \quad 0$

$0 \quad 0$

- hyperventillation

O

O

0

0

0

$0 \quad 0$

- lumbago

o

0

0

0

0

- headache

o

0

$\begin{array}{ll}0 & 0 \\ 0 & 0\end{array}$

- M. Scheuermann

0

- osteoporosis

- stress incontinence

$0 \quad 0$

0

0

0

0

0

0

0

0

0

0

0

o

0

0

0

0

0

0

O

47. The same disorder again, now with the question to what extent psychosocial factors affect the occurrence, worsening of persistence of the patient's complaint.

Pliease give your personal impression.

psychosocial factors have:

$\begin{array}{llll}\text { no effect little } & \text { neither } & \text { much } & \text { very } \\ \text { at all } & \text { effect } & \text { little nor } & \text { effect } \\ & & \text { much effect } & \text { much } \\ & & \text { effect }\end{array}$

complaints in connection with

- frozen shoulder

$\begin{array}{lllll}0 & 0 & 0 & 0 & 0 \\ 0 & 0 & 0 & 0 & 0 \\ 0 & 0 & 0 & 0 & 0\end{array}$

- tennis elbow

- chronic non-specific lung disease

$0 \quad 0 \quad 0$

$0 \quad 0$

$0 \quad 0$

O

O

0

$\begin{array}{ll}0 & 0 \\ 0 & 0\end{array}$

- Lumbago

0

0

$\begin{array}{ll}0 & 0\end{array}$

0

0

0

$\begin{array}{ll}0 & 0 \\ 0 & 0\end{array}$

0

0

0

0

0

0

0

0

0

o

0

0

- M. Scheuermann

- osteoporosis

- stress incontinence

o

0

0
0
0
0
0
0
0
0
0


48. Below three opinions appear on the task of the physical therapists with respect to psychosocial problems. Tick the one that appeals to you the most.

O Offering assistance with psychosocial problems is not really a task for physical therapists.

O Offering assistance with psychosocial problems is subordinate in physical therapy to the treatment of physical complaints.

O Ofering assistance with psychosocial problems is an essential part of physical therapeutic treatment.

Please try to give an estimate for the following two questions and circle the answer.

49. This question relates to the period

during which the patient is undergoing

treatment:

What percentage of the patients

whom you provide with a home

exercise programme also falth-

fully do these exercising during

treatment

$\begin{array}{lllllllllll}0 \% & 10 & 20 & 30 & 40 & 50 & 60 & 70 & 80 & 90 & 100 \%\end{array}$

50. This question relates to the period during which the patient is no longer undergoing treatment:

what percentages of your patients who, even upon completion of the treatment, ought to continue exercising keep that up after the treatment is stopped (say for about
1 year'
$\begin{array}{lllllllllll}0 \% & 10 & 20 & 30 & 40 & 50 & 60 & 70 & 80 & 90 & 100 \%\end{array}$ 
51. There are various aspects of information that may give problems in the performance in practice. Do you experience problems in informing patients?

O no, no problems

O yes, namely

Thank you very much for completing this questionnaire!

\section{Emmy Sluijs}




\section{Appendix 5}

Respondents and non-respondents compared
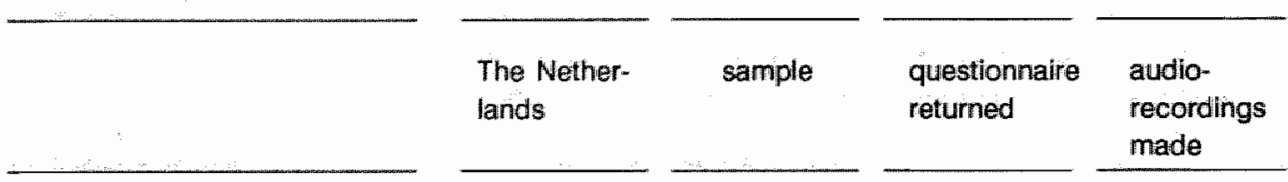

Physical theraplsts in non-institutional care

$$
N=8986 \quad n=300 \quad n=222 \quad n=84
$$

\section{Sex}

men

women

$\begin{array}{rrrrrrrr}4736 & 52,7 \% & 170 & 56,7 \% & 129 & 58,1 \% & 63 * & 75 \% \\ 4250 & 47,3 \% & 130 & 43,3 \% & 93 & 41,9 \% & 21 * & 25 \%\end{array}$

\section{Age}

$<30$

$\geq 30<45$

$\geq 45$

$\begin{array}{rrrrrrrr}1209 & 13,5 \% & 25 & 8,3 \% & 20 & 9,0 \% & 5 & 6,0 \% \\ 6338 & 70,5 \% & 230 & 76,7 \% & 172 & 77,5 \% & 70 & 83,3 \% \\ 1221 & 13,6 \% & 45 & 15,0 \% & 30 & 13,5 \% & 9 & 10,7 \%\end{array}$

\section{Worksetting}

health centre

private practice

$\begin{array}{rrrrrrrr}121 & 1,3 \% & 7 & 2,3 \% & 7 & 3,2 \% & 5 & 6,0 \% \\ 8865 & 98,7 \% & 293 & 97,7 \% & 215 & 96,8 \% & 79 & 94,0 \%\end{array}$

\section{Urbanisation}

rural

$\begin{array}{llllllll}2497 & 27,8 \% & 74 & 24,7 \% & 60 & 27,0 \% & 28 & 33,3 \%\end{array}$

suburban

$\begin{array}{llllllll}2459 & 27,4 \% & 89 & 29,7 \% & 71 & 32,2 \% & 24 & 28,6 \%\end{array}$

urban

\begin{tabular}{llllllll}
4030 & $44,8 \%$ & $137 \quad 45,7 \%$ & 91 & $41,0 \%$ & 32 & $38,1 \%$ \\
\hline
\end{tabular}

*) significant difference $p<.01$ 
Appendix 5 (continued)

Physical therapists who did and who did not make audiorecording compared

audiorecordings made $(n=84)$ no audiorecordings $(n=138)$

1 Expectation of percentage of patients who comply with home exercises

- short-term compliance

$63,0 \%$

$65,1 \%$

- long-term compliance

2 Mean score on attitude scales:

- preventive tasks

- preventive possibilities

- counseling tasks

- perceived effects of education

3 Percentage of physical therapists who encounter problems in educating patients

$67,9 \%$

$42,0 \%$

4 Kind af problems encountered

- communication problems

- problems attributed to the patients

- lack of time and material

- vague or psychosocial problerns

- other problems

\begin{tabular}{rr}
46 & $34 \%$ \\
42 & $31 \%$ \\
22 & $17 \%$ \\
15 & $11 \%$ \\
9 & $7 \%$ \\
\hline 134 & $100 \%$ \\
\hline
\end{tabular}

\begin{tabular}{rr}
31 & $27 \%$ \\
35 & $31 \%$ \\
17 & $15 \%$ \\
16 & $14 \%$ \\
15 & $13 \%$ \\
\hline 114 & $100 \%$ \\
\hline
\end{tabular}

*) significant difference p.<.01 


\begin{tabular}{l}
$\begin{array}{l}\text { information given } \\
\text { yes }\end{array}$ \\
\hline
\end{tabular}

\section{TEACHING AND PROVIDING INFORMATION ABOUT ILLNESS}

- about diagnosis and complaints

- about the prognosis

- Illustrative material to clarify information

- miscellaneous or remaining topics

2. INSTRUCTHONS FOR HOME EXERCISES $(n=1178)$ *

- explaining home exercises

- frequency of each exercise

- number of sessions per day

- exercise instructions

- the bulld-up of the exercise program

- the bulld-up of each exercise

- exercise leaflet

- instructions written by the theraplist

- Integrating exercises to daily activities

- motlvating the patient to comply

- monitoring the patient's compliance

- resolving compliance problems

- milscellaneous or remaining topics

\section{ADVICE AND INFORMATION}

- on taking rest

- on correct posture and movement

- on work, sports or hobbies

- an daily activities

- on selt care and domestic medicines

- on adaptations

- on ailds and appliances

- on health services

- on famlly physicians or specialists

- motivating the patient to comply

- maniloring the patient's compliance

- resolving compliance problems

- miscellaneous or remaining topics

\section{GENERAL HEALTH EDUCATION}

- on sports or exercise

- on welght control or nutrition

- on smolking or alcohol or drugsintake

- on painkillers or medicine

- on health and illiness in general

- motivating the patient to comply

- monitoring the patient's compllance

- resolving compliance problems

- miscellaneous or remaining toplics

$\begin{array}{rr}143 & 7,8 \% \\ 52 & 2,8 \% \\ 12 & 0,7 \% \\ 82 & 4,5 \% \\ 114 & 6,2 \% \\ 32 & 1,7 \% \\ 28 & 1,5 \% \\ 5 & 0,3 \% \\ 128 & 7,0 \%\end{array}$


(continued)

Information given

yes

\%

\section{COUNSELING ON STRESS-RELATED PROBLEMS}

- explaining mind-body relations

- exploring stress-related problems

- supportive care with handicaps

- supportive care with personal distress

B PLANNED AND SYSTEMATIC APPROACH

- explaining treatment session

- explaining follow-up treatment(s)

- explaining duration of treatment

- communicating findings from history taking

- communicating findings of the physical examination(s)

- communicating findings of therapy

- explaining aim of physical examination

- explaining aim of exercise therapy

- explaining aim of massage

- explaining aim of a physical agent

- explaining possible side-effects of treatment

- evaluating the course of treatment

\section{PATIENT'S DEMANDS AND PERCEPTIONS}

- exploring demands and expectations.

- exploring ideas and perceptions

- exploring self-care activities

- checking the patient's understanding

\section{A THERAPIST-PATIENT RELATIONSHIP}

- reinforcing the patient's performance

- showing concern for pain

- showing interest in the patient

- showing involvement in treatment

- facilitating patient participation

- Instructions for home exercises anly concern the $117 \mathrm{~B}$ sessions in which home exercises were prescribed. 


\section{Appendix 7}

Scale 1: Therapist-patient relationship $N=1837$

Scale value

1 reinforcing patient's performance

2. showing concern for pains

3 showing interest in the patient

4 showing inwolvement in treatment

5 facilltating patient particlpation minimum 1

70.0

59.4

0.3

1.7

19.0
2

15.3

26.2

8.2

12.9

36.7

3

4 maximum

Alpha $=.85$ 


\section{Appendix 8}

Scale 2: Preventive possibilities

avoidance of the complaints requiring treatment again is:

\begin{tabular}{|c|c|c|c|c|}
\hline $\begin{array}{c}\text { not } \\
\text { possible }\end{array}$ & $\begin{array}{c}\text { some } \\
\text { what } \\
\text { possible }\end{array}$ & $\begin{array}{c}\text { reason- } \\
\text { ably } \\
\text { possible }\end{array}$ & $\begin{array}{c}\text { quitie } \\
\text { possible }\end{array}$ & $\begin{array}{l}\text { highly } \\
\text { possible }\end{array}$ \\
\hline
\end{tabular}

complaints in connection with

\begin{tabular}{|c|c|c|c|c|c|c|}
\hline frozen shoulder & 10.8 & 20.7 & 23.4 & 32.0 & 10.8 & 2.3 \\
\hline non-fixation scoliosis & 3.2 & 21.2 & 30.6 & 34.7 & 7.2 & 3.2 \\
\hline tennis elbow & 5.4 & 19.4 & 32.9 & 31.1 & 9.5 & 11.8 \\
\hline $\begin{array}{l}\text { chronic non-specilfic } \\
\text { lung disease }\end{array}$ & 32.9 & 43.2 & 16.2 & 3.6 & 1.8 & 2.3 \\
\hline arthrosis of the kmee & 18.5 & 51.4 & 23.9 & 4.1 & 0.9 & 1.4 \\
\hline hyperventilation & 3.2 & 13.1 & 24.3 & 41.0 & 17.1 & 1.4 \\
\hline lumbago & 3.6 & 19.4 & 35.6 & 32.4 & 7.7 & 1.4 \\
\hline headache & 4.1 & 36.9 & 33.3 & 16.7 & 5.0 & 4.1 \\
\hline sprained ankle & 8.1 & 16.2 & 18.9 & 27.0 & 27.0 & 2.7 \\
\hline M. Scheuermann & 22.5 & 30.6 & 25.7 & 14.0 & 5.0 & 23 \\
\hline asteoporosis & 44.1 & 35.6 & 14.4 & 3.2 & 0.9 & 1.8 \\
\hline stress incontinence & 9.0 & 29.7 & 23.4 & 2.2 .5 & 6.8 & 8.6 \\
\hline
\end{tabular}

* item deleted for skewness

** itern deleted to raise Alpha-value

Remaining 8 items: Alpa $=.71$ 


\section{Appendix 9}

Scale 3: Perceived effects of education

\begin{tabular}{ccc}
$\begin{array}{c}\text { definitely don't } \\
\text { don't agree } \\
\text { agree }\end{array}$ & $\begin{array}{c}\text { partly agree, } \\
\text { partly } \\
\text { don't } \\
\text { agree }\end{array}$ & $\begin{array}{r}\text { fully agree } \\
\text { agree }\end{array}$ \\
\hline
\end{tabular}

The information that I give contributes towards patients becoming more independent

13.5

25.7

49.5

9.0

0.5

My information ensures that even uninterested passive patients proceed to cooperate actlvely in the treatment

15.8

42.3

32.4

9.0

I consider that I possess

sufflcient skills to give good information

29.7

57.2

9.5

Through the information that I give patients are much sooner free of complaints

0.9

12.2

51.4

29.7

5.0

My information has considerable effect on the extent to which patients feel responsible for their own health

34.2

50.5

10.4

If I devoted considerable attention to information, 1 have more pleasure in my work*

20.3

51.4

20.3

Whether patients faithfully do their home exercises depends above all on my information

44.1

29.7

8.6

Through the information that I give patients can make better decisions about their own health"

0.9

6.3

32.4

53.6

6.3

The quality of my work as a physical therapist is determined above all by the information that $\llbracket$ give 3.6 29.3 46.4 16.7 3.6 
Scale 3 (continued)

\begin{tabular}{|c|c|c|c|c|c|}
\hline $\begin{array}{l}\text { definitely } \\
\text { don't } \\
\text { agree }\end{array}$ & $\begin{array}{l}\text { don't } \\
\text { agnee }\end{array}$ & $\begin{array}{c}\text { partly } \\
\text { agree " } \\
\text { partly" } \\
\text { don't } \\
\text { agree }\end{array}$ & agree & $\begin{array}{l}\text { fully } \\
\text { agree }\end{array}$ & missing \\
\hline
\end{tabular}

As a result of good informa-

tion I rarely see patients

again with the same complaints

2.7

44.1

41.9

9.9

0.5

0.9

Giving information is for me

a way of showing the patient

that I take him/her seriously

20.7

23.0

45.0

7.7

0.9

Giving good information costs

me considerable energy

50.5

19.8

21.2

2.3

0.9

Patients nowadays expect that

I give extensive information

32.9

46.4

16.7

0.9

0.9

If I devote little attention

to information I do not

consilder myself a good

physilcal therapist.

1.4

11.3

17.6

56.3

12.6

0.9

Through information it is often

possible to change the

behavior of patients permanently

1.8

14.9

45.0

31.1

6.3

0.9

I find it a disadvantage that

giving extensive information

is at the expense of treat-

ment time

10.8

59.9

12.2

14.0

2.3

0.9

I consider that I am not entitled to concern miyself with unhealthy lifestyles of patients

40.5

7.7

Through the information that I give I contribute to cost-cutting in health care

The satisfaction of patients does not depend on the information that \| give

* item deleted for skewness

** item deleted to raise Alpha

Remaining 12 items: Alpha $=.75$ 
Appendix 10

Scale 4: psychosocial influence

psychosocial factors have:

\begin{tabular}{|c|c|c|c|c|}
\hline $\begin{array}{l}\text { no } \\
\text { effect } \\
\text { at all }\end{array}$ & $\begin{array}{l}\text { Iittle } \\
\text { effect }\end{array}$ & $\begin{array}{l}\text { neither } \\
\text { little nor } \\
\text { much effect }\end{array}$ & $\begin{array}{l}\text { much } \\
\text { effect }\end{array}$ & $\begin{array}{l}\text { very } \\
\text { much } \\
\text { effect }\end{array}$ \\
\hline
\end{tabular}

complaints in connection with

\begin{tabular}{|c|c|c|c|c|c|c|}
\hline frozen shoulder & 14.9 & 42.8 & 21.6 & 14.9 & 3.2 & 2.7 \\
\hline non-fixation scollosis & 18.5 & 39.2 & 23.9 & 13.1 & 2.7 & 2.7 \\
\hline tennis ellbow & 22.5 & 41.0 & 23.9 & 7.7 & 2.3 & 2.7 \\
\hline chronic non-specific & & & & & & \\
\hline lung disease" & 1.4 & 10.8 & 14.4 & 58.1 & 12.6 & 2.7 \\
\hline arthrosis of the knee & 25.7 & 40.1 & 23.4 & 6.8 & 1.4 & 2.7 \\
\hline hyperventillat lon" & - & 0.5 & 1.8 & 35.1 & 60,8 & 1.8 \\
\hline lumbago" & 1.8 & 6.8 & 37.8 & 40.5 & 11.3 & 1.8 \\
\hline headache" & - & 0.9 & 10.8 & 56.3 & 29.7 & 2.3 \\
\hline sprained ankle" & 46.4 & 36.9 & 12.6 & 1.4 & 0.5 & 2.3 \\
\hline M. Schesermann" & 37.8 & 33.8 & 18.5 & 6.3 & 1.4 & 2.3 \\
\hline osteoporosis" & 40.5 & 35.6 & 14.0 & 5.9 & 1.4 & 2.7 \\
\hline stressincontinence & 2.7 & 5.4 & 11.3 & 41.0 & 34.7 & 5.0 \\
\hline
\end{tabular}

* item deleted for skewness

**: Item deleted to raise Alpha

Remaining 4 iterns: Alpha $=.81$ 


\section{Dankwoord}

Allereerst wil ik mijn promotoren Prof.Dr.J.van der Zee en Prof.Dr.G.J.Kok bedanken voor hun stimulerende begeleiding en voor de efficiënte wijze waarop zij de kwaliteit van het onderzoek bewaakten. I $k$ bewaar de beste herinneringen aan deze begeleiding mede dankzij de altijd positieve en constructieve wijze waarop zij hun commentaar wisten te verwoorden.

Stimulerend was ook de betrokkenheid en de collegialiteit van alle aardige en waardevolle mensen die tezamen het Nivel vormen. Ik beschouw het als een voorrecht temidden van hen onderzoek te kunnen doen en dat bepaalt voor een groot deel mijn plezier in het werk. De vele adviezen die collega's mij belangeloos gaven waren (en zijn) bovendien een geweldige steun, waarvoor ik ledereen hartelijk dank.

Het Nivel was vooral in de beginjaren voor mij een continue leerschool zonder welke ik dit onderzoek niet had kunnen doen. Van Jozien Bensing en Peter Verhaak heb ik het meest geleerd. $\mathrm{k}$ ben hen oprecht dankbaar voor dle grondige en enthousiaste wijze waarop zij mij het vak hebben geleerd.

Peter Verhaak was bovendien projectleider van dit onderzoek. Zijn leiding was nooit opdringerig maar hij was er altijd als ik hem nodig had. Hij toonde steeds het volste vertrouwen in de wijze waarop ik het project aanpakte. Ik heb dat zeer gewaardeerd. Eenzelfde belangrijke rol vervulde Joost Dekker met zijn doordacht commentaar en verstandige adviezen. Ik heb altijd veel waarde aan zijn oordeel gehecht.

Veel mensen hebben enthousiast en met grote inzet aan dit onderzoek meegewerkt. Jeanette Fennema, Irma Hermans en Eli Kuijper schreven samen met mij artikelen en hebben bovendien een groot deel van de geluidsbanden gescoord. Dit was een taaie klus die volharding en zelfdiscipline eiste maar daardoor ook een band schiep waar ik met weemoed aan terugdenk. Irma regelde bovendien allerleil organisatorische en administratieve zaken op een zeer nauwgezette en efficiënte wijze. Inspirerend en plezierig was ook de samenwerking met Hanneke Knibbe. Zil bewaakte continu de aansluiting van het onderzoek met de dagelijkse praktijk van de fysiotherapie en gaf altijd enthousiast en ter zake kundig tal van inhoudelijke adviezen. Ik hoop dat zich nog eens een gelegenheid tot samenwerken voordoet.

Zonder de hulp van Marleen Duister en Bernadette Kamphuys lag dit proefschrift er niet in deze vorm. Marleen zorgde op vakkundige wijze voor de computerverwerking van de ingewikkelde databestanden en was altijd bereid mij met raad en daad bi] te staan. Bernadette besteedde veel zorg aan de tekstverwerking en lay-out en accepteerde zonder zuchten de zoveelste versie van een artikel. Bedankt Marleen en Bernadette. 
Ook anderen die aan diverse onderdelen van het onderzoek een bijdrage geleverd hebben wil ik hierbij bedanken, met name Willemien Coenen, Mieke Cornelius, Effie Deirkauf, Ed Hackenitz, Jaqueline de Klerk, Alma de Leeuw, Paul van Leeuwen, Guusje Verweij, Henk Jan van Vliet en Renate Wiegers.

De leden van de begeleidingscommissie, Drs.H.W.Kanters, Dhr.H.A. van der Linden, fysiotherapeut, MW. H.A.W.Wams en Dhr.A. de Wijer, fysiotherapeut, ben ik erkentelijk voor de moeite die zil hebben genomen om de diverse stukken te becommentariëren. Dhr. De Wijer was bovendien de eerste fysiotherapeut die video-opnamen van zijn behandelingen voor onderzoeksdoeleinden aan ons ter beschikking stelde.

Dit onderzoek heeft plaats kunnen vinden dankzij alle fysiotherapeuten en patiënten die in dit onderzoek geparticipeerd hebben. Ik heb respect voor de fysiotherapeuten die het aangedurfd hebben hun handelen door ons kritisch te laten beoordelen.

In de privé steer, tenslotte, waren het vooral Annie en Jan Peterse die mij op velerlei manieren tot steun waren; oprecht bedankt daarvoor. 


\section{Curriculum vitae}

Emmarentiana Maria Sluijs werd geboren op 12 mei 1944 te Polsbroek. Zij volgde de driejarige H.B.S. te Gouda en de Kaderschool voor de Confectie Industrie te 'sHertogenbosch en haalde enkele vakdiploma's op confectiegebied. Van 1962 tot 1970 werkte zi] als arbeidsanaliste in diverse confectiebedrijven en van 1970 tot 1975 als secretaresse aan de Universiteit van Utrecht.

Na het behalen van een Colloquium Doctum in 1976 begon zij met de studie psychologie. In 1979 slaagde zij voor het kandidaatsexamen (cum laude) en in 1984 voor het doctoraalexamen klinische psychologie met methodologie en statistiek als nevenrichting. Tijdens de studie vervulde zij een aantal assistentschappen.

Sinds 1984 werkt zij op het Nederlands Instituut voor Onderzoek van de Eerstelijnsgezondheidszorg, de eerste jaren als wetenschappelijk assistent van de directeur en sinds 1987 als onderzoeker. Zij hield zich bezig met aspecten van arts-patiënt communicatie zoals Methodisch Werken en Compliance en met activiteiten op het gebied van Onderzoeksprogrammering. De laatste jaren lag het zwaartepunt van haar activiteiten op onderzoek naar patiëntenvoorlichting door fysiotherapeuten, sinds kort aangevuld met onderzoek naar kwaliteitsbewaking in de gezondheidszorg.

Het onderzoek waarop dit proefschrift is gebaseerd werd gesubsidieerd door het Praeventiefonds. Het maakt deel uit van een langlopend onderzoeksprogramma van het Nivel naar hulpverleningsprocessen, communicatie en voorlichting in de eerstelijnsgezondheidszorg. 